\title{
Assessing the Fire Integrity Performance of Cross-Laminated Timber Floor Panel-to-Panel Joints
}

\author{
By
}

\section{Christian Dagenais}

\author{
A thesis submitted to \\ the Faculty of Graduate and Postdoctoral Affairs \\ in partial fulfilment of the requirements for the degree of \\ Doctor of Philosophy \\ in \\ Civil Engineering \\ Department of Civil and Environmental Engineering \\ Fire Safety Engineering \\ Carleton University \\ Ottawa (Ont.), Canada
}

January, 2016

CCopyright 2016, Christian Dagenais 


\section{Abstract}

During the past few years, a relatively new technology has emerged in North America and changed the way professionals design and build wood structures: Cross-laminated Timber (CLT). CLT panels are manufactured in width ranging from $600 \mathrm{~mm}$ to $3 \mathrm{~m}$. As such, fastening them together along their major strength axis is required in order to form a singular structural assembly resisting to in-plane and out-of-plane loading. Typical panel-to-panel joint details of CLT assemblies may consist of internal spline(s), single or double surface splines or half-lapped joints. These tightly fitted joint profiles should provide sufficient fire-resistance, but have yet to be properly evaluated for fire-resistance in CLT assemblies.

The experimental portion of the study consisted at conducting ten (10) intermediate-scale fire-resistance tests of CLT floor assemblies with four (4) types of panel-to-panel joints and three (3) CLT thicknesses. The data generated from the intermediate-scale fire tests were used to validate a finite element heat transfer model, a coupled thermal-structural model and a simplified design model. The latter is an easy-to-use design procedure for evaluating the fire integrity resistance of the four commonly-used CLT floor assemblies and could potentially be implemented into building codes and design standards. Based on the test data and models developed in this study, joint coefficient values were derived for the four (4) types of CLT panel-to-panel joint details. Joint coefficients are required when assessing the fire integrity of joints using simple design models, such as the one presented herein and inspired from Eurocode 5: Part 1-2. 
The contribution of this study is to increase the knowledge of CLT exposed to fire and to facilitate its use in Canada and US by complementing current fire-resistance design methodologies of CLT assemblies, namely with respect to the fire integrity criterion. Being used as floor and wall assemblies, designers should be capable to accurately verify both the load-bearing and separating functions of CLT assemblies in accordance with fire-related provisions of the building codes, which are now feasible based on the findings of this study. 


\section{Acknowledgment}

The realization of the present thesis was made possible from the supervision and collaboration of my supervisor Professor George Hadjisophocleous, to whom I express my sincere gratitude for trusting my capability of undertaking doctoral studies while working full-time and being located off campus. Your advice, guidance and patience throughout the process are greatly appreciated.

I would also like to thank $\mathrm{Ba}$ Lam-Thien for his continuous support, collaboration and hard work during the fire experiments as well as Matt Turco, Aaron Akotuah Ohene and Jordan Giberson for providing valuable help and labour in preparing the fire experiments.

I also express special thanks to my current work colleagues Richard Desjardins, Erol Karacabeyli, Mohammad Mohammad, Sylvain Gagnon, Lindsay Osborne, Oliver Baës and Anes Omeranovic for supporting and accommodating me throughout. I also express special thanks to Louis Poliquin who formerly allowed me to undertake these doctoral studies in 2008 while working full-time with him. Merci!

Moreover, I would like to express my appreciation to Professors Pierre Quenneville and Andy Buchanan as well as Dr. Noureddine Bénichou for providing valuable comments and recommendations with respect to the research objectives and methodology. 
Furthermore, I am also thankful to my friends Julie Frappier and Williams Muñoz at Nordic Engineered Wood for sharing technical and proprietary information on their cross-laminated timber. The excellent technical support from Mathieu Baril and Max Closen of MyTiCon is also acknowledged for understanding properly ASSY ${ }^{\circledR}$ selftapping screws design provisions.

The funding support of the experimental portion of this research was provided by the Forestry Innovation Investment of British Columbia (BC FII) through an agreement existing between FPInnovations and BC FII. I am also very grateful of the financial support provided by FPInnovations throughout my studies.

With the permission of the Canadian Standards Association (operating as CSA Group), material is reproduced from CSA Group standard, 'O86-14 - Engineering design in wood', which is copyrighted by CSA Group, 178 Rexdale Blvd., Toronto, ON, M9W1R3. This material is not the complete and official position of CSA Group on the referenced subject, which is represented solely by the standard in its entirety. While use of the material has been authorized, CSA Group is not responsible for the manner in which the data is presented, nor for any interpretations thereof. For more information or to purchase standards from CSA Group, please visit http://shop.csa.ca/ or call 1-800-4636727.

Lastly, I could not have made it without the most important support from my wife and kids, mom, dad, my brother, family and friends who thought I was crazy for getting into this adventure while working full-time, at home and at the office. I made it! 
Je dédie cette thèse à mon épouse Julie et à mes filles, Josiane, Florence et Sofia qui m'ont fourni le support moral et affectif nécessaire à l'accomplissement de ce projet.

Concilier le travail, les études et la vie familiale n'est pas une tâche facile.

Je vous aime énormément. Merci infiniment pour tout! 


\section{Table of Contents}

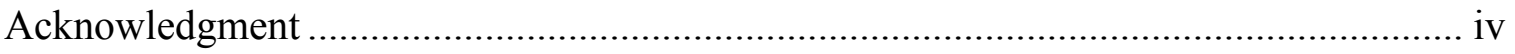

Table of Contents ...................................................................................................... vii

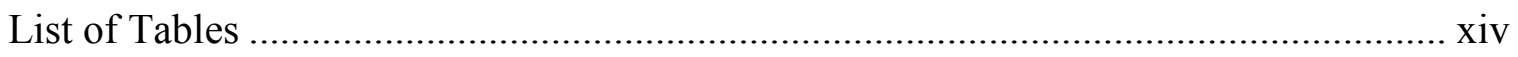

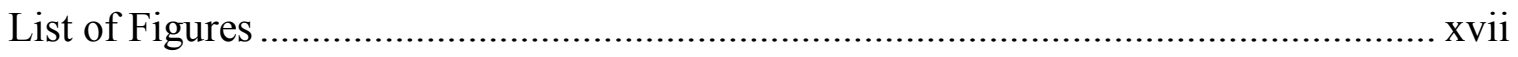

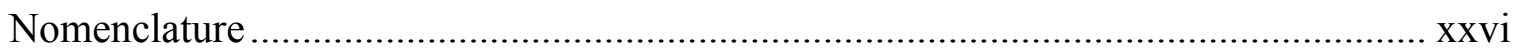

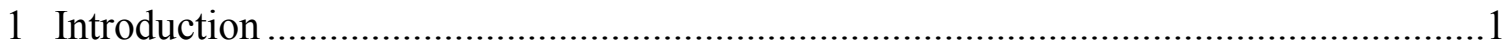

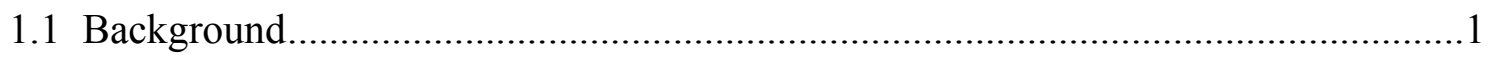

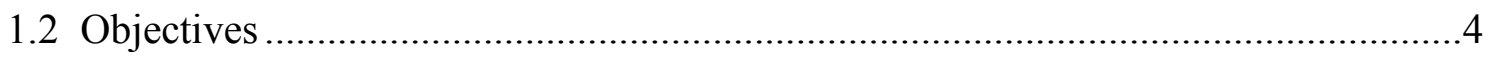

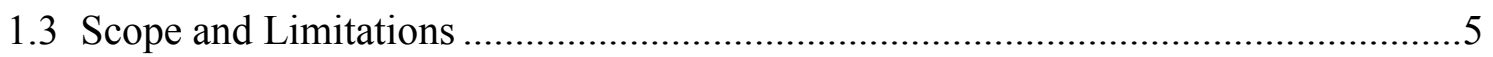

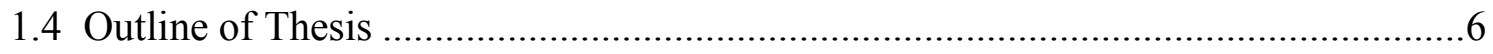

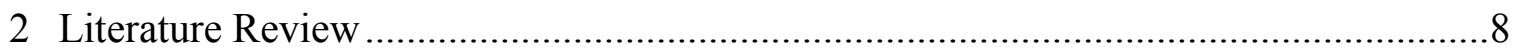

2.1 Fire-Resistance of Building Construction Materials ......................................... 10

2.1.1 Fire-Resistance Test Method ................................................................... 10

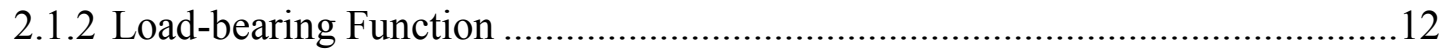

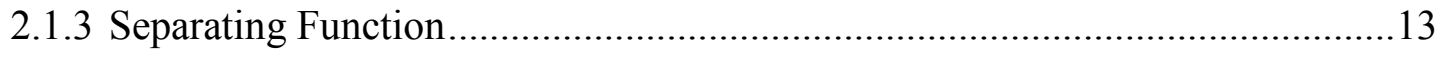

2.2 Fire-Resistance of Cross-Laminated Timber Assemblies ...................................13

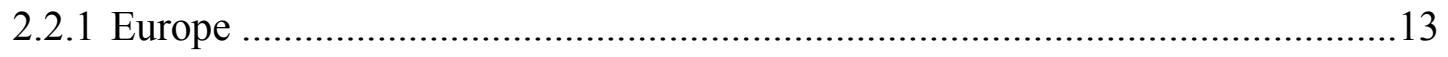




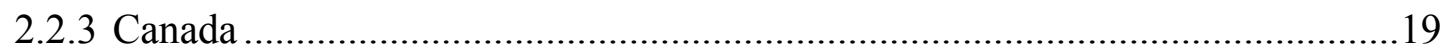

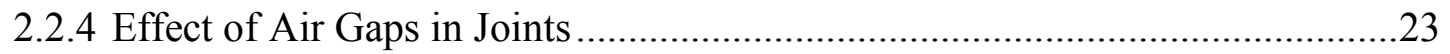

2.2.5 Effect of Floor Topping ...........................................................................2

2.2.6 Comparison between Test Data and Current Models.......................................28

2.3 Cross-Laminated Timber Panel-to-Panel Connection Details...................................32

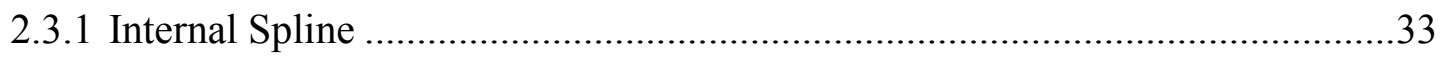

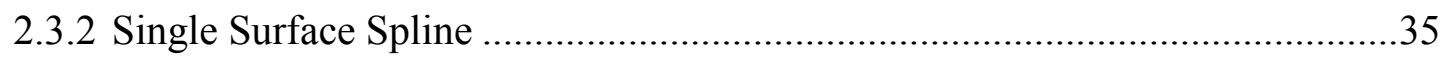

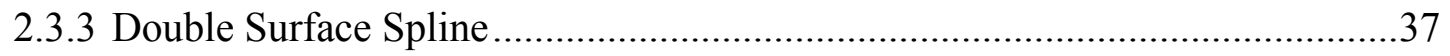

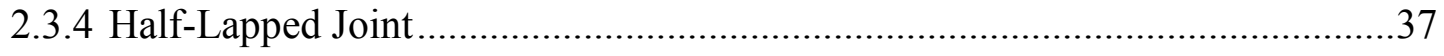

2.4 Cross-Laminated Timber Panel-to-Panel Connection Resistance..............................39

2.4.1 Failure Modes in CLT Panel-to-Panel Joints ....................................................40

2.4.2 Wood Screws (of diameter up to $5.48 \mathrm{~mm}$ ) …………...................................

2.4.3 Lag Screws and Wood Screws (of diameter greater than $5.48 \mathrm{~mm}$ ) .................48

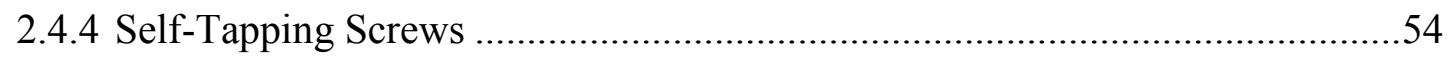

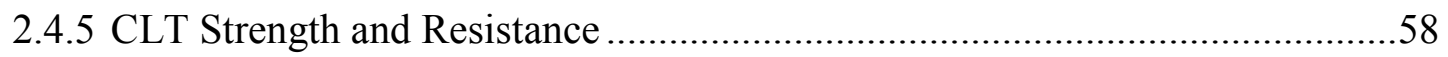

$$
\text { - viii - }
$$


2.5 Material Properties at Elevated Temperatures.....................................................61

2.5.1 Wood Properties at Elevated Temperatures ....................................................61

2.5.1.1 Mechanical Properties ........................................................................61

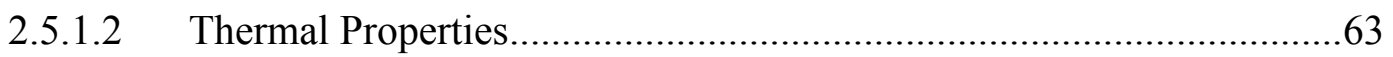

2.5.2 Steel Properties at Elevated Temperatures ......................................................67

2.5.2.1 Mechanical Properties ………………….......................................67

2.5.2.2 Thermal Properties...........................................................................69

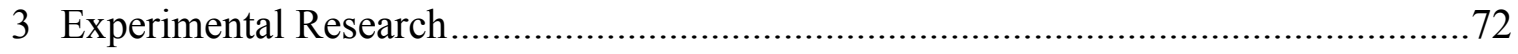

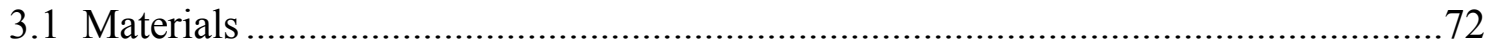

3.1.1 Cross-Laminated Timber Panels ………………...........................................72

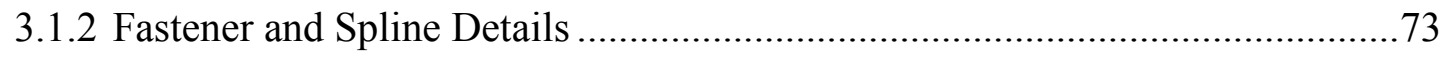

3.1.3 Construction of the CLT Panel-to-Panel Joints..................................................74

3.2 Bending Test at Ambient Conditions ………........................................................

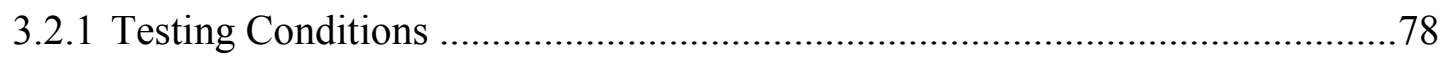

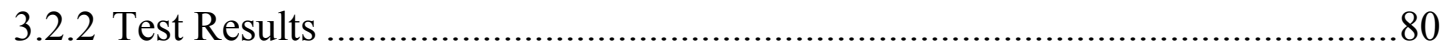

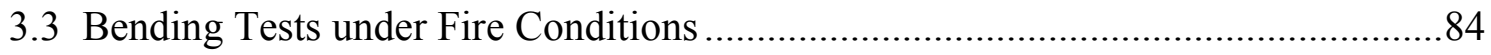


3.7 Fire Test 4 - 3-ply with double surface splines......................................................106

3.8 Fire Test 5-5-ply with internal spline

3.9 Fire Test 6 - 5-ply with half-lapped joint

3.10Fire Test $7-5$-ply with single surface spline

3.11Fire Test 8 - 5-ply with double surface splines..................................................118

3.12Fire Test 9 - 7-ply with half-lapped joint ..............................................................121

3.13Fire Test 10 - 7-ply with double surface splines..................................................124

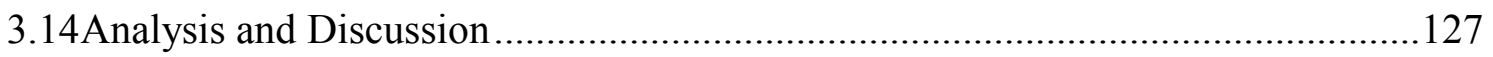

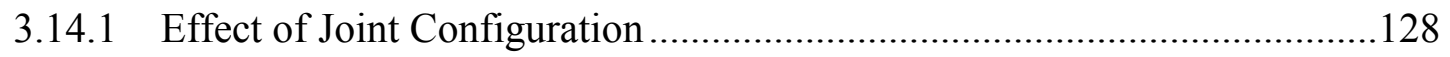

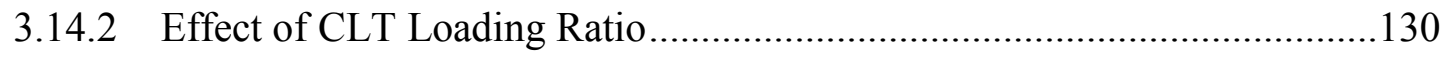

3.14.3 Charring Rate and Effect of Adhesive Heat Delamination ........................131

3.14.4 Effect from heating of the self-tapping screws.........................................136 
3.15Summary.....

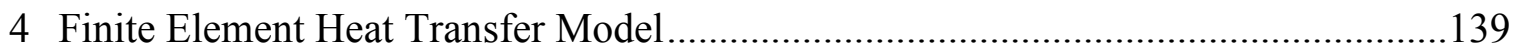

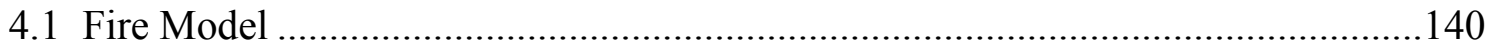

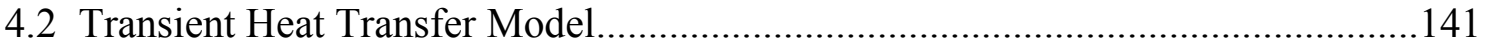

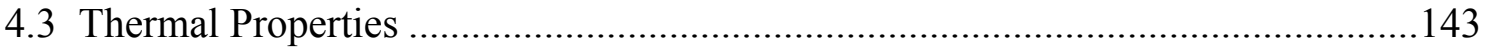

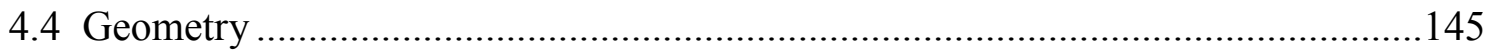

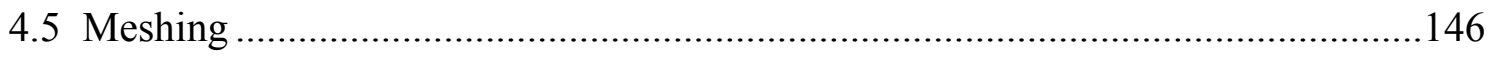

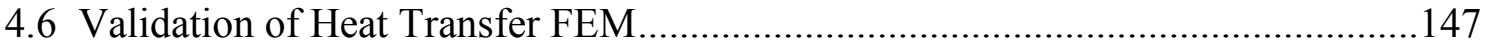

4.6.1 Intermediate-Scale Fire-Resistance Tests .....................................................147

4.6.2 Full-Scale Fire-Resistance Tests …………………....................................149

4.6.3 Charring Rate from FEM ………………………...................................151

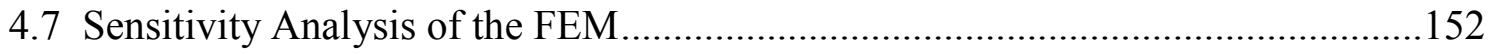

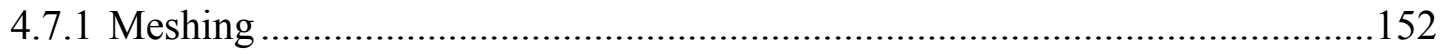

4.7.2 Self-Tapping Screw Threaded Shank ............................................................154

4.7.3 Wood Thermal Properties ……………………….......................................156

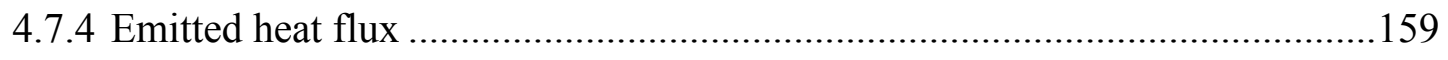

4.8 Summary

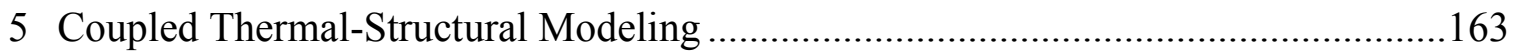

$-x i-$ 
5.1 Methodology and Assumptions

5.2 Predictions from the Coupled Thermal-Structural Model......................................168

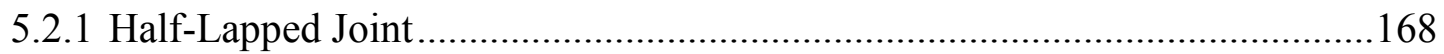

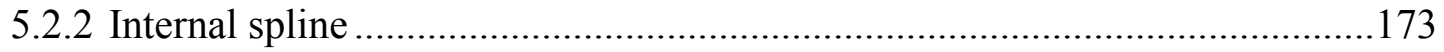

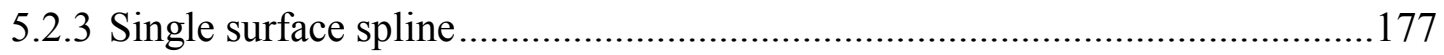

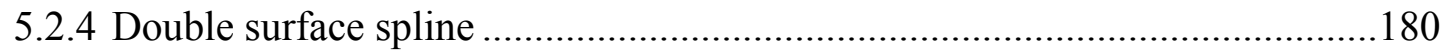

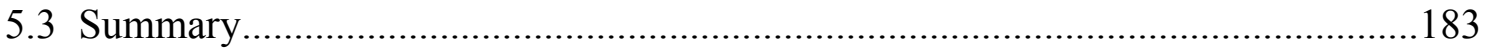

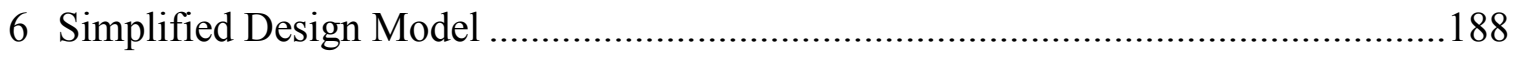

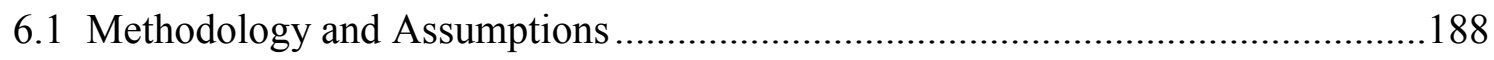

6.2 Predictions from the Simplified Design Model ...................................................189

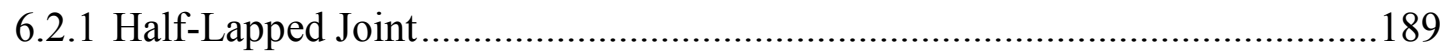

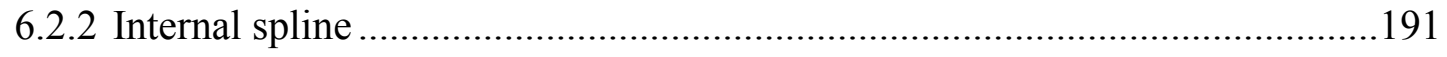

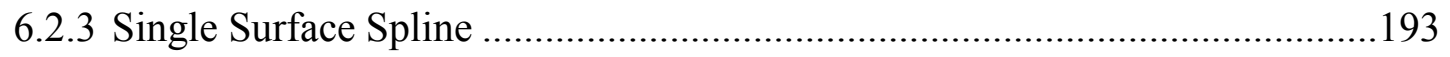

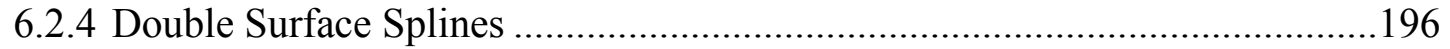

6.3 Summary

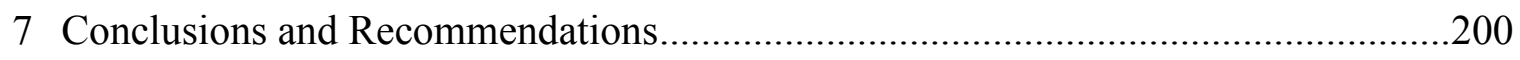

7.1 Summary

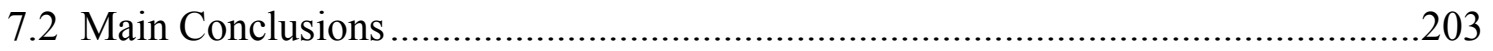


7.4 Recommendations for Future Research........................................................206

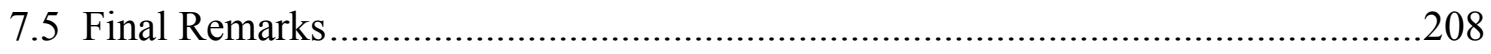

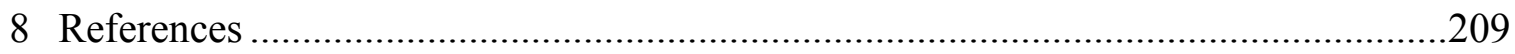

Appendix I - Fire Test 1 - 3-ply CLT with internal spline .....................................224

Appendix II - Fire Test 2 - 3-ply CLT with half-lapped joint ...................................225

Appendix III - Fire Test 3 - 3-ply CLT with single surface spline.............................229

Appendix IV - Fire Test 4 - 3-ply CLT with double surface spline ...........................233

Appendix V - Fire Test 5 - 5-ply CLT with internal spline ......................................237

Appendix VI - Fire Test 6 - 5-ply CLT with half-lapped joint.....................................241

Appendix VII - Fire Test 7 - 5-ply CLT with single surface spline ...........................245

Appendix VIII - Fire Test 8 - 5-ply CLT with double surface spline .........................248

Appendix IX - Fire Test 9 - 7-ply CLT with half-lapped joint..................................252

Appendix X - Fire Test 10 - 7-ply CLT with double surface spline ...........................256

Appendix XI - Example from Coupled Thermal-Structural Model .............................260 


\section{List of Tables}

Table 2.1 - Joint Coefficient per Eurocode 5 : Part 1-2 [27] ....................................... 17

Table 2.2 - FPInnovations CLT Fire-Resistance Test Summary [10] ........................... 30

Table 2.3 - FPInnovations Test Results Compared to European, American and Canadian Models 31

Table 2.4 - Thermal protection from the reduced CLT thickness using test configurations from $[10]$ 32

Table 2.5 - Fire Integrity provided by the reduced CLT thickness using CSA O86 wood screw minimum penetration length provisions [48] 47

Table 2.6 - Fire integrity provided by the reduced CLT thickness using CSA O86 lag screw minimum penetration provisions $[48]$ 52

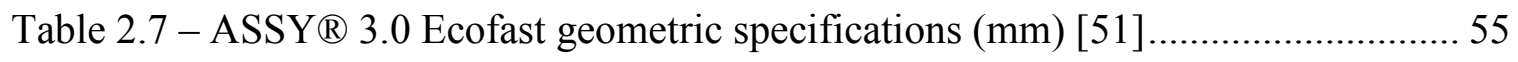

Table 2.8 - Specified strength and stiffness of CLT grade, per ANSI/APA PRG-320-12

[14] 58

Table 2.9 - Design charring rates for wood products [27] 64

Table 2.10 - Thermal properties used in some numerical models, as presented in [68].. 67

Table 3.1 - CLT panel-to-panel joint test matrix for fire testing. 74

$$
\text { - xiv - }
$$


Table 3.2 - Predicted time to fire integrity failure using Eurocode 5: part 1-2 85

Table 3.3 - Instrumentation with thermocouples for fire testing. 90

Table 3.4 - Specified load producing the maximum factored bending moment 94

Table 3.5 - Specified load reproducing an initial deformation of $20 \mathrm{~mm}$ 95

Table 3.6 - Summary of CLT panel-to-panel joint fire test results 128

Table 3.7 - Time to 300 isotherm and resulting charring rate from test data. 132

Table 4.1 - Thermal properties used in FEM for E1 Stress Grade CLT panels 145

Table 4.2 - Charring rates from FEM compared to test data. 152

Table 5.1 - Coupled Thermal-Structural Failure Times - Half-lapped Joint 169

Table 5.2 - Coupled Thermal-Structural Failure Times - Internal Spline Joint 175

Table 5.3 - Coupled Thermal-Structural Failure Times - Single Surface Spline Joint . 179

Table 5.4 - Coupled Thermal-Structural Failure Times - Double Surface Spline Joint 181

Table 6.1 - Joint coefficient $\left(\mathrm{K}_{\mathrm{j}}\right)$ from test data and model predictions - Half-lapped joint 190

Table 6.2 - Joint coefficient $\left(\mathrm{K}_{\mathrm{j}}\right)$ from test data and model predictions - Internal spline 192 
Table 6.3 - Joint coefficient $\left(\mathrm{K}_{\mathrm{j}}\right)$ from test data and model predictions - Single surface spline. 194

Table 6.4 - Joint coefficient $\left(\mathrm{K}_{\mathrm{j}}\right)$ from test data and model predictions - Double surface spline. 196

Table 6.5 - CLT panel-to-panel joint coefficients from test data and simplified design model. 199 


\section{List of Figures}

Figure 1.1 - CLT panels at the manufacturing plant ............................................. 2

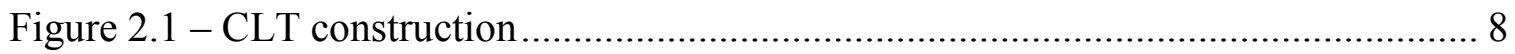

Figure 2.2 - Configuration (left) and possible cross-section (right) of a CLT panel [3].... 9

Figure 2.3 - CAN/ULC S101 standard time-temperature curve using Equation (2.1).... 11

Figure 2.4 - CLT panel-to-panel fire integrity failure (flame-through) (credit: NRC/FPInnovations).................................................................. 21

Figure 2.5 - Timber joints studied by Kampmeir [40] ........................................ 25

Figure 2.6 - Flaming through a half-lapped joint during a fire test by Medina [42] ....... 26

Figure 2.7 - Ratchet and hooks used for CLT panel-to-panel connection (photo:

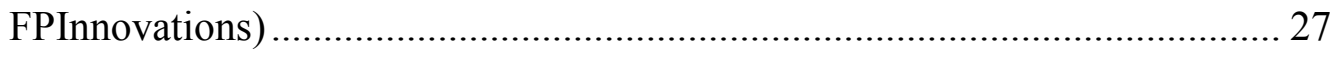

Figure 2.8 - Example of a composite concrete-timber slab assembly [24] ................... 28

Figure 2.9 - Half-lapped joint detail used in full-scale fire tests [24] ......................... 29

Figure 2.10 - Test results from [10] compared to predictions from $[12,27,24] \ldots \ldots \ldots . . .31$

Figure 2.11 - In-plane (left) and out-of-plane (right) loading conditions [45]............... 33

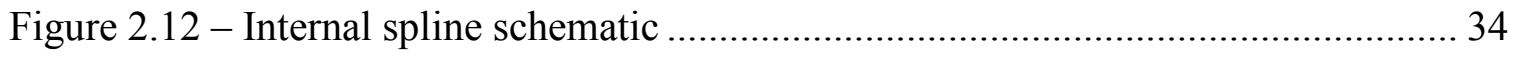


Figure 2.13 - Internal spline made from a plywood strip 34

Figure 2.14 - Internal splines profiling from BinderHolz [46]..................................... 35

Figure 2.15 - Typical and wider internal splines from BinderHolz [46] ........................ 35

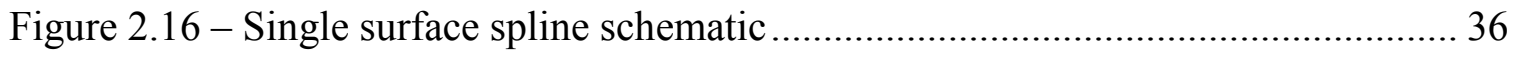

Figure 2.17 - Single surface spline made from a plywood strip...................................... 36

Figure 2.18 - Double surface splines schematic ....................................................... 37

Figure 2.19 - Half-lapped joint schematic ................................................................ 38

Figure 2.20 - Failure mode due to connection reduced withdrawal capacity................... 41

Figure 2.21 - Shear force in a simple span flexural member ........................................ 42

Figure 2.22 - Failure mode due to reduced shear resistance of lower section of the exposed CLT 43

Figure 2.23 - Wood screw unit lateral strength resistance [48] (reproduced with permission from CSA Group). 46

Figure 2.24 - Wood screw minimum penetration length and member thickness [48] (reproduced with permission from CSA Group)

Figure 2.25 - Predicted fire integrity failure using CSA O86 wood screw minimum penetration length provisions [48] 48 
Figure 2.26 - Lag screw unit lateral strength resistance [48] (reproduced with permission from CSA Group) 50

Figure 2.27 - Predicted integrity failure time using CSA O86 lag screw minimum penetration length provisions [48] 53

Figure 2.28 - ASSY® 3.0 Ecofast self-tapping screw (adapted from [51]) 55

Figure 2.29 - Configuration of typical CLT panel-to-panel joints (image: [51]) 56

Figure 2.30 - Shear orientation in panel products [48] (reproduced with permission from CSA Group) 60

Figure 2.31 - Wood thermal degradation when exposed to fire [60] 62

Figure 2.32 - Wood strength and MOE reduction factors at elevated temperatures as per [27] 63

Figure 2.33 - Carbon steel strength and MOE reduction factors at elevated temperatures as per [71] 69

Figure 2.34 - Carbon steel thermal conductivity at elevated temperatures as per [71]... 70

Figure 2.35 - Carbon steel specific heat at elevated temperatures as per [71] 71

Figure 3.1 - CLT panels ready to assemble (left) and under side pressure by clamps (right) 73

Figure 3.2 - Firestop sealant before joining CLT panels 75 - xix - 
Figure 3.3 - CLT panel-to-panel joints before testing 76

Figure 3.4 - CLT bending Test 1 under ambient conditions 79

Figure 3.5 - CLT bending Test 2 under ambient conditions 79

Figure 3.6 - Bending Test 1-retest failure mode 80

Figure 3.7 - Bending Test 1 plywood spline and fasteners after failure 81

Figure 3.8 - Bending Test 2 failure mode (head pull-through of self-tapping screws) .... 82

Figure 3.9 - Bending Test 2 failure mode (tension at lower laminations). 83

Figure 3.10 - Load-displacement data from CLT bending test under ambient conditions 83

Figure 3.11 - Intermediate-scale test furnace at Carleton University 86

Figure 3.12 - Third-point bending - Asymmetrical loading (fire test 1) 88

Figure 3.13 - Third-point bending - Symmetrical loading (fire tests 2 to 10). 88

Figure 3.14 - Bending moment and shear force diagrams of a beam in third-point bending 89

Figure 3.15 - Thermocouple locations in 3-ply CLTs 91

Figure 3.16 - Self-tapping screw instrumented with thermocouples. 92 
Figure 3.17 - Instrumented self-tapping screws drilled in middle third-span of a CLT assembly 92

Figure 3.18 - Fire Test 1 specimen prior to testing 97

Figure 3.19 - Fire Test 1 asymmetrical loading condition 98

Figure 3.20 - Fire Test 1 failure (fire integrity). 99

Figure 3.21 - Fire Test 1 residual cross-section after testing 100

Figure 3.22 - Fire Test 2 specimen installed inside the furnace frame 101

Figure 3.23 - Fire Test 2 failure (fire integrity) at $45 \mathrm{~min}$ 102

Figure 3.24 - Fire Test 2 residual cross-section after testing 103

Figure 3.25 - Fire Test 3 specimen prior to testing. 104

Figure 3.26 - Fire Test 3 after $54 \mathrm{~min}$ of fire exposure (no failure) 105

Figure 3.27 - Fire Test 3 residual cross-section after testing 106

Figure 3.28 - Fire Test 4 specimen prior to testing 107

Figure 3.29 - Fire Test 4 failure (fire integrity) at $43 \mathrm{~min}$ 108

Figure 3.30 - Fire Test 4 residual cross-section after testing 109

Figure 3.31 - Fire Test 5 specimen prior to testing 110

$$
\text { - xxi - }
$$


Figure 3.32 - Fire Test 5 failure (fire integrity) at $76 \mathrm{~min}$

Figure 3.33 - Fire Test 5 residual cross-section after testing ..... 112

Figure 3.34 - Fire Test 6 specimen installed inside the furnace frame 113

Figure 3.35 - Fire Test 6 failure (fire integrity) at $98 \mathrm{~min}$ 114

Figure 3.36 - Fire Test 6 residual cross-section after testing 115

Figure 3.37 - Fire Test 7 specimen installed inside the furnace frame 116

Figure 3.38 - Fire Test 7 with several burn-throughs along its perimeter. 117

Figure 3.39 - Fire Test 7 residual cross-section after testing 118

Figure 3.40 - Fire Test 8 prior to testing 119

Figure 3.41 - Fire Test 8 burn-through along the perimeter and at one location 120

Figure 3.42 - Fire Test 8 residual cross-section after testing 121

Figure 3.43 - Fire Test 9 specimen installed inside the furnace frame 122

Figure 3.44 - Fire Test 9 experiencing differential displacement between CLT panels 123

Figure 3.45 - Fire Test 9 fire integrity failure at $140 \mathrm{~min}$ 123

Figure 3.46 - Fire Test 9 residual cross-section after testing 124

Figure 3.47 - Fire Test 10 specimen prior to testing 125 - xxii - 
Figure 3.48 - Fire Test 10 burn-through along the CLT specimen perimeter 126

Figure 3.49 - Fire Test 10 residual cross-section after testing

Figure 3.50 - Heat delamination observed during fire testing. 133

Figure 4.1 - Flow chart for calculation structural fire-resistance (adapted from [37]) .. 140

Figure 4.2 - Example of the geometry used in the FEM 146

Figure 4.3 - Temperature profile - FEM compared to fire tests (at $35 \mathrm{~mm}$ ). 148

Figure 4.4 - Temperature profile - FEM compared to fire tests (at $70 \mathrm{~mm}$ ). 148

Figure 4.5 - Temperature profile - FEM compared to fire tests (at $105 \mathrm{~mm}$ ). 149

Figure 4.6 - Temperature profile - Comparison between FEM and test data from [10] 150

Figure 4.7 - Visualization of the FEM temperature profiles 151

Figure 4.8 - Various meshing evaluated for sensitivity analysis 153

Figure 4.9 - Temperature profiles using 3 various meshing sizes..... 154

Figure 4.10 - Meshing of the self-tapping screw (with and without threaded shank)... 155

Figure 4.11 - Temperature profiles with and without the threaded shank 156

Figure 4.12 - Temperature profiles with various sources for wood thermal properties 157

Figure 4.13 - Temperature profiles of CLT compared to solid nailed 2x8 slab [87] ..... 159 - xxiii - 
Figure 4.14 - Temperature profiles of CLT from various net emitted heat fluxes 160

Figure 5.1 - Example of half-lapped joint with air gap (not thightly fit) 165

Figure 5.2 - Schematic of the coupled thermal-structural model 167

Figure 5.3 - Failure time comparisons - Half-lapped joint. 170

Figure 5.4 - Coupled thermal-structural model prediction for the 5-ply half-lapped joint 171

Figure 5.5 - Observed fastener yield mode with half-lapped joints. 171

Figure 5.6 - Effect of moving the lapped joint interface on the predicted failure time.. 172

Figure 5.7 - Observed fastener yield mode with internal spline joint (Test 1) 174

Figure 5.8 - Failure time comparisons - Internal spline joint 176

Figure 5.9 - Coupled thermal-structural model prediction for the 5-ply internal spline 176

Figure 5.10 - Coupled thermal-structural model prediction for the 3-ply single surface spline 179

Figure 5.11 - Predicted failure time from the coupled thermal-structural model. 185

Figure 5.12 - Failure time from the coupled thermal-structural model compared to test data 185

Figure 6.1 - Comparison of fire integrity failure time for the half-lapped joint. 191 - xxiv - 
Figure 6.2 - Comparison of fire integrity failure time for the internal spline joint ........ 193

Figure 6.3 - Comparison of fire integrity failure time for the single surface spline joint 195

Figure 6.4 - Comparison of fire integrity failure time for the double surface spline joint 198 


\section{Nomenclature}

$c_{p} \quad$ Specific heat $\left(\mathrm{J} \cdot \mathrm{kg}^{-2} \cdot \mathrm{K}^{-1}\right)$

$D \quad$ CLT assembly total thickness (mm)

$d_{F} \quad$ Fastener shank diameter $(\mathrm{mm})$

$d_{o} \quad$ Zero-strength layer $(\mathrm{mm})$

$d_{v} \quad$ Effective shear depth (mm)

$E I_{e f f, 0} \quad$ Effective bending stiffness $\left(\mathrm{N} \cdot \mathrm{mm}^{2} \cdot \mathrm{m}^{-1}\right)$

$f_{b} \quad$ Specified strength in bending $(\mathrm{MPa})$

$f_{1} \quad$ Embedment strength of side member (MPa)

Embedment strength of main member where failure is wood bearing $(\mathrm{MPa})$

$f_{2}$

$=50 G\left(1-0.01 d_{F}\right)$ for parallel-to-grain loading (lag screw, nail, wood screw)

$=22 G\left(1-0.01 d_{F}\right)$ for perpendicular-to-grain loading (lags screw only)

$f_{3} \quad$ Embedment strength of main member where failure is fastener yielding (MPa)

$=110 G^{1.8}\left(1-0.01 d_{F}\right)$ for nail and wood screw

$f_{y} \quad$ Lag screw, nail or wood screw yield strength (MPa)

$G \quad$ Mean relative density

$G_{i} \quad$ Permanent load (dead load, also labeled $\left.D\right)$

$G A_{e f f, 0} \quad$ Effective shear stiffness $\left(\mathrm{N} \cdot \mathrm{m}^{-1}\right)$

$J_{A} \quad$ Toe-screwing factor

$J_{E} \quad$ End grain factor

$J_{G} \quad$ Group factor

$J_{P L} \quad$ Factor for reduced penetration

$K_{D} \quad$ Duration of load factor

$K_{j} \quad$ Joint coefficient

$K_{L} \quad$ Lateral stability factor

$K_{r b} \quad$ Adjustment factor for bending moment resistance of CLT panels

$K_{S F} \quad$ Service condition factor for connection or fastener

$K_{T} \quad$ Treatment factor

$K_{z b} \quad$ Size factor in bending for sawn lumber 


\begin{tabular}{|c|c|}
\hline$k_{x, y, z}$ & Thermal conductivity in $\mathrm{x}, \mathrm{y}, \mathrm{z}\left(\mathrm{W} \cdot \mathrm{m}^{-1} \cdot \mathrm{K}^{-1}\right)$ \\
\hline$k_{f i}$ & Specified strength adjustment factor for fire design \\
\hline$k_{m o d, f i}$ & Modification factor for fire design \\
\hline$L$ & Span $(\mathrm{m})$ \\
\hline$L_{g}$ & Length of gusset splice subjected to shear (mm) \\
\hline$L_{t}$ & Length of threaded shank penetration into main member $(\mathrm{mm})$ \\
\hline$L_{p t}$ & Fastener threaded shank penetration length $(\mathrm{mm})$ \\
\hline \multirow[t]{2}{*}{$l_{e f}$} & Embedment depth into member of a self-tapping screw (mm) \\
\hline & $=$ thread length - tip length \\
\hline$M_{\max }$ & Maximum applied bending moment $(\mathrm{N} \cdot \mathrm{m})$ \\
\hline$N_{r}$ & Factored lateral resistance $(\mathrm{N})$ \\
\hline$n_{F}$ & Number of fastener in a connection \\
\hline$n_{s}$ & Number of shear planes per screw \\
\hline$n_{u}$ & Unit lateral strength resistance of a connection $(\mathrm{N})$ \\
\hline$P$ & Applied load $(\mathrm{N})$ \\
\hline$P_{p t}$ & Factored head pull-through resistance $(\mathrm{N})$ \\
\hline$P_{r}$ & Factored lateral resistance parallel to grain $(\mathrm{N})$ \\
\hline$P_{r w}$ & Factored withdrawal resistance of wood screws $(\mathrm{N})$ \\
\hline$p_{u}$ & Unit lateral strength resistance of a lag screw connection for parallel-to-grain \\
\hline & loading $(\mathrm{N})$ \\
\hline$\dot{Q}$ & Internally generated heat $\left(\mathrm{W} \cdot \mathrm{m}^{-3}\right)$ \\
\hline$Q_{1}$ & Principal variable load (live load, also labeled $L$ ) \\
\hline$Q_{r}$ & Factored lateral resistance perpendicular to grain $(\mathrm{N})$ \\
\hline$q$ & Shear flow along the interface $\left(\mathrm{N} \cdot \mathrm{m}^{-1}\right)$ \\
\hline$\dot{q}_{c r}$ & Critical heat flux $\left(\mathrm{kW} \cdot \mathrm{m}^{-2}\right)$ \\
\hline$q^{\prime \prime}$ & Net heat flux impinging on a surface $\left(\mathrm{kW} \cdot \mathrm{m}^{-2}\right)$ \\
\hline$q_{c o n v}^{\prime \prime}$ & Emitted heat flux emitted by convection $\left(\mathrm{kW} \cdot \mathrm{m}^{-2}\right)$ \\
\hline$q_{r a d}^{\prime \prime}$ & Emitted heat flux emitted by radiation $\left(\mathrm{kW} \cdot \mathrm{m}^{-2}\right)$ \\
\hline
\end{tabular}




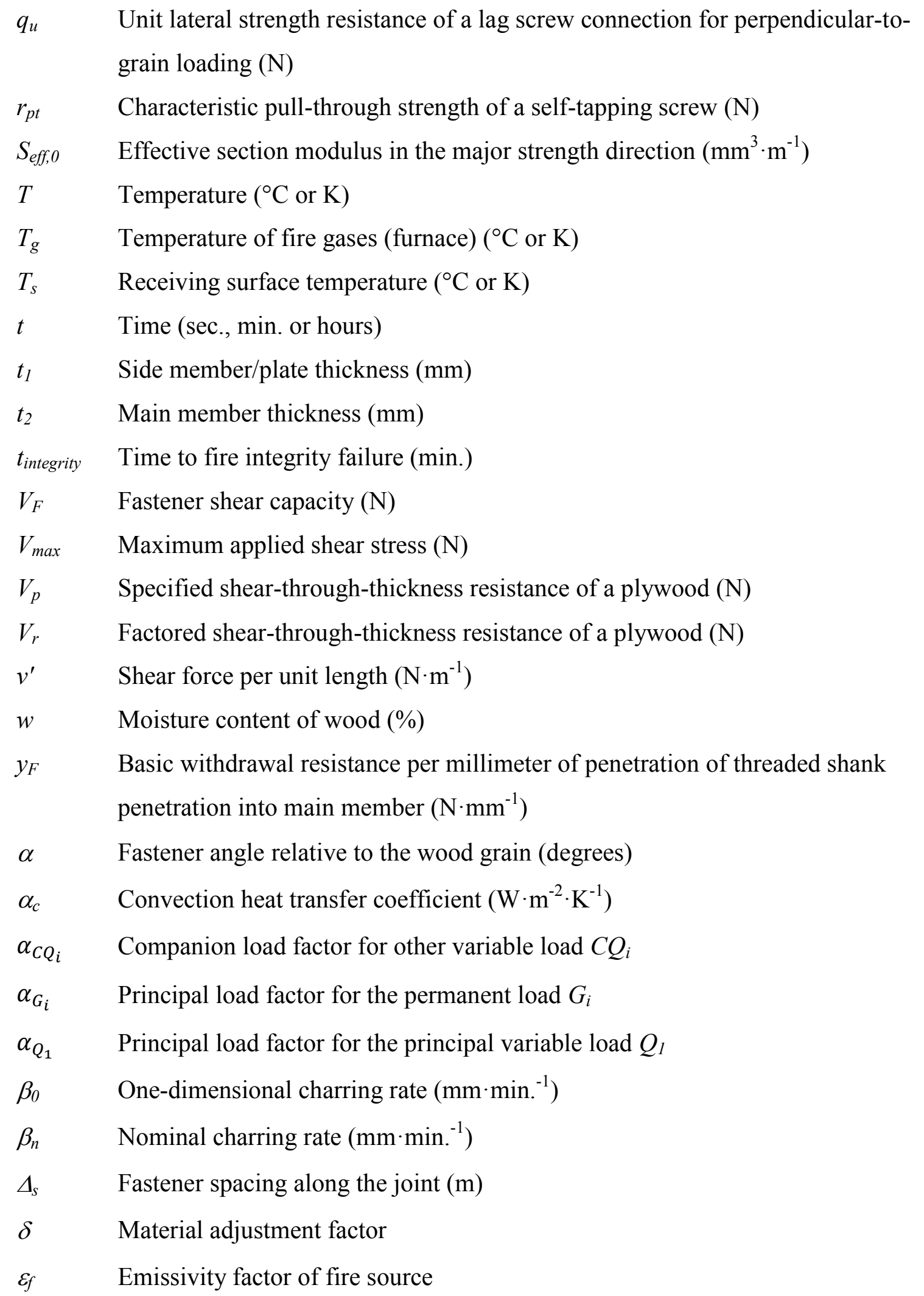




$\begin{array}{ll}\varepsilon_{m} & \text { Emissivity factor of material surface } \\ \phi & \text { Outside diameter for self-tapping screw }(\mathrm{mm}) \\ \varphi & \text { Resistance factor } \\ \Phi & \text { View factor } \\ \psi_{2,1} & \text { Load combination factor for quasi-permanent action } \\ \gamma_{M, f i} & \text { Partial safety factor for fire design } \\ \kappa & \text { Shear coefficient factor } \\ \rho & \text { Mean oven-dry relative density }\left(\mathrm{kg} \cdot \mathrm{m}^{-3}\right) \\ \sigma & \text { Stefan-Boltzmann constant }\left(5.67 \mathrm{x} 10^{-8} \mathrm{~W} \cdot \mathrm{m}^{-2} \cdot \mathrm{K}^{-4}\right)\end{array}$




\section{Introduction}

\subsection{Background}

During the past few years, a relatively new technology has emerged in North America and changed the way professionals design and build wood structures: Cross-laminated Timber (CLT) also called mass timber panels. These mass timber structural components consist of lumber boards stacked crosswise and connected together using a structural adhesive, mechanical fasteners or wooden dowels over their entire surface forming a flat massive wood panel (Figure 1.1). Mayo [1] states that mass timber is representing a comeback in wood construction and advancement in wood building technology that exceeds structural limits afforded by traditional wood-frame construction. According to Moses \& Gagnon [2], CLT has unique benefits and aesthetic, structural, thermal, fireresistance and low-environmental footprint properties when compared to other typical building materials. They have also been used in cost-effective applications such as residential buildings greater than four storeys and large industrial facilities $[3,4,5,6]$, which would typically require a non-combustible construction in accordance with the prescriptive "acceptable solutions" given in Division B of the National Building Code of Canada (NBCC) $[7,8]$. The latter historically limits the use of wood construction to buildings with a maximum of four storeys and relatively small areas, mainly due to potential fire safety issues related to the use of combustible structural materials, finishes and insulation. 


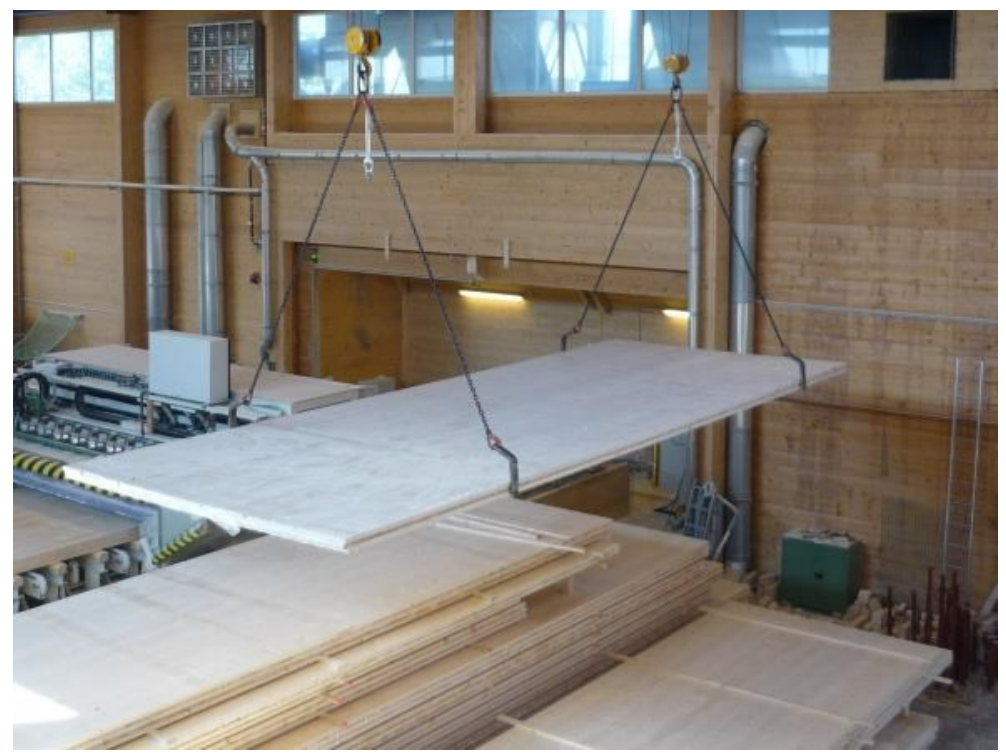

Figure 1.1 - CLT panels at the manufacturing plant

While CLT is well-established in Europe, it is not, as of 2015, a recognized building system within the "acceptable solutions" of the NBCC. As such, work on their implementation has just begun in Canada and the US. Among other design issues such as seismic and serviceability performance, one of the most important issues that need to be addressed in order to obtain code acceptance is the question of fire performance and compliance with fire-related provisions of the building codes.

CLT panels have the potential to provide good fire-resistance, often comparable to typical massive assemblies of non-combustible construction mainly due to the inherent nature of thick timber members to char slowly at a predictable rate. This material specific property allows massive wood systems to be designed in such a way to maintain their load-bearing function for extended durations when exposed to fire [9]. However, according to recent full-scale fire-resistance tests, fire integrity failure of CLT panel-to-panel connection in 
floor assemblies seems one of the predominant failure modes when using a half-lapped joint detail [10]. ISO 834-1 [11] defines fire integrity as the "ability of a separating element of building construction, when exposed to fire on one side, to prevent the passage through it of flames and hot gases or the occurrence of flames on the unexposed side". Although few tests have been performed, such failure mode was not observed in CLT wall assemblies under load. The latter usually exhibits buckling due to increasing secondorder effects (i.e. P- $\Delta$ effects) due to charring of the exposed surface. Nevertheless, the panel-to-panel joint configuration can affect the fire integrity performance of CLT assemblies when panel-to-panel joints can no longer prevent the passage of flames and hot gases. As reported in the revised Chapter 8 of the Canadian CLT Handbook [12], the sides of individual CLT panels are shielded from full fire exposure by adjacent panels collectively acting as a joint and partial exposure may occur as panels shrink and joints between panel open, leading to integrity failure at the joint.

Moreover, typical panel-to-panel joint configurations of CLT assemblies may consist of internal spline(s), single or double surface splines or half-lapped joints. These tightly fitted joint profiles should provide sufficient fire-resistance, but have yet to be properly evaluated for fire-resistance in CLT assemblies. What fire-resistance can be obtained from these joint details? How can one predict the fire-resistance of these joint details? Which joint detail provides better fire-resistance and achieves the best balance between structural resistance, ease of assembly and fire-resistance? It is the intent of this study to answer these questions through fire testing as well as numerical and analytical analyses. 


\subsection{Objectives}

The main objective of this study is to develop design models that would predict the fire integrity resistance of four (4) panel-to-panel connection details commonly used in CLT floor assemblies. More specifically, this study aims at:

- Evaluating the fire integrity resistance of various CLT panel-to-panel joints exposed to the CAN/ULC S101 standard time-temperature curve in an intermediate-scale test furnace;

- Developing a finite element heat transfer model to predict the temperature profiles and charring rates of CLT floor assemblies exposed to a standard fire

- Developing a coupled thermal-structural to simulate the mechanical behaviour of connections subjected to lateral loads;

- Developing joint coefficient values for use in a simplified design model that would calculate the fire integrity resistance of CLT constructions;

- Providing details for achieving the best balance between structural resistance, ease of assembly and fire integrity resistance. 


\subsection{Scope and Limitations}

Various experimental tests have been carried throughout this research for properly understanding the thermal and mechanical behaviour of CLT panel-to-panel joint configurations. While the mechanical model developed in this study is intended to simulate the mechanical behaviour of connections subjected to lateral loads, the scope of the fire tests was not to evaluate the actual structural fire-resistance of the connections but rather at investigating the influence of the presence of metal fasteners and splines on the fire integrity resistance of CLT floor elements (i.e. flame-through).

Furthermore, The CLT panels used in this study were manufactured with $35-\mathrm{mm}$ thick lumber laminations and a polyurethane structural adhesive compliant with ANSI/APA PRG-320 standard. The panel-to-panel joints were assembled in such a way to avoid gaps between the adjacent CLT panels. The specimens were subjected to one-way bending and the joints were oriented parallel to the major strength axis of the CLT panels.

As such, the models developed in this study are limited to CLT floor assemblies designed and solicited in one-way bending, in which the panel-to-panel joints are tightly fitted (no air gaps). The models are also limited to ANSI/APA PRG-320 compliant CLT panels manufactured with laminations of $35 \mathrm{~mm}$ in thickness and exposed to the standard CAN/ULC S101 time-temperature curve. 


\subsection{Outline of Thesis}

This thesis is presented in seven (7) chapters. Chapter 1 introduces cross-laminated timber as a building element and states the objectives of the study along with its scope and limitations.

A literature review given in Chapter 2 includes an overview of the concept of fireresistance of building materials, fire-resistance of CLT assemblies, current CLT panel-topanel connection detail, connection capacities as well as wood and steel properties at elevated temperatures used in finite element modeling.

Chapter 3 presents a series of ten (10) intermediate-scale fire-resistance tests, which generated valuable information with respect to the thermal and mechanical behaviour of the panel-to-panel joints. They were also used in the development and verification of the models, namely for joint coefficient values for the simplified design model.

Chapter 4 presents a three-dimensional (3D) finite element heat transfer model (FEM) for predicting the temperature profiles within CLT floor assemblies exposed to a standard fire. The FEM allows determining the charring rate for each lamination and the time for the char front to reach a given depth within the CLT joint. The thermal properties used in the FEM were calibrated accordingly to replicate the charring rate for each lamination and heat delamination of the adhesive.

The second model detailed in Chapter 5 is intended to simulate the mechanical behaviour of connections subjected to lateral loads (i.e. in-plane of the CLT panels) when exposed 
to a standard fire. Such coupled thermal-structural model provides benchmarking as to which floor panel-to-panel joint configuration provides better fire-resistance by optimizing the joint geometry and achieving the best balance between structural resistance, ease of assembly and fire-resistance. A minimum penetration depth of the selftapping screw into the main member taken as five times the fastener's shank diameter (5 $\left.d_{F}\right)$ is suggested as a failure criterion for fire integrity resistance.

A simplified design model is presented in Chapter 6 for predicting the fire integrity resistance of the four (4) evaluated panel-to-panel joints. The simplified design model requires joint coefficient values applicable to all four (4) joint configurations evaluated in this study.

Finally, conclusions, recommendations and suggestions for future research are presented in Chapter 7. 


\section{Literature Review}

An innovative wood building system was born in Austria and Germany in the early 1990's and since then, is increasingly being used in European non-residential constructions replacing concrete, masonry and steel [13]. Cross-Laminated Timber panels (CLT) are widely used in building systems in a similar manner to concrete slabs and solid wall elements (Figure 2.1) as well as those from heavy timber construction by limiting concealed spaces due to the nature of massive timber elements.

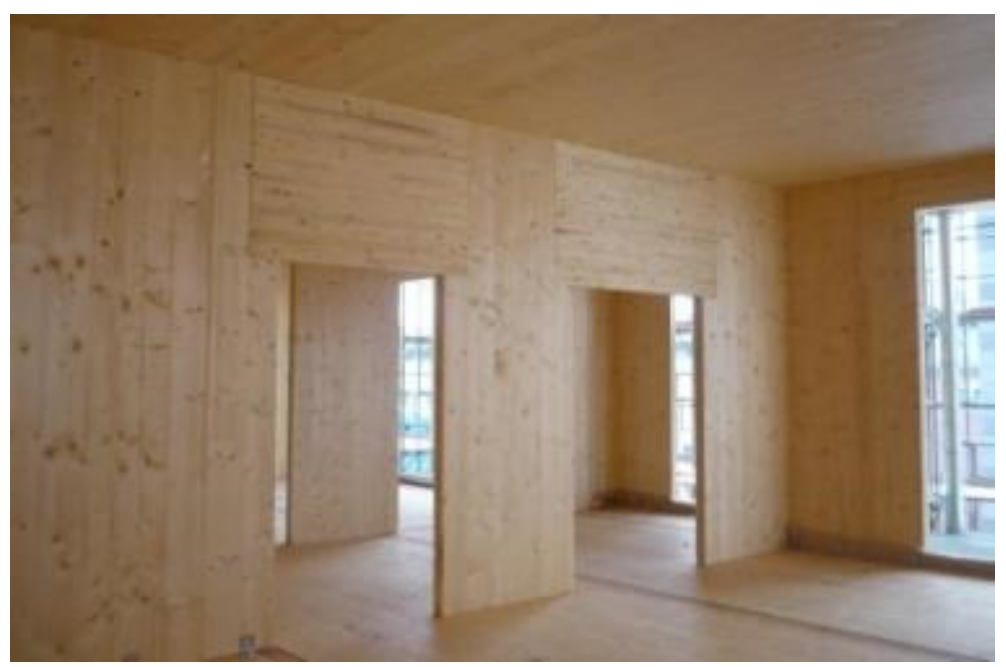

Figure 2.1 - CLT construction

CLT is a prefabricated solid engineered wood panel made of at least three orthogonally bonded layers of solid-sawn or structural composite lumber that are laminated by gluing of longitudinal and transverse layers with structural adhesives to form a solid rectangularshaped, straight, and plane timber slab intended for roof, floor or wall applications [14] (Figure 2.2). CLT can also be manufactured using mechanical fasteners or wooden 
dowels. It can be manufactured in panels up to a thickness of $600 \mathrm{~mm}$, width ranging from $600 \mathrm{~mm}$ to $3 \mathrm{~m}$ and lengths up to $18 \mathrm{~m}$.
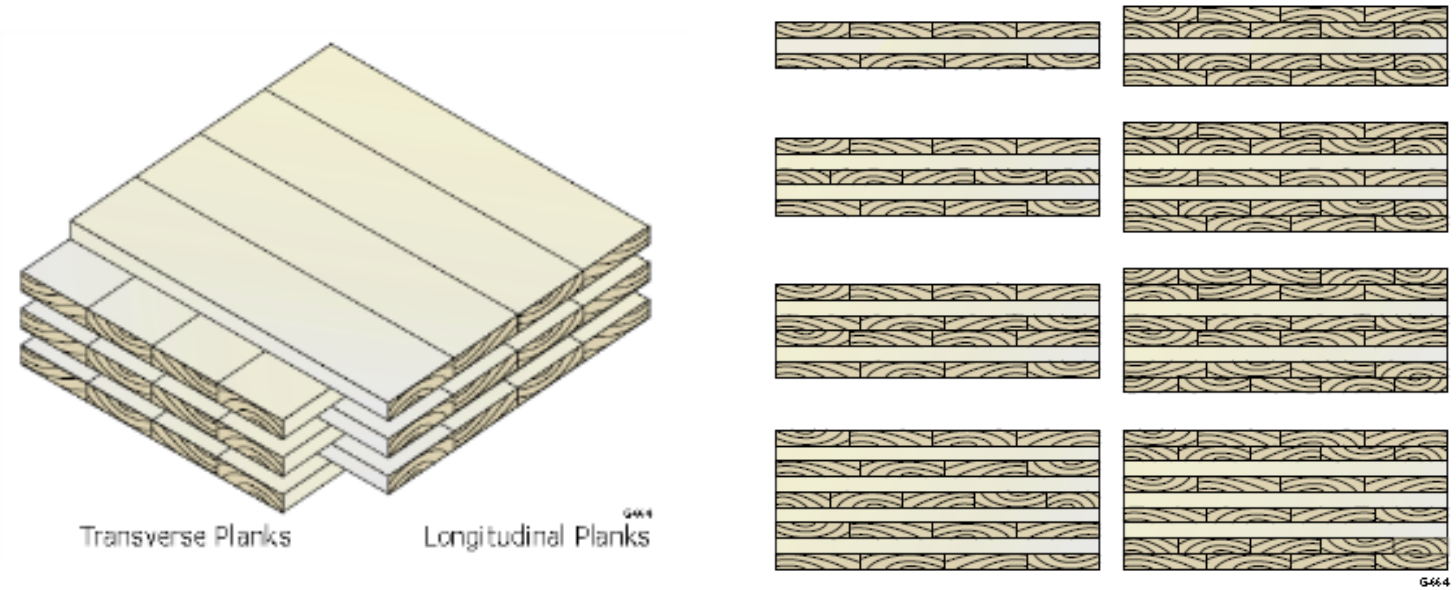

Figure 2.2 - Configuration (left) and possible cross-section (right) of a CLT panel [3]

As CLT construction is, to date, not a recognized building system within the "acceptable solutions" of the NBCC, its performance attributes such as fire-resistance need to be assessed by conducting full-scale fire-resistance tests or using published listings from accredited agencies.

To fully understand the performance requirements for CLT panel-to-panel fire performance, this literature review includes an overview of the concept of fire-resistance of building materials, fire-resistance of CLT assemblies, current CLT panel-to-panel connection detail, connection capacities as well as wood and steel properties at elevated temperatures. 


\subsection{Fire-Resistance of Building Construction Materials}

Fire safety in buildings can be provided through various methods. Typically, designers will follow the prescriptive provisions given in Division B of the National Building Code of Canada (NBCC) [15]. Providing fire-resistance rated compartments in buildings aims at limiting the probability of fire spread beyond its point of origin. Such compartmentalization allows meeting the "fire impact management" objective of the NFPA 550 "Guide to the Fire Safety Concepts Tree" [16]. The performance level of such separating function is typically evaluated through standard fire-resistance tests.

\subsubsection{Fire-Resistance Test Method}

The fire-resistance of a building assembly is traditionally assessed by subjecting a replicate of the assembly to a standard fire-resistance test method such as CAN/ULC S101 "Standard Method of Fire Endurance Tests of Building Construction Materials" [17]. The test method requires a wall or floor assembly to be exposed to a severe fire in which the temperature of the fire gases $\left(T_{g}\right.$ in $\left.{ }^{\circ} \mathrm{C}\right)$ increases over time ( $t$ in minutes) following a standardized time-temperature curve as shown in Figure 2.3, which can be numerically computed using Equation (2.1).

$$
T_{g}=20+750\left(1-e^{-0.49 \sqrt{t}}\right)+22 \sqrt{t}
$$




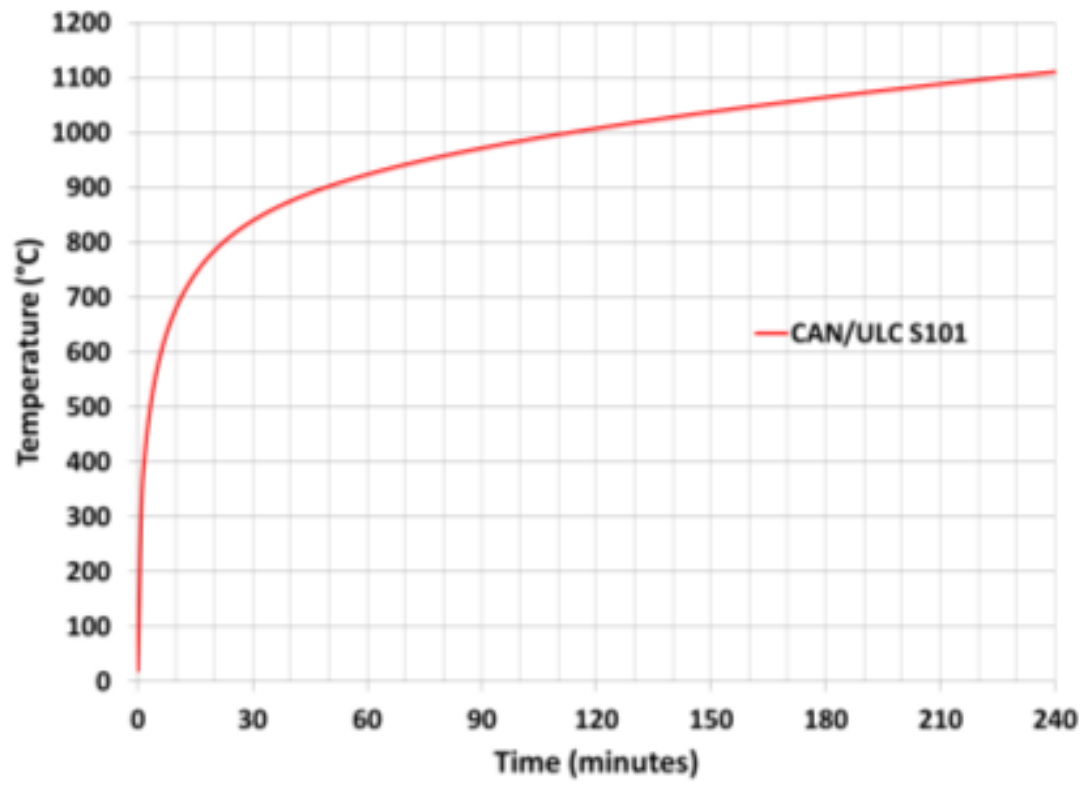

Figure 2.3 - CAN/ULC S101 standard time-temperature curve using Equation (2.1)

As defined in ISO 13943 "Fire safety - Vocabulary" [18], fire-resistance is "the ability of a test specimen to fulfil, for a stated period of time, the required criterion or criteria specified in a standard fire-resistance test". The criteria evaluated in standard fireresistance test relates to the fire integrity, fire stability and thermal insulation. The time at which the assembly can no longer satisfy any one of these criteria defines the assembly's fire-resistance.

Building systems such as floor and roof assemblies are evaluated for all three criteria while singular structural components such as beams and columns are only evaluated for their fire stability. 


\subsubsection{Load-bearing Function}

The load-bearing function (i.e. fire stability) requires that the assembly be capable of supporting the design load for the entire duration of the fire test. The CAN/ULC S101 test method also requires the assembly to be loaded to a specified gravity load that produces a factored load effect as close as practically possible to the factored resistance of the test assembly (as opposed to a specified gravity load limited by serviceability criteria such as deflection or vibration). This ensures that the fire-resistance obtained for a particular assembly is appropriate for use in any building independently of the loading conditions.

However, the rationale of such loading requirements seems neither reasonable, nor economical when assessing fire-resistance of high load-carrying assemblies such as concrete, steel and even CLT, as it would require applying very heavy loads. Moreover, the maximum loading capacity from laboratories steel-framed test apparatus make it very difficult for CLT assemblies to be evaluated under full load conditions. In fact, most North American fire test facilities do not have the capacity to load CLT assemblies to their full loading conditions. It is also doubtful that CLT floor assemblies will be structurally loaded anywhere near their ultimate capacity due to serviceability limits (deflection or vibration). Testing CLT floor assemblies under full loading conditions would have a large impact on their fire-resistance duration and would most likely not provide the most economical design. As such, a rationalization of the fire-resistance test loading conditions, based on first principles such as charring rate, should then be 
considered when developing a more efficient and economical mechanics-based calculation methods for mass timber assemblies [12, 19].

\subsubsection{Separating Function}

The separating function consists of two specific requirements, namely fire integrity and thermal insulation. The fire integrity criterion requires that the assembly be capable of restraining the passage of flame or gases hot enough to ignite a cotton pad on the unexposed side while the thermal insulation criterion requires that the assembly be capable to prevent the temperature rise on the unexposed surface from being greater than $180^{\circ} \mathrm{C}$ at any location, or an average of $140^{\circ} \mathrm{C}$ measured at 9 specific locations, above the initial temperature.

\subsection{Fire-Resistance of Cross-Laminated Timber Assemblies}

Few research organizations have studied the fire performance of CLT assemblies around the globe during the past decade. Work started in Europe, where CLT was born, and expanded to Canada as well as in the United States where various mechanics-based fireresistance models have been developed [12, 20, 21, 22, 23, 24]. As of 2012, Japan has also started their work related to fire performance of CLT and the calculation method is not yet defined [25].

\subsubsection{Europe}

Very limited full-scale fire-resistance testing has been performed with CLT constructions. Frangi et al. [20] conducted experiments on unloaded CLT specimens for only evaluating 
their charring rates [26]. The fire tests were based on the ISO 834 standard fire exposure and performed on a small horizontal furnace of $1.0 \times 0.8 \mathrm{~m}$. The results showed that the behaviour of CLT panels exposed to fire is strongly influenced by the thermal behaviour of the adhesive used for gluing the lumber boards. Indeed, it was observed that depending on the adhesive performance at elevated temperatures, falling off of the charred layers was clearly observed during the fire tests, leading to increased charring rates when compared to that of a homogenous timber slab.

An adapted methodology for CLT assemblies has thereby been developed in Europe and is currently being used on proprietary basis by European CLT manufacturers and recommended to use for fire durations no greater than 2 hours $[20,21,22,23]$. The European model follows the same principles as those prescribed in Eurocode 5: part 1-2 [27] applicable to timber components. However, due to heat delamination characteristics observed during fire-resistance tests, the charring rate increases due to the fall-off of the charred layer. As such, the model suggests using a constant charring rate until a first glue line is reached. At that time, the charring rate is doubled until a charred layer of $25 \mathrm{~mm}$ is formed and then drops back to the normal rate (e.g. $0.65 \mathrm{~mm} / \mathrm{min}$ ) until the next glue line is reached, and so on. According to Klippel et al. [28], the effect of falling off of the charred layer is not significant for CLT walls and thus a constant charring rate could be applied throughout.

Moreover, the model evaluates only the load-bearing function of CLT assemblies and follows the classical laminates wood composite theory as described by Bodig \& Jayne 
[29], neglecting the shear deflection and assuming that the cross plies are not taken into account in the calculation of the design moment resistance of floors and wall axial compression capacity. A CLT European standard is being drafted as of 2012 [30] and only the load-bearing function of CLT fire-resistance is being addressed. It also refers to Eurocode 5: part 1-2 cross-section design procedure. As of 2015, this new standard has yet to be officially implemented into the European regulatory environment.

The design procedure prescribed in Eurocode 5: part 1-2 describes the calculation of the structural stability and the fire integrity of timber components. The structural requirement can be determined using the reduced cross-section method using a constant charring rate as a function of time. The European fire-resistance calculation method uses a strength adjustment factor $\left(k_{f i}\right)$, a modification factor for fire design $\left(k_{\text {mod,fif }}\right)$, a partial safety factor for fire design $\left(\gamma_{M, f i}\right)$ as well as a zero-strength layer $\left(d_{o}\right)$ of $7 \mathrm{~mm}$ to account for the wood heated zone (assumed to provide no strength, nor rigidity). According to Schmid et al. [21], the zero-strength layer for CLT assemblies should however be taken as $10 \mathrm{~mm}$ for floors and $16 \mathrm{~mm}$ for walls, and is a function of the number of plies, residual thickness, whether the assembly is initially protected or unprotected, and the stress distribution (exposed side in tension or compression). The strength adjustment factor allows converting the $5^{\text {th }}$ percentile strength property to the $20^{\text {th }}$ percentile in normal conditions and is based on products' coefficient of variation (COV). For example, a solid timber beam would have a strength adjustment factor of 1.25 while a glued-laminated timber (which typically exhibits a lower COV than timber) would have a 1.15 strength adjustment factor. The modification and partial safety factors are both set to unity in fire 
design. Furthermore, a combination factor for quasi-permanent action $\left(\psi_{2,1}\right)$ ranging from 0.3 to 0.8 depending on the building occupancy group in accordance with Eurocode 0 [31] is also recommended, thus providing a reduced load combination for fire design. From the European methodology detailed in [23], a CLT floor panel made from 5 plies of $35 \mathrm{~mm}$ in thickness (175 $\mathrm{mm}$ total), the effective residual depth after 2 hours of standard fire exposure would be $42.5 \mathrm{~mm}$, resulting in only the $5^{\text {th }}$ (longitudinal) ply remaining for carrying loads (neglecting the cross layers).

Eurocode 5: part 1-2 also prescribes a joint coefficient $\left(K_{j}\right)$ for determining the fire integrity of timber cladding and gypsum boards having gaps no greater than $2 \mathrm{~mm}$. The methodology is, however, not yet evaluated for applicability to CLT assemblies. Typical joint profiles and their assigned joint coefficient are shown in Table 2.1. Based on the European procedure, it may be appropriate to determine the fire integrity of CLT assemblies by using Equation (2.2).

$$
t_{\text {integrity }}=K_{j} \cdot \frac{D}{\beta_{0}}
$$

where $K_{j}$ is the joint coefficient as per Table $2.1, D$ is the CLT assembly total thickness and $\beta_{0}$ is the one-dimensional charring rate taken as $0.65 \mathrm{~mm} / \mathrm{min}$ for softwood gluedlaminated timber. It can be seen from Table 2.1 that the butt joint is the less effective in regards to fire integrity, closely followed by the half-lapped joint. The double tongueand-groove is the better joint detail in accordance with the European model. Assuming 5- 
plies CLT floor panels of $175 \mathrm{~mm}$ total thickness, joined together with a half-lapped joint of $64 \mathrm{~mm}$, one can assume that a fire integrity of $80 \mathrm{~min}$ may be assigned.

Table 2.1 - Joint Coefficient per Eurocode 5 : Part 1-2 [27]

Type

Butt-joint

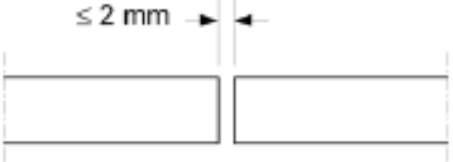

0.2

0.3

Half-lapped Joint

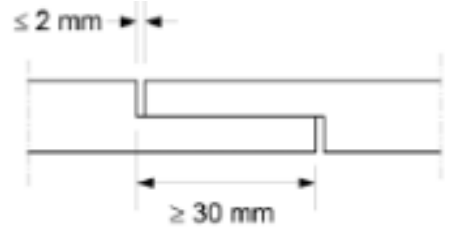

0.4 Spline

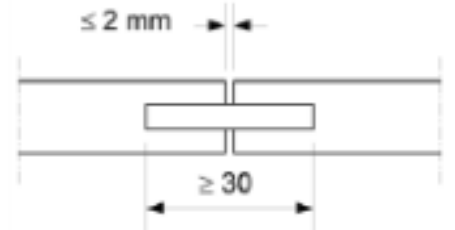

Single Tongue \& Groove

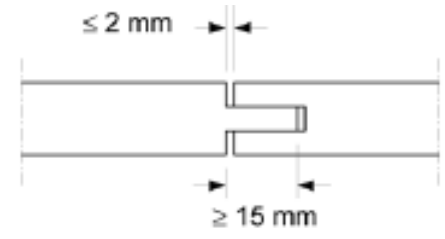

0.4

0.6
Double Tongue \& Groove

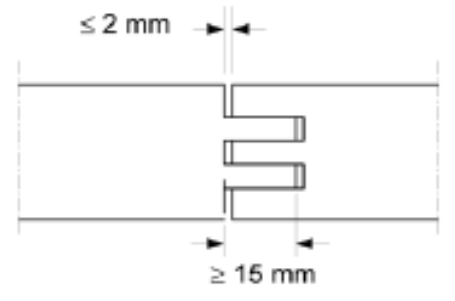


Lastly, there are no known studies published with respect to the fire performance of connections and fasteners in CLT assemblies, which are somewhat a fundamental design aspect for ensuring that CLT panels are securely fastened together and kept structurally sound for any specific fire exposure and duration.

\subsubsection{United States}

In order to facilitate market acceptance of CLT assemblies in the United States, an American edition of FPInnovations' CLT Handbook was published in early 2013 [32]. The handbook was intended to provide the latest technical and scientific knowledge of CLT attributes, including structural, seismic and fire performance. The US edition of the chapter on fire performance of CLT assemblies [12] has been developed using the current design procedure prescribed in the 2005 ASD/LRFD Manual for Engineered Wood Construction [33] with respect to strength adjustment factors to the mean values and adapted with a stepped non-linear charring rate model to account for potential adhesive delamination when exposed to elevated temperatures.

The structural integrity can be established by using a reduced cross-section, similarly to the European and Canadian methods described herein. The reduced cross-section geometric properties are determined using the laminated wood composite theory as described by Bodig \& Jayne [29], neglecting the shear deflection and assuming that the cross plies are not taken into account in the calculation of the design moment resistance of floors and wall axial compression capacity. The US methodology uses a standard nominal charring rate of $0.635 \mathrm{~mm} / \mathrm{min}(1.5 \mathrm{in} / \mathrm{hr}$.), a non-linear stepped charring rate 
adjustment, a zero-strength layer multiplier of 1.2, and an adjustment factor from design to ultimate strength values. From this US methodology for a CLT floor panel made from 5 plies of $35 \mathrm{~mm}$ in thickness (175 $\mathrm{mm}$ total), the effective residual depth after 2 hours of standard fire exposure would be $78 \mathrm{~mm}$, thus $8 \mathrm{~mm}$ from the $3^{\text {rd }}$ ply and the entire $5^{\text {th }}$ (longitudinal) ply remaining for supporting the loads.

Moreover, the 2013 American edition of the CLT handbook provides a design procedure for estimating the fire integrity of half-lapped joints using the same equation as that of the European approach given in Equation (2.2). The American design procedure assigns a joint coefficient for half-lapped joints of 0.35 and a constant nominal charring rate $\left(\beta_{n}\right)$ of $1.5 \mathrm{in} /$ hour $(0.635 \mathrm{~mm} / \mathrm{min})$. The joint coefficient value of 0.35 for half-lapped joint was derived from the recorded times to failure, CLT thicknesses and test configuration from full-scale fire-resistance tests conducted by Osborne et al. [10]. Assuming 5-ply CLT floor panels of $175 \mathrm{~mm}$ total thickness, joined together with a half-lapped joint of $64 \mathrm{~mm}$, one can assign a fire integrity of 96 min, which is 16 min greater than the European prediction (that uses a joint coefficient of 0.30 ).

\subsubsection{Canada}

The first Canadian fire-resistance design method for CLT has been published by Craft [34] in 2011. The method is largely based on the European model. The Canadian model, as of 2011, allowed only for evaluating the structural fire-resistance of CLT assemblies using a constant one-dimensional charring rate of $0.65 \mathrm{~mm} / \mathrm{min}$. However, it is also mentioned that the constant charring rate assumes that the CLT will behave similarly to 
solid wood (i.e. unglued). It is also mentioned that should the adhesive used cannot provide sufficient strength and durability when exposed to temperatures beyond that associated with charring of the wood, thus would exhibit heat delamination (fall-off) characteristics, special considerations should be given to the impact on the charring rate. While no precise information is provided on how to consider heat delamination, it does reference the design methodology developed by Frangi et al. [20] for further guidance. From this methodology for a CLT floor panel made from 5 plies of $35 \mathrm{~mm}$ in thickness (175 mm total), the effective residual depth after 2 hours of standard fire exposure would be $90 \mathrm{~mm}$, thus part of the $3^{\text {rd }}$ and the entire $5^{\text {th }}$ (longitudinal) plies remaining for carrying the loads. When compared to the European model, a char depth located in the longitudinal layer (major strength axis) significantly affects the residual structural capacity, especially when neglecting the cross layers.

The 2011 Canadian fire design procedure also stipulates that the half-lapped joints tested in full-scale wall and floor fire-resistance tests prove to have sufficient fire integrity resistance. It also suggests that the use of splines, tongue-and-groove joints, or lap joints that are tightly fitted should provide sufficient fire resistance. It was however recommended, in the case of a lap joint, that either a bead of construction adhesive or a gasket material be used to ensure that the joint is properly sealed. Lastly, it is suggested that provided the fire separating criteria (thermal insulation and fire integrity) are met, the fire-resistance rating for all loadbearing CLT assemblies would be governed by the loss of structural resistance during fire exposure. 
Further investigations have since then been carried out by FPInnovations and the National Research Council of Canada in an attempt to better understand the fire behaviour of CLT assemblies subjected to the CAN/ULC S101 standard fire exposure. It has been found that fire integrity (i.e. flame-through the joint as shown in Figure 2.4) is one of the predominant failure modes of CLT floor assemblies under load [10]. Such failure mode was not observed in CLT wall assemblies under load. The latter usually exhibits buckling failure due to increasing second-order effects (i.e. P- $\Delta$ effects) due to charring of the fire-exposed surface. One can assume that the joint fire integrity may be less critical for wall applications as it is for floors as the fasteners are less likely to be subjected to combined in-plane and out-of-plane loading.

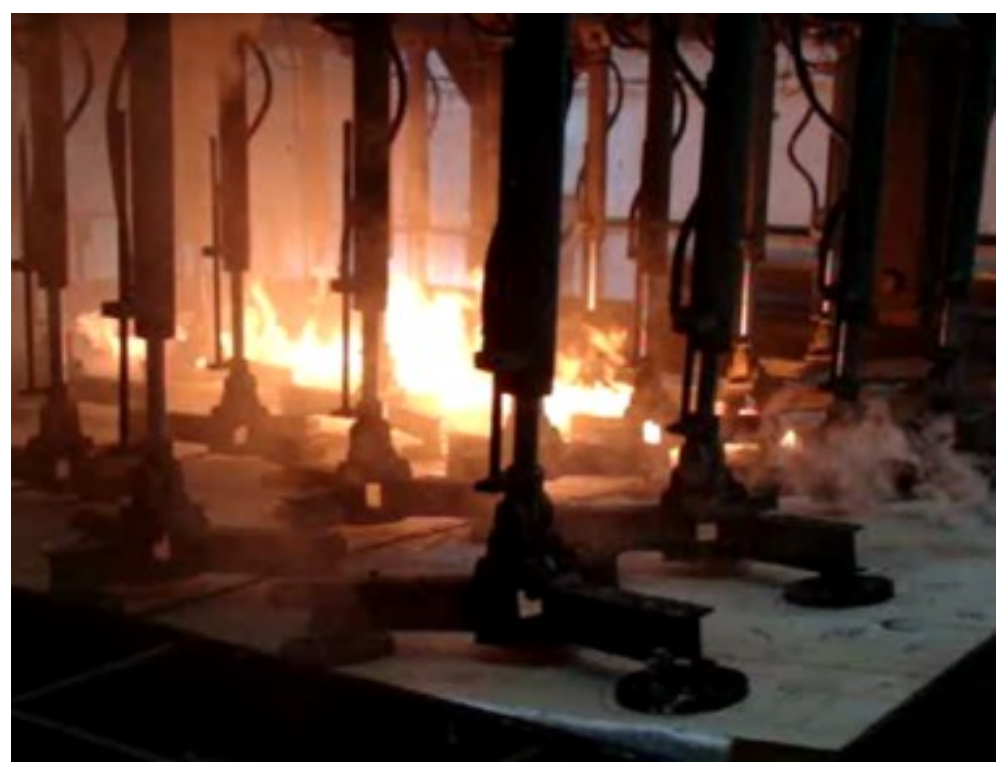

Figure 2.4-CLT panel-to-panel fire integrity failure (flame-through) (credit: NRC/FPInnovations) 
The findings of this test series helped refining the 2011 method and a new structural model has been published by FPInnovations in 2014 [24]. Mainly, the charring model accounts for an increase in the rate of charring for laminations thinner than $35 \mathrm{~mm}$ and for adhesive heat delamination by resetting the zero-strength layer every time a glue line is reached. By resetting the zero-strength layer, it effectively increases the charring rate for the first 20 minutes of fire exposure and then the rate drops back to normal until the next glue line is reached (e.g. $0.65 \mathrm{~mm} / \mathrm{min}$ for $35-\mathrm{mm}$ thick lamination). The structural fire-resistance calculation method is detailed in subsection 5.4 of [24], in which specific considerations are provided for CLT walls subjected to second-order effects (P- $\Delta$ effects). The structural model is based on the reduced cross-section determined by subtracting the char depth from the initial panel thickness. Guidance for determining the fire integrity is also given in subsection 5.5 of [24], but is limited to half-lapped joints. The latter is determined using Equation (2.2) and the same joint coefficient value of 0.35 (for halflapped) prescribed in the US methodology.

From this 2014 methodology for a CLT floor panel made from 5 plies of $35 \mathrm{~mm}$ in thickness (175 $\mathrm{mm}$ total), the effective residual depth after 2 hours of standard fire exposure would be $77 \mathrm{~mm}$, thus $7 \mathrm{~mm}$ of the $3^{\text {rd }}$ ply and the entire $5^{\text {th }}$ (longitudinal) ply remaining for carrying the loads. Moreover, the same 5-plies CLT floor panels of 175 $\mathrm{mm}$ total thickness, joined together with a half-lapped joint of $64 \mathrm{~mm}$, would have a fire integrity resistance of $94 \mathrm{~min}$. 
Lastly, as suggested in the 2011 Canadian Model, the thermal insulation criterion can be verified using Janssens \& White's model [35], as per Equation (2.3) and can be shown that it is more likely to be always fulfilled due to the inherently low thermal conductivity of wood.

$$
T=T_{i}+\left(T_{p}+T_{i}\right) \cdot\left(1-\frac{x}{a}\right)^{2}
$$

where $T$ is the temperature $\left({ }^{\circ} \mathrm{C}\right), T_{i}$ is the initial ambient temperature (usually assumed to be $20^{\circ} \mathrm{C}$ ), $T_{p}$ is the char front temperature (taken as $300^{\circ} \mathrm{C}$ ), $x$ is the distance from the char front ( $\mathrm{mm})$ and $a$ is the thermal penetration depth (mm). A thermal penetration depth for softwoods exposed to the standard time-temperature curve between 33 and $35 \mathrm{~mm}$ is suggested by White \& Dietenberger [36]. Enrocode 5: part 1-2 recommends a value of 40 mm [27]. According to Equation (2.3), a residual thickness between 11 and $12 \mathrm{~mm}$ between the char front and the unexposed side would allow the temperature to be less than $160^{\circ} \mathrm{C}$, which would fulfill the CAN/ULC S101 thermal insulation criterion of limiting a temperature rise below $140^{\circ} \mathrm{C}$ above initial temperature $\left(T \leq 20^{\circ} \mathrm{C}+140^{\circ} \mathrm{C}=\right.$ $\left.160^{\circ} \mathrm{C}\right)$.

\subsubsection{Effect of Air Gaps in Joints}

As explained by Buchanan [37], joints between wood-based systems, such as CLT floor assemblies, may increase due to wood shrinkage as a result of varying interior conditions (moisture content and relative humidity) during the service life of buildings. Being an anisotropic material, wood shrinks (and swells) the most in the tangential direction (along 
the annual rings), approximatively half as much in the radial direction (across the annual rings) and very little longitudinally (along the wood grain). As an example, shrinkage from green to oven-dry moisture content for Black Spruce varies from $6.8 \%$ to $4.1 \%$ for the tangential and radial direction, respectively. A value of $0.1 \%$ to $0.2 \%$ for the longitudinal shrinkage is typically assigned to most wood species [38]. It is reported by Buchanan [37] that if a gap is not greater than $3 \mathrm{~mm}$, the design for fire-resistance may not be significantly impacted from flaming through the joint.

Richardson \& Batista [39] evaluated the fire-resistance of timber decking and concluded that the assumptions regarding the joint coefficients set forth in Eurocode 5: part 1-2, while being conservative, are justifiable. However, the gap limitations of $2 \mathrm{~mm}$ may not be appropriate for North American building constructions during winter season where the moisture content of wood components may be low and gaps between timber decking would be wider. The authors suggested that joint coefficients be reduced by half if the European methodology is to be used in North America. As an example, a 5-ply CLT floor panels used in North American climate conditions, of $175 \mathrm{~mm}$ total thickness, joined together with a half-lapped joint of $64 \mathrm{~mm}$, would have a fire integrity resistance of 40 min, which is significantly lower than the 94 min predicted using the 2014 Canadian methodology, suggesting that Richardson \& Batista's recommendations may be overly conservative.

In a study on multi-storey timber buildings, Kampmeir [40] conducted a series of compartment fire tests to assess the fire behaviour of joints in timber construction. Three 
(3) different types of joints were evaluated, as shown in Figure 2.5. During the fire experiments, several smoke leakages were observed. The author concluded that a maximum the double tongue-and-groove detail performed better and that the gap between elements must not exceed $2 \mathrm{~mm}$ to prevent an integrity failure. If the gap is greater, it is recommended that non-combustible insulation be used to fill the gap and be smoke-tight using a fire stop sealant.
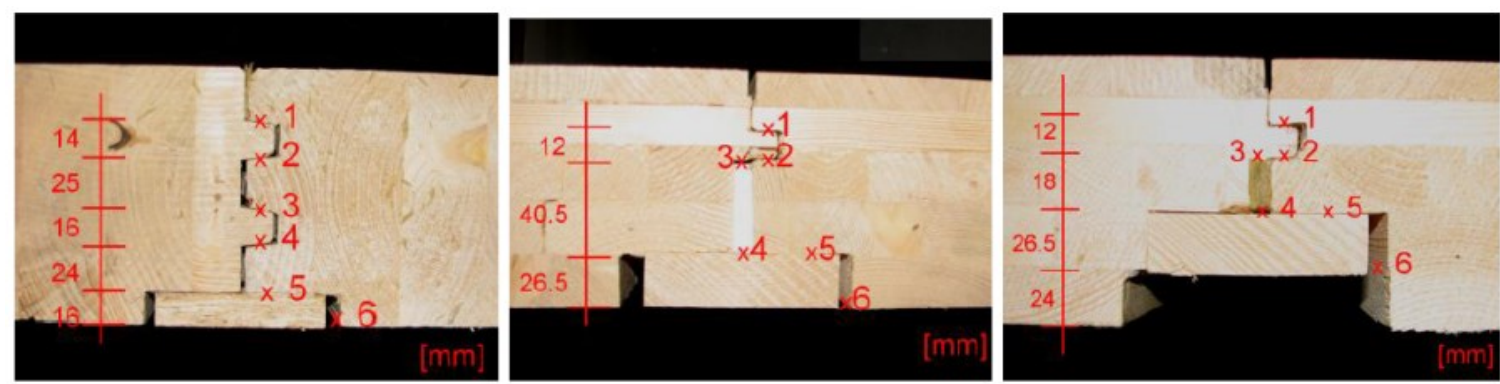

Figure 2.5 - Timber joints studied by Kampmeir [40]

In a recent study on the fire performance of timber floors in multi-storey buildings, O'Neil [41] evaluated the load-bearing and separating functions of timber floor assemblies. His criterion for determining a fire integrity failure was to limit the residual thickness to $15 \mathrm{~mm}$ to ensure that the top surface would not significantly increase in temperature (i.e. would fulfil the integrity temperature rise criteria detailed in subsection 2.1.3). This minimum thickness was set arbitrary and considered a conservative value. It was deemed that $15 \mathrm{~mm}$ would allow meeting both the insulation and integrity criteria.

Medina [42] also observed flame-through between CLT panels in fire compartment experiments. The CLT walls were joined using a typical half-lapped joint detail and was 
initially planned to be sealed as with his previous experiments. Unfortunately, the sealant was not applied and significant hot gases flowed through the joint and led to flaming outside the compartment in the early stage of the fire test (Figure 2.6), clearly demonstrating the importance of proper installation and sealing of the joints.

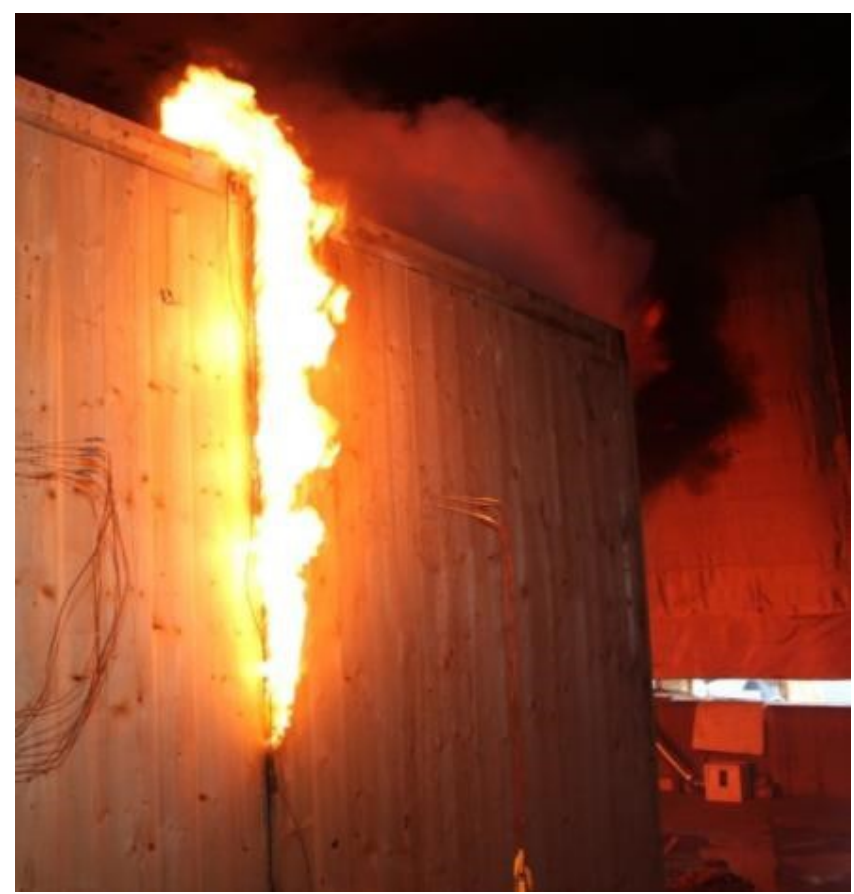

Figure 2.6 - Flaming through a half-lapped joint during a fire test by Medina [42]

Considering all the previous studies, it is important to mention that CLT panel-to-panel configurations typically require to be tightly fit by using, as an example, a beam grip with ratchet and hooks before fastening the panels together, as shown in Figure 2.7. A small gap between the panels may negatively influence the fire integrity resistance of a CLT assembly by providing a path for flames and hot gases to pass through to the unexposed side of the assembly. As such, it may be assumed that the suggestion from Richardson \& 
Batista [39], as detailed above, may not be as critical to CLT construction as it would be for traditional decking used in heavy timber construction.

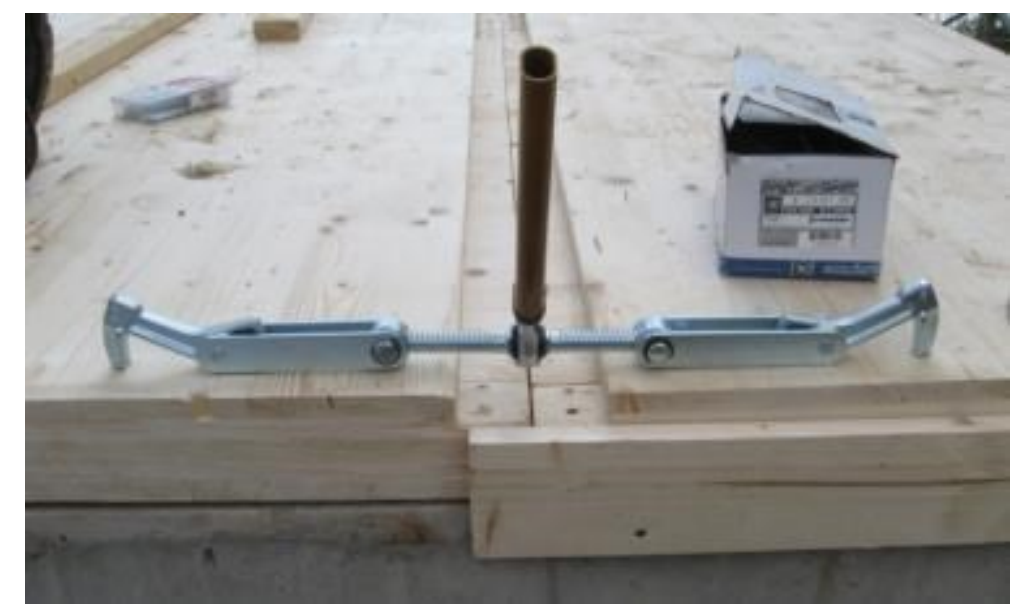

Figure 2.7-Ratchet and hooks used for CLT panel-to-panel connection (photo: FPInnovations)

\subsubsection{Effect of Floor Topping}

It is common practice to use concrete topping for improving acoustic and serviceability performance or to form a long-span composite concrete-CLT slab where the concrete is subjected to compression stresses and CLT to tension (Figure 2.8). Structural sheathing or gypsum boards may also be directly installed on one or both sides of a CLT wall. The use of such overlay materials may positively influence the fire integrity resistance of a CLT assembly by restraining flames and hot gases to pass through to the unexposed side of the assembly. 


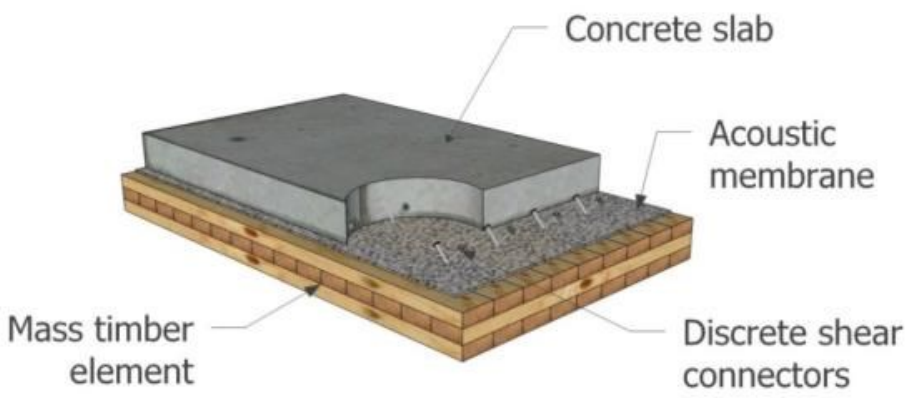

Figure 2.8 - Example of a composite concrete-timber slab assembly [24]

When adding a concrete topping or floor covering, the fire integrity criterion may be assumed to be respected as the concrete topping or floor covering will effectively prevent the flame penetration through the assembly. The joint coefficient $\left(K_{j}\right)$ may thereby be set to unity [43]. Equation (2.2), used for estimating the fire integrity resistance time, becomes reduced to only the assembly thickness divided by the applicable onedimensional charring rate. Assuming 5-plies CLT floor panels of $175 \mathrm{~mm}$ total thickness, joined together with a half-lapped joint of $64 \mathrm{~mm}$, and covered by a $38 \mathrm{~mm}$ concrete topping, one can assign a fire integrity resistance of $270 \mathrm{~min}$, which is significantly greater than the European, American and 2014 Canadian predictions from unprotected CLT panels (80, 96 and 94 min respectively). Such increase in the time prediction would most likely shift the failure mode from fire integrity to structural stability failure.

\subsubsection{Comparison between Test Data and Current Models}

FPInnovations, in collaboration with the National Research Council of Canada (NRCC), conducted eight fire-resistance tests to develop and validate a generic fire-resistance calculation procedure of CLT assemblies for code compliance. Different load ratios were 
applied depending on the number of plies and the assembly type (wall or floor). The assemblies were outfitted with thermocouples, embedded throughout the assemblies at five locations and in the panel-to-panel joints, and deflection gauges at nine locations.

Assemblies consisted of CLT panels, which were constructed of Spruce-Pine-Fir (SPF) No.1, No.2, No.3 or MSR lumber boards from different manufacturers across Canada. The dimensions of the floor assemblies were $3.61 \mathrm{~m}$ by $4.85 \mathrm{~m}$ long and the wall assemblies were $3.66 \mathrm{~m}$ by $3.05 \mathrm{~m}$ high. All of the assemblies used a $64 \mathrm{~mm}$ half-lapped panel-to-panel joint which was fastened with self-tapping screws. The joints were also sealed during assembly using $6 \mathrm{~mm}$ bead of construction adhesive as suggested in the 2011 and 2014 Canadian CLT Handbooks (Figure 2.9).

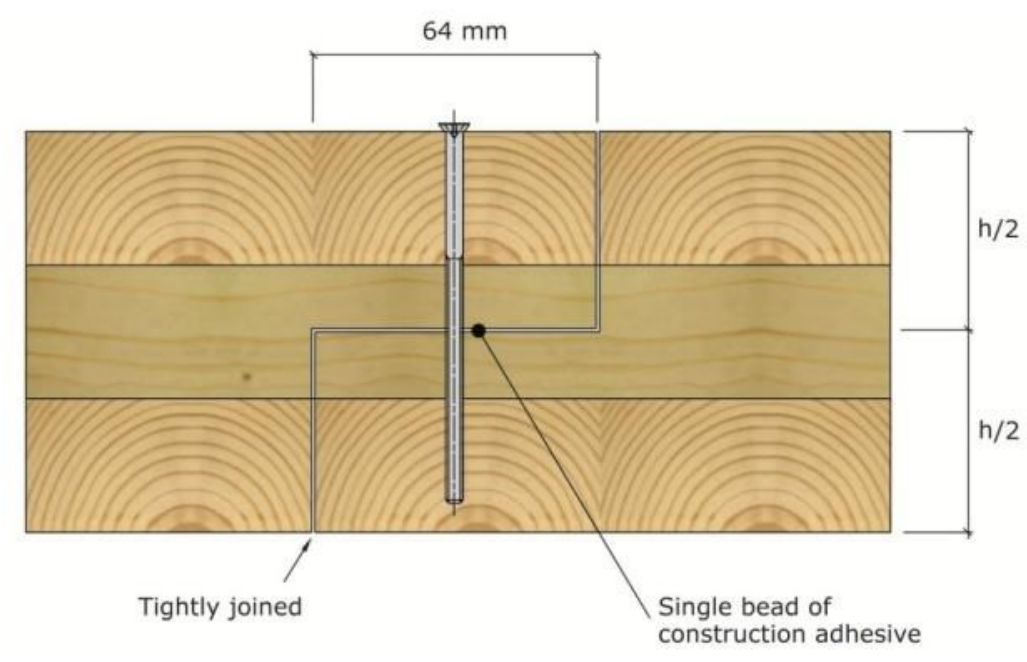

Figure 2.9 - Half-lapped joint detail used in full-scale fire tests [24]

The panels were manufactured with a structural polyurethane adhesive conforming to ANSI/APA PRG 320 standard [14]. Some of the CLT panels were fully exposed to fire 
(unprotected) while others were protected with Type X gypsum boards. It can be seen from the test results summary that 3 out of 4 CLT floor assemblies reached a fire integrity failure before a structural failure (1 test actually did not reach failure due to laboratory equipment safety concerns). Such high ratio of failure mode suggests a potential weakness at the floor panel-to-panel joints. Table 2.2 summarizes the test results. It is noted that these floor assemblies were not backed with concrete topping or floor covering on the unexposed side, thus evaluating a worst case scenario.

According to these test results, one can derive the predicted integrity failure times according to the European, American and Canadian models, as shown in Table 2.3. It can be seen from the results shown in Table 2.3 and Figure 2.10 that the European model provides conservative fire integrity failure times while the Canadian and American models seem more accurate.

Table 2.2 - FPInnovations CLT Fire-Resistance Test Summary [10]

\begin{tabular}{cccccccc}
\hline & $\begin{array}{c}\text { \# of } \\
\text { Plies }\end{array}$ & $\begin{array}{c}\text { Depth } \\
\text { (mm) }\end{array}$ & $\begin{array}{c}\text { Gypsum } \\
\text { Protection } \\
\text { (Type X) }\end{array}$ & $\begin{array}{c}\text { Applied } \\
\text { Load }\end{array}$ & $\begin{array}{c}\text { Load } \\
\text { Ratio }\end{array}$ & $\begin{array}{c}\text { Failure } \\
\text { Mode }\end{array}$ & $\begin{array}{c}\text { Failue } \\
\text { Time } \\
\text { (min) }\end{array}$ \\
\hline 3 & 114 & $2 \times 12.7 \mathrm{~mm}$ & $333 \mathrm{kN} / \mathrm{m}$ & $76 \% \mathrm{P}_{\mathrm{r}}$ & Structural & 106 \\
& 5 & 175 & Unprotected & $333 \mathrm{kN} / \mathrm{m}$ & $37 \% \mathrm{P}_{\mathrm{r}}$ & Structural & 113 \\
& 5 & 105 & Unprotected & $72 \mathrm{kN} / \mathrm{m}$ & $34 \% \mathrm{P}_{\mathrm{r}}$ & Structural & 57 \\
\hline & 3 & 114 & $2 \times 12.7 \mathrm{~mm}$ & $2.70 \mathrm{kPa}$ & $36 \% \mathrm{M}_{\mathrm{r}}$ & No failure & $77 *$ \\
& 5 & 175 & Unprotected & $11.75 \mathrm{kPa}$ & $59 \% \mathrm{M}_{\mathrm{r}}$ & Integrity & 96 \\
\hline
\end{tabular}


Table 2.3 - FPInnovations Test Results Compared to European, American and Canadian Models

\begin{tabular}{ccccccc}
\hline CLT Assembly & $\begin{array}{c}\text { Gypsum Board } \\
\text { Protection } \\
\text { (Type X) }\end{array}$ & $\begin{array}{c}\text { Test Failure } \\
\text { Time [10] } \\
\text { (min) }\end{array}$ & $\begin{array}{c}\text { European } \\
\text { Model [27] } \\
\text { (min) }\end{array}$ & $\begin{array}{c}\text { American } \\
\text { Model [12] } \\
\text { (min) }\end{array}$ & $\begin{array}{c}\text { Canadian } \\
\text { Model [24] } \\
\text { (min) }\end{array}$ \\
\hline 1 & $\begin{array}{c}3-\mathrm{ply} \\
(105 \mathrm{~mm})\end{array}$ & $1 \times 15.9 \mathrm{~mm}$ & $86-30^{(1)}=56$ & 48 & 57 & 56 \\
\hline 2 & $\begin{array}{c}5-\mathrm{ply} \\
(175 \mathrm{~mm})\end{array}$ & Unprotected & 96 & 80 & 96 & 94 \\
\hline 3 & $\begin{array}{c}5-\mathrm{ply} \\
(175 \mathrm{~mm})\end{array}$ & $1 \times 15.9 \mathrm{~mm}$ & $124-30^{(1)}=94$ & 80 & 96 & 94 \\
\hline
\end{tabular}

(1) A time of 30 minutes for a single layer of $15.9 \mathrm{~mm}$ Type $\mathrm{X}$ can be added to the fire-resistance of exposed timber [12, 24]. As such, 30 minutes is being subtracted in 2 of the 3 assemblies listed above, that were initially protected during the fire tests.

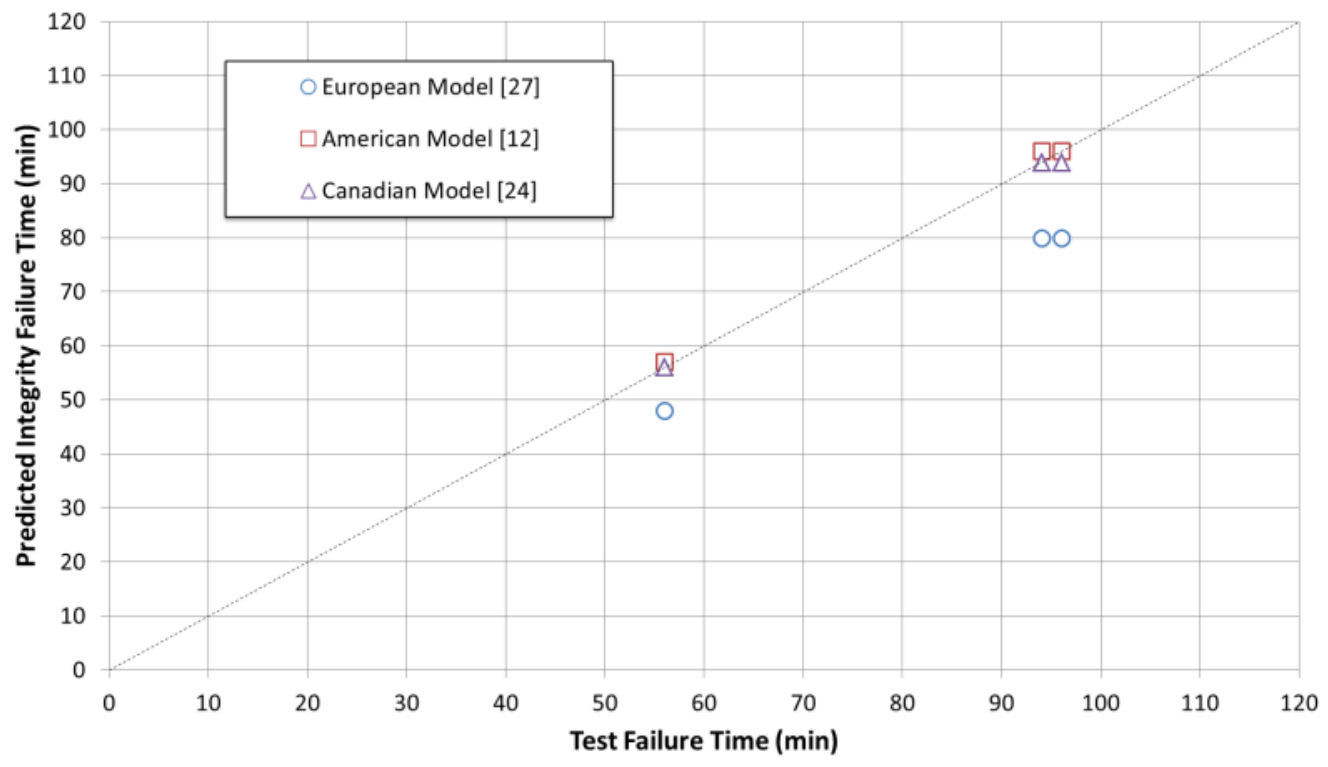

Figure 2.10 - Test results from [10] compared to predictions from [12, 27, 24]

Based on the series of tests conducted by FPInnovations [10] where self-tapping screws of different lengths depending on the CLT thickness where used, one can determine the thermal protection provided by the remaining wood portion between the tip of the selftapping screw and the exposed face of the CLT. The results from such approach would be 
very conservative as it would assume that a connection would fail as soon as the char front would reach the tip of the fastener and would therefore not allow any further reduction in the thickness of the main member (i.e. lower portion of a joint, which is exposed to fire). Table 2.4 shows the thermal protection when assuming a constant onedimensional charring rate of $0.65 \mathrm{~mm} / \mathrm{min}$. It can be seen from the predicted times shown in Table 2.4 that the calculation of the thermal protection provided by this kind of engineering approach is not reasonable nor accurate when compared to the test data.

Table 2.4 - Thermal protection from the reduced CLT thickness using test configurations from [10]

\begin{tabular}{lcccc}
\hline $\begin{array}{l}\text { CLT } \\
\text { Assembly }\end{array}$ & $\begin{array}{c}\text { Screw length } \\
(\mathbf{m m})\end{array}$ & $\begin{array}{c}\text { Residual thickness } \\
(\mathbf{m m})\end{array}$ & $\begin{array}{c}\text { Predicted Time } \\
(\mathbf{m i n})\end{array}$ & $\begin{array}{c}\text { Test Failure } \\
\text { Time } \\
(\mathbf{m i n})\end{array}$ \\
\hline $\begin{array}{l}\text { 3-ply } \\
(105 \mathrm{~mm})\end{array}$ & 90 & $105-90=15$ & $\frac{15}{0.65}=23$ & 56 \\
\hline $\begin{array}{l}5-\mathrm{ply} \\
(175 \mathrm{~mm})\end{array}$ & 160 & $175-160=15$ & $\frac{15}{0.65}=23$ & 96 \\
\hline $\begin{array}{l}7-\mathrm{ply} \\
(245 \mathrm{~mm})\end{array}$ & 220 & $245-220=25$ & $\frac{25}{0.65}=38$ & n.a. \\
\hline
\end{tabular}

\subsection{Cross-Laminated Timber Panel-to-Panel Connection Details}

Connections in CLT construction play an essential role in providing strength, stiffness, stability and ductility to the structure; consequently, they require careful attention by designers. As mentioned by Mohammad \& Muñoz [44], the structural efficiency of the floor system acting as a diaphragm and that of walls in resisting lateral loads depends on the efficiency of the fastening systems and connection details used to interconnect individual panels and assemblies. 
As CLT panels are manufactured in width ranging from $600 \mathrm{~mm}$ to $3 \mathrm{~m}$, fastening them together along their major strength axis (e.g. along the longitudinal edges) is required in order to form a singular structural assembly resisting to in-plane (e.g. seismic and wind loads) and out-of-plane loading (e.g. bending/gravity loads) (Figure 2.11).
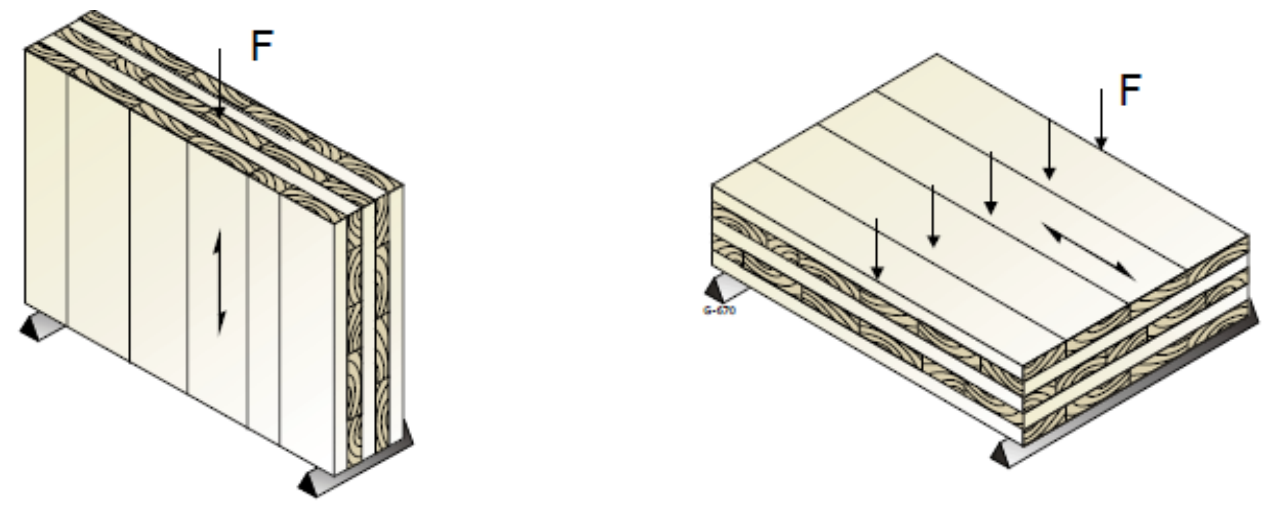

Figure 2.11 - In-plane (left) and out-of-plane (right) loading conditions [45]

Although long self-tapping screws are usually recommended by CLT manufacturers and commonly used for panel-to-panel connections in floors and wall assemblies, traditional dowel-type fasteners such as wood screws, nails, lag screws, rivets, bolts and dowels could also be effectively used in connecting panel elements together.

\subsubsection{Internal Spline}

The first type of panel-to-panel connection is the internal spline (Figure 2.12). Such connection requires a high level of prefabrication from the CLT manufacturers to form the groove into the edge of the CLT panels. It also requires accurate workmanship at the job site for properly installing the spline, which could be of either solid sawn, structural composite lumber or structural sheathing (Figure 2.13). Typically, wood screws, self- 
tapping screws or nails are used to fasten the panels together and to resist in-plane and out-of-plane loading by developing double shear resistance.

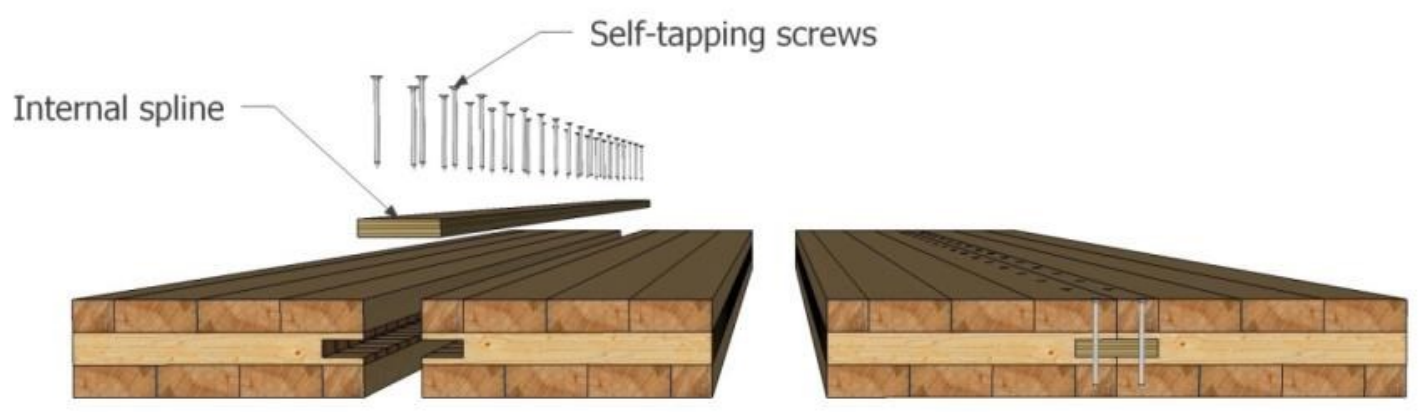

Figure 2.12 - Internal spline schematic

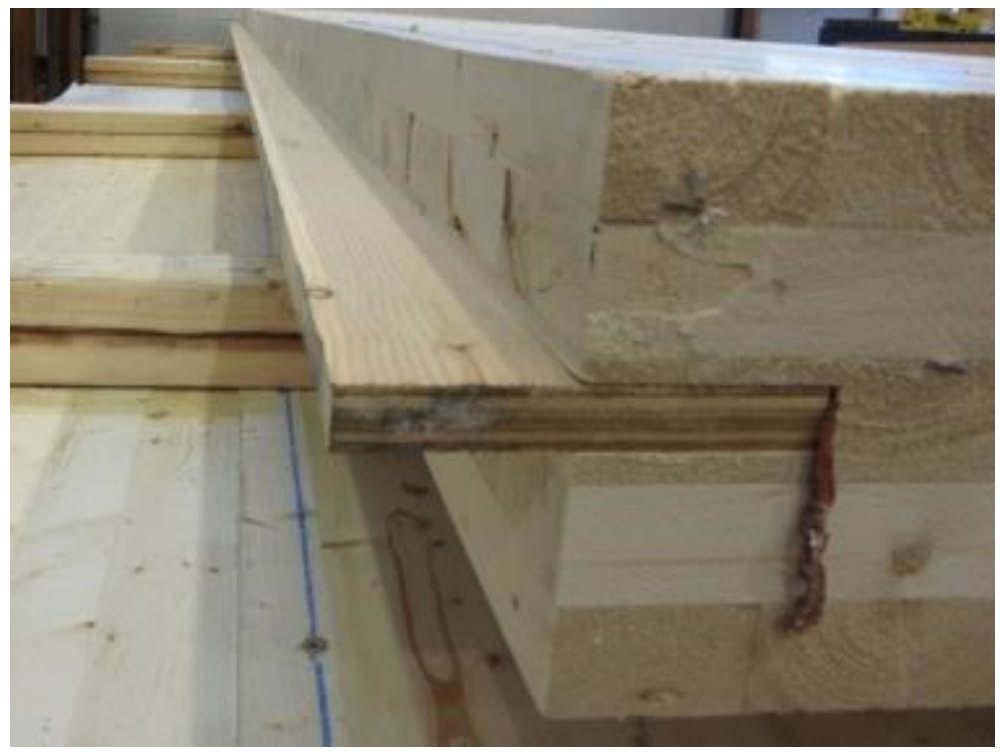

Figure 2.13 - Internal spline made from a plywood strip

This panel-to-panel configuration can also be manufactured with more than one groove for multiple internal splines connection. Figure 2.14 shows some configurations from 
BinderHolz, a European CLT manufacturer, depending on the CLT thickness as well as wall-to-wall or floor-to-floor connection [46]. For these typical connections, the internal spline usually consists of a $27 \times 54 \mathrm{~mm}$ component inserted into a $28 \times 58 \mathrm{~mm}$ groove. Greater splines may also be used for specific applications such as for allowing pipes and wiring to pass along the splines as shown in Figure 2.15.
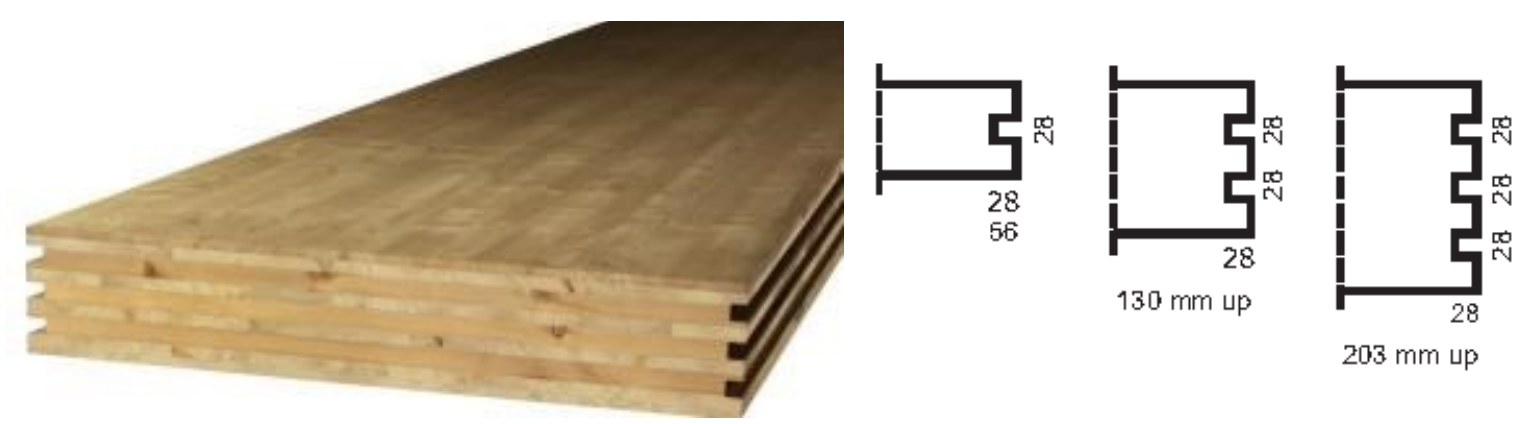

Figure 2.14 - Internal splines profiling from BinderHolz [46]
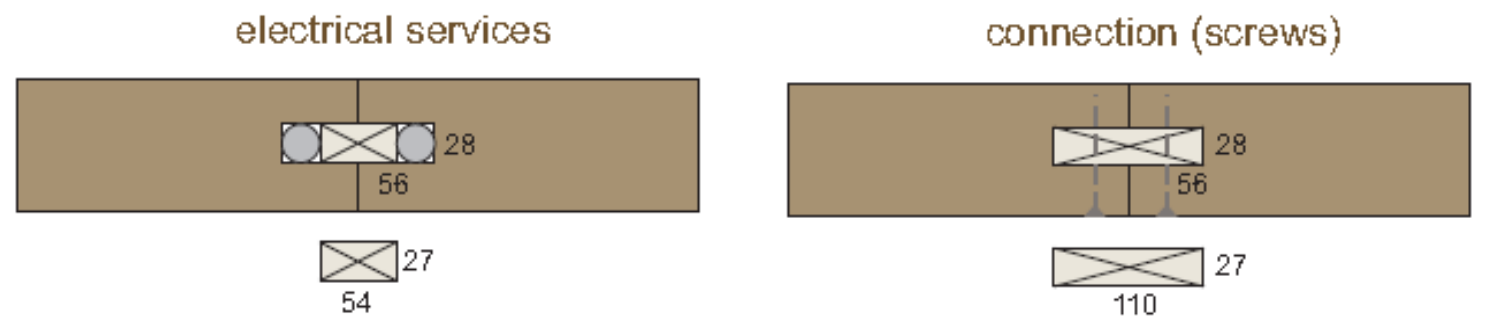

Figure 2.15 - Typical and wider internal splines from BinderHolz [46]

\subsubsection{Single Surface Spline}

Another type of panel-to-panel connection is the single surface spline (Figure 2.16 and Figure 2.17). This type of connection is similar to the internal spline, with the exception that the groove is made on one surface of the CLT panels. However, such connection 
provides lower capacity against in-plane loading due to the single shear resistance of the fasteners. The single surface spline may be used on either sides of a CLT wall assembly, while it is usually made on the top side of a CLT floor assembly due to the ease of placing the spline in the groove and driving the fasteners downward. According to Canadian CLT manufacturers, the spline is traditionally made from strips of plywood in the range of 19 to $25 \mathrm{~mm}$ in thickness and 125 to $130 \mathrm{~mm}$ in width.

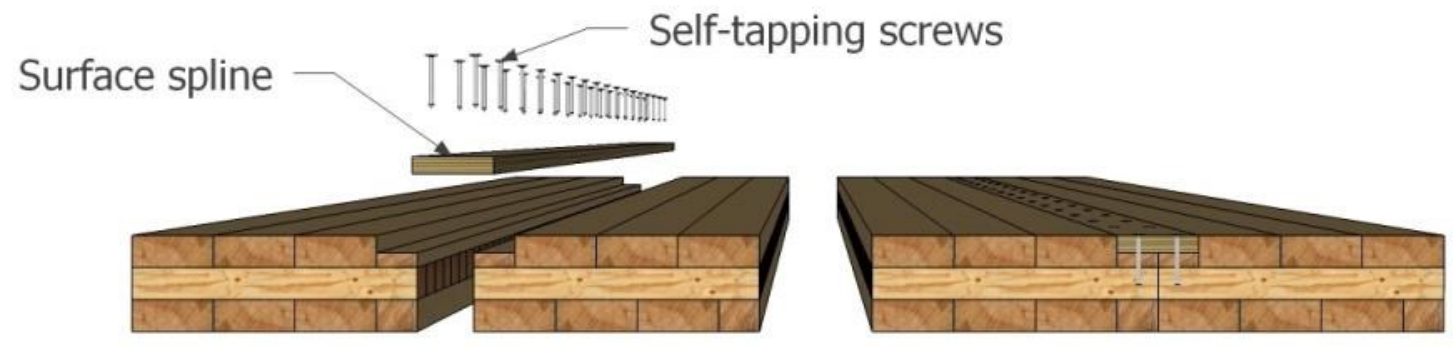

Figure 2.16 - Single surface spline schematic
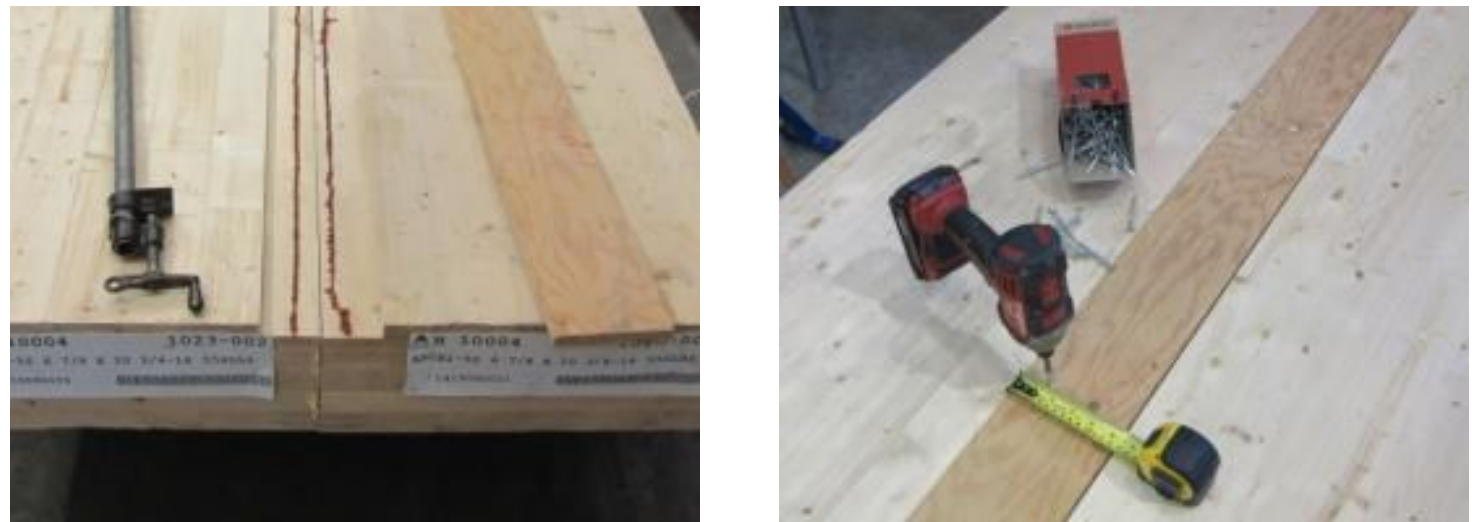

Figure 2.17- Single surface spline made from a plywood strip 


\subsubsection{Double Surface Spline}

An enhanced version of the single surface spline is the double surface spline. Although the fasteners are still loaded in single shear, two (2) rows of fasteners are installed on each side of the CLT panels, developing a greater capacity against in-plane loading (Figure 2.18).

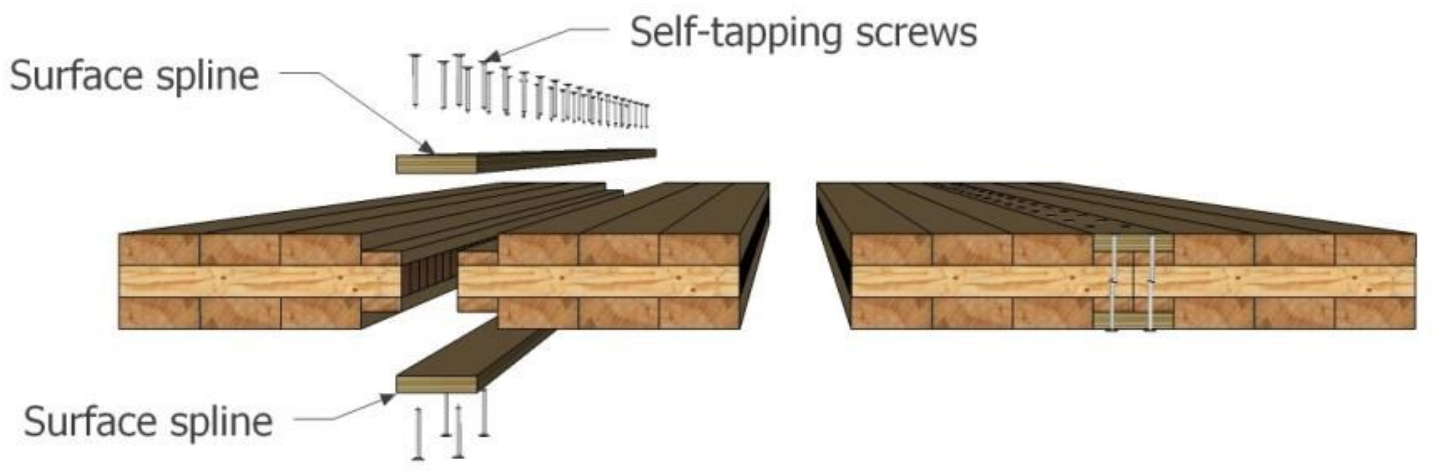

Figure 2.18-Double surface splines schematic

While this configuration would provide greater resistance against in-plane loading when compared to the single surface spline, its installation may be more labour intensive due to the fact that the bottom spline and screws would require to be installed from beneath, thus not the most convenient method at the job site.

\subsubsection{Half-Lapped Joint}

Lastly, the most commonly used CLT panel-to-panel joint configuration by North American CLT manufacturers is the half-lapped joint shown in Figure 2.19. In this configuration, the CLT panels are machined in such way that an overlapping section 
serves for connecting the panels together. The overlapping section can be located anywhere along the thickness of the CLT panels, but is usually located at mid-depth.

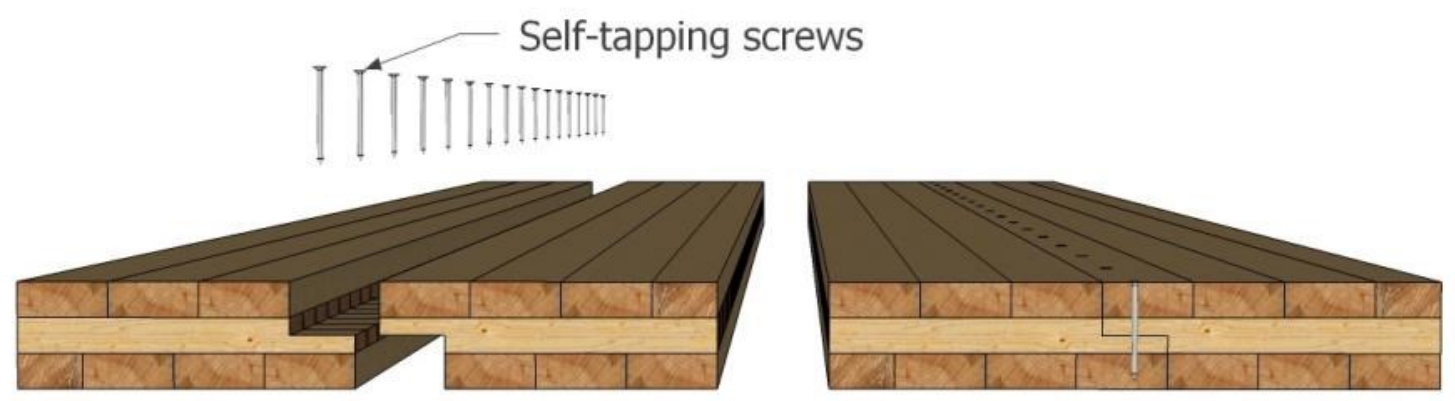

Figure 2.19-Half-lapped joint schematic

Although the fasteners are loaded in single shear similarly to the single surface spline, such configuration allows for a higher capacity as it requires the use of self-tapping screws, while providing a greater thickness of the main and side members when calculating the unit lateral strength resistance of the fastener. Self-tapping screws also typically provide greater lateral and withdrawal strength when compared to traditional dowel-type fasteners such as wood screws, nails and spikes, which are often used with the single surface spline. Its installation is quite easy as it does not require a spline and the fasteners can easily be driven downward.

Testing of the in-plane capacity of CLT panel-to-panel joints was recently conducted by Sheikhtabaghi [47]. The results indicated that half-lapped joints using self-tapping screws exhibited superior strength and ductility to that of single surface spline joint detail. The 
study also highlighted the importance of eccentricities affecting the mechanical behaviour of connections, especially for single surface spline joint details.

\subsection{Cross-Laminated Timber Panel-to-Panel Connection Resistance}

Timber connection design is influenced by the loading direction relative to the wood grain direction, especially for fasteners with diameter of $6 \mathrm{~mm}$ or greater such as lag screws, whereas the embedment strength of slender fasteners such as wood screws is less sensitive to grain orientation [44]. As such, CSA O86 "Engineering Design in Wood" [48] provides different design equations for determining the unit lateral strength of fasteners loaded either parallel or perpendicular to grain, whether the fastener diameter is greater or less than $5.48 \mathrm{~mm}$. Moreover, special considerations should be given when designing connections in CLT due to its nature of cross-lamination as well as lay-up and/or wood species configurations (i.e. relative density).

From all joint configurations described in subsection 2.3 , the fasteners are mainly used to provide in-plane resistance (e.g. diaphragm resistance against seismic and wind loads). Out-of-plane resistance is used mainly to resist wind loads for wall applications or gravity loads for floor applications, but is most likely less critical than in-plane resistance in normal design conditions.

Under normal design conditions, the fasteners develop withdrawal capacities in order to share the loads to adjacent CLT panels and to keep them securely joined to each other. However, out-of-plane resistance (i.e. withdrawal) may become problematic in fire 
design, which may lead to premature fire integrity failure of the CLT panel-to-panel joint, especially in the unlikely event of a significant unbalanced loading condition where one CLT panel may be loaded at a higher level than the adjacent panel.

\subsubsection{Failure Modes in CLT Panel-to-Panel Joints}

As the CLT panel exposed surface chars with time, the fastener penetration length $\left(L_{t}\right.$ or $\left.L_{p t}\right)$ and the exposed wood member embedment strength are reduced. Wood becomes more brittle when heated, dried and turned into char, thus reducing the resistance of the connection. Several factors may influence the connection between two adjacent CLT panels such as the location of the half-lapped or the spline joint (i.e. whether or not the joint interface is reached during the fire), the penetration length reduction (effective penetration length, $L_{p t}$ ), heat transfer occurring through the exposed CLT and the potential heating of the fasteners when exposed to fire (causing the wood fibers to char and lose their capacity around the fasteners' perimeter). When considering all these factors, the connection resistance may come to a critical level where the loss of the resistance generates a fire integrity failure by providing an opening between the CLT panels and allowing flames and hot gases to pass through the panel-to-panel joint profile (Figure 2.20). 


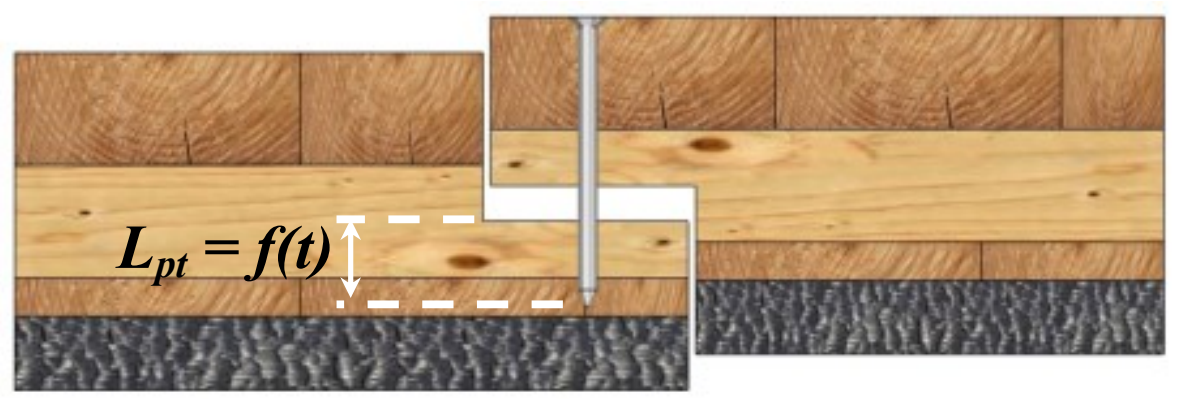

Figure 2.20 - Failure mode due to connection reduced withdrawal capacity

As described by Craig Jr. [49], shear stress generated from bending forces can be transferred between adjoining parts of a built-up element (e.g. CLT) in 3 methods:

1. By shear distributed over the interface areas, as when surfaces are glued together;

2. By shear distributed along a line, as when elements are joined by a linear shear connector (e.g. weld beads in steel beams or a plywood spline), or;

3. By discrete shear connectors, as when two elements are nailed, screwed or bolted together.

Built-up element, when subjected to flexure, will behave as a single element provided that shear connectors are rigid enough to transfer the shear forces between adjacent parts. The required shear flow, corresponding to the shear force $(v$ ') per unit length that must be transferred between adjacent elements under a given loading condition, needs to be considered. Such shear flow does not necessarily correspond to the effects of lateral loads (in-plane) when designing a floor diaphragm, but may correspond to the effects of 
fasteners used to connect together CLT floor panels subjected to out-of-plane loading (i.e. bending) (Figure 2.21).

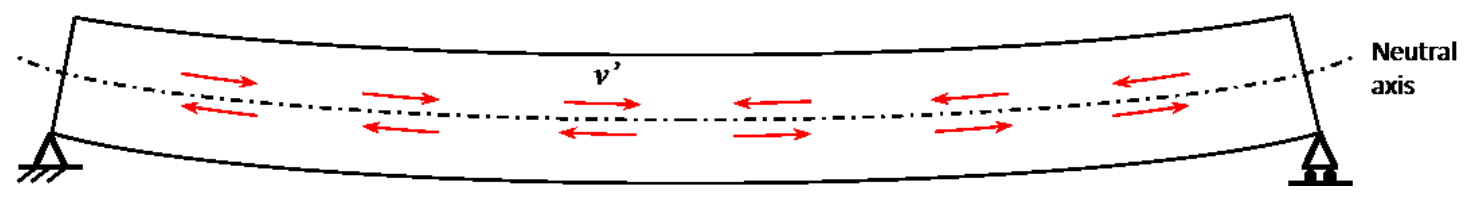

Figure 2.21 - Shear force in a simple span flexural member

When layers are connected using discrete fasteners, they must be spaced along the joint at a specific spacing so the fasteners' shear capacity respects the following Equation (2.4):

$$
V_{F} \geq q \Delta_{s}
$$

where $V_{F}$ is the fastener's shear resistance, $q$ is shear flow along the interface and $\Delta_{s}$ is the fastener's spacing along the joint. The fastener's shear resistance can be determined with the relevant design provisions from CSA O86 from either yielding of the fastener or crushing of the wood members (i.e. embedment). When using a spline (plywood or other material), the shear flow must also be transferred through the spline. As such, the limiting resistance may be due to the spline longitudinal shear resistance as opposed to the fasteners, or the fastener's head pull-through resistance in the spline.

Assuming that the panel-to-panel connection is sufficiently strong to withstand the shear stress, another potential failure mode would be in shear through the loaded end/edge grain of the lower section of the CLT panel. This other potential failure mode is also 
influenced by the length of penetration in the bottom section exposed to fire as this section (effective shear depth, $d_{v}$ ) reduces with time due to charring (Figure 2.22).

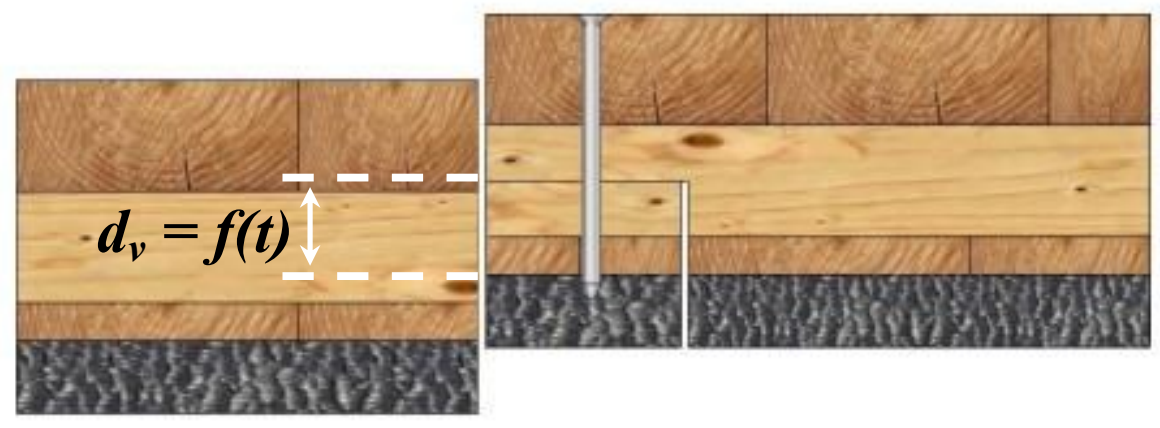

Figure 2.22 - Failure mode due to reduced shear resistance of lower section of the exposed CLT

Moreover, yielding modes of the connectors may no longer be the same in fire conditions as they were under normal design conditions. For instance, a unit lateral strength resistance may be determined from yielding mode (e), as shown in Figure 2.23, where crushing of the wood fibers in the exposed layer (i.e. side member) occurs and plastic hinges are developed in the fastener. In fire conditions, as the exposed side member thickness and embedment strength reduce with time, yield mode (b) may be the limiting mode due to a reduced side member thickness creating a ductile failure.

In summary, CLT panel-to-panel connection resistance is largely influenced by the reduced cross-section whereas failure modes may be of either yielding of the fastener or crushing of the wood fibers (or spline) due to longitudinal shear forces. It may also occur aside of the connection where the shear resistance provided from the reduced effective 
shear depth can no longer sustain the transverse shear forces between adjacent CLT panels.

\subsubsection{Wood Screws (of diameter up to $5.48 \mathrm{~mm}$ )}

According to CSA O86, the factored withdrawal resistance $\left(P_{r w}\right)$ of wood screws of diameters up to $5.48 \mathrm{~m}$ is directly linked to the threaded length penetration in the member as given in Equation (2.5).

$$
P_{r w}(N)=\varphi\left(59 d_{F}^{0.82} G^{1.77} K_{D} K_{T} K_{S F}\right) L_{p t} n_{F}
$$

where $\varphi$ is the resistance factor (taken as 0.6 ), $d_{F}$ is the fastener diameter, $G$ is the mean relative density of the wood members, $K_{D}, K_{T}$ and $K_{S F}$ are respectively duration of load, treatment and service condition factors, $L_{p t}$ is threaded shank penetration and $n_{F}$ is the number of fasteners.

The factored withdrawal resistance may also be limited by the fastener's head pullthrough $\left(P_{p t}\right)$ resistance of the side member, determined by Equation (2.6) for connections with lumber or structural panel side plates (e.g. a plywood surface spline).

$$
P_{p t}(N / m m)=65 \varphi t_{1} n_{F} K_{D}
$$

where $\varphi$ is the resistance factor (taken as 0.4 ), $t_{l}$ is the side plate thickness, $n_{F}$ is the number of wood screws in the connection and $K_{D}$ is the duration of load factor. 
The factored lateral resistance $\left(N_{r}\right)$ of wood screws of diameter of $5.48 \mathrm{~mm}$ or less is calculated by using Equation (2.7). The latter is not limited to short term loading conditions and thereby does not incorporate implicitly a fixed load duration factor.

$$
N_{r}(N)=\varphi\left(n_{u} K_{D} K_{T} K_{S F}\right) n_{F} n_{s} J_{A} J_{E}
$$

where $\varphi$ is the resistance factor (taken as 0.8 ), $n_{u}$ is unit lateral strength resistance, $K_{D}$, $K_{S F}$ and $K_{T}$ are respectively duration of load, service condition and treatment factors, $n_{F}$ is the number of fasteners, $n_{s}$ is the number of shear planes per screw, $J_{A}$ is a toe-screwing factor and $J_{E}$ is an end grain factor.

For two-member connections (i.e. single shear), the unit lateral strength resistance is taken as the smallest value from yielding modes (a), (b), (d), (e), (f) and (g) shown in Figure 2.23. For three-member connections (i.e. double shear), where screws fully penetrate all three members, the unit lateral strength resistance is taken as the smallest value from yielding modes (a), (c), (d) and (g). The unit lateral strength resistance is primarily influenced by the thickness of the main and side members $\left(t_{1}\right.$ and $\left.t_{2}\right)$, their embedment strength $\left(f_{1}, f_{2}\right.$ and $\left.f_{3}\right)$ and the fastener shank diameter $\left(d_{F}\right)$.

Furthermore, according to CSA O86, the minimum penetration length into the main member must be 5 times the fastener shank diameter (Figure 2.24). When fasteners are used in double shear, the middle member needs to be at least 8 times the fastener shank diameter. In both single and double shear configuration, there is no specific requirement related to the wood species group. With respect to minimum length of wood screw penetration, the National Design Specifications for Wood Construction (NDS) seems 
slightly more liberal as it requires that the minimum length (including the length of the tapered tip) into the main member is at least $6 d_{F}$, for either single or double shear connections [50].

(a) $\quad f_{1} d_{f} t_{1}$

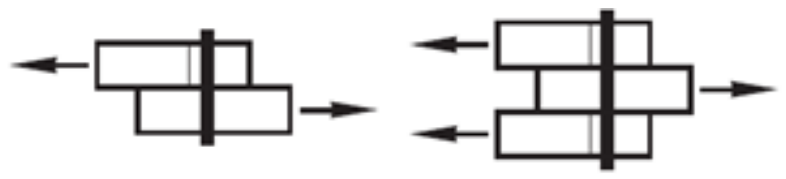

(b) $f_{2} d_{f} t_{2}$

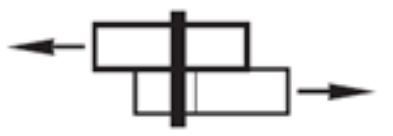

(c) $\frac{1}{2} f_{2} d_{r} t_{2}$

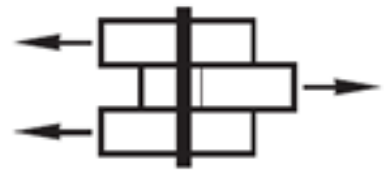

(d)

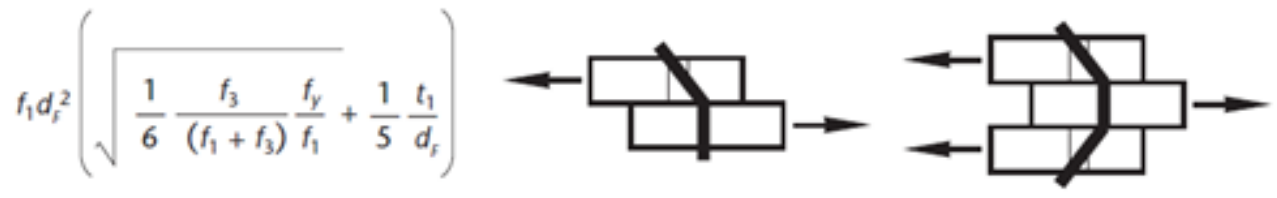

(e)

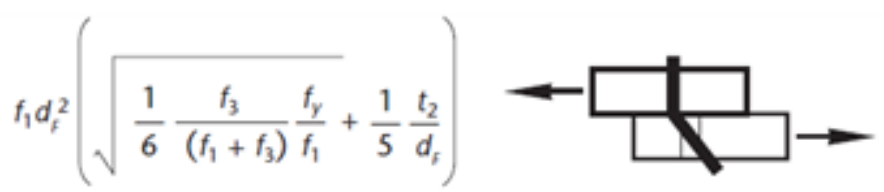

(f) $f_{1} d_{f}^{2} \frac{1}{5}\left(\frac{t_{1}}{d_{f}}+\frac{f_{2}}{f_{1}} \frac{t_{2}}{d_{f}}\right)$

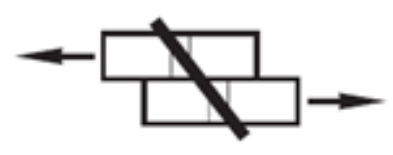

(g) $f_{1} d_{f}^{2} \sqrt{\frac{2}{3} \frac{f_{3}}{\left(f_{1}+f_{3}\right)}} \frac{f_{y}}{f_{1}}$
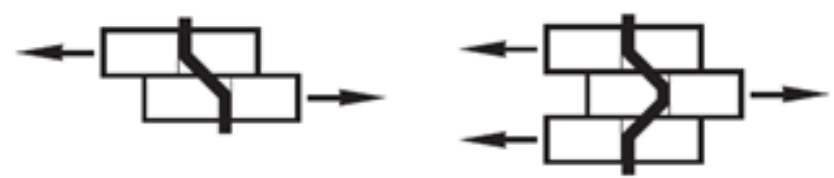

Figure 2.23 - Wood screw unit lateral strength resistance [48] (reproduced with permission from CSA Group) 
Assuming 5-ply CLT floor panels of $175 \mathrm{~mm}$ total thickness joined together with a halflapped joint located at mid-depth $(87.5 \mathrm{~mm}$ ), a minimum penetration depth of $27.4 \mathrm{~mm}$ would be required for 12 gauge $(5.48 \mathrm{~mm}$ diameter) wood screws. A maximum sacrificial layer of $60.1 \mathrm{~mm}$ may then be charred before the withdrawal or lateral capacity of the connection becomes affected by heat. Assuming a one-dimensional charring rate of 0.65 $\mathrm{mm} / \mathrm{min}$, this sacrificial layer would provide $92 \mathrm{~min}$ of fire-resistance. Table 2.5 shows the predicted failure times when following this approach.

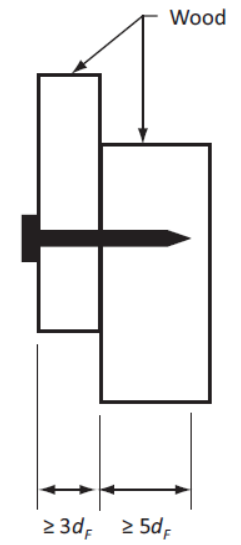

a) Fastener in single shear

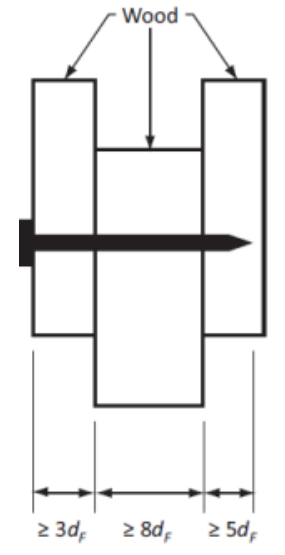

b) Fastener in double shear

Figure 2.24 - Wood screw minimum penetration length and member thickness [48] (reproduced with permission from CSA Group)

Table 2.5 - Fire Integrity provided by the reduced CLT thickness using CSA 086 wood screw minimum penetration length provisions [48]

\begin{tabular}{lccccc}
\hline $\begin{array}{l}\text { CLT } \\
\text { Assembly }\end{array}$ & $\begin{array}{c}\text { Screw } \\
\text { diameter } \\
(\mathbf{m m})\end{array}$ & $\begin{array}{c}\text { Min. } \boldsymbol{L}_{\boldsymbol{p}} \\
(\mathbf{m m})\end{array}$ & $\begin{array}{c}\text { Residual thickness } \\
(\mathbf{m m})\end{array}$ & $\begin{array}{c}\text { Predicted } \\
\text { Time } \\
(\mathbf{m i n})\end{array}$ & $\begin{array}{c}\text { Test Failure } \\
\text { Time } \\
(\mathbf{m i n})\end{array}$ \\
\hline $\begin{array}{l}\text { 3-ply } \\
(105 \mathrm{~mm})\end{array}$ & 5.48 & $\begin{array}{l}5 \times 5.48 \\
=27.4\end{array}$ & $\frac{105}{2}-27.4=25.1$ & $\frac{25.1}{0.65}=39$ & 56 \\
\hline $\begin{array}{l}5 \text {-ply } \\
(175 \mathrm{~mm})\end{array}$ & 5.48 & $\begin{array}{l}5 \times 5.48 \\
=27.4\end{array}$ & $\frac{175}{2}-27.4=60.1$ & $\frac{60.1}{0.65}=92$ & 96 \\
\hline $\begin{array}{l}7 \text {-ply } \\
(245 \mathrm{~mm})\end{array}$ & 5.48 & $\begin{array}{l}5 \times 5.48 \\
=27.4\end{array}$ & $\frac{245}{2}-27.4=95.1$ & $\frac{95.1}{0.65}=146$ & n.a. \\
\hline
\end{tabular}


It can be seen that the predicted times shown in Table 2.5 and Figure 2.25 seem reasonable for the 5-ply assembly, while quite conservative for the 3-ply assembly, when compared to the test data. However, it is difficult to properly confirm such assumption with only 2 single data points. Interestingly, the residual thicknesses represent respectively a ratio of $0.24,0.34$ and 0.39 of the total CLT thickness, which are quite close to the joint coefficients $\left(K_{j}\right)$ assigned in the European as well as the 2014 Canadian and American models ( 0.30 and 0.35 of the total thickness respectively).

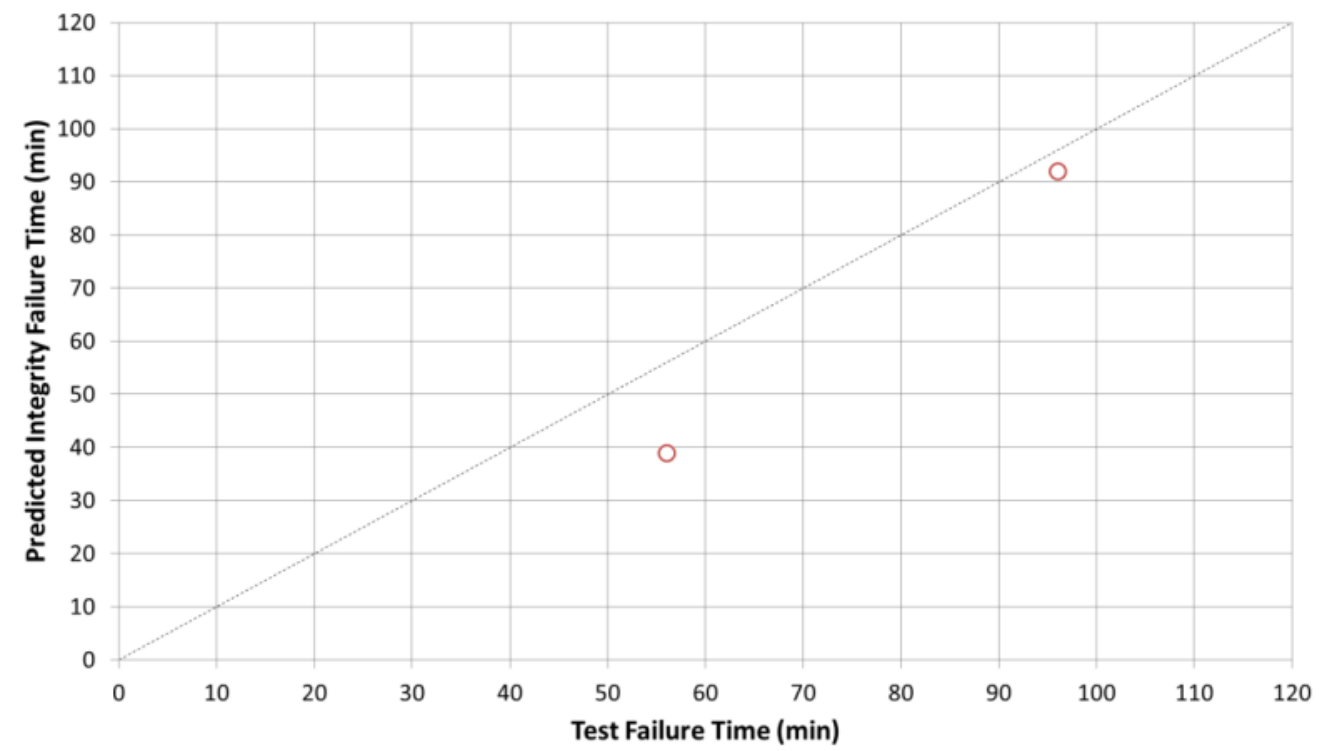

Figure 2.25 - Predicted fire integrity failure using CSA 086 wood screw minimum penetration length provisions [48]

\subsubsection{Lag Screws and Wood Screws (of diameter greater than $5.48 \mathrm{~mm}$ )}

The factored withdrawal resistance of wood screws having a diameter greater than 5.48 $\mathrm{mm}$ is slightly different from the procedure detailed previously for wood screws with a diameter no greater than $5.48 \mathrm{~mm}$. It should be calculated by using the lag screws 
provisions of CSA O86 as per Equation (2.8). As opposed to wood screws, lag screw provisions do not require evaluating the head pull-through resistance and it allows end grain withdrawal.

$$
P_{r w}(N)=\varphi\left(y_{w} K_{D} K_{T} K_{S F}\right) L_{t} n_{F} J_{E}
$$

where $\varphi$ is the resistance factor (taken as 0.6 ), $y_{w}$ is the basic withdrawal resistance per millimeter of penetration, $K_{D}, K_{S F}$ and $K_{T}$ are respectively load duration, service condition and treatment factors, $L_{t}$ is the length of penetration of threaded portion of lag screw in main member, $n_{F}$ is the number of fasteners and $J_{E}$ is an end grain factor.

Following the lag screw design provisions in CSA O86, the factored lateral resistance is influenced by the load orientation to the grain and shall be calculated from Equations (2.9) and (2.10) whether the load is applied parallel $\left(P_{r}\right)$ or perpendicular $\left(Q_{r}\right)$ to the grain of the wood member, respectively. Both equations are not limited to short term loading conditions and thereby do not incorporate implicitly a fixed load duration factor.

$$
\begin{aligned}
& P_{r}(N)=\varphi\left(p_{u} K_{D} K_{T} K_{S F}\right) n_{F} J_{G} J_{P L} \\
& Q_{r}(N)=\varphi\left(q_{u} K_{D} K_{T} K_{S F}\right) n_{F} J_{G} J_{P L}
\end{aligned}
$$

where $\varphi$ is the resistance factor (taken as 0.6 ), $p_{u}$ and $q_{u}$ are respectively the unit lateral strength resistances parallel-to-grain and perpendicular-to-grain loading, $K_{D}, K_{S F}$ and $K_{T}$ are respectively duration of load, service condition and treatment factors, $n_{F}$ is the number of fasteners, $J_{G}$ is a group factor $J_{P L}$ is a factor for reduced penetration. The unit 
lateral strength resistance $\left(p_{u}\right.$ and $\left.q_{u}\right)$ is taken as the smallest value from yielding modes (a) to (f) shown in Figure 2.26.

(a) $f_{1} d_{F} t_{1}$

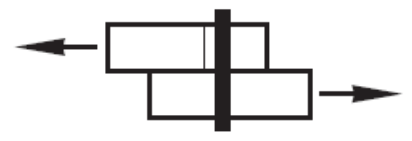

(b) $\quad f_{2} d_{F} t_{2}$

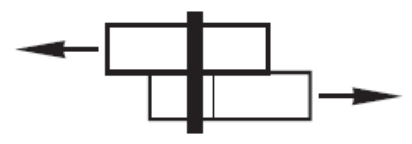

(c) $f_{1} d_{F}^{2}\left(\sqrt{\frac{1}{6} \frac{f_{2}}{\left(f_{1}+f_{2}\right)} \frac{f_{y}}{f_{1}}}+\frac{1}{5} \frac{t_{1}}{d_{F}}\right)$

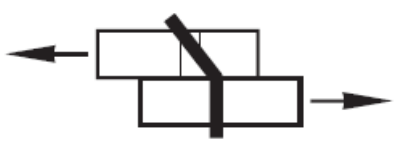

(d)

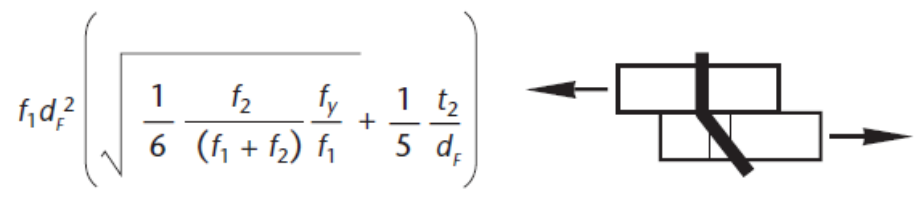

(e) $f_{1} d_{F}^{2} \frac{1}{5}\left(\frac{t_{1}}{d_{F}}+\frac{f_{2}}{f_{1}} \frac{t_{2}}{d_{F}}\right)$

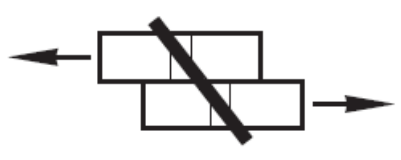

(f) $\quad f_{1} d_{F}^{2} \sqrt{\frac{2}{3} \frac{f_{2}}{\left(f_{1}+f_{2}\right)} \frac{f_{y}}{f_{1}}}$

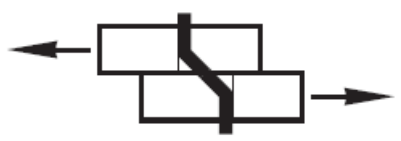

Figure 2.26 - Lag screw unit lateral strength resistance [48] (reproduced with permission from CSA Group)

Although the procedure is slightly different from that of wood screws, lag screw unit lateral strength resistance is also influenced by the thickness of the main and side members $\left(t_{1}\right.$ and $\left.t_{2}\right)$, their embedment strength $\left(f_{1}\right.$ and $\left.f_{2}\right)$ and the fastener diameter $\left(d_{F}\right)$. The maximum penetration length into the main member for calculating the withdrawal and lateral resistances of connections is to be at least 11 times the fastener shank diameter 
when used in SPF group species (having a relative density of 0.42 ) or 9 times the shank diameter when used in Douglas Fir-Larch group species (having a relative density of 0.49). When determining the penetration length of a lag screw into a member, the length of the tapered tip of the threaded shank is not considered.

Moreover, when loaded laterally, lag screws shall penetrate the main member $\left(t_{2}\right)$ by at least 5 times the shank diameter $\left(d_{F}\right)$ without any specific requirements related to the wood species group, which is the same provision as that of wood screws (Figure 2.24). There is no specific guidance for calculating lag screws in double shear. As with wood screw provisions, the NDS seems slightly more liberal as it requires that the minimum length (excluding the length of the tapered tip) into the main member is at least $4 d_{F}$, for either single or double shear connections [50].

Assuming 5-ply CLT floor panels of $175 \mathrm{~mm}$ total thickness, made from MSR $1950 \mathrm{f}_{\mathrm{b}^{-}}$ 1.7E lumber boards, joined together with a half-lapped joint at mid-depth, a minimum penetration depth of $40 \mathrm{~mm}$ would be required for lag screws of $8 \mathrm{~mm}$ diameter. A maximum sacrificial layer of $47.5 \mathrm{~mm}$ may then be charred before the withdrawal capacity of the connection becomes affected by heat. Assuming a one-dimensional charring rate of $0.65 \mathrm{~mm} / \mathrm{min}$, this sacrificial layer would provide $73 \mathrm{~min}$. Table 2.6 gives the predicted failure times when following this approach. 
Table 2.6 - Fire integrity provided by the reduced CLT thickness using CSA 086 lag screw minimum penetration provisions [48]

\begin{tabular}{lccccc}
\hline $\begin{array}{l}\text { CLT } \\
\text { Assembly }\end{array}$ & $\begin{array}{c}\text { Screw } \\
\text { diameter } \\
(\mathbf{m m})\end{array}$ & $\begin{array}{c}\text { Min. } L_{p} \\
(\mathbf{m m})\end{array}$ & $\begin{array}{c}\text { Residual thickness } \\
(\mathbf{m m})\end{array}$ & $\begin{array}{c}\text { Predicted } \\
\text { Time } \\
(\mathbf{m i n})\end{array}$ & $\begin{array}{c}\text { Test Failure } \\
\text { Time } \\
(\mathbf{m i n})\end{array}$ \\
\hline $\begin{array}{l}\text { 3-ply } \\
(105 \mathrm{~mm})\end{array}$ & 6 & $5 \times 6=30$ & $\frac{105}{2}-30=22.5$ & $\frac{22.5}{0.65}=34$ & 56 \\
\hline $\begin{array}{l}5-\mathrm{ply} \\
(175 \mathrm{~mm})\end{array}$ & 8 & $5 \times 8=40$ & $\frac{175}{2}-40=47.5$ & $\frac{47.5}{0.65}=73$ & 96 \\
\hline $\begin{array}{l}7 \text {-ply } \\
(245 \mathrm{~mm})\end{array}$ & 8 & $5 \times 8=40$ & $\frac{245}{2}-40=82.5$ & $\frac{82.5}{0.65}=127$ & n.a. \\
\hline
\end{tabular}

It can be seen that the predicted times given in Table 2.6 and shown in Figure 2.27 are conservative when compared to the test data. Interestingly, the residual thicknesses represent respectively a ratio of $0.21,0.27$ and 0.34 of the total CLT thickness, which are close, while lower, to the joint coefficients $\left(K_{j}\right)$ assigned in the European as well as the 2014 Canadian and American models ( 0.30 and 0.35 of the total thickness respectively).

In summary, approaches based on fasteners minimum penetration length seem to predict conservatively failure times when compared with actual test results. In fact, when looking at Figure 2.25 and Figure 2.27, a linear relationship is suggested. However, it is difficult to properly confirm such linear trend with only 2 single data points. As a minimum, a third point is needed to capture any trend line. 


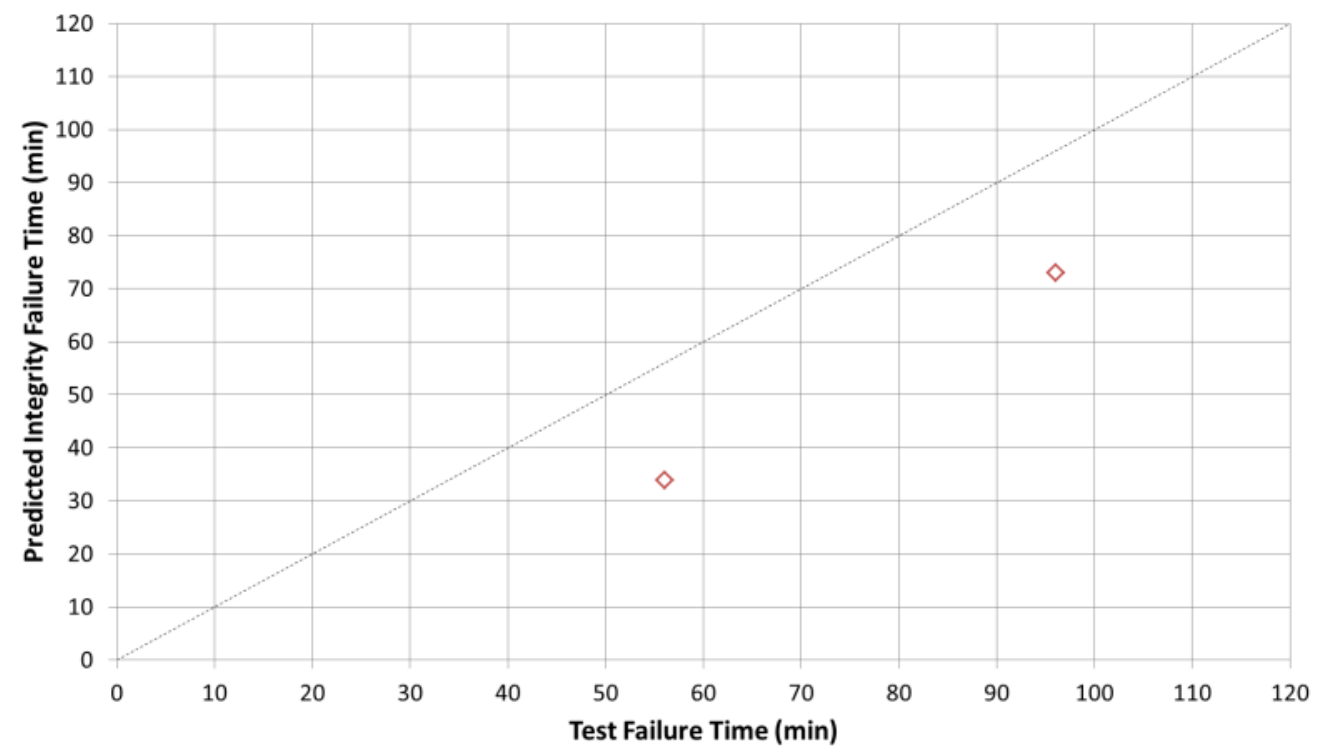

Figure 2.27 - Predicted integrity failure time using CSA 086 lag screw minimum penetration length provisions [48]

The approaches also suggest that there may be a relationship between the fasteners penetration length reduction due to heat transfer through the CLT panels exposed to fire conditions. Such reduction implies a reduced withdrawal capacity and/or a reduced lateral resistance.

Furthermore, as no fire integrity failure test data is available for CLT assemblies of 245 $\mathrm{mm}$ (7-ply), there is a need to evaluate the integrity fire-resistance of thick CLT panels in order to develop and validate a model that would be applicable to commonly used CLT thicknesses, ranging from 105 to $245 \mathrm{~mm}$ (3- to 7-ply). It should be noted that CLT floor assemblies of $245 \mathrm{~mm}$ in thickness (7-ply) are high load-carrying elements suitable for long spans and would most likely be solicited at high bending stress ratios. 


\subsubsection{Self-Tapping Screws}

Partially-threaded self-tapping screws are widely used in CLT construction. The tapping tip of the screws eliminates the need for pre-drilling as required with most timber fasteners, and therefore reduces the risk of oversized pilot holes which may reduce the withdrawal resistance of the connection. The 2014 edition of CSA O86 does not have design provisions for such fasteners.

Figure 2.28 illustrates an ASSY® 3.0 Ecofast partially-threaded self-tapping screw as well as its specific characteristics that differentiate it from traditional wood screws and lag screws. Table 2.7 provides the specifications of the $6 \mathrm{~mm}$ "outside" diameter ASSY® 3.0 Ecofast partially-threaded self-tapping screw used in this study. These self-tapping screws made from carbon steel are typically designated by their outside diameter followed by their total and threaded lengths. As an example, a screw designated " $\phi 6$ $100 / 60$ " would mean that it has a $6 \mathrm{~mm}$ outside diameter, a total length of $100 \mathrm{~mm}$ and a threaded length of $60 \mathrm{~mm}$. 


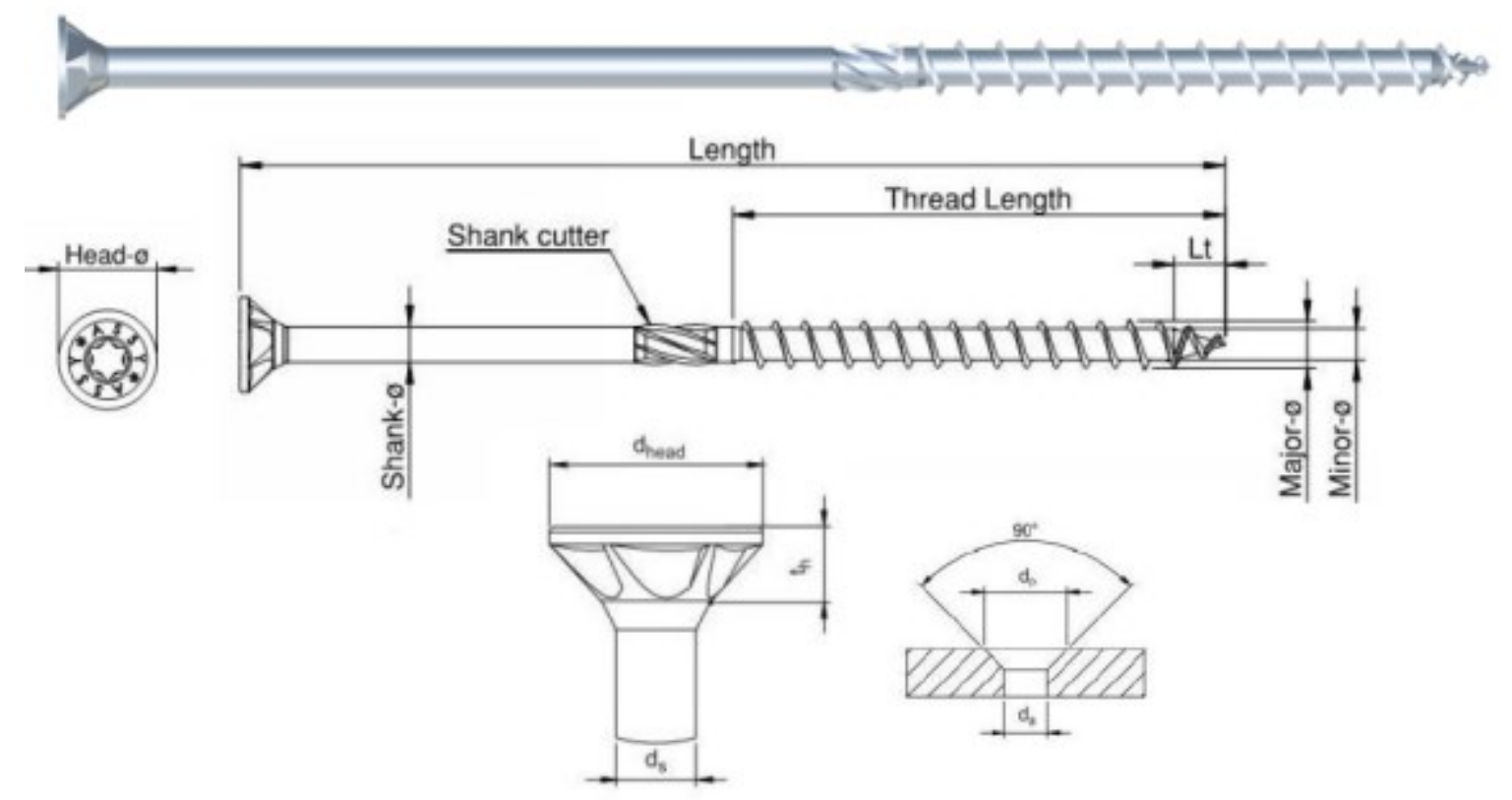

Figure 2.28 - ASSY ${ }^{\circledR} 3.0$ Ecofast self-tapping screw (adapted from [51])

According to the Canadian Construction Materials Centre (CCMC) product evaluation [52], the factored lateral resistance of ASSY ${ }^{\circledR}$ self-tapping screws must be calculated following the lag screw provisions of CSA O86, as per Equations (2.9) and (2.10), depending on the load orientation. The embedment depths $\left(t_{1}\right.$ and $\left.t_{2}\right)$ are determined based on the actual joint configuration, as shown in Figure 2.29.

Table 2.7-ASSY ${ }^{\circledR}$ 3.0 Ecofast geometric specifications $(\mathrm{mm})$ [51]

\begin{tabular}{cccccccccc}
\hline $\begin{array}{c}\text { Major } \\
\phi\end{array}$ & Length & $\begin{array}{c}\text { Thread } \\
\text { Length }\end{array}$ & $\boldsymbol{L}_{\boldsymbol{t}}$ & $\begin{array}{c}\text { Head } \\
\boldsymbol{\phi}\end{array}$ & $\begin{array}{c}\text { Minor } \\
\boldsymbol{\phi}\end{array}$ & $\begin{array}{c}\text { Shank } \\
\boldsymbol{\phi}\end{array}$ & $\boldsymbol{d}_{\boldsymbol{a}}$ & $\boldsymbol{t}_{\boldsymbol{h}}$ & $\boldsymbol{d}_{\boldsymbol{p}}$ \\
\hline \multirow{2}{*}{6} & 70 & 42 & & & & & & & \\
& 100 & 60 & 6 & 12 & 3.9 & 4.4 & 7 & 4.2 & 14.5 \\
& 160 & 70 & & & & & & & \\
\hline
\end{tabular}



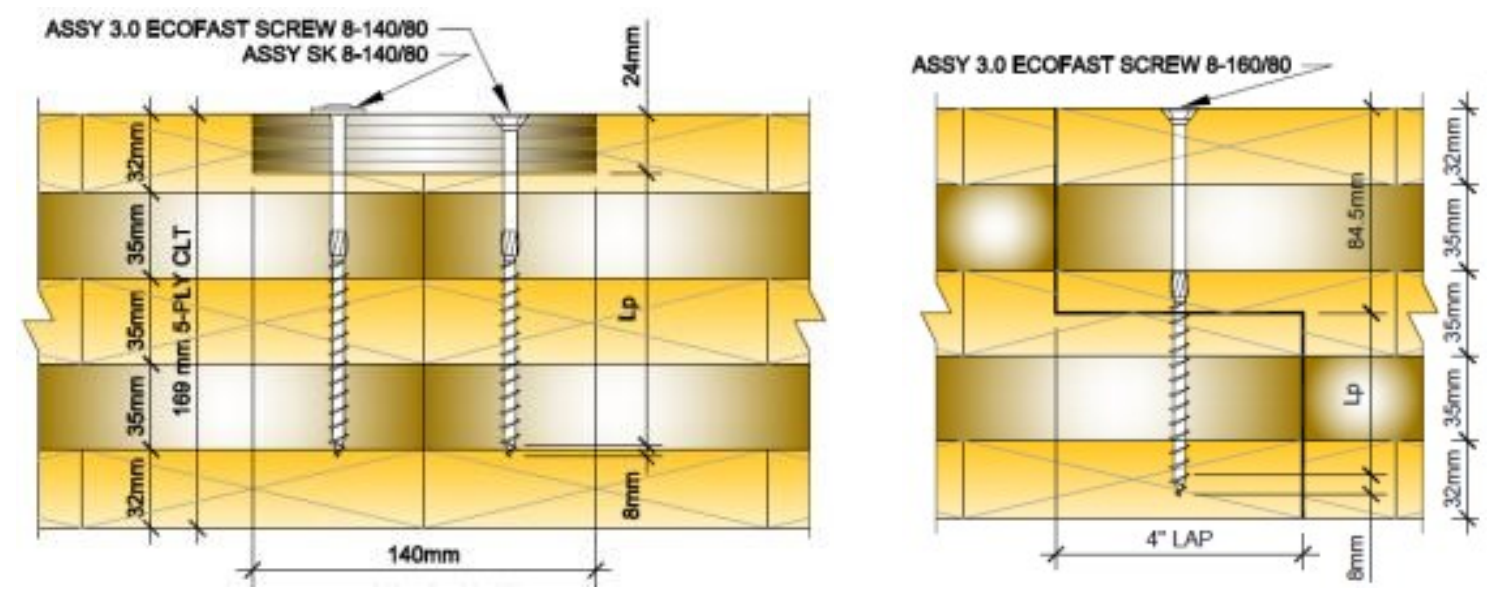

Figure 2.29 - Configuration of typical CLT panel-to-panel joints (image: [51])

The CCMC evaluation report also states that the factored withdrawal resistance can be calculated using Equation (2.11). According to [53], it can be taken as $0.91 \mathrm{kN}$ per 20 $\mathrm{mm}$ of threaded length for a mean oven-dry relative density of the CLT boards of 0.42 , outside screw diameter $(\phi)$ of $6 \mathrm{~mm}$ and a load orientation $(\alpha)$ of $90^{\circ}$ (perpendicular to grain).

$$
P_{r w}(N)=\varphi \frac{0.8 \cdot \delta \cdot(b \cdot 0.84 \rho)^{2} \cdot \phi \cdot l_{e f} \cdot 10^{-6}}{\sin ^{2} \alpha+\frac{4}{3} \cos ^{2} \alpha} K_{D} K_{S F}
$$

Where $\varphi$ is the resistance factor (taken as 0.9 ), $\delta$ is a material adjustment factor (taken as 85 for materials with $\rho$ less than $\left.440 \mathrm{~kg} \cdot \mathrm{m}^{-3}\right), b$ is taken as unity for lumber, $\rho$ is the mean oven-dry relative density (Table A.10.1 of CSA O86, $\mathrm{x} 10^{3}$ ), $\phi$ is the outside screw diameter $(\mathrm{mm}), l_{\text {ef }}$ is the embedment depth into member $(\mathrm{mm})$ and $\alpha$ is the screw angle relative to the wood grain. The embedment depth $\left(l_{e f}\right)$ is determined based on the actual 
joint configuration, self-tapping screw total and threaded length, as shown in Figure 2.29. As an example, a 3-ply CLT (105 $\mathrm{mm}$ thick and $\left.420 \mathrm{~kg} \cdot \mathrm{m}^{-3}\right)$ with a half-lapped joint connected with a partially-threaded ASSY ${ }^{\circledR} 3.0$ Ecofast $\phi 6-100 / 60 \mathrm{~mm}$ would have an embedment depth of $41.5 \mathrm{~mm}(100-(105 \div 2)-6=41.5 \mathrm{~mm})$ and its factored withdrawal resistance would be $1897 \mathrm{~N}\left(1897 \mathrm{~N} \div 41.5 \mathrm{~mm}=45.7 \mathrm{~N} \cdot \mathrm{mm}^{-1}\right.$, same as the published value in [53] of $0.91 \mathrm{kN}$ per $20 \mathrm{~mm}$ of threaded penetration).

The factored head pull-through resistance can be calculated using Equation (2.12) and, per the CCMC evaluation report [52], is taken as $1.32 \mathrm{kN}$ for a $6 \mathrm{~mm}$ diameter ASSY ${ }^{\circledR}$ 3.0 Ecofast partially-threaded screw used in timber of a mean oven-dry relative density of 0.42 (such as the lumber used in CLT of the E1 stress grade, per CSA O86).

$$
P_{p t}=\varphi r_{p t} K_{D} K_{S F}=1.32 \mathrm{kN}
$$

Where $\varphi$ is the resistance factor (taken as 0.7 ), $r_{p t}$ is the characteristic pull-through strength adjusted to standard duration of load $(\mathrm{kN})$.

Lastly, it was found by Muñoz et al. [54] that CSA O86 wood screw design provisions seem to provide reasonable estimates and would therefore be applicable to withdrawal resistance of self-tapping screws. The authors also reported that half-lapped connections using self-tapping screws exhibited better lateral capacity, stiffness and ductility when compared to that of single surface spline configurations. Based on a wide series of experiments on threaded fasteners, Kennedy et al. $[55,56]$ also suggest that the current 
wood screw withdrawal equation can reasonably be applicable to all threaded fasteners, including self-tapping and lag screws.

\subsubsection{CLT Strength and Resistance}

Cross-laminated timber used in North America shall be manufactured in accordance with ANSI/APA PRG-320-12 "Standard for Performance-Rated Cross-Laminated Timber" [14]. Generic specified strengths for CLT currently used in Canada are shown in Table 2.8 .

Table 2.8 - Specified strength and stiffness of CLT grade, per ANSI/APA PRG-320-12 [14]

\begin{tabular}{|c|c|c|c|c|c|c|c|c|c|c|c|}
\hline \multirow[b]{2}{*}{$\begin{array}{c}\text { CLT } \\
\text { Grade }\end{array}$} & \multirow[b]{2}{*}{$\begin{array}{l}\text { Thickness } \\
\text { (mm) }\end{array}$} & \multicolumn{7}{|c|}{$\begin{array}{c}\text { Lamination thickness and } \\
\text { orientation }(\mathrm{mm})\end{array}$} & \multicolumn{3}{|c|}{ Major Strength Direction } \\
\hline & & $=$ & $\perp$ & $=$ & $\perp$ & $=$ & $\perp$ & $=$ & $\begin{array}{c}f_{b} S_{e f f ; 0} \\
\left(\mathbf{x} 10^{6}\right) \\
\left(\mathbf{N} \cdot \mathbf{m m} \cdot \mathbf{m}^{-1}\right) \\
\end{array}$ & $\begin{array}{c}E I_{\text {eff; } 0} \\
\left.(\mathbf{x 1 0})^{9}\right) \\
\left(\mathbf{N} \cdot \mathbf{m m}^{2} \cdot \mathbf{m}^{-1}\right) \\
\end{array}$ & $\begin{array}{l}G A_{\text {eff; },} \\
\left(\mathbf{x} 10^{6}\right) \\
\left(\mathbf{N} \cdot \mathbf{m}^{-1}\right) \\
\end{array}$ \\
\hline \multirow{3}{*}{ V2 } & 105 & 35 & 35 & 35 & - & - & - & - & 18 & 884 & 7.2 \\
\hline & 175 & 35 & 35 & 35 & 35 & 35 & - & - & 41 & 3,388 & 14.0 \\
\hline & 245 & 35 & 35 & 35 & 35 & 35 & 35 & 35 & 72 & 8,388 & 22.0 \\
\hline \multirow{3}{*}{ E1 } & 105 & 35 & 35 & 35 & - & - & - & - & 42 & 1,088 & 7.3 \\
\hline & 175 & 35 & 35 & 35 & 35 & 35 & - & - & 98 & 4,166 & 15.0 \\
\hline & 245 & 35 & 35 & 35 & 35 & 35 & 35 & 35 & 172 & 10,306 & 22.0 \\
\hline
\end{tabular}

The factored bending moment for a CLT panel is calculated from Equation (2.13), as suggested in Chapter 3 of the CLT handbook [45].

$$
M_{r}=\phi F_{b} S_{e f f, 0} K_{Z b} K_{L} K_{r b}
$$

Where $\phi$ is the resistance factor (taken as 0.9 ), $F_{b}$ is the specified strength in bending adjusted by all applicable factors and $S_{\text {eff, }, 0}$ is the effective section modulus in the major 
strength direction, $K_{z b}$ is the size factor in bending (taken as unity for CLT), $K_{L}$ is the lateral stability factor (taken as unity) and $K_{r b}$ is an adjustment factor in bending (taken as 0.85 for bending along the major strength direction [14]). As an example, a 3-ply CLT of the E1 stress grade would have a factored bending moment resistance of $32.1 \mathrm{kN} \cdot \mathrm{m} \cdot \mathrm{m}^{-1}$ for standard load duration.

Should serviceability be a limiting design criterion, the deflection of CLT floor panels must be taken as the sum of the deflection due to bending moment and shear deformation. Equation (2.14) details the deflection equation for a CLT floor panel subjected to thirdpoint bending.

$$
\Delta_{T}=\Delta_{\text {Bending }}+\Delta_{\text {Shear }}=\frac{23 P L^{3}}{648 E I_{\text {eff }, 0}}+\left(\frac{P L}{3} \frac{\kappa}{G A_{\text {eff }, 0}}\right)
$$

Where $P$ is the applied load (at each loading point) and $L$ is the span, $E I_{\text {eff, },}$ is the effective bending stiffness, $G A_{\text {eff }, 0}$ is the effective shear stiffness and $\kappa$ is a shear coefficient factor taken as 1.2 for rectangular sections as recommended in Chapter 3 of the CLT Handbook [45].

\subsubsection{Plywood Spline}

In a plywood spline, there are two types of shear forces that can be generated when subjected to loads. The first type is the shear force acting across the panel cross-section and is called the "shear through the thickness". The other type occurs in the plane of the plies and is often called "planar shear" or "rolling shear". Both types of shear are 
illustrated in Figure 2.30. In the case of plywood spline used to connect CLT panels together, only the shear through the thickness needs to be considered.

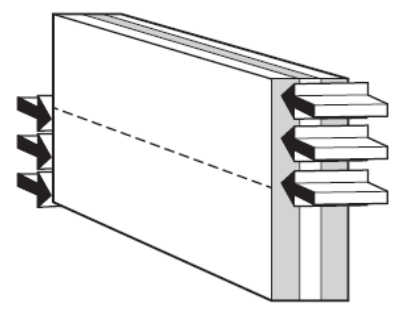

Shear through thickness $v_{p}, \mathrm{~N} / \mathrm{mm}$

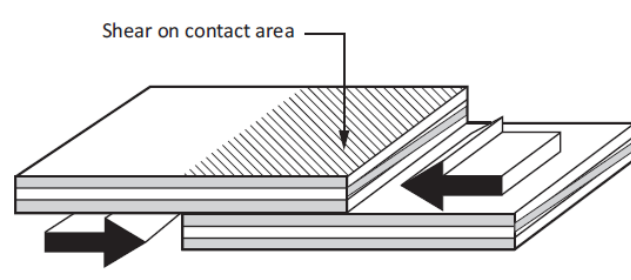

Planar shear due to in-plane forces in a gusset or splice plate, $v_{\rho f}, \mathrm{MPa}$

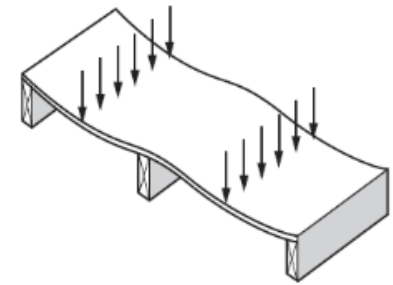

Planar shear due to bending, $v_{p b} \mathrm{MPa}$

Figure 2.30 - Shear orientation in panel products [48] (reproduced with permission from CSA Group)

The factored shear through the thickness of a plywood spline is given by Equation (2.15) When used as a gusset plate or a structural spline (e.g. splice), the actual length subjected to shear is considered, per clause 9.5.5.2 of CSA O86-14 [48].

$$
V_{r}=\phi V_{p} L_{g}
$$

Where $\phi$ is the resistance factor (taken as 0.95 ), $V_{p}$ is the specified strength in shear through thickness adjusted by all applicable factors and $L_{g}$ is the length of splice subjected to shear. As an example, the factored shear through the thickness resistance of an $18.5 \mathrm{~mm}(3 / 4$ in. nominal) Canadian Softwood Plywood would be $43.7 \mathrm{kN}$ per millimeter of splice length $\left(L_{g}\right)$ for standard load duration. 


\subsection{Material Properties at Elevated Temperatures}

Proper knowledge of the materials' properties at elevated temperatures is fundamental in order to evaluate and model CLT panel-to-panel connections for fire-resistance, namely with respect to heat transfer through CLT panels (i.e. wood) and within fasteners (i.e. steel).

\subsubsection{Wood Properties at Elevated Temperatures}

\subsubsection{Mechanical Properties}

Structural lumber used in Canada is graded in accordance with the grading rules of the National Lumber Grades Authority (NLGA) [57] and with the provisions of CSA O141 "Softwood Lumber" [58]. There are four species combinations within CSA O86: 1) Douglas Fir-Larch, 2) Hem-Fir, 3) Spruce-Pine-Fire and 4) Northern Species. All of these groups are further divided into different lumber grades. The most common lumber grades are visually stress-graded, such as Select Structural or No.1/No.2, and machine stressrated lumber (MSR) such as $1950 \mathrm{f}_{\mathrm{b}}-1.7 \mathrm{E}$. MSR lumber can be of any species and needs to be evaluated in accordance with NLGA SPS-2 "Special Products Standard for Machine Graded Lumber" [59]. Mechanical design values used in structural design are shown in Table 5.3.1A of CSA O86 for visually stress-graded lumber and Table 5.3.2 for machine stress-rated lumber.

When exposed to elevated temperatures, wood chemical components undergo thermal degradation that affects wood mechanical properties. This material-specific degradation property, called pyrolysis, occurs at approximately $200^{\circ} \mathrm{C}$ while the remaining wood 
converts afterwards to char at temperatures ranging from 280 to $300^{\circ} \mathrm{C}$ (Figure 2.31 ). As illustrated in Figure 2.32, it is typically assumed that strength and modulus of elasticity $(M O E)$ of charred wood (above $300^{\circ} \mathrm{C}$ ) are set to zero and they are thus neglected when determining the residual cross-section of a structural wood element. The remaining crosssection is considered to remain at ambient temperature, thus maintaining full design strength.

As such, it is important to determine the char front position as a function of time when calculating the structural response of timber. The position of the char front is a function of heat being conducted into the wood and is explained in subsection 2.5.1.2.

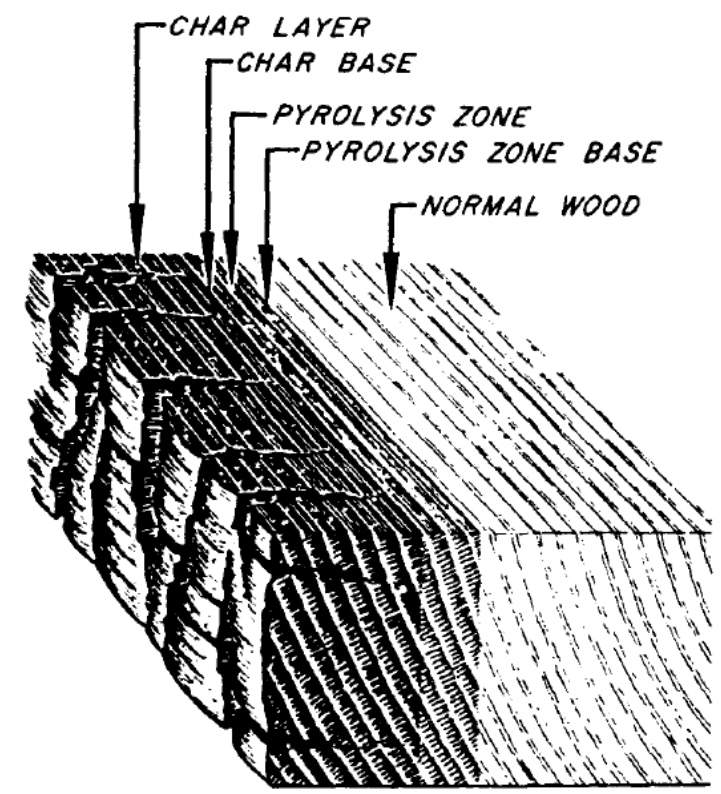

Figure 2.31 - Wood thermal degradation when exposed to fire [60] 

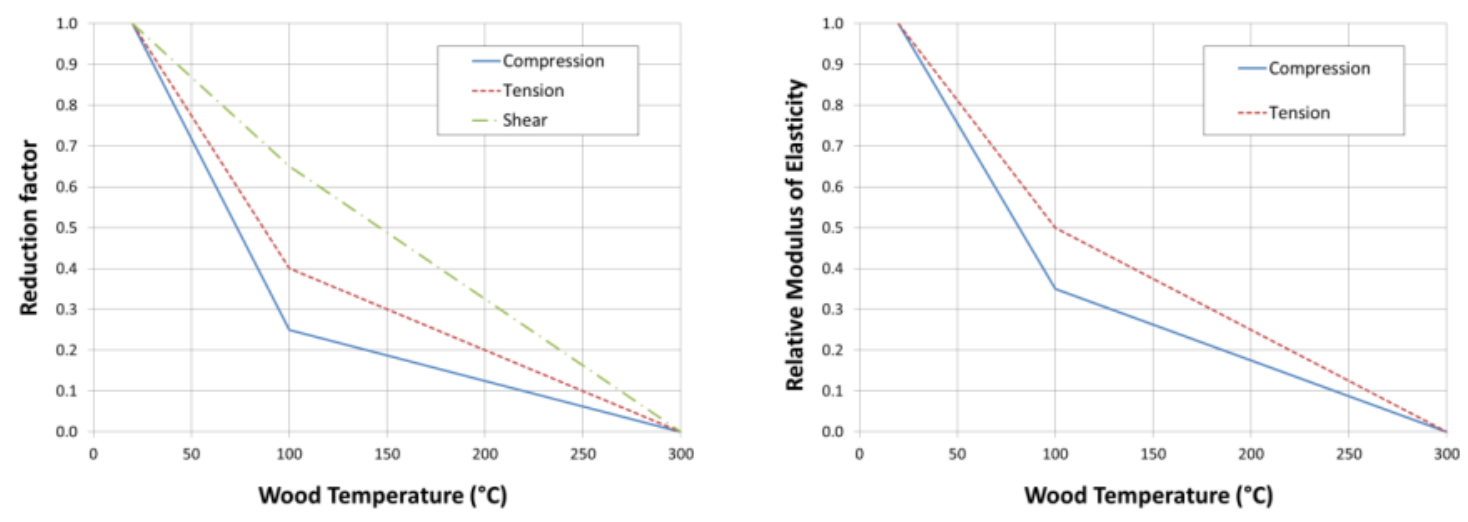

Figure 2.32 - Wood strength and MOE reduction factors at elevated temperatures as per [27]

\subsubsection{Thermal Properties}

Wood is a combustible material that exhibits charring when exposed to fire conditions. Charring is influenced by various factors such as density, moisture content, wood contraction (shrinkage) as well as radiant and convective heat fluxes (fire severity). Usually, a decrease in charring rate is seen with an increase of density and with an increase of moisture content of wood. Schaffer [60] evaluated the charring rate of selected woods of different density, among other parameters. Douglas-Fir specimens with relative density ranging from 0.359 to 0.622 (average of 0.488 ) were exposed to the standard ASTM E119 time-temperature for evaluating their charring rate. The relation for determining the charring rate $\left(\beta_{0}\right)$ based on density and moisture content can be found in White \& Dietenberger [36] and shown in Equation (2.16).

$$
\beta_{0}(\mathrm{~mm} / \mathrm{min})=\frac{1}{[(0.002269+0.00457 w) \rho+0.331]}
$$


Where $w$ is the wood moisture content (as fraction of oven-dry mass) and $\rho$ is the mean oven-dry relative density $\left(\mathrm{kg} \cdot \mathrm{m}^{-3}\right)$. Using Equation (2.16) with $12 \%$ moisture content, a charring rate of $0.66 \mathrm{~mm} / \mathrm{min}$ is obtained for a wood density of $420 \mathrm{~kg} / \mathrm{m}^{3}$. Table 2.9 shows design charring rates applicable to various wood products. One-dimensional charring rate is applicable to wide cross-section exposed to fire on one side, while notional charring rate includes the effect of corner rounding and fissures and should be applicable to cross-section exposed to fire from at least 2 sides.

Table 2.9-Design charring rates for wood products [27]

\section{Wood Product}

One-dimensional

$\beta_{o}(\mathrm{~mm} / \mathrm{min})$
Notional

$\beta_{n}(\mathrm{~mm} / \mathrm{min})$

\begin{tabular}{lll}
\hline Softwood and beech & & \\
- Glued-laminated timber $\left(\rho \geq 290 \mathrm{~kg} / \mathrm{m}^{3}\right)$ & 0.65 & 0.70 \\
Solid timber $\left(\rho \geq 290 \mathrm{~kg} / \mathrm{m}^{3}\right)$ & 0.65 & 0.80 \\
\hline Hardwood & & \\
- Solid or Glued-laminated hardwood $\left(\rho=290 \mathrm{~kg} / \mathrm{m}^{3}\right)$ & 0.65 & 0.70 \\
Laminated Veneer Lumber $\left(\rho \geq 480 \mathrm{~kg} / \mathrm{m}^{3}\right)$ & 0.50 & 0.55 \\
\hline Panels (of thickness $\geq 20 \mathrm{~mm}$ and $\left.\rho \geq 450 \mathrm{~kg} / \mathrm{m}^{3}\right)$ & 0.65 & 0.70 \\
- Wood paneling & & - \\
- Plywood & 0.90 & - \\
\hline
\end{tabular}

When wood is exposed to a constant heat flux, from radiation, convection or both, its surface temperature starts to rise causing its inner temperature to rise as well, but at a slower rate. if the heat flux is sufficient, the surface temperature will reach a level where pyrolysis will occur. As described previously, wood pyrolysis requires a certain heat flow or heat flux from a fire or another heat source. 
According to Janssens \& Douglas [61], piloted ignition, from a flame for example, may occur at wood surface temperatures ranging from 350 to $365^{\circ} \mathrm{C}$ (for softwoods) and 300 to $310^{\circ} \mathrm{C}$ (hardwoods). Piloted ignition can occur when wood is exposed to a constant heat flux between 10 to $13 \mathrm{~kW} / \mathrm{m}^{2}$ [38]. A critical heat flux $\left(\dot{q}_{c r}\right)$ of $12.5 \mathrm{~kW} / \mathrm{m}^{2}$ is commonly accepted for piloted ignition of wood, while a heat flux $33 \mathrm{~kW} / \mathrm{m}^{2}$ is recognized for auto-ignition of wood [62]. No ignition source is required to ignite wood when its surface temperature is between 400 and $500^{\circ} \mathrm{C}$ for a prolonged duration of time.

Wood exposed to a fire may ignite and the charring rate is influenced by the rate of heat transfer conducted into the solid. The main thermal properties affecting conductive heat transfer are the thermal conductivity, density, specific heat and moisture content of wood, including the partially and fully charred portions of wood [63]. As described previously, charring of wood is a complex process and defining thermal properties for every stage of pyrolysis can be onerous. A thorough literature review of wood's thermal properties has been reported by Saidu [64], Craft [65] and Benichou \& Sultan [66] in developing thermal models of light-frame wood assemblies. Annex B in Eurocode 5: Part 1-2 also provides wood thermal properties for advanced fire design calculations.

As mentioned by König [67], a numerical model solves transient heat transfer differential equation based on thermal properties that vary with temperatures. Typically, such models do not account for mass transfer, reaction energy released inside the wood due to pyrolysis and degradation of the material which increases the heat transfer (e.g. cracking 
of the charred layer). Moreover, heat is being transferred at the boundaries by convection and radiation modelled as functions of time.

As such, numerical models used to assess heat transfer through materials require thermal properties to be validated and calibrated, if required, such that the predictions fit well to the test data. Similar calibration, or "adjustment" of the thermal properties, are also discussed and compared in a recent paper by Fragiacomo et al. [68] in an attempt to replicate heat transfer in laminated veneer lumber (LVL) elements exposed to fire. In their model, the authors used the density ratio and specific heat values suggested in Eurocode 5: Part 1-2, but required an increase adjustment of the thermal conductivity in temperature range between $550^{\circ} \mathrm{C}$ to $1200^{\circ} \mathrm{C}$, to account for an increase of heat transfer due to convection and radiation in the cracks of the charred layer (Table 2.10). As mentioned previously, the various changes in wood physical and thermal properties when exposed to fire will influence potential failure modes when connecting CLT panels together. 
Table 2.10 - Thermal properties used in some numerical models, as presented in [68]

\begin{tabular}{|c|c|c|c|c|c|}
\hline \multirow{2}{*}{$\begin{array}{c}\text { Temperature } \\
\left({ }^{\circ} \mathrm{C}\right)\end{array}$} & $\begin{array}{c}\text { Specific Heat } \\
\left(\mathrm{kJ} \mathrm{kg}^{-1} \mathrm{~K}^{-1}\right)\end{array}$ & $\begin{array}{l}\text { Density } \\
\text { Ratio }\end{array}$ & \multicolumn{3}{|c|}{$\begin{array}{l}\text { Thermal Conductivity } \\
\left(\mathbf{W} \mathbf{m}^{-1} \mathrm{~K}^{-1}\right)\end{array}$} \\
\hline & \multicolumn{2}{|c|}{$\begin{array}{c}\text { Eurocode } 5 \text { and } \\
\text { Fragiacomo et al. }[68]\end{array}$} & $\begin{array}{c}\text { Fragiacomo } \\
\text { et al. }[68]\end{array}$ & Frangi [69] & EC 5:1-2 [27] \\
\hline 20 & 1.53 & $1+\omega$ & 0.132 & 0.132 & 0.120 \\
\hline 99 & 1.77 & $1+\omega$ & 0.203 & 0.203 & 0.133 \\
\hline 99 & 13.60 & $1+\omega$ & 0.203 & 0.203 & 0.133 \\
\hline 120 & 13.50 & 1.00 & 0.223 & 0.223 & 0.137 \\
\hline 120 & 2.12 & 1.00 & 0.223 & 0.223 & 0.137 \\
\hline 200 & 2.00 & 1.00 & 0.295 & 0.295 & 0.150 \\
\hline 250 & 1.62 & 0.93 & 0.228 & 0.228 & 0.123 \\
\hline 300 & 0.71 & 0.76 & 0.162 & 0.162 & 0.097 \\
\hline 350 & 0.85 & 0.52 & 0.096 & 0.096 & 0.070 \\
\hline 400 & 1.00 & 0.38 & 0.104 & 0.104 & 0.077 \\
\hline 500 & 1.20 & 0.33 & 0.119 & 0.119 & 0.090 \\
\hline 550 & 1.30 & 0.31 & 0.127 & 0.127 & 0.133 \\
\hline 600 & 1.40 & 0.28 & 0.180 & 0.225 & 0.177 \\
\hline 800 & 1.65 & 0.26 & 0.450 & 0.617 & 0.350 \\
\hline 1200 & 1.65 & 0.00 & 1.500 & 1.400 & 1.500 \\
\hline
\end{tabular}

\subsubsection{Steel Properties at Elevated Temperatures}

Steel is widely used in the construction of railways, infrastructures and buildings. Most modern structures such as sport complexes, buildings and bridges are made using steel. On a much smaller scale, it is also used in a broad range of fastenings such as bolts, nails, screws and plates.

\subsubsection{Mechanical Properties}

Structural steel is formed with specific shapes or cross-sections and certain standards of chemical composition and mechanical properties. The Canadian Institute for Steel Construction (CISC) publishes various shapes and sizes of structural steel elements 
readily available in Canada. I-beams, hollow structural sections, angles (L-shaped crosssection), channels, bars, rods, plates, decks and open web steel joists are some of the many examples of structural steel profiles. In Canada, design of steel structures is in accordance with CSA S16 "Design of Steel Structures" [70].

Structural steel used in Canada has to meet the requirements of CSA G40.20/G40.21, ASTM A572 or ASTM A992/A992M standards [70]. Typical steel grades of 300W and 350W exhibit a high yield strength $\left(F_{y}\right)$ of 300 and $350 \mathrm{MPa}$ respectively and a very high modulus of elasticity of $200000 \mathrm{MPa}$. Structural steel also has a high ultimate tensile strength ranging from 450 to $650 \mathrm{MPa}$. While these high strength values allow structural steel elements to be manufactured in small and shallow cross-sections, the overall weight of a steel element is quite heavy due to its very high density of $7850 \mathrm{~kg} / \mathrm{m}^{3}$, resulting in a high building mass.

Similarly to wood, steel exposed to elevated temperatures exhibits a strength and stiffness reduction. Such strength reduction influences the serviceability and load-carrying functions of steel elements to a point where structural failure may occur. A materialspecific property linked to steel components is its critical temperature. This critical temperature is often used as a failure criterion for structural steel components. According to $\mathrm{CAN} / \mathrm{ULC} \mathrm{S} 101$ [17], a critical temperature of $538^{\circ} \mathrm{C}\left(1000^{\circ} \mathrm{F}\right)$ is used for structural beams and columns while $593^{\circ} \mathrm{C}\left(1100^{\circ} \mathrm{F}\right)$ is used for reinforcing steel used in reinforced concrete. At those temperatures, steel components will lose about half of their initial strength and stiffness (a 50\% reduction). Figure 2.33 shows a graphical representation of 
carbon steel yield strength $\left(F_{y}\right)$ and modulus of elasticity $(M O E)$ reduction factors when exposed to elevated temperatures, as given in Eurocode 3: Part 1-2 "Design of Steel Structures - Part 1-2: General - Structural Fire Design" [71].

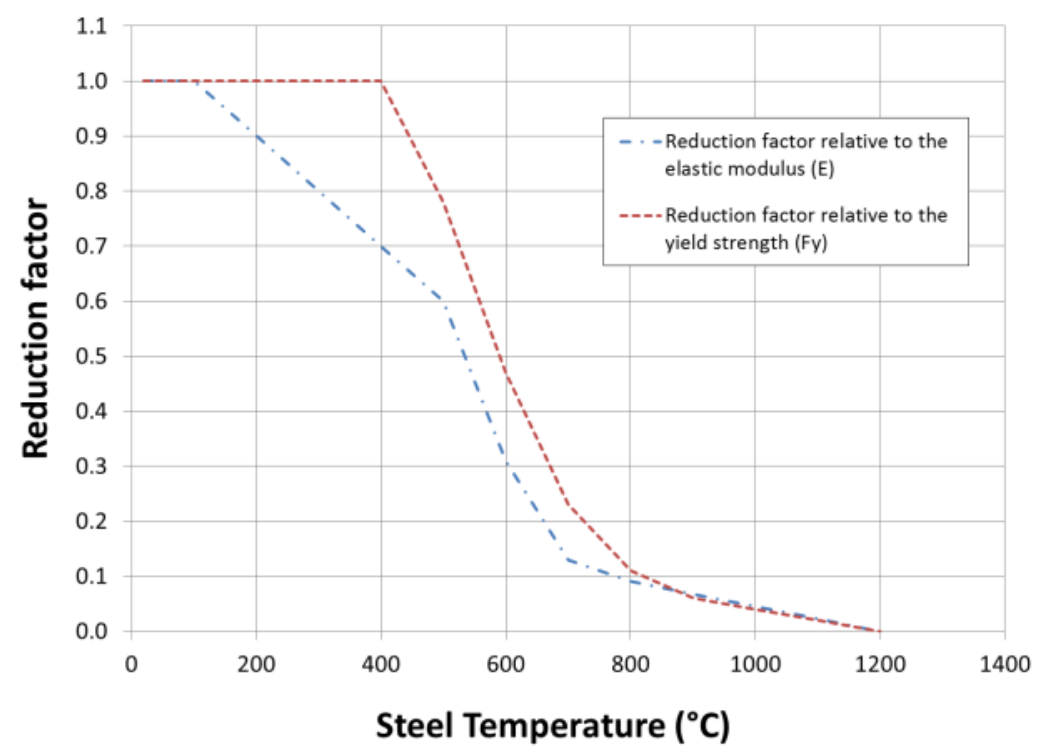

Figure 2.33 - Carbon steel strength and MOE reduction factors at elevated temperatures as per [71]

\subsubsection{Thermal Properties}

Eurocode 3: Part 1-2 provides the most complete set of information on thermal properties of carbon and stainless steel elements. As illustrated in Figure 2.34, carbon steel has a very high thermal conductivity $(k)$, varying linearly from $54 \mathrm{~W} \cdot \mathrm{m}^{-1} \cdot \mathrm{K}^{-1}$ at $0^{\circ} \mathrm{C}$ to a constant value of $27.3 \mathrm{~W} \cdot \mathrm{m}^{-1} \cdot \mathrm{K}^{-1}$ at $800^{\circ} \mathrm{C}$. Due to its relatively high thermal conductivity, steel is recognized as a very good thermal conductor, thus a very poor thermal insulator. 


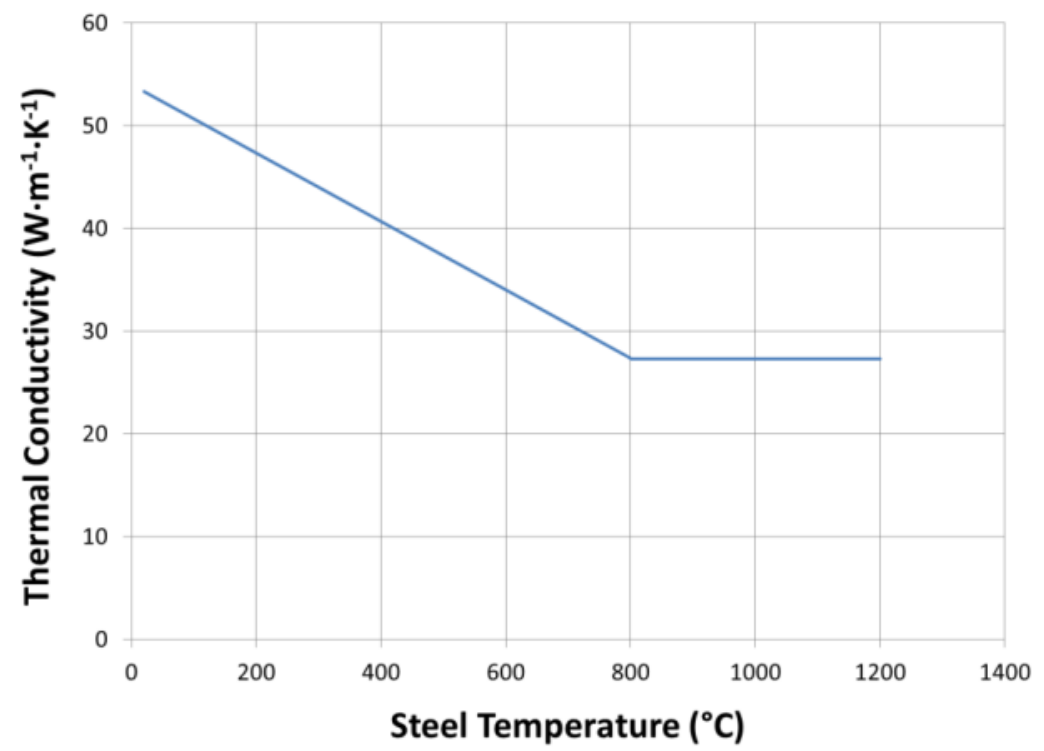

Figure 2.34 - Carbon steel thermal conductivity at elevated temperatures as per [71]

Another important thermal property is specific heat $\left(c_{p}\right)$ which can be defined as the characteristic of a material describing the amount of heat required to raise a unit mass of the material by a unit temperature. When carbon steel undergoes a metallurgical phase change, the specific heat has an abrupt peak value of $5000 \mathrm{~J} \cdot \mathrm{kg}^{-1} \cdot \mathrm{K}^{-1}$ at about $735^{\circ} \mathrm{C}$. Figure 2.35 shows a graphical representation of steel specific heat as a function of temperature, as given in [71]. Steel specific heat is not easy to define and varies with an increase in temperature, which can create possible numerical complication in computer modeling. 


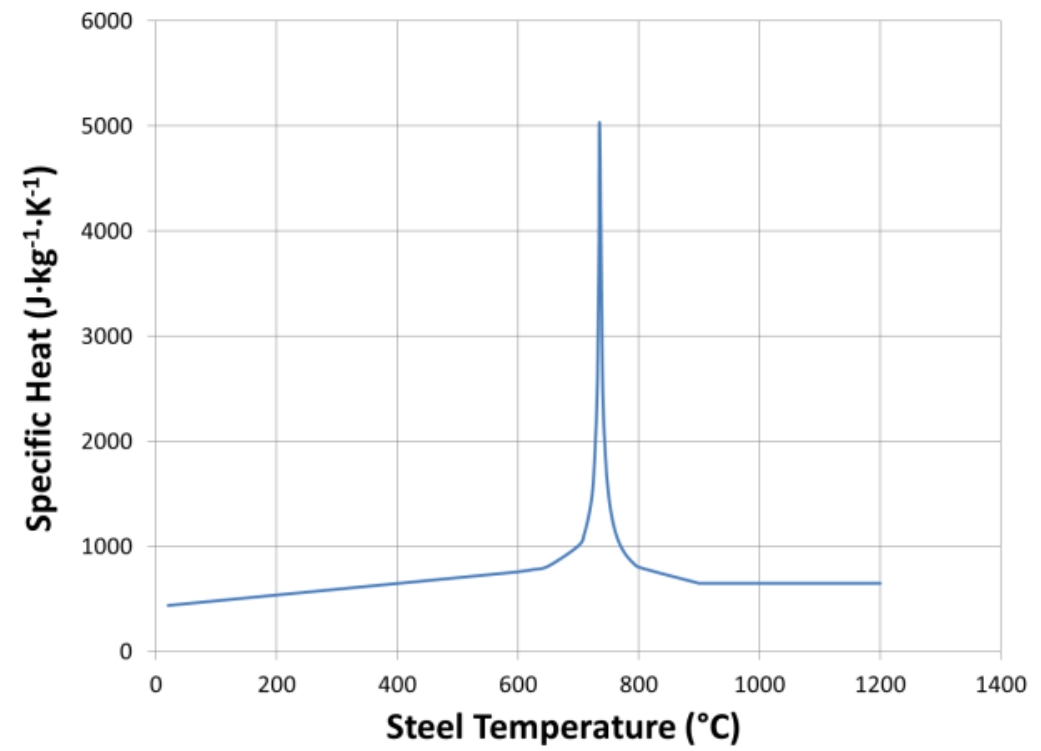

Figure 2.35 - Carbon steel specific heat at elevated temperatures as per [71] 


\section{Experimental Research}

An experimental campaign carried out for properly understanding the thermal and mechanical behaviour of CLT panel-to-panel joint configurations is the core of the study. This chapter provides the details of the experimentation.

At first, bending tests have been performed at ambient (normal) conditions to better understand the behaviour of a typical CLT panel-to-panel joint configuration. The results were used to determine reasonable loading conditions and stress levels for the second phase of the study, the intermediate-scale fire-resistance tests.

It should be noted that the fire tests were part of a project funded by the Forestry Innovation Investment (FII) of British Columbia, of which a detailed test report has been released prior to completing this thesis. As such, some of the discussion provided herein reflects those already reported by the author [72].

\subsection{Materials}

\subsubsection{Cross-Laminated Timber Panels}

Due to its close proximity to the fire laboratory, CLT specimens have been obtained from Nordic Engineered Wood located in the province of Quebec. The CLT were of the E1 stress grade manufactured with a polyurethane structural adhesive conforming to ANSI/APA PRG 320-12 [14, 73]. The laminations consist of 1950f $\mathrm{f}_{\mathrm{b}}-1.7 \mathrm{E}$ machine-stress rated black spruce lumber in the major strength direction and visually stress-graded SPF No.3 in the minor strength direction. The specified strengths and stiffness for this CLT 
stress grade are given in Table 2.8. Panel thicknesses range from 3-ply (105 mm) to 7-ply (245 mm). The CLT panels were pre-cut and assembled using the 4 panel-to-panel joint configurations, as described in Subsection 2.3, previously machined at the manufacturing plant through a computer numerically controlled (CNC) machine (Figure 3.1).
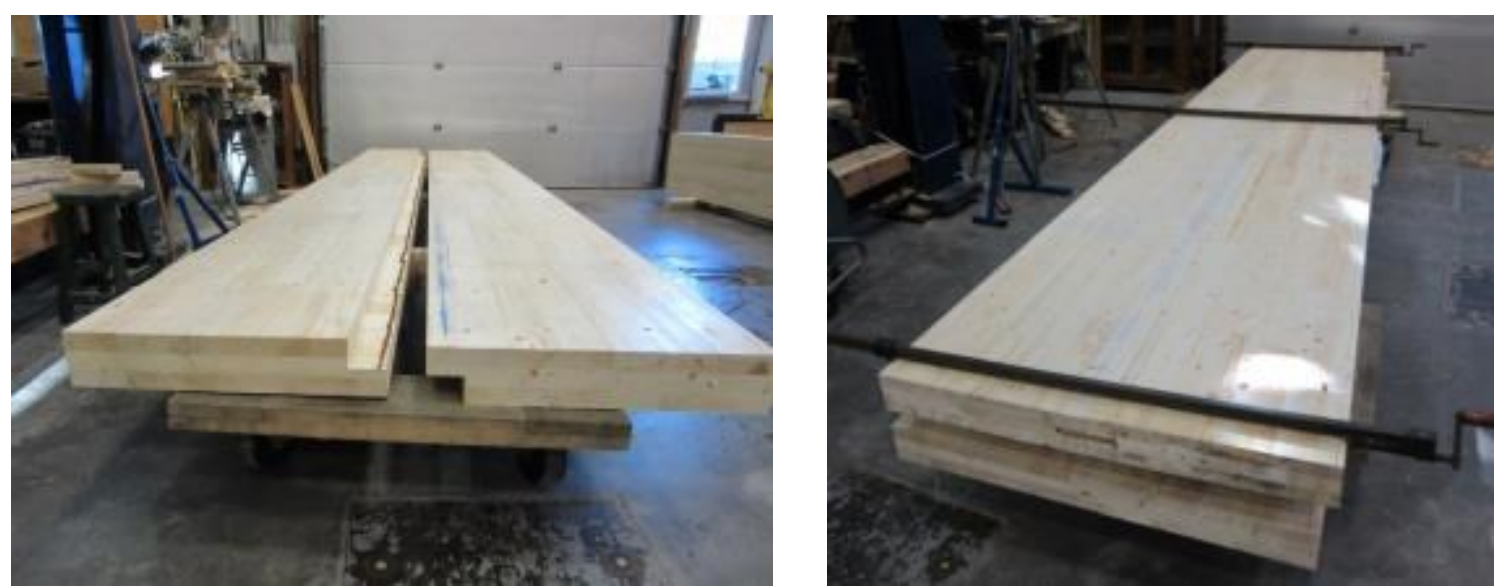

Figure 3.1 - CLT panels ready to assemble (left) and under side pressure by clamps (right)

\subsubsection{Fastener and Spline Details}

As explained in subsection 2.4.1, joints connected using discrete fasteners must be designed so that the fastener's lateral resistance respects the relation shown in Equation (2.4). In a typical lateral load resisting system design, the connection between components of a floor diaphragm needs to be designed in such way to transfer the applied shear flow through the fasteners and the splines, when applicable.

Partially-threaded ASSY ${ }^{\circledR} 3.0$ Ecofast self-tapping screws of a $6 \mathrm{~mm}$ outside diameter were used in this study. Except for the half-lapped joint configuration, all other panel-topanel joints required the use of plywood splines to fasten the CLT panels together. The 
plywood splines used in this study were cut along the major strength direction of $1.22 \mathrm{x}$ $2.44 \mathrm{~m}$ panels of Canadian softwood plywood (CSP) to dimensions of $18.5 \mathrm{~mm}$ in thickness by $130 \mathrm{~mm}$ in width. Table 3.1 summarizes the fasteners and plywood spline used for connected CLT floor panels together. A total of 10 tests were conducted for evaluating the fire integrity performance of CLT panel-to-panel joints.

Table 3.1 - CLT panel-to-panel joint test matrix for fire testing

\begin{tabular}{ccccc}
\hline \multirow{2}{*}{ CLT Assembly } & \multicolumn{4}{c}{ Panel-to-Panel Joint Detail } \\
\cline { 2 - 5 } & Half-Lapped & Internal Spline & $\begin{array}{c}\text { Single Surface } \\
\text { Spline }\end{array}$ & $\begin{array}{c}\text { Double Surface } \\
\text { Spline }\end{array}$ \\
\hline 3-ply $(105 \mathrm{~mm})$ & $\mathrm{x}$ & $\mathrm{x}$ & $\mathrm{x}$ & $\mathrm{x}$ \\
\hline 5-ply $(175 \mathrm{~mm})$ & $\mathrm{x}$ & $\mathrm{x}$ & $\mathrm{x}$ & $\mathrm{x}$ \\
\hline 7-ply $(245 \mathrm{~mm})$ & $\mathrm{x}$ & n.a. & n.a. & $\mathrm{x}$ \\
\hline
\end{tabular}

To limit the variables in this study, the plywood thickness and fastener spacing were fixed. It was decided to use Canadian softwood plywood (CSP) splines along its strength direction and by spacing the fasteners at $305 \mathrm{~mm}$ on center, which is a typical spacing for joints subjected to in-plane loading (e.g. seismic and wind loads). The maximum shear flow that such joint details can withstand can easily be calculated. The spacing of fasteners is typically determined based on the in-plane load (i.e. seismic and wind loads) that needs to be transferred from one component to another, not from out-of-plane loading conditions as in a bending situation (i.e. gravity loads).

\subsubsection{Construction of the CLT Panel-to-Panel Joints}

For the half-lapped and internal spline configurations, partially-threaded screws with a 6 $\mathrm{mm}$ diameter and in lengths of 100, 160 and $240 \mathrm{~mm}$ were used for 3-ply, 5-ply and 7-ply 
CLT specimens respectively ( $\phi 6 \times 100 / 60 \mathrm{~mm}, \phi 6 \times 160 / 70$ and $\phi 6 \times 240 / 70$ ). Selftapping screws, of $70 \mathrm{~mm}$ in length $(\phi 6 \times 70 / 42)$, were used throughout for all CLT specimens with the single and double spline configurations.

The plywood splines were cut along the major strength direction of $1.22 \times 2.44 \mathrm{~m}$ sheets of Canadian softwood plywood (CSP) to dimensions of $18.5 \mathrm{~mm}$ in thickness and 130 $\mathrm{mm}$ in width. Two plywood splines were butt-jointed together along their length (buttjoint located at mid-span). Screws were spaced at $305 \mathrm{~mm}$ on center for all specimens.

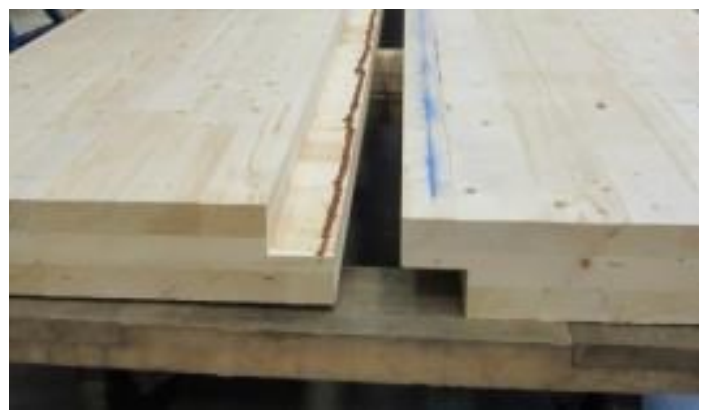

a) Half-lapped

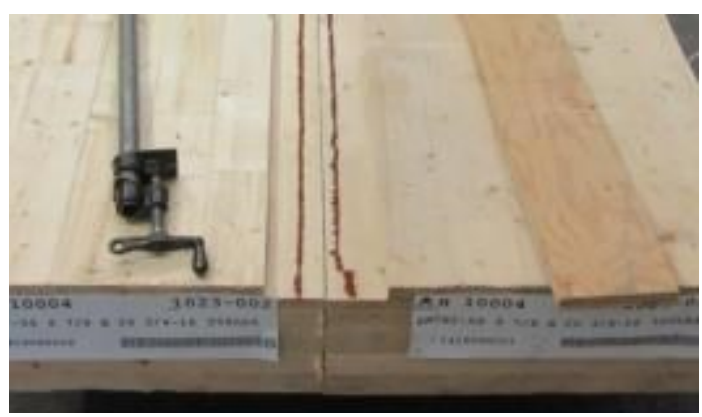

c) Single surface spline

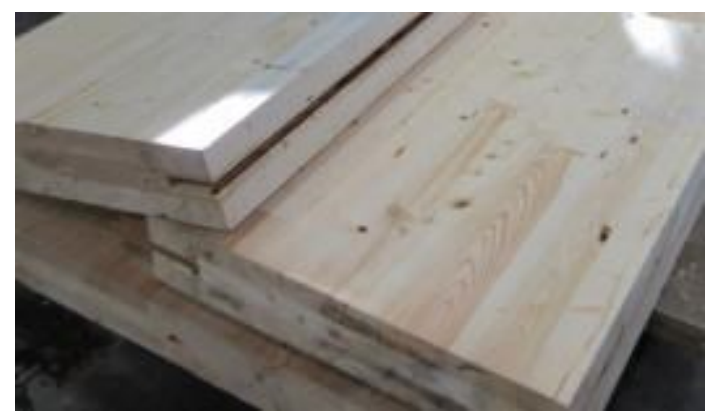

b) Internal spline

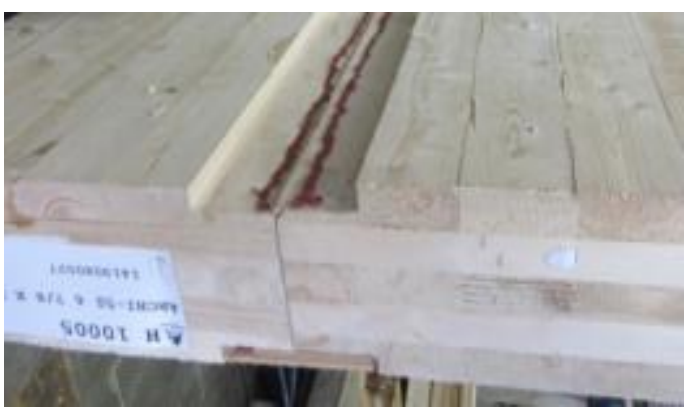

d) Double surface spline

Figure 3.2 - Firestop sealant before joining CLT panels

All joint assemblies were tightly fit and sealed using a $6 \mathrm{~mm}$ bead of Hilti FS-One intumescent firestop sealant [74] to prevent smoke leakage, as shown in Figure 3.2. Figure 3.3 shows four joint configurations of 5-ply CLT panels fully assembled before testing. 


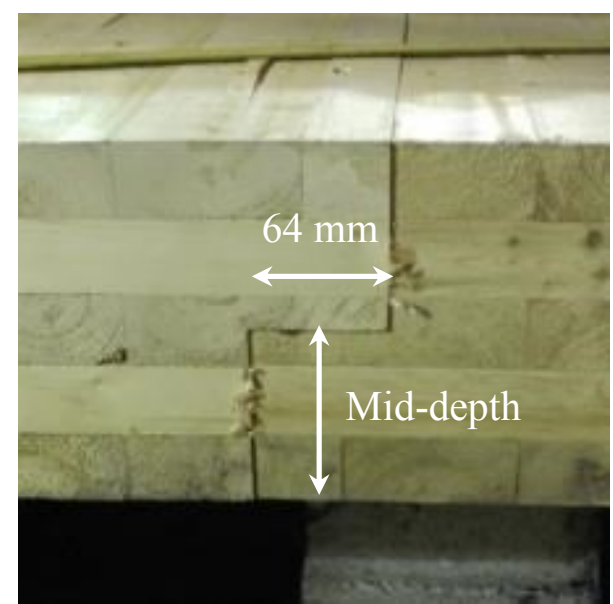

a) Half-lapped joint

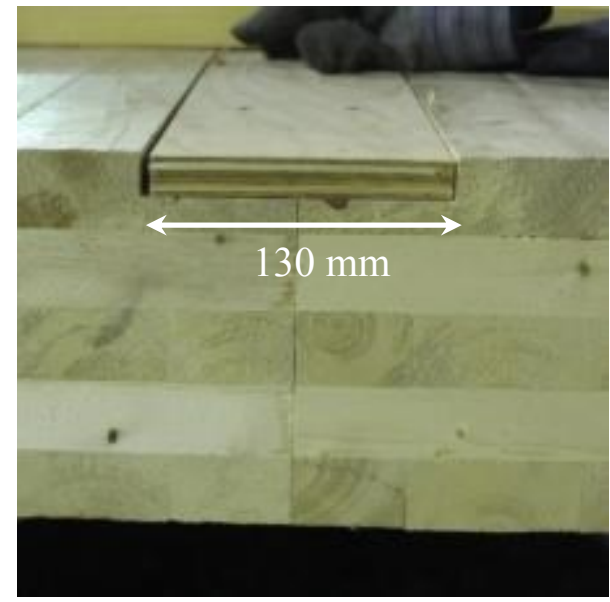

c) Single surface spline

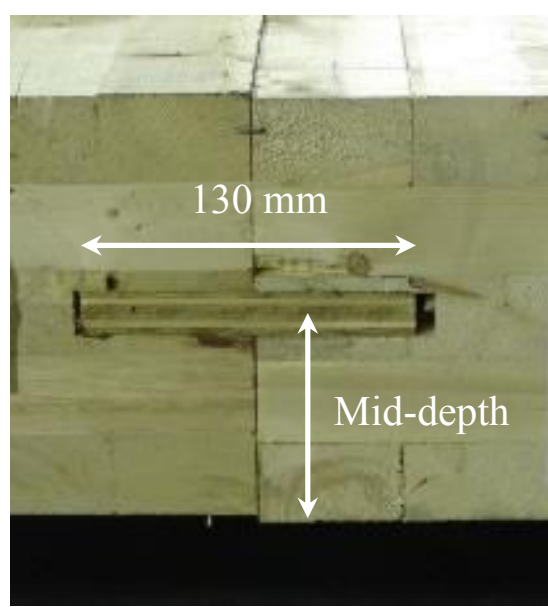

b) Internal spline

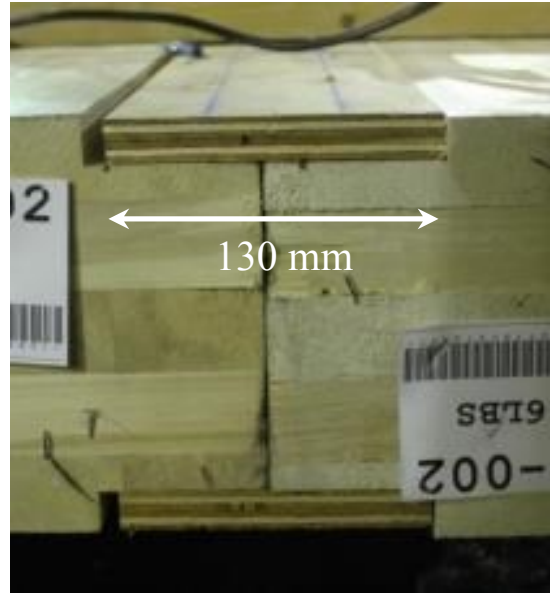

d) Double surface spline

Figure 3.3 - CLT panel-to-panel joints before testing

\subsection{Bending Test at Ambient Conditions}

Typically, connections between CLT floor panels are designed to transfer lateral shear forces resulting from floor diaphragm action (i.e. in-plane loading) and not for transverse loading where fasteners may be subject of withdrawal. As such it appears logical that the 
loading condition should be representative of a CLT floor assembly subjected to bending as it would be during the normal service life of a structure.

As stipulated in subsection 1.3, the intent of the fire tests is to investigate the influence of the presence of metal fasteners and splines on the fire integrity resistance of CLT floor elements (i.e. flame-through). The fire tests are not intended to evaluate the actual structural fire-resistance of the connections. Therefore, subjecting the connections between the CLT panels to a stress ratio significantly higher than that of the components they connect together is somewhat questionable. Individual structural members of a floor system are typically expected to resist the loads imposed on them. Even in a worst case scenario, no systems or members are expected to resist an imposed load with the assumptions that the load will be transferred from adjacent members through the fasteners or connections. Such a case would be a "less than worst case" scenario [75]. In other words, if one CLT panel is subjected to out-of-plane loads, the adjacent CLT panels are not expected to carry these loads that are not directly applied to them. They are designed to carry their own imposed loads, regardless of the panel-to-panel connection details.

Fasteners and splines connecting CLT panels together have the sole mandate of transferring horizontal shear forces resulting from a floor diaphragm action (i.e. in-plane loading). These connections, even if they have the ability to transfer some shear though thickness forces between the CLT slabs, are usually not designed for this function. 
The four CLT panel-to-panel joint configurations selected in this study are connections that are meant to transfer horizontal loads between CLT panels. For CLT panels that are part of a floor, the application of any horizontal loading will result in a horizontal sliding between each CLT slab element. The self-tapping screws and plywood splines that serve as a link between CLT panels are designed to resist this sliding action and no other action is taken into account in design of the connection.

\subsubsection{Testing Conditions}

The first experimental phase of this study consisted in bending tests performed at ambient conditions. To better understand the behavior of the assemblies with respect to potential failure modes. All tests were performed at FPInnovations Materials Evaluation laboratory in Quebec City (Qc).

The test setup consisted of three CLT panels, $203 \mathrm{~mm}$ wide each, connected side-by-side using single surface splines made from $18.5 \mathrm{~mm}$ by $130 \mathrm{~mm}$ strips of plywood and partially-threaded ASSY ${ }^{\circledR} 3.0$ Ecofast self-tapping screws $(\phi 6 \times 70 / 42 \mathrm{~mm})$ spaced at $305 \mathrm{~mm}$ on center. The total width of the assemblies was $610 \mathrm{~mm}$.

The set-up was of a simple span of $3.5 \mathrm{~m}$ (138 in.) subjected to a third-point bending. The loading points were spaced at $1.17 \mathrm{~m}$ (46 in.), replicating a similar stress distribution as that planned to be used for the fire tests. The load was applied at a constant displacement rate of $8 \mathrm{~mm} / \mathrm{min}$ so that the maximum load is reached in not less than $4 \mathrm{~min}$, as required in ASTM D198 [76]. Loading points and end supports allowed for rotation of the CLT slabs. The end supports were mounted on ball bearings to allow for translation. The 
testing and data acquisition were controlled through MTS Systems Corporation's TestWorks ${ }^{\mathrm{TM}}$ program.

In Test 1, the loading points were applied through $305-\mathrm{mm}$ wide steel plates located across the plywood splines in attempt for subjecting the entire assembly to bending (Figure 3.4). By doing so, lateral shear forces are induced in the splines and in the fasteners. In Test 2, the loading points were applied directly on top of the middle CLT panel, thus only soliciting the fasteners, mainly in withdrawal (Figure 3.5).
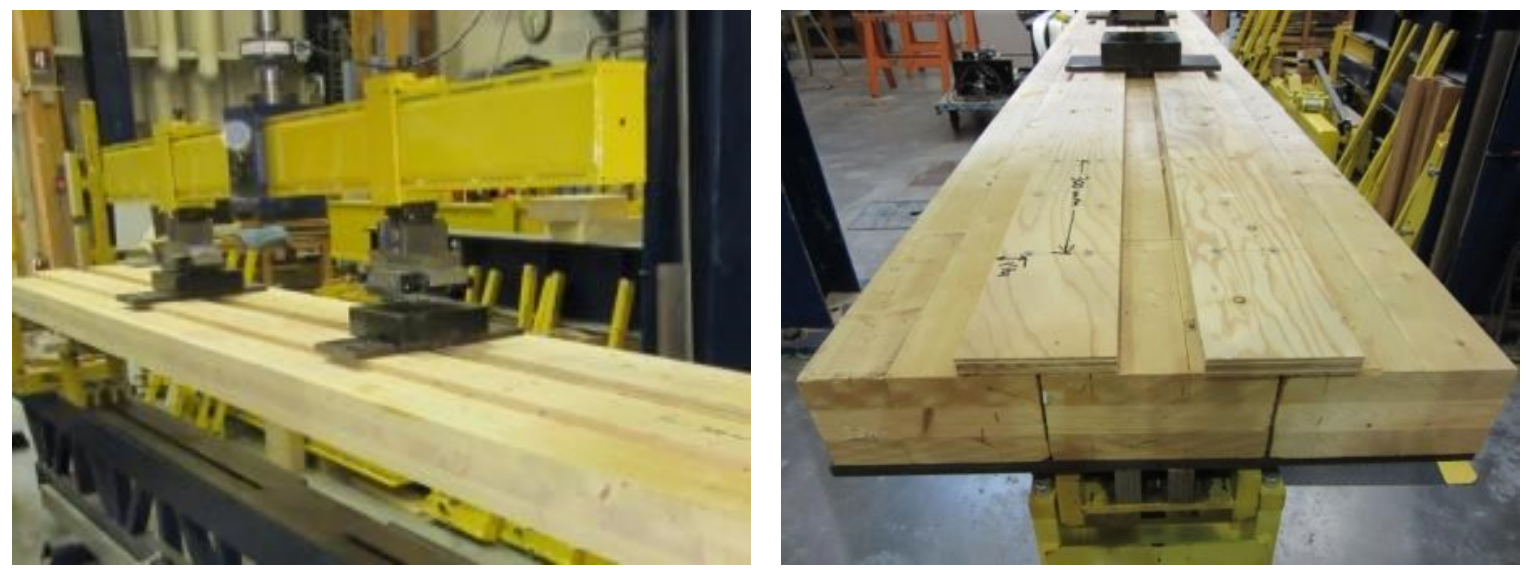

Figure 3.4-CLT bending Test 1 under ambient conditions
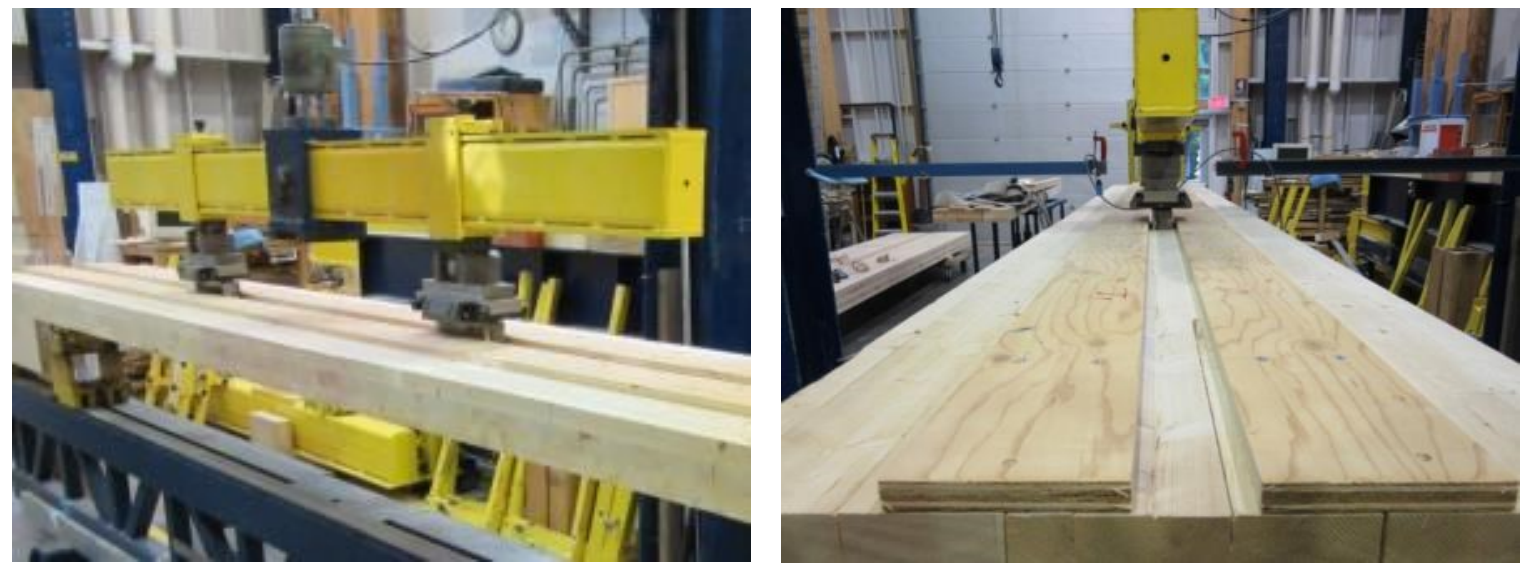

Figure 3.5 - CLT bending Test 2 under ambient conditions 


\subsubsection{Test Results}

Test 1 assembly was tested up to a load of $45.4 \mathrm{kN}$ at which the test was terminated due to the load cell capacity being close to its maximum. No failure was achieved from Test 1 with the initial load cell. For laboratory equipment safety, the load cell was changed and Test 1 assembly was reloaded with a higher capacity load cell.

Test 1-retest was brought to structural failure where the CLT panels failed due to axial tension forces at the lower laminations, as shown in Figure 3.6. The peak load was recorded at $66.5 \mathrm{kN}$ when failure occurred. It could be observed after the failure that the plywood splines and self-tapping screws were still mostly intact, although a light gap was observed between one of the plywood spline and the CLT panels (Figure 3.7).

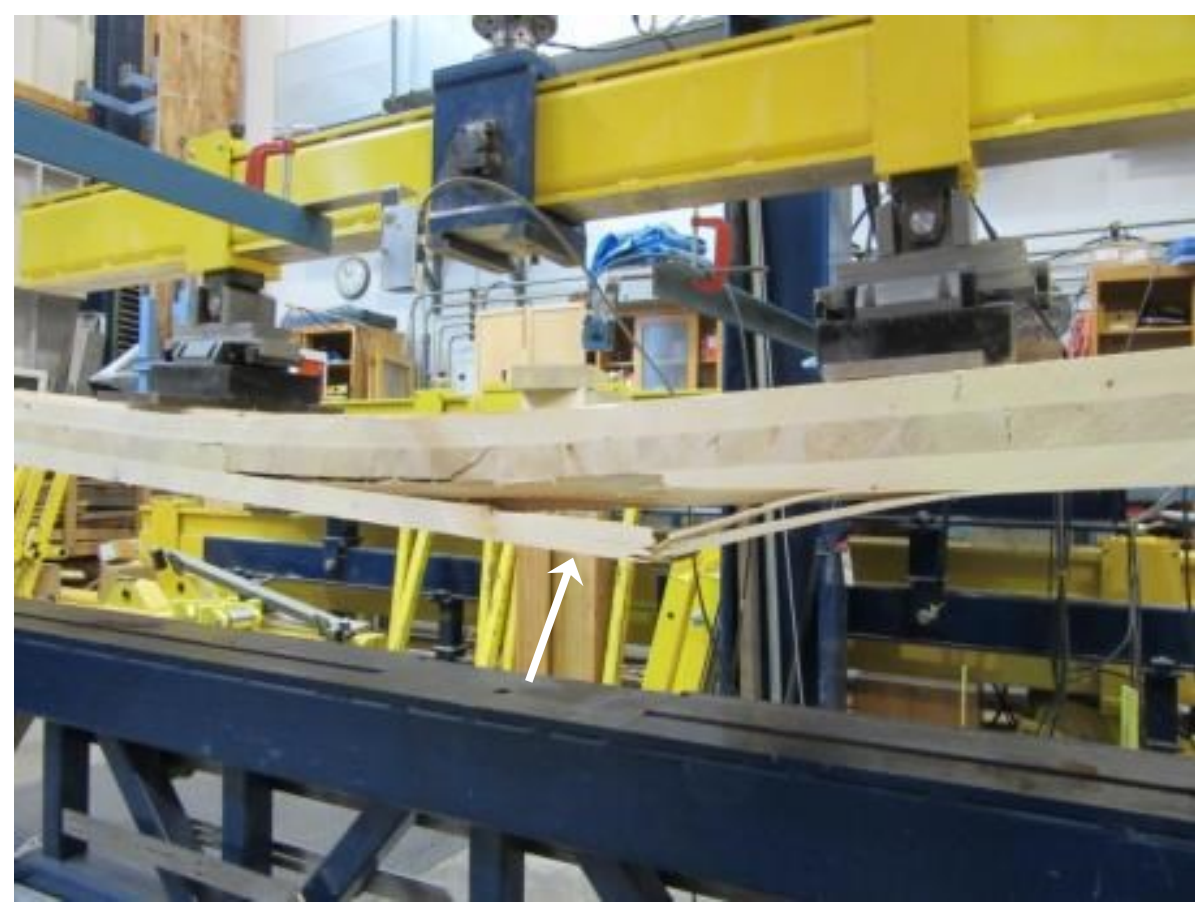

Figure 3.6 - Bending Test 1-retest failure mode 


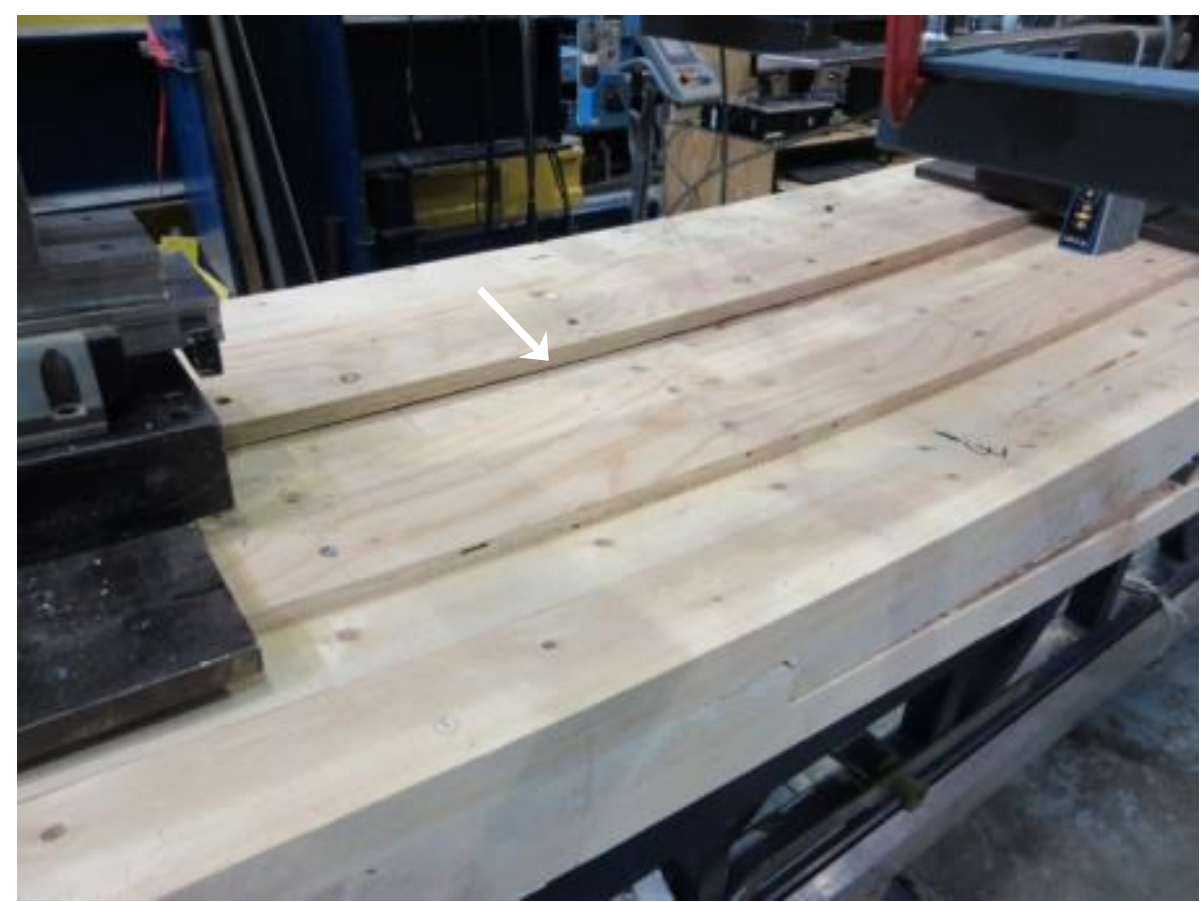

Figure 3.7-Bending Test 1 plywood spline and fasteners after failure

Test 2 was also brought to structural failure. In this particular test, two failures modes could be observed: 1) head pull-through of the fasteners (Figure 3.8) and 2) excessive tensile forces in the lower laminations (Figure 3.9). It is unclear whether the fasteners or the CLT failure occurred first, or even quasi-simultaneously. The peak load was recorded at $64.2 \mathrm{kN}$ when failure occurred.

Figure 3.10 shows the load-displacement plot obtained from the bending tests. It can be observed that specimens Test 1-retest and Test 2 exhibited similar behaviour until structural failure occurred. 


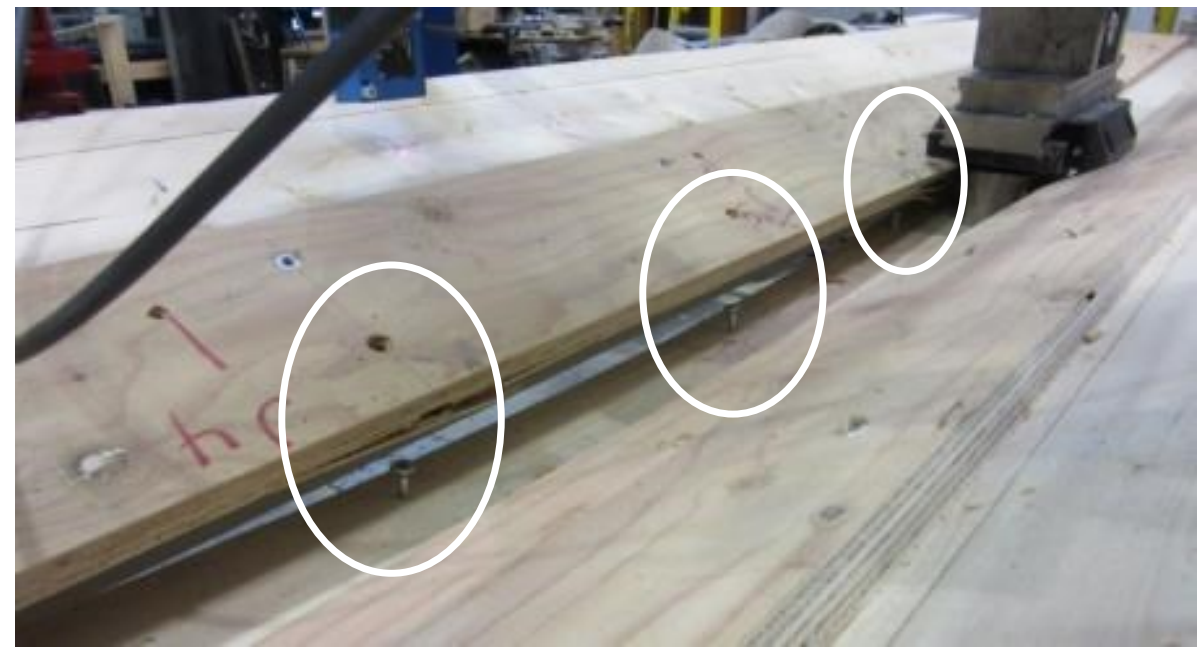

Figure 3.8 - Bending Test 2 failure mode (head pull-through of self-tapping screws)

According to Table A2 of ANSI/APA PRG-320, a 3-ply CLT of the E1 stress grade has an allowable bending capacity in the major strength direction of $20.1 \mathrm{kN} \cdot \mathrm{m} / \mathrm{m}(4,525 \mathrm{lbf}-$ $\mathrm{ft} / \mathrm{ft}$ ). Assuming a normal distribution with a coefficient of variation of $15 \%$ and a bending strength reduction factor of 2.1 per ASTM D2915 [77], the total load applied in third-point bending on a CLT panel of $610 \mathrm{~mm}$ width to achieve structural failure would be approximately $58 \mathrm{kN}$, on average, if $K_{r b}$ is ignored. The peak loads obtained from both bending tests were greater than the estimated value of $58 \mathrm{kN}$. 


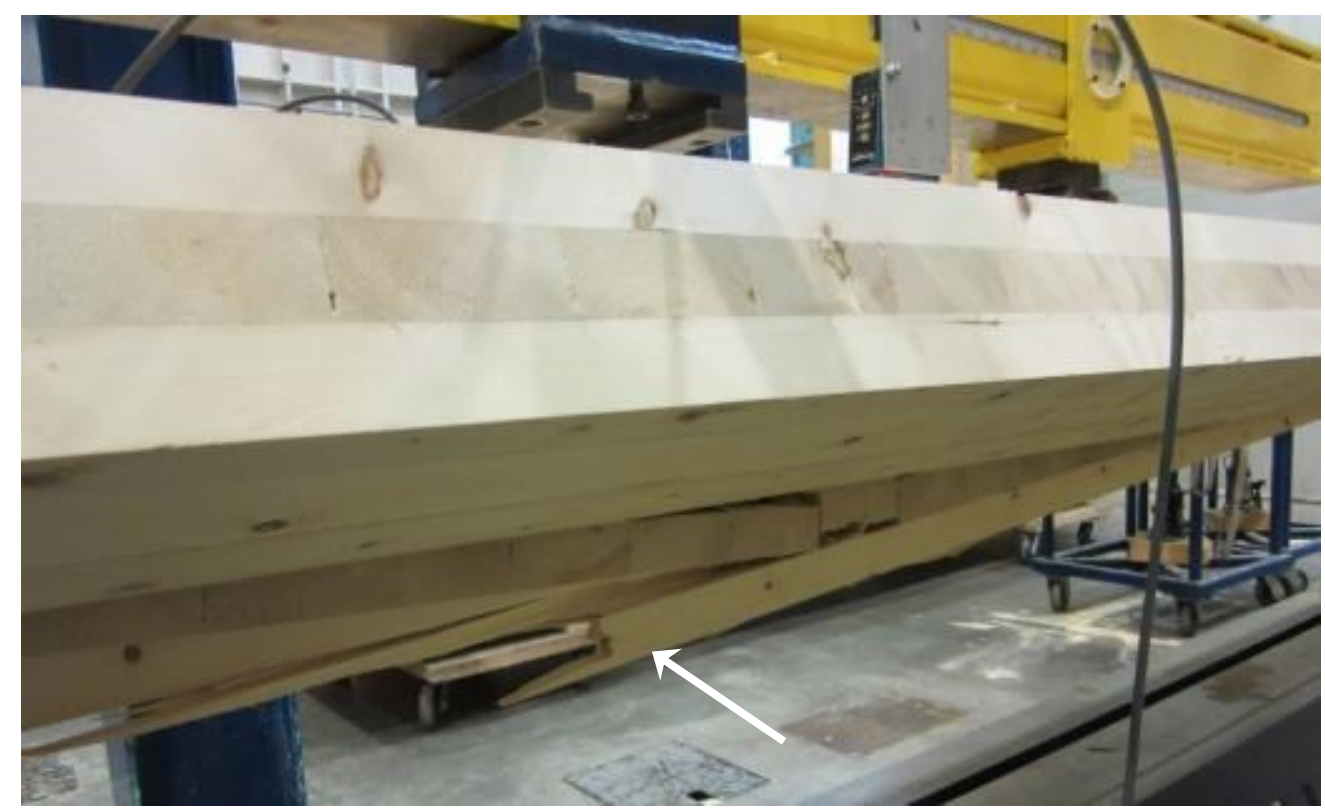

Figure 3.9-Bending Test 2 failure mode (tension at lower laminations)

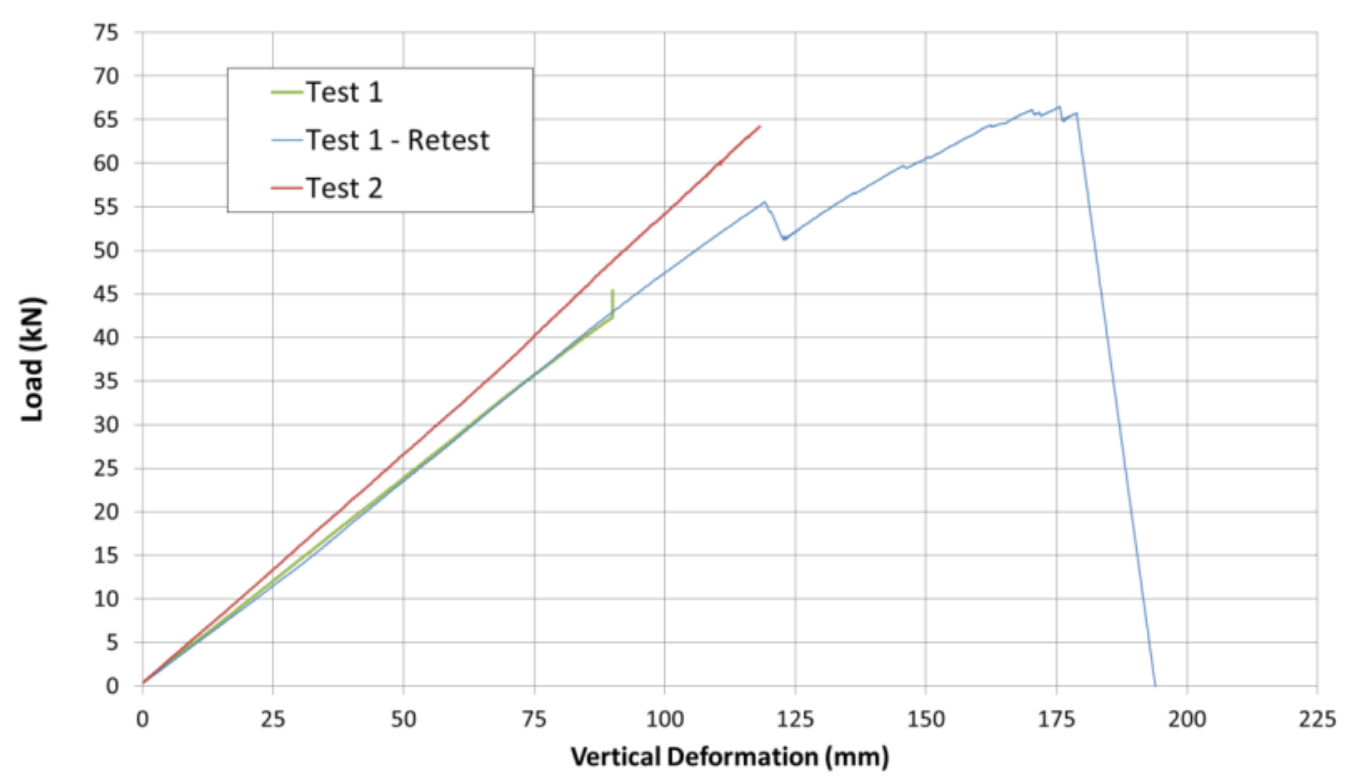

Figure 3.10 - Load-displacement data from CLT bending test under ambient conditions

Based on the failure modes observed from the bending tests and the primary purpose of connections used as link between adjacent CLT panels in a standard structural design, it appears reasonable that the loading configuration for the fire tests should be in such way 
as to subject the CLT assemblies based on their moment resistance and not that of the connections. It was thereby decided that, during the fire tests, all CLT panels in the assembly would be subjected to the same stress level as opposed to a partial loading (where only one panel element is loaded and the adjacent panels are not) and in such way as not to force premature failure of the fasteners. In other words, failure from pullthrough should not occur, but withdrawal or fastener yielding could.

\subsection{Bending Tests under Fire Conditions}

The second and main objective of this study consists in an evaluation of the fire integrity performance of the 4 panel-to-panel joint configurations described in Subsection 2.3. The CLT panels were fully exposed (i.e. unprotected) to fire from underneath. The test matrix shown in Table 3.2 details the various configurations selected for evaluation of their fire integrity performance along with the predicted failure times based on the European methodology, as detailed in Subsection 2.2.1.

It should be noted that the single and double surface splines are not specifically addressed in the European or the American procedures. As such, using the single and double tongue-and-groove joint coefficients shown in Table 2.1 seems, at first, a reasonable assumption of their fire integrity performance. It should also be noted that 7-ply CLT panels (245 mm thick) are typically used in applications requiring high strength and bending stiffness. As such, connecting them with thin plywood splines is most likely unrealistic. Therefore, assemblies of 7-ply CLT with single surface and internal splines have not been evaluated in this study. 
Table 3.2 - Predicted time to fire integrity failure using Eurocode 5: part 1-2

CLT joint detail

\begin{tabular}{ccc}
\hline & $105 \mathrm{~mm}(3 \times 35 \mathrm{~mm})$ & $0.4 \times \frac{105}{0.65}=64 \mathrm{~min}$ \\
\cline { 2 - 3 } $\begin{array}{c}\text { Internal spline } \\
\left.\text { using } K_{j}=0.4\right)\end{array}$ & $175 \mathrm{~mm}(5 \times 35 \mathrm{~mm})$ & $0.4 \times \frac{175}{0.65}=107 \mathrm{~min}$ \\
\cline { 2 - 3 } & $245 \mathrm{~mm}(7 \times 35 \mathrm{~mm})$ & $0.4 \times \frac{245}{0.65}=150 \mathrm{~min}$ \\
\hline $\begin{array}{c}\text { Single surface spline } \\
\left.\text { assuming } K_{j}=0.4\right)\end{array}$ & $105 \mathrm{~mm}(3 \times 35 \mathrm{~mm})$ & $0.4 \times \frac{105}{0.65}=64 \mathrm{~min}$ \\
\hline & $175 \mathrm{~mm}(5 \times 35 \mathrm{~mm})$ & $0.4 \times \frac{175}{0.65}=107 \mathrm{~min}$ \\
\hline $\begin{array}{c}\text { Double surface spline } \\
\left.\text { (assuming } K_{j}=0.6\right)\end{array}$ & $105 \mathrm{~mm}(3 \times 35 \mathrm{~mm})$ & $0.4 \times \frac{245}{0.65}=150 \mathrm{~min}$ \\
\hline & $245 \mathrm{~mm}(7 \times 35 \mathrm{~mm})$ & $0.6 \times \frac{175}{0.65}=96 \mathrm{~min}$ \\
\hline & $105 \mathrm{~mm}(3 \times 35 \mathrm{~mm})$ & $0.6 \times \frac{245}{0.65}=226 \mathrm{~min}$ \\
\hline $\begin{array}{c}\text { Half-lapped joint } \\
\left.\text { (using } K_{j}=0.3\right)\end{array}$ & $175 \mathrm{~mm}(5 \times 35 \mathrm{~mm})$ & $0.3 \times \frac{105}{0.65}=48 \mathrm{~min}$ \\
\hline & $245 \mathrm{~mm}(7 \times 35 \mathrm{~mm})$ & $0.3 \times \frac{175}{0.65}=80 \mathrm{~min}$ \\
\hline
\end{tabular}

\subsubsection{Testing Conditions}

Fire-resistance tests have been carried out at Carleton University's intermediate-scale furnace, as shown in Figure 3.11. The furnace was designed to accommodate CLT panels up to $4.88 \mathrm{~m}$ in length and $1.06 \mathrm{~m}$ in width. The fire exposure followed, as closely as possible, the CAN/ULC S101 standard time-temperature curve. 


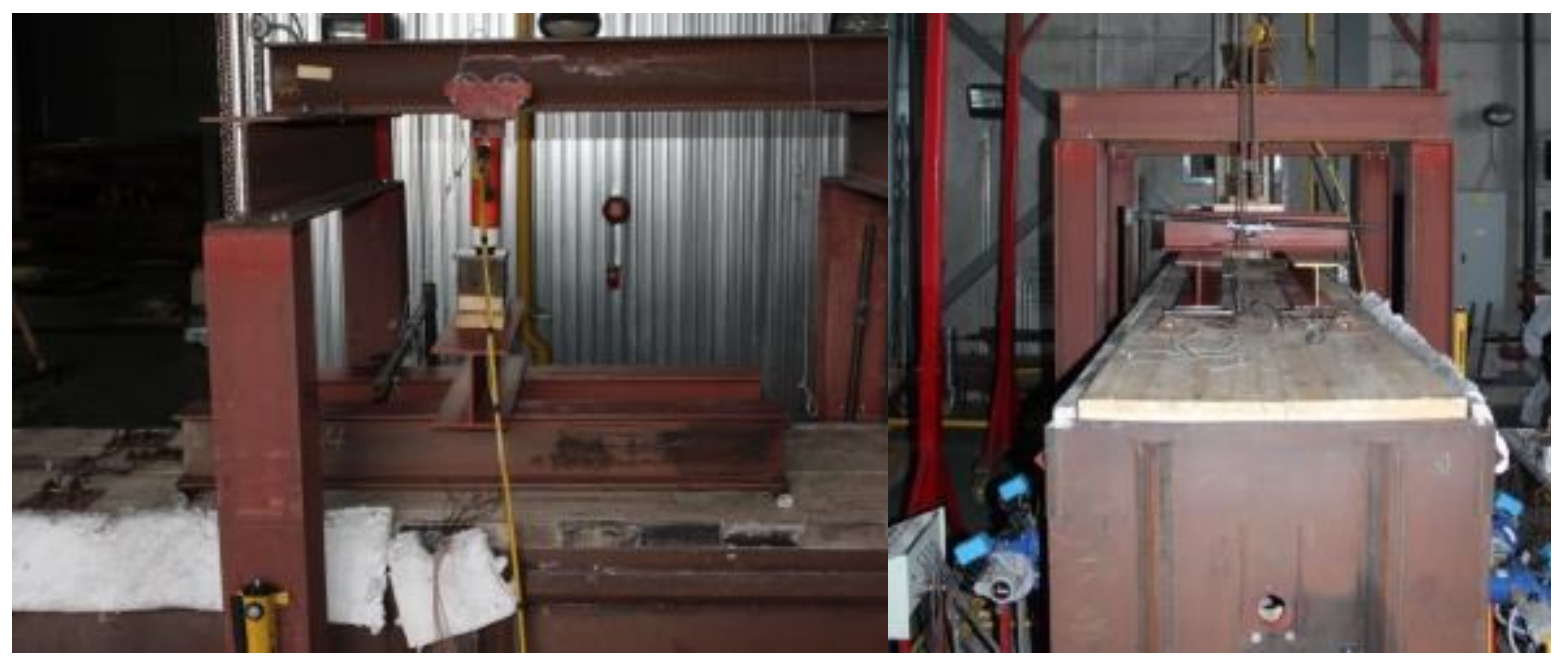

Figure 3.11 - Intermediate-scale test furnace at Carleton University

Loading conditions are critical in order to properly evaluate the panel-to-panel connection fire performance. In an attempt to force failure at the CLT panel-to-panel joint, it was initially decided that the loading heads be placed on one side of the panel-to-panel joint and be free to rotate (i.e. roller bearing point), as shown in Figure 3.12. It is noted that in a standard fire-resistance test, floor assemblies are typically evaluated under a uniform load over their entire surface. An asymmetrical loading condition creates much greater and unrealistic stress to the fasteners than a uniform loading where both panels would be equally subjected to bending. Further to the $1^{\text {st }}$ fire test conducted with an asymmetrical loading condition and the bending tests conducted at ambient conditions (detailed previously in subsection 3.2), it was decided to change to a symmetrical loading condition for the $2^{\text {nd }}$ to $10^{\text {th }}$ fire tests, as shown in Figure 3.13. It allowed for a better monitoring of the applied load and a better uniform deformation throughout the entire test duration. 
The set-up was of a simple span of $4.88 \mathrm{~m}$ (192 in.) subjected to a third-point bending. The loading points were spaced at $1.63 \mathrm{~m}$ (64 in.), replicating a similar stress distribution as that used for the ambient bending tests. The load was manually applied from a hydraulic jack soliciting the CLT panels in one-way bending and up to a $200 \mathrm{~mm}$ maximum deflection inside the furnace, corresponding to the maximum extension of the hydraulic jack. The later was applying a vertical force on a transverse steel beam, which in turn spread the force to the loading points that consisted at steel rods welded underneath longitudinal steel beams. While efforts were made to replicate a balanced and symmetrical loading condition, there were no rigid connections between the transverse and longitudinal steel beams and between the hydraulic jack and the transverse steel beam which may result in some differential loading during the fire tests.

Center-span deflection measurements were taken using a linear variable differential transformer (LVDT). The end supports consisted of steel angle welded to the furnace frame with a fire brick wall beneath it. The end supports were free to rotate and translate, replicating an unrestrained assembly per CAN/ULC S101. The data acquisition system was controlled using LabVIEW software from National Instruments. 


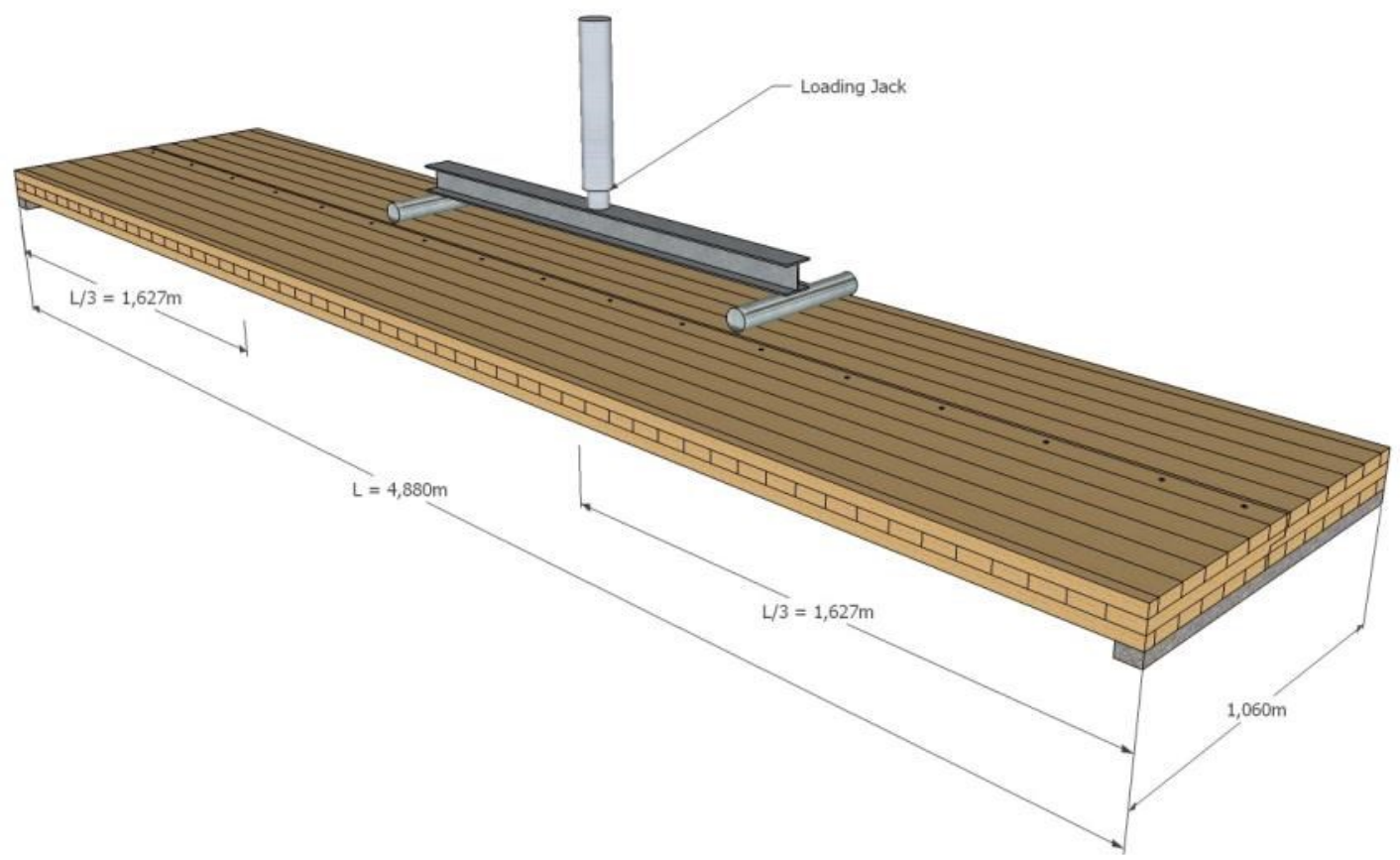

Figure 3.12 - Third-point bending - Asymmetrical loading (fire test 1)

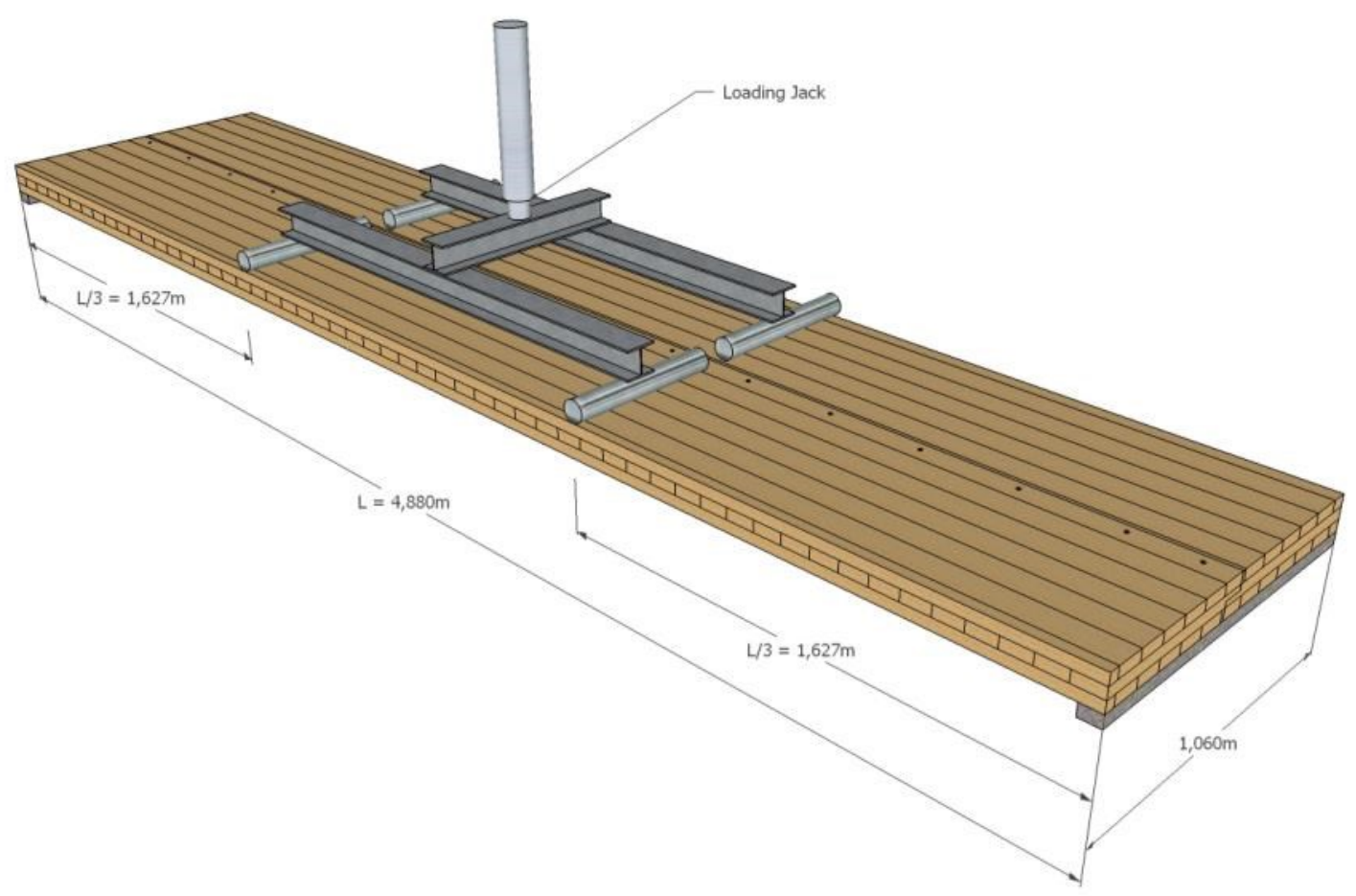

Figure 3.13 - Third-point bending - Symmetrical loading (fire tests 2 to 10) 
Moreover, a third-point bending condition is preferred as it allows for generating withdrawal stress at the fasteners located between the loading points and longitudinal shear stress along the fasteners located outside the loading points. When using such loading condition, the maximum applied bending moment $\left(M_{\max }\right)$ is located between the loading points and can be calculated using Equation (3.1), while the shear force $\left(V_{\max }\right)$ is constant on both sides of the loading points $(P)$, leaving a shear-free zone in the middle. Figure 3.14 illustrates the moment and shear stress diagrams of a single span beam solicited in third-point bending.

$$
M_{\max }=\frac{P L}{3} \leq M_{r}=\phi F_{b} S_{e f f, 0} K_{Z b} K_{L} K_{r b}
$$

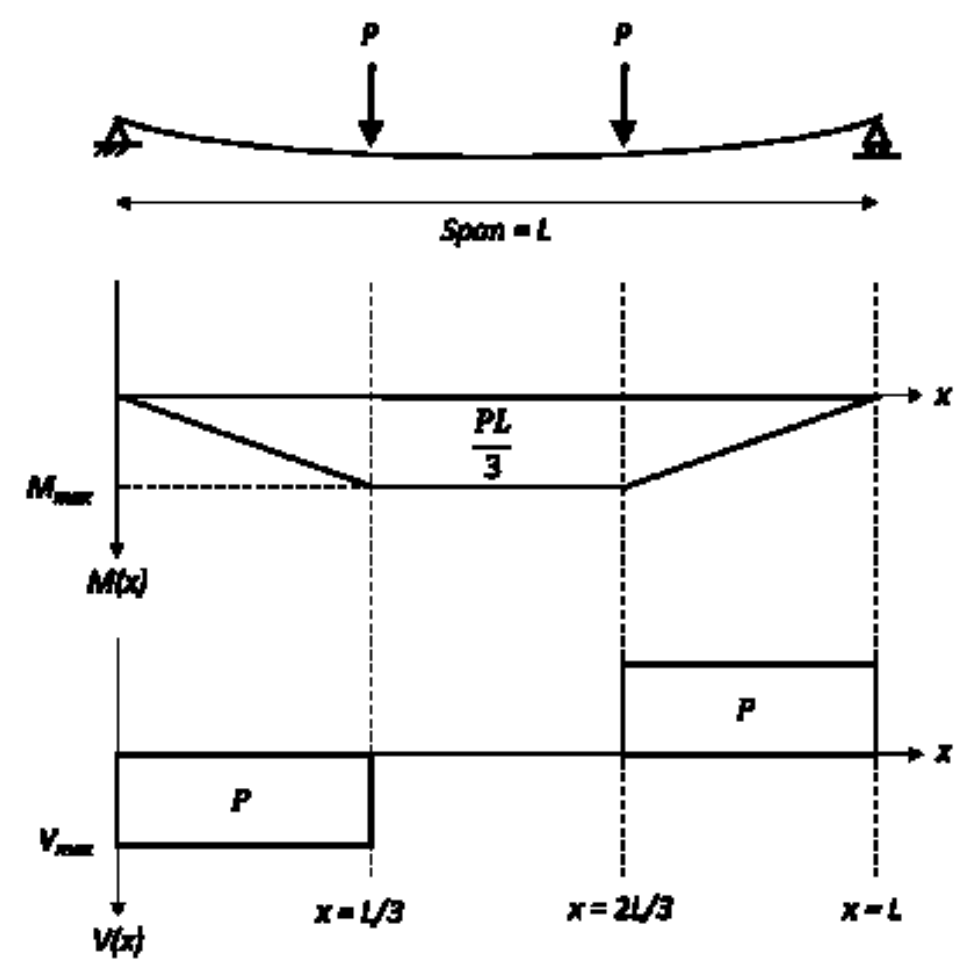

Figure 3.14 - Bending moment and shear force diagrams of a beam in third-point bending 


\subsubsection{Instrumentation for temperature measurements}

The CLT panels were instrumented with fiberglass insulated thermocouples (type G/G24-KK) of calibration tolerances of $\pm 1.1^{\circ} \mathrm{C}\left(2^{\circ} \mathrm{F}\right)$ or $0.4 \%$, whichever is greater [78]. The thermocouples were placed from the unexposed side (i.e. top of the panels) at various depths within the CLT panels located close to mid-span along the length of the furnace. Thermocouples were also installed within the joint connection in order to measure the temperature profile through the joint. Figure 3.15 illustrates the location of the thermocouples within 3-ply CLT assemblies. Table 3.3 provides the details with respect to the instrumentation for measuring the temperature profiles during the fire tests.

The position of the char front is taken as the position of the $300^{\circ} \mathrm{C}$ isotherm recorded from the thermocouples, as specified in Eurocode 5: part 1-2. The measured char depths divided by the duration of the fire tests gives the overall charring rate. The temperature profile allows a better understanding of how heat is being transferred within the joint as a function of time and is typically used to evaluate the failure time.

Table 3.3 - Instrumentation with thermocouples for fire testing

\begin{tabular}{|c|c|c|c|c|c|}
\hline \multirow{2}{*}{\multicolumn{2}{|c|}{ CLT Assembly }} & \multicolumn{3}{|c|}{ Thermocouple } & \multirow{2}{*}{ Total } \\
\hline & & CLT & Joint & Fastener & \\
\hline \multirow{4}{*}{$\begin{array}{c}\text { 3-ply } \\
(105 \mathrm{~mm})\end{array}$} & Internal spline & 8 & 8 & 8 & 24 \\
\hline & Half-lapped & 4 & 4 & 4 & 12 \\
\hline & Single surface spline & 12 & 4 & 8 & 24 \\
\hline & Double surface spline & 12 & 8 & 16 & 36 \\
\hline \multirow{4}{*}{$\begin{array}{c}5-\text { ply } \\
(175 \mathrm{~mm})\end{array}$} & Internal spline & 12 & 8 & 8 & 28 \\
\hline & Half-lapped & 6 & 4 & 4 & 14 \\
\hline & Single surface spline & 20 & 8 & 16 & 44 \\
\hline & Double surface spline & 20 & 4 & 8 & 32 \\
\hline \multirow{2}{*}{$\begin{array}{c}\text { 7-ply } \\
(245 \mathrm{~mm})\end{array}$} & Half-lapped & 8 & 2 & 4 & 14 \\
\hline & Double surface spline & 28 & 8 & 16 & 52 \\
\hline
\end{tabular}



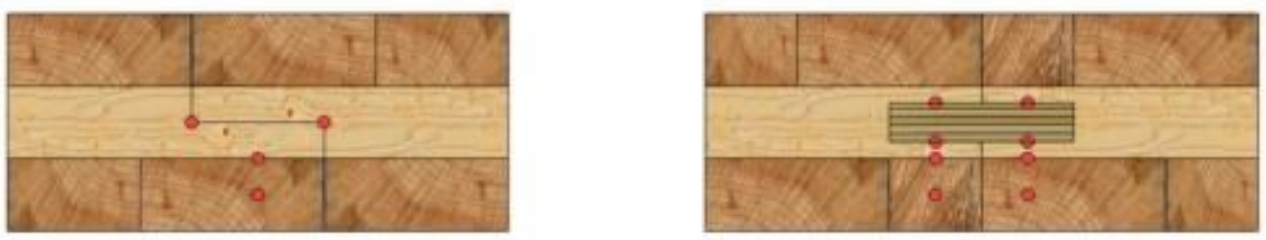

- Thermocouple
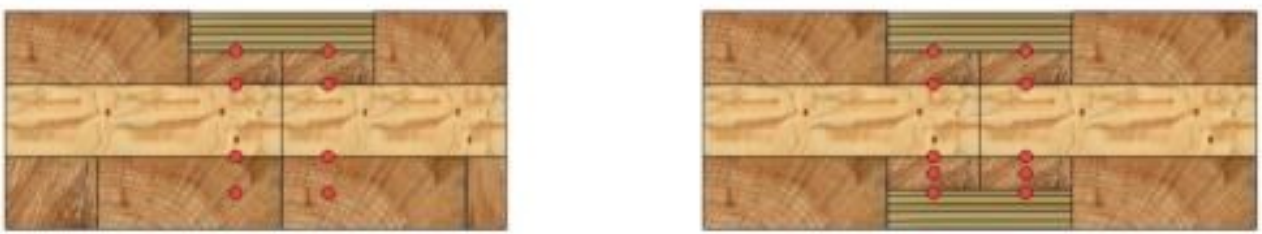

Figure 3.15 - Thermocouple locations in 3-ply CLTs

Moreover, some self-tapping screws were instrumented with similar thermocouples to measure the temperature profile of the fasteners at their tip and mid-length. Epoxy glue was used to secure the thermocouples within the grooves (Figure 3.16) at their tip and at mid-length. Since each of the instrumented screws was grooved on 2 sides to insert the thermocouples, self-tapping screws of $8 \mathrm{~mm}$ outside diameter were used, assuming that this very small quantity of $8 \mathrm{~mm}$ diameter screws would have an insignificant impact on the overall fire integrity resistance of the connections. All self-tapping screws used for the half-lapped and internal spline joint configuration were of the same length. For the single and double surface spline joint detail, instrumented self-tapping screws of $\phi 8$ $80 / 54 \mathrm{~mm}$ GRK RSS ${ }^{\mathrm{TM}}$ screws [79] were used as opposed to $\phi 6-70 / 42 \mathrm{~mm}$ ASSY® 3.0 Ecofast, simply due to availability of the fasteners. In all specimens, the instrumented screws were located in the middle third-span (i.e. in the shear-free zone between the 
loading points) and close to those embedded in the CLT panels for measuring the charring rate, as shown in Figure 3.16 and Figure 3.17.
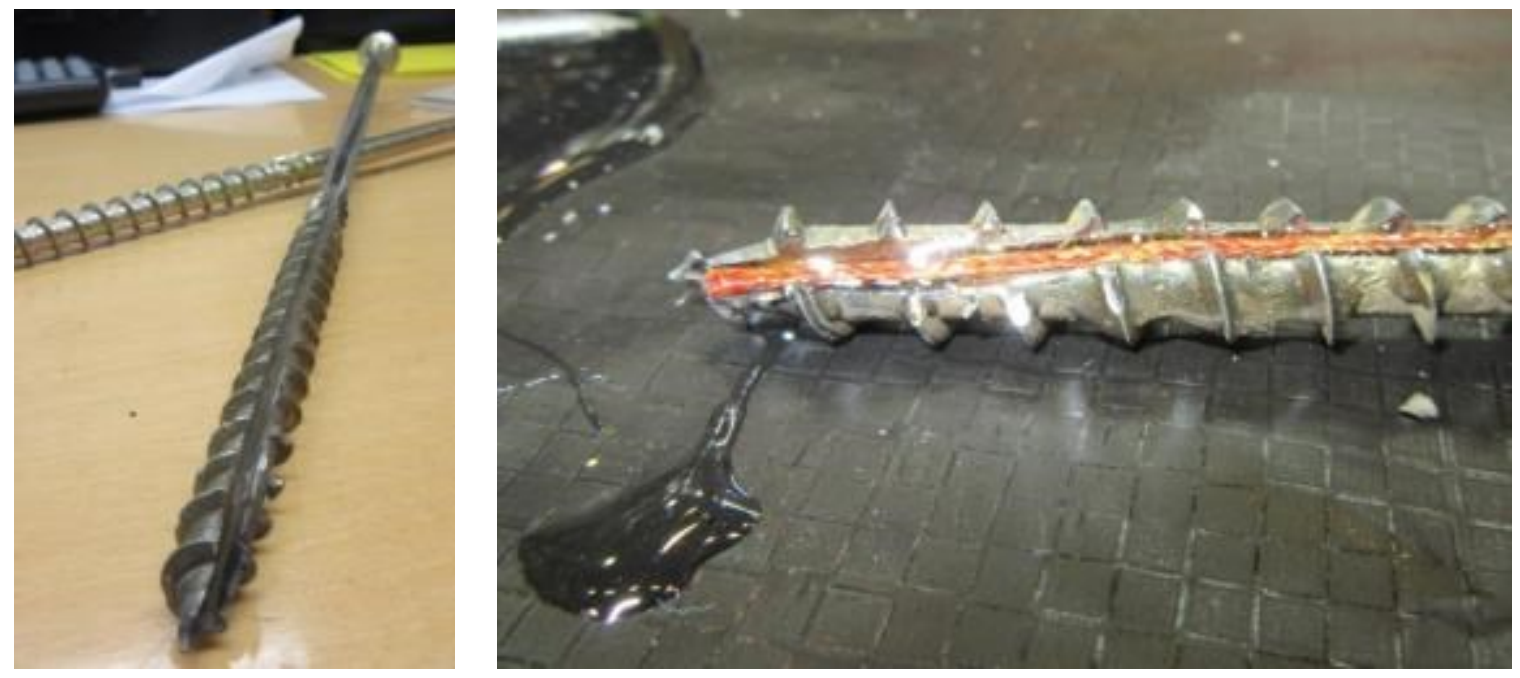

Figure 3.16 - Self-tapping screw instrumented with thermocouples

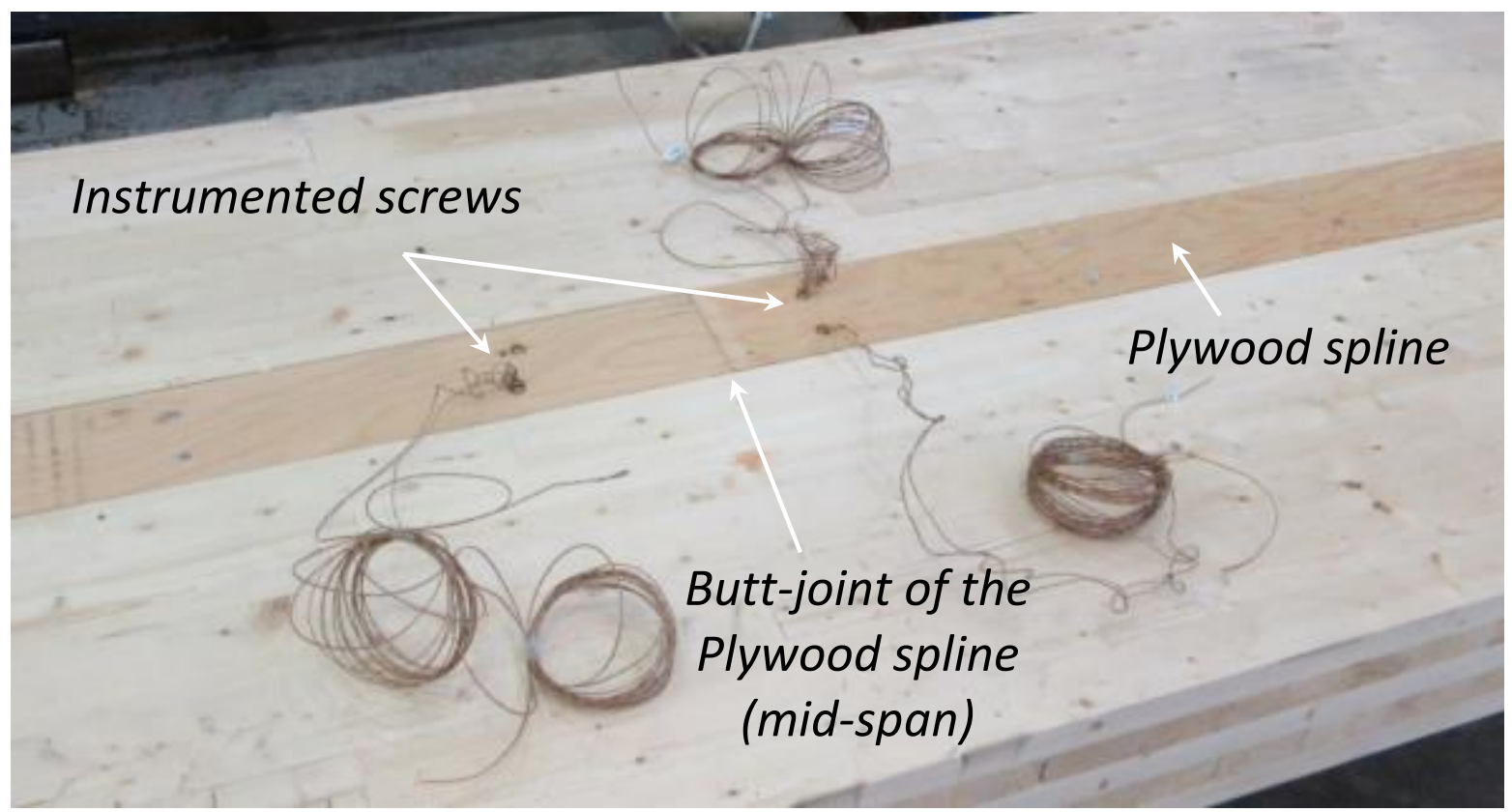

Figure 3.17 - Instrumented self-tapping screws drilled in middle third-span of a CLT assembly 


\subsubsection{Loading level for fire testing}

As explained in subsection 3.2, the applied load is to be based on the bending moment resistance of the CLT panels as opposed to that of the connection (self-tapping screws and/or plywood spline). As such, the general form of safety criteria for ultimate limit states used in part 4 of Division B of the NBCC is used to determine the required load that would produce a factored load effect as close as practically possible to the factored resistance of the test assembly, as required by the CAN/ULC S101 standard.

Equation (3.2) is the general form of safety criteria for ultimate limit states, as detailed in the User's Guide - NBC 2010 Structural Commentaries (Part 4 of Division B) [80], of where the factored load is then obtained from Equation (3.3).

$$
\begin{aligned}
\text { Factored Resistance } & \geq \text { Effect of Factored Loads } \\
\text { Factored Resistance } & \geq \sum \alpha_{G_{i}} G_{i}+\alpha_{Q_{i}} Q_{i}+\sum \alpha_{C Q_{i}} C Q_{i} \\
\geq & 1.25 G_{i}+1.5 Q_{i}
\end{aligned}
$$

Where $\alpha_{G_{i}}$ is the principal load factor for the permanent load $G_{i}$ (typically the dead load $D$ ), $\alpha_{Q_{1}}$ is the principal load factor for the principal variable load $Q_{1}$ (typically the live load $L$ ) and $\alpha_{C Q_{i}}$ is the companion load factor for other variable loads $C Q_{i}$. Load factors for permanent load used with a variable load (e.g. superimposed load) are taken as 1.25 and 1.5, respectively, in accordance with load combination No.2 provided in Table 4.3.1.2.A from Division B of NBCC. 
As such, the load combination that would produce the maximum factored bending moment as close as practicable to the factored bending moment resistance of the CLT panels is determined from Equation (3.4) and the applied load can thereby be determined from Equation (3.5).

$$
\begin{aligned}
& M_{\max }=1.5 \frac{P L}{3}+1.25 \frac{D L^{2}}{8} \leq M_{r}=\phi F_{b} S_{e f f, 0} K_{Z b} K_{L} K_{r b} \\
& P \leq \frac{2}{L}\left[\phi F_{b} S_{e f f, 0} K_{Z b} K_{L} K_{r b}-1.25 \frac{D L^{2}}{8}\right]
\end{aligned}
$$

Where $P$ is the applied load (at each loading head) and $D$ is the assembly uniformly distributed self-weight based on a published CLT density of $515 \mathrm{~kg} / \mathrm{m}^{3}$. Table 3.4 shows the required loading conditions for developing the full factored bending moment resistance of the CLT panels.

\begin{tabular}{|c|c|c|c|c|c|c|}
\hline $\begin{array}{c}\text { CLT } \\
\text { Stress }\end{array}$ & Thickness & $\begin{array}{l}\text { Test } \\
\text { Span }\end{array}$ & $\begin{array}{c}\text { Self-Weight } \\
\text { (per unit width) }\end{array}$ & $\begin{array}{c}\text { Specified } \\
\text { Bending } \\
\text { Resistance }\end{array}$ & $\begin{array}{l}\text { Applied Load } \\
\text { (per unit width) }\end{array}$ & $\begin{array}{l}\text { Total Load } \\
\text { (hydr. jack) }\end{array}$ \\
\hline Grade & & $\begin{array}{c}L \\
(\mathrm{~m})\end{array}$ & $\begin{array}{c}D \\
(\mathrm{kN} / \mathrm{m})\end{array}$ & $\begin{array}{c}\phi F_{b} S_{e f f, 0} K_{Z b} K_{L} K_{r b} \\
\left(\mathbf{x} 10^{3} \mathbf{k N} \cdot \mathbf{m}\right)\end{array}$ & $\begin{array}{c}P \\
(\mathrm{kN} / \mathrm{m})\end{array}$ & $\begin{array}{r}P_{\text {total }} \\
(\mathrm{kN})\end{array}$ \\
\hline \multirow{3}{*}{ E1 } & $3 \times 35 \mathrm{~mm}$ & & 0.5 & 37.8 & 15.2 & 32.1 \\
\hline & $5 \times 35 \mathrm{~mm}$ & 4.74 & 0.9 & 88.2 & 35.9 & 76.1 \\
\hline & $7 \times 35 \mathrm{~mm}$ & & 1.2 & 154.8 & 63.5 & 134.6 \\
\hline
\end{tabular}

Table 3.4 - Specified load producing the maximum factored bending moment

However, serviceability of CLT floor panels subjected to bending also needs to be verified, as per Equation (2.14). Considering the fact that the maximum deflection inside the furnace is limited to $200 \mathrm{~mm}$ due to the hydraulic jack maximum extension, it is 
important to limit potential damage inside the furnace and to the instrumentation. Table 3.5 shows the required loading conditions for generating an arbitrary initial deflection of $20 \mathrm{~mm}$ (neglecting deformation from the self-weight), thus leaving clearance for deflecting up to a maximum of $200 \mathrm{~mm}$ as charring of the CLT occurs.

Table 3.5 - Specified load reproducing an initial deformation of $20 \mathrm{~mm}$

\begin{tabular}{|c|c|c|c|c|c|c|}
\hline \multirow{2}{*}{$\begin{array}{c}\text { CLT } \\
\text { Stress } \\
\text { Grade }\end{array}$} & \multirow{2}{*}{ Thickness } & Span & \multicolumn{2}{|c|}{ Effective Stiffness } & \multirow{2}{*}{$\begin{array}{c}\text { Applied Load } \\
\text { (per unit width) } \\
P \\
(\mathrm{kN} / \mathrm{m})\end{array}$} & $\begin{array}{l}\text { Total Load } \\
\text { (hydr. jack) }\end{array}$ \\
\hline & & $\begin{array}{c}L \\
(\mathbf{m})\end{array}$ & $\begin{array}{c}E I_{e f f, 0} \\
\left(\times 10^{9} \mathrm{~N} \cdot \mathrm{mm}^{2} / \mathbf{m}\right)\end{array}$ & $\begin{array}{c}G A_{e f f, 0} \\
\left(\times 10^{6} \mathrm{~N} / \mathrm{m}\right)\end{array}$ & & $\begin{array}{l}P_{\text {total }} \\
(\mathbf{k N})\end{array}$ \\
\hline & $3 \times 35 \mathrm{~mm}$ & & 1088 & 7.3 & 5.3 & 11.2 \\
\hline E1 & $5 \times 35 \mathrm{~mm}$ & 4.74 & 4166 & 15 & 19.3 & 40.9 \\
\hline & $7 \times 35 \mathrm{~mm}$ & & 10306 & 22 & 44.1 & 93.5 \\
\hline
\end{tabular}

As explained in Subsection 2.1.2, the CAN/ULC S101 test method requires that assembly be loaded to a specified gravity load that produces a factored load effect as close as practically possible to the factored resistance of the assembly (as opposed to serviceability criteria). However, in real building design, CLT floors will most likely be governed by serviceability limit states (deflection or vibration) as opposed to ultimate limit states (maximum factored resistance). Serviceability limit would result in loads which would solicit CLT floors at a much lower stress ratio compared to that of an ultimate limit state. However, given that the load cell was limited to $50 \mathrm{kN}$, it was decided to select load levels that would either be limited by the factored bending resistance or an initial deformation of $20 \mathrm{~mm}$, whichever is greater and within the load cell capacity. As such, applied loads of $32 \mathrm{kN}\left(100 \% M_{r}\right), 42 \mathrm{kN}\left(55 \% M_{r}\right)$ and $50 \mathrm{kN}$ 
(40\% $M_{r}$ ) were chosen for fire testing of the 3-ply, 5-ply and 7-ply CLT specimens, respectively.

The CLT specimens were not conditioned prior to fire testing as typically required by CAN/ULC S101. As detailed by White [81], wood thermal degradation process is influenced by, among others, its temperature. Moreover, as shown in Table 2.10, the thermal properties governing transient heat transfer in wood elements are significantly influenced by the temperature. Therefore, the time to ignition and rate of charring are influenced by the initial conditions of the wood specimens and the data generated from this test series may not be fully comparable to those obtained from conditioned specimens.

The following subsections provide the results and analysis of the ten (10) fire-resistance tests. The fire tests are labelled from a numbering based on the number of laminations and the types of joints.

\subsection{Fire Test 1 - 3-ply with internal spline}

The 3-ply CLT specimen joined with an internal spline, as shown in Figure 3.18, was the first out of a series of 10 fire tests. The test was conducted on November 19, 2014. The ambient conditions inside the unheated laboratory were not recorded, but the outdoor temperature was $-6^{\circ} \mathrm{C}$. Additional information and results are presented in Appendix I. 


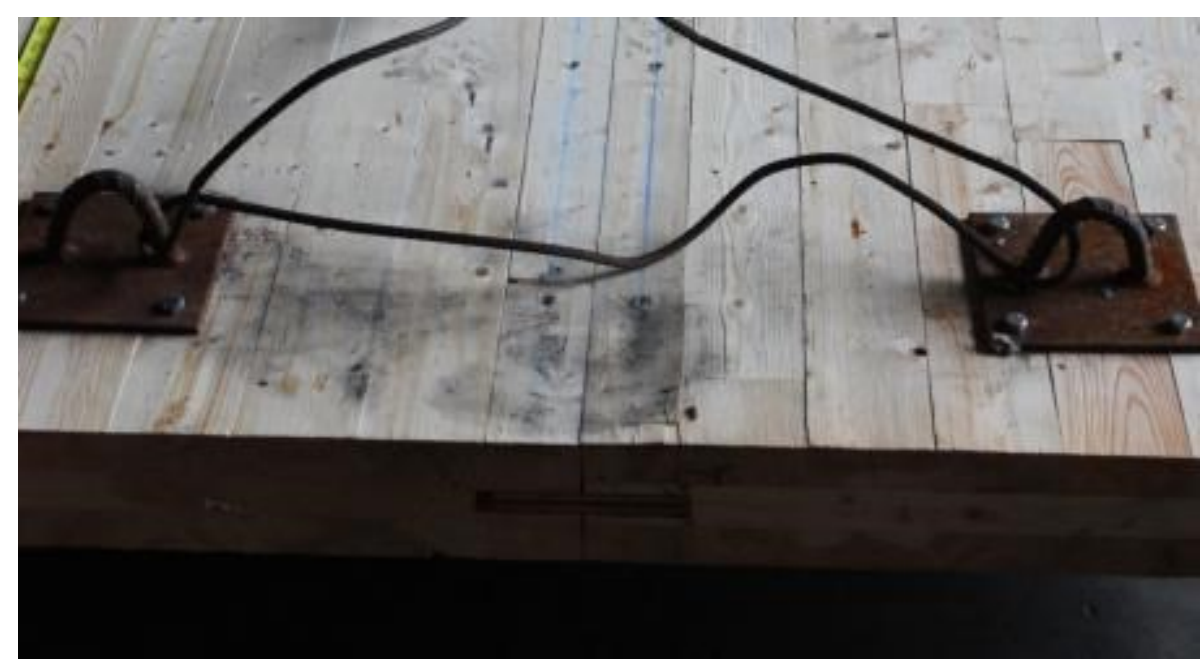

Figure 3.18 - Fire Test 1 specimen prior to testing

Significant problems occurred during this fire test, namely with the gas burners not igniting all the times and the data acquisition system not recording the thermocouple temperature measurements. Moreover, as a trial test to subject the CLT panel-to-panel connection to a certain stress level, the CLT specimens were loaded only on one side (as per Figure 3.19), resulting in significant differential deflection between both sides. Therefore, very little conclusive test data was recorded throughout the test, including furnace temperature and temperature readings from the thermocouples. As with all other 3-ply CLT specimens, a target load of $32 \mathrm{kN}$ was to be applied manually from the hydraulic jack, representing a full loading condition. An initial deflection of $48 \mathrm{~mm}$ was recorded. 


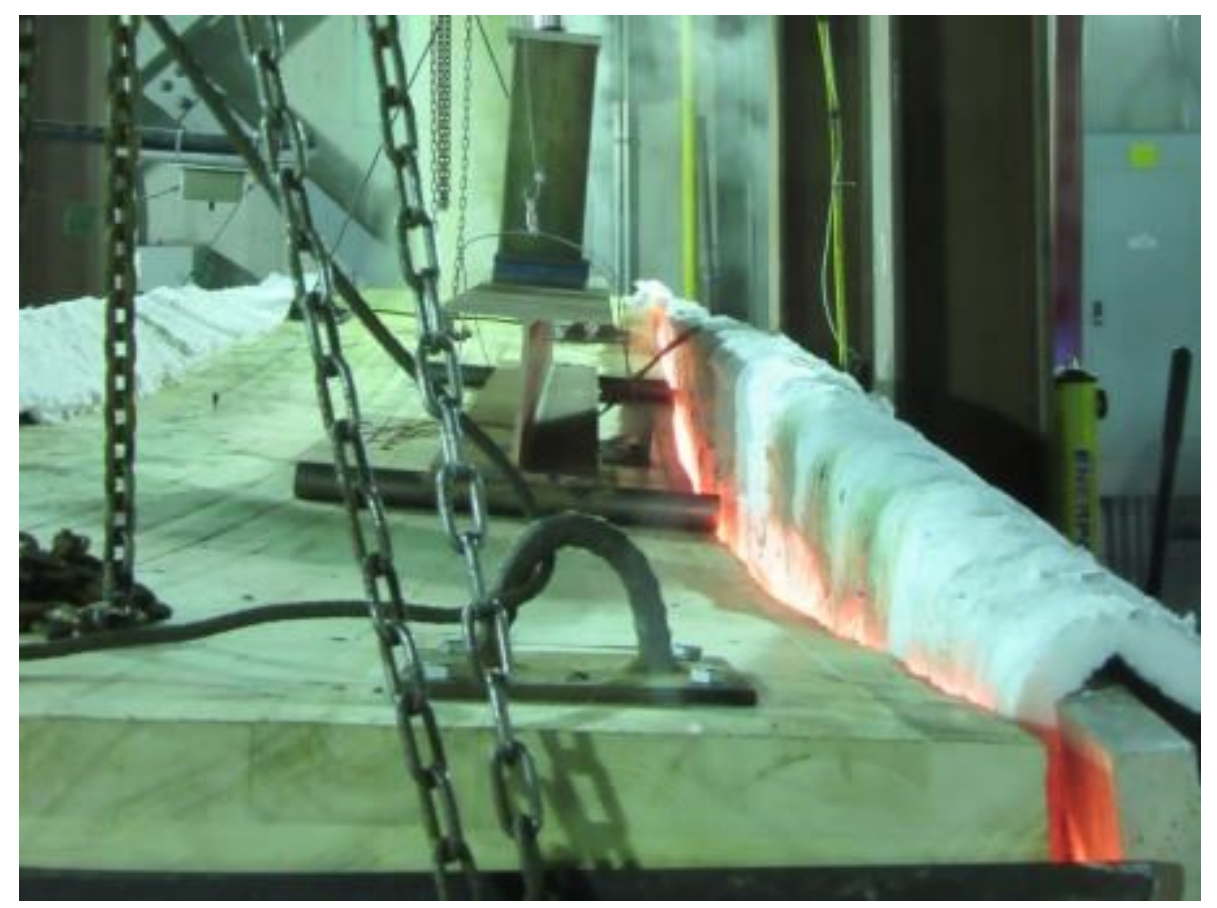

Figure 3.19 - Fire Test 1 asymmetrical loading condition

While the recorded test data was inconclusive according to visual observations and manual timing, flame-through occurred around $35 \mathrm{~min}$ after the start of the test. The flame-through (i.e. glowing at the surface) was observed close to the mid-span, close to the plywood splines butt-joint. Furthermore, due to the furnace internal pressure, flaming was not observed flowing outside the CLT panels, but rather from flaming inside the furnace, as observed in Figure 3.20. According to the European model, a fire integrity failure time of 64 min was predicted. According to the Canadian CLT calculation method [24], a structural failure time of 22 minutes was predicted. 


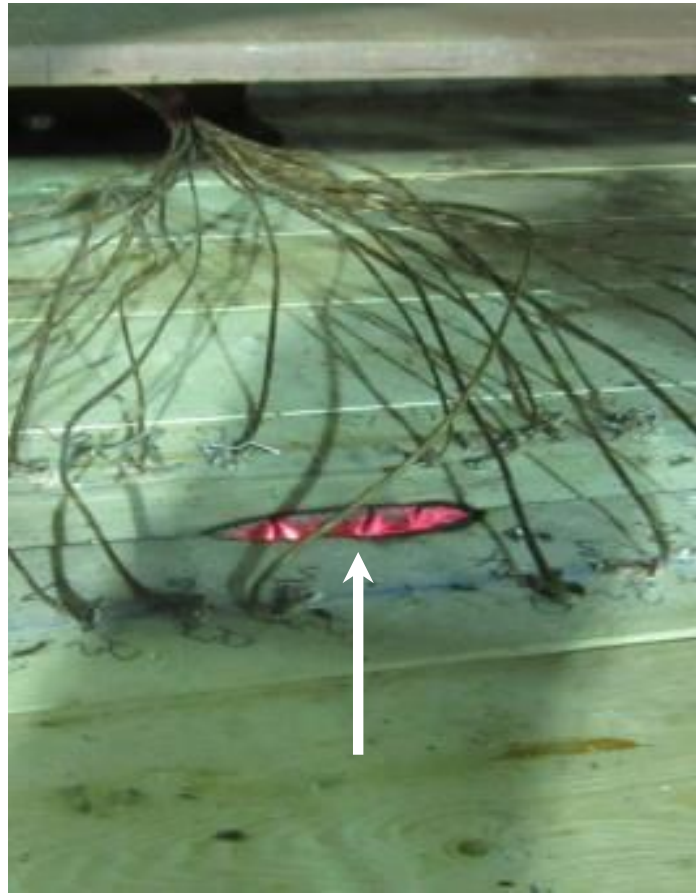

a) Glowing at unexposed surface

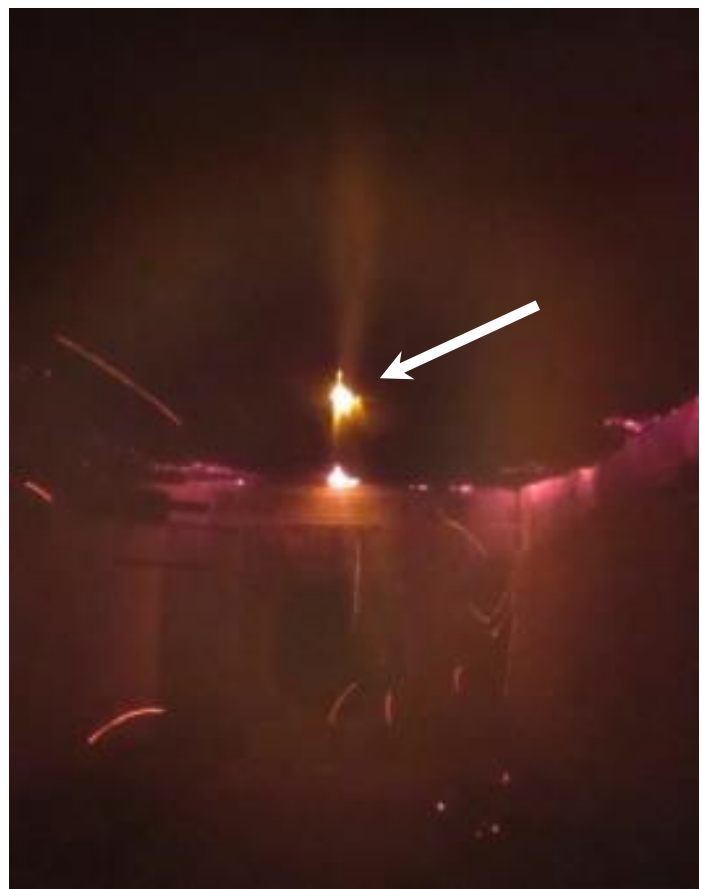

b) Flaming from inside the furnace

Figure 3.20 - Fire Test 1 failure (fire integrity)

Since there were no valid data recorded from the thermocouples, the residual crosssection has been measured by manually removing the char layer. The residual thickness of the CLT was $72 \mathrm{~mm}$, resulting in an effective charring rate of $0.94 \mathrm{~mm} / \mathrm{min}$. A closer analysis of the residual cross-section shows that roughly $8 \mathrm{~mm}$ was left underneath the internal plywood spline as shown in Figure 3.21. 


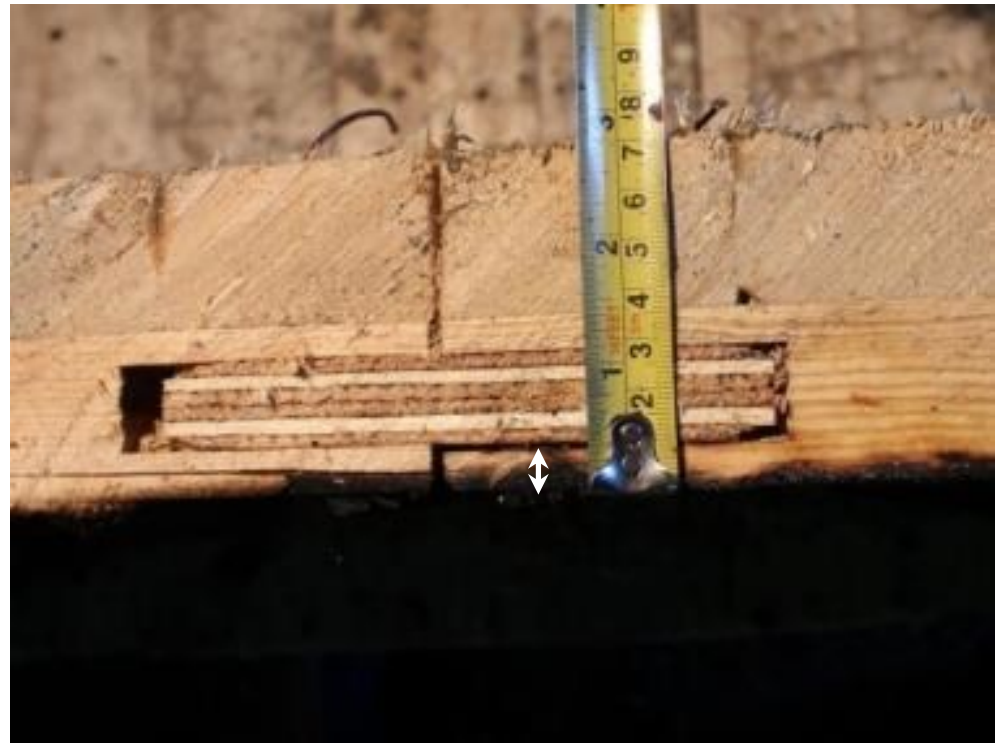

Figure 3.21 - Fire Test 1 residual cross-section after testing

\subsection{Fire Test 2 - 3-ply with half-lapped joint}

The second fire test was conducted on December 3, 2014 (Figure 3.22). The ambient conditions inside the unheated laboratory were $-7^{\circ} \mathrm{C}$ and $39 \%$ relative humidity and the outdoor temperature was $-3^{\circ} \mathrm{C}$. Additional information and results are presented in Appendix II.

This second fire test was conducted without any significant problems, except for the burners that did not accurately follow the standard time-temperature curve given in Equation (2.1), especially during the first 20 minutes. The early stage of fire exposure is of most importance given the fact that it is during that period that the heated zone is formed, protecting afterward the inner core from thermal degradation. A load of $32 \mathrm{kN}$ was manually applied from the hydraulic jack, representing a full loading condition. It 
was however difficult to maintain a constant loading level as the CLT cross-section reduces. An initial deflection of $47 \mathrm{~mm}$ was recorded.

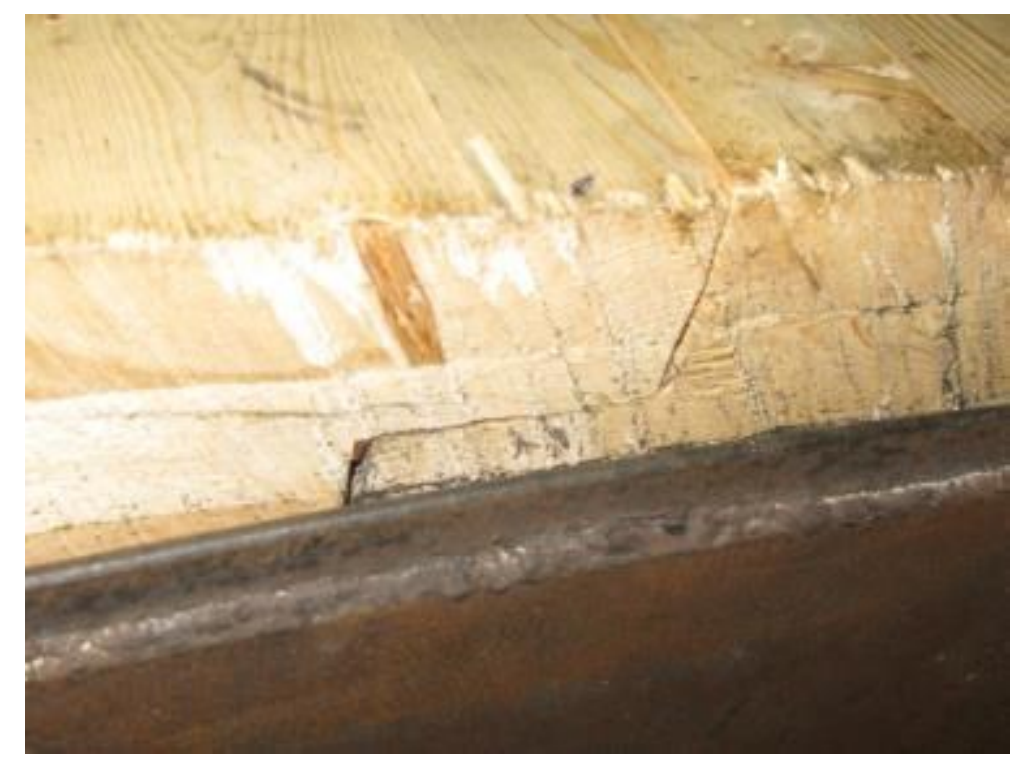

Figure 3.22 - Fire Test 2 specimen installed inside the furnace frame

Nevertheless, glowing was observed on the unexposed side of the CLT assembly after 45 min into the test. The glowing was observed close to a loading point, at the junction between the two CLT panels as shown in Figure 3.23. According to the Canadian CLT calculation method, structural and fire integrity failure times of 22 and 56 minutes are predicted respectively, suggesting that structural failure would occur first. However, since the maximum deflection of $20 \mathrm{~cm}$ was reached before the $22 \mathrm{~min}$ prediction and the sides of the CLT were then resting on the sides of the furnace frame, structural failure could not be obtained and thus fire integrity was observed shortly after $45 \mathrm{~min}$ of fire exposure. 


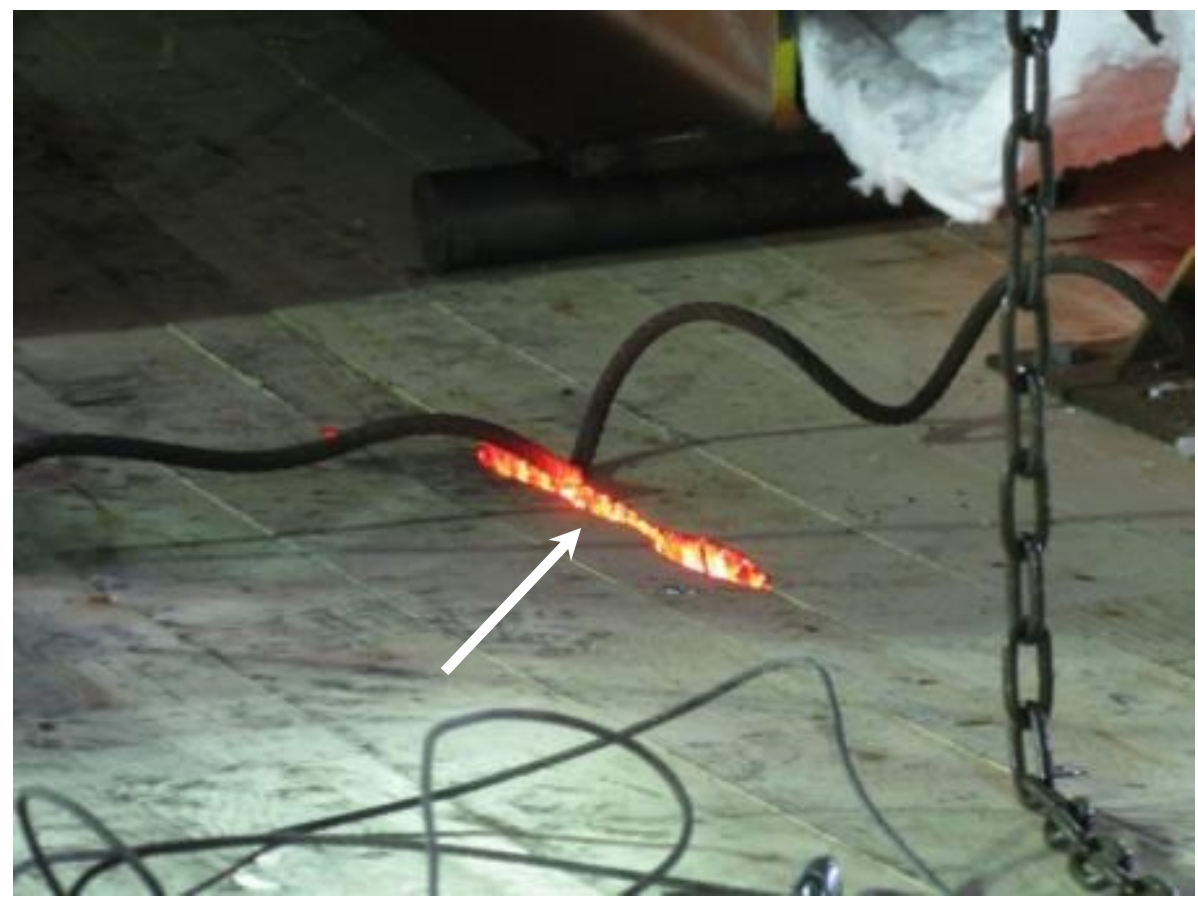

Figure 3.23 - Fire Test 2 failure (fire integrity) at $45 \mathrm{~min}$

The char front was reached at $17.5 \mathrm{~mm}$ after $28 \mathrm{~min}$, which results in a charring rate of $0.63 \mathrm{~mm} / \mathrm{min}$. Such rate is similar to those obtained by Osborne et al. [10] when only the $1^{\text {st }}$ layer was consumed. At the end of the test $(53 \mathrm{~min})$, a maximum temperature of $290^{\circ} \mathrm{C}$ was measured at the right corner of the half-lapped joint indicating that the char front almost reached the joint interface and that not much wood was left underneath to properly tightly join the CLT panels together.

The tip reached the steel critical temperature of $538^{\circ} \mathrm{C}\left(1000^{\circ} \mathrm{F}\right)$ after $35 \mathrm{~min}$, while the mid-length of the screw did not reach it during the test.

After manually removing the char layer, it was observed that $30 \mathrm{~mm}$ of the CLT has charred (average of $75 \mathrm{~mm}$ residual thickness, Figure 3.24), resulting in an effective 
charring rate of $0.66 \mathrm{~mm} / \mathrm{min}$. Moreover, it can be seen that the half-lapped joint was not close to being reached as roughly $23 \mathrm{~mm}$ of wood was still uncharred underneath the half-lapped joint.

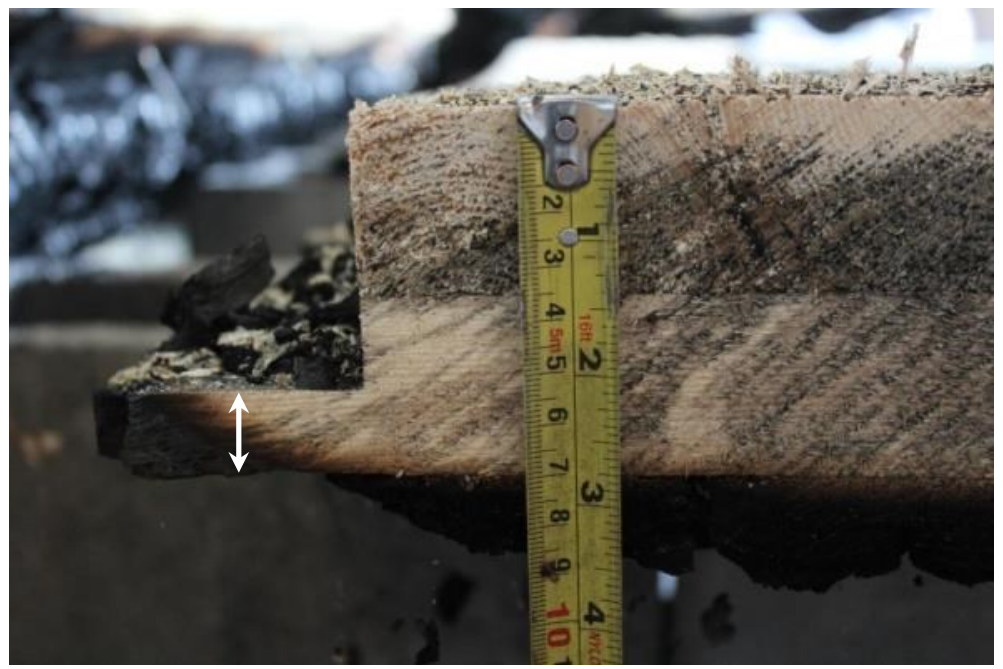

Figure 3.24 - Fire Test 2 residual cross-section after testing

\subsection{Fire Test 3 - 3-ply with single surface spline}

The third fire test was conducted on December 9, 2014. The ambient conditions inside the unheated laboratory were $2^{\circ} \mathrm{C}$ and $58 \%$ relative humidity and the outdoor temperature was $-3^{\circ} \mathrm{C}$. The specimens were not conditioned prior to fire testing. Figure 3.25 shows the assembly before being mounted onto the furnace. Additional information and results are presented in Appendix III. 


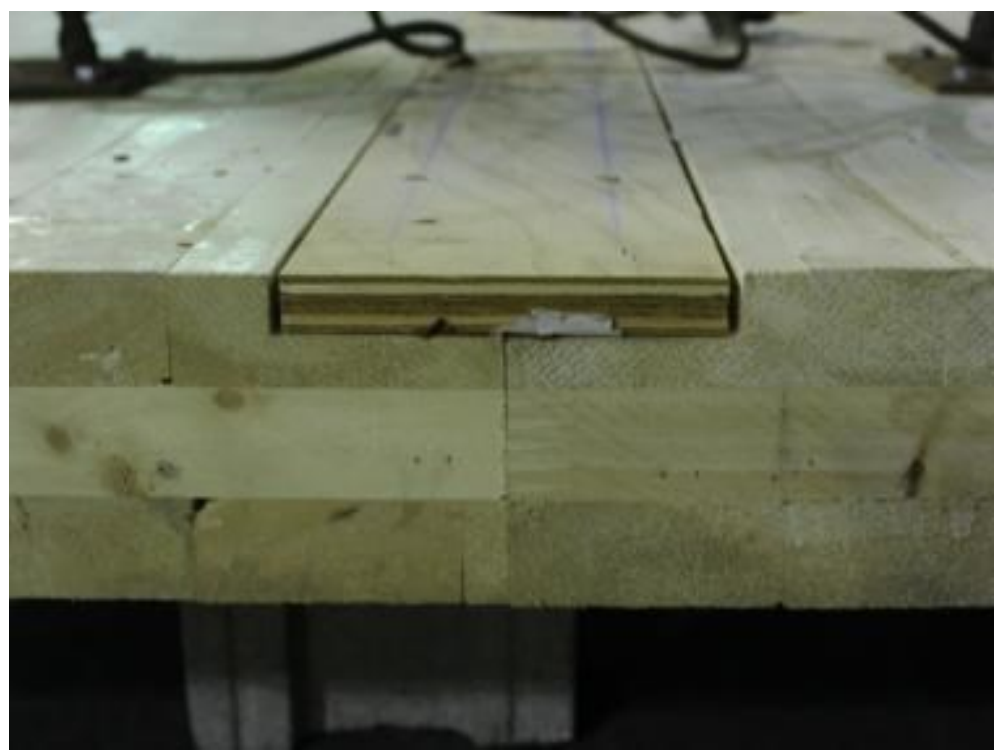

Figure 3.25 - Fire Test 3 specimen prior to testing

This third fire test was conducted without any significant problems, except again for the burners that did not accurately follow the standard time-temperature curve, especially during the first 20 minutes. As with other 3-ply specimens, a load of $32 \mathrm{kN}$ was manually applied from the hydraulic jack, representing a full loading condition and an initial deflection of $46 \mathrm{~mm}$ was recorded. As with the previous tests, it was difficult to properly maintain a constant loading level.

After 54 min into the test, it was decided to shut down the burners due to laboratory equipment safety concerns. No failure time was recorded for this test. According to the Canadian CLT calculation method, a structural failure time of 22 minutes was predicted. According to the European model, a fire integrity failure time of 64 min was predicted. However, as with Fire Test 2, the maximum deflection was reached before the 22 min threshold and thus no structural failure could be obtained (Figure 3.26). 


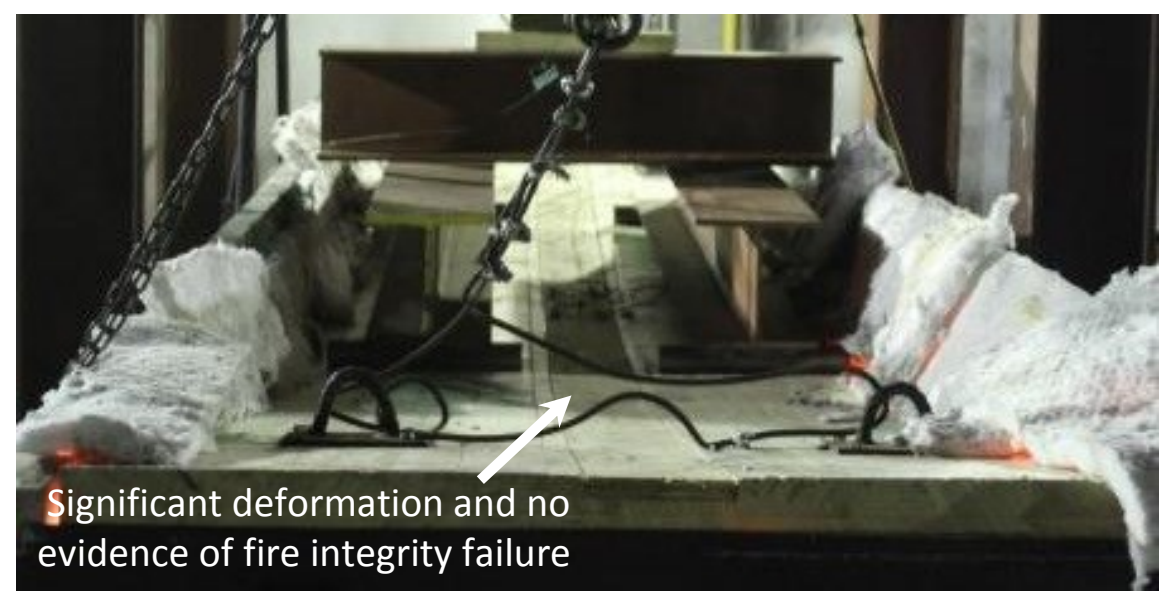

Figure 3.26 - Fire Test 3 after 54 min of fire exposure (no failure)

The char front was reached at 17.5 and $35 \mathrm{~mm}$ after 30 and $52 \mathrm{~min}$, which resulted in a charring rate of 0.58 and $0.67 \mathrm{~mm} / \mathrm{min}$ respectively. The tip reached the steel critical temperature of $538^{\circ} \mathrm{C}\left(1000^{\circ} \mathrm{F}\right)$ after $52 \mathrm{~min}$, while the middle of the screw was still far from reaching it.

After scraping off the char layer, an average residual thickness of $67 \mathrm{~mm}$ was measured (Figure 3.27), resulting in an effective charring rate of $0.71 \mathrm{~mm} / \mathrm{min}$. Moreover, it can be seen that the surface spline was not close to being reached. 


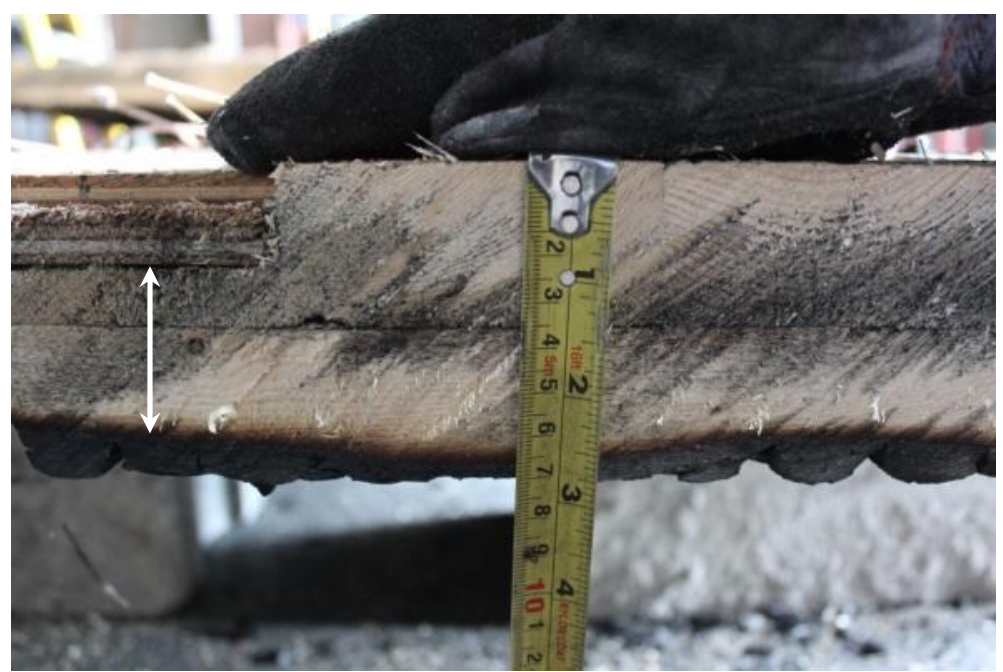

Figure 3.27 - Fire Test 3 residual cross-section after testing

\subsection{Fire Test 4-3-ply with double surface splines}

The fourth test was a 3-ply CLT joined with double surface splines, as shown in Figure 3.28, and was conducted on December 16, 2014. The ambient conditions inside the unheated laboratory were $3^{\circ} \mathrm{C}$ and $75 \%$ relative humidity and the outdoor temperature was $-2^{\circ} \mathrm{C}$. Additional information and results are presented in Appendix IV.

The specimens were not conditioned prior to fire testing. While there were still some difficulties in properly following the standard time-temperature curve, the variations were much less significant than in previous tests. A load of $32 \mathrm{kN}$ was manually applied from the hydraulic jack, with similar difficulties to the other 3-ply specimens, representing a full loading condition. An initial deflection of $55 \mathrm{~mm}$ was recorded. 


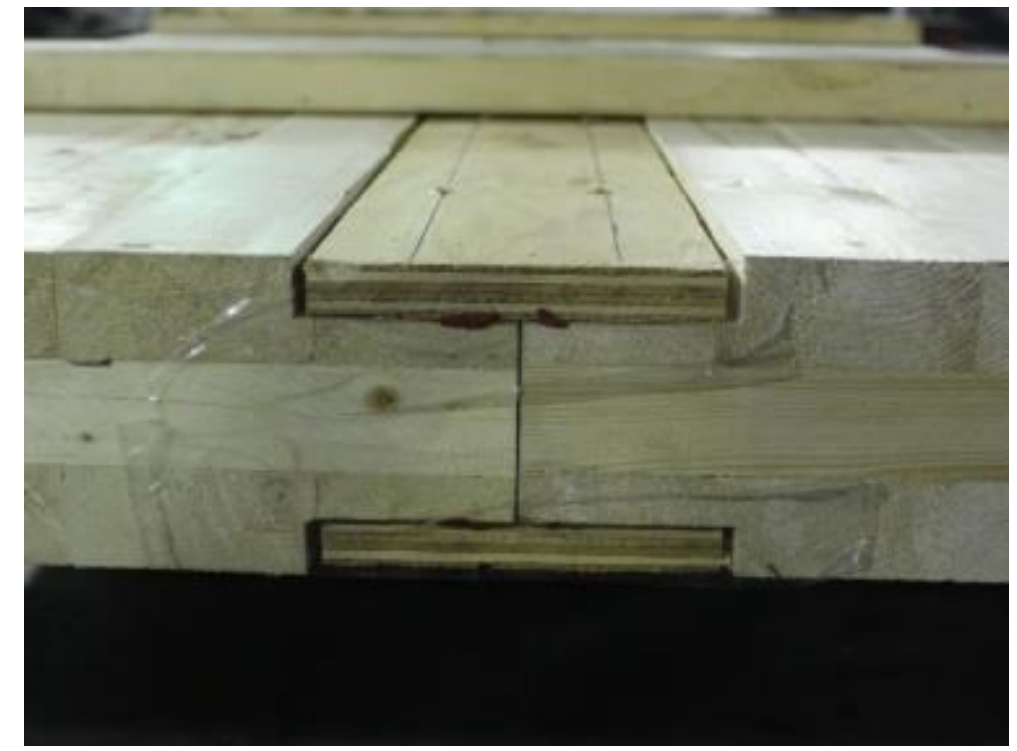

Figure 3.28 - Fire Test 4 specimen prior to testing

As with the previous 3-ply specimens, a structural failure time of 22 min was predicted from the Canadian CLT calculation method. The European model estimates a fire integrity failure time of 96 min for such joint detail. However, the maximum deflection was again reached at around $22 \mathrm{~min}$, thus allowing for fire integrity failure to occur around $43 \mathrm{~min}$ into the test. The specimen was however left exposed to fire for $63 \mathrm{~min}$.

The test continued until glowing was observed on the unexposed surface, at the plywood spline and CLT groove interface and near one of the loading points (Figure 3.29). After visual observations of the test specimen, it remained unclear as to why such early failure occurred. However, given that edge-gluing is not mandatory in CLT manufacturing in accordance with ANSI/APA PRG-320, this premature glowing may be due to the presence of voids (gaps) between lumber boards within the same lamination. 


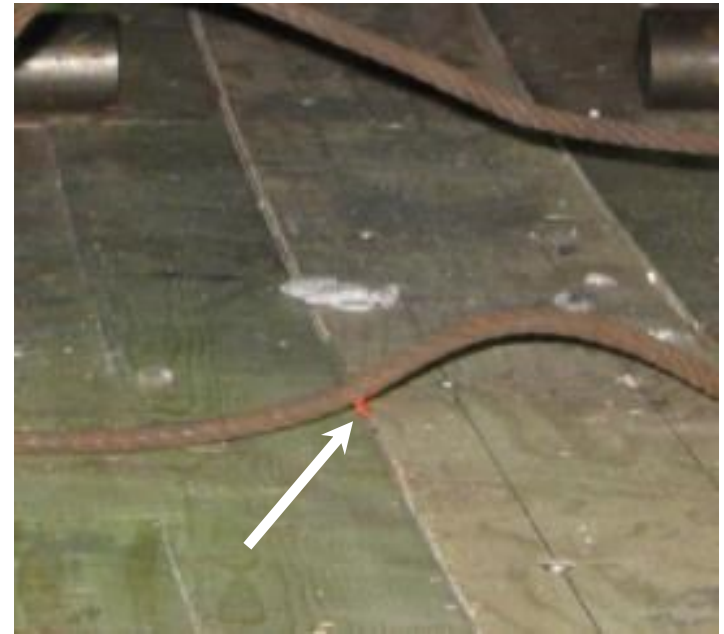

a) Glowing at unexposed surface

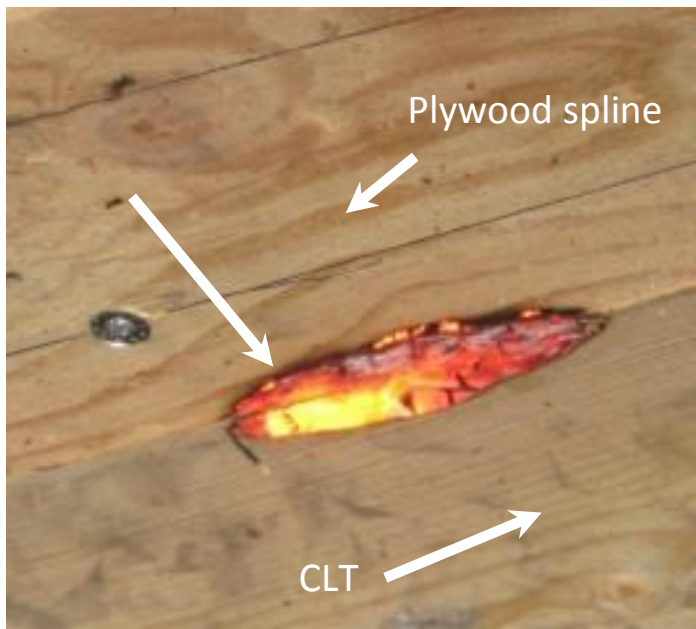

b) Close-up view of glowing

Figure 3.29 - Fire Test 4 failure (fire integrity) at $43 \mathrm{~min}$

The char front was reached at 17.5 and $35 \mathrm{~mm}$ after 46 and $60 \mathrm{~min}$, which results in a charring rate of 0.38 and $0.58 \mathrm{~mm} / \mathrm{min}$ respectively. There was no significant temperature rise recorded at the $2^{\text {nd }}$ glueline $(70 \mathrm{~mm})$. No significant temperature rise was recorded underneath the top surface plywood spline.

Heat was rapidly conducted to the bottom self-tapping screws, which were directly exposed to the fire, and that they somewhat followed the furnace temperature throughout the test. Very little difference in the temperature profile was observed between the middle and the tip of the bottom self-tapping screws. The critical temperature of $538^{\circ} \mathrm{C}\left(1000^{\circ} \mathrm{F}\right)$ was reached shortly after 2 min into the test.

On the other hand, the top self-tapping screws constantly increased in temperature as the $1^{\text {st }}$ CLT ply was consumed. In fact, the temperature profile of the tip of the top selftapping screws followed closely the temperature profile from the $17.5 \mathrm{~mm}$ thermocouple 
embedded into the CLT panels. No temperature readings from the top self-tapping screws reached the steel critical temperature of $538^{\circ} \mathrm{C}\left(1000^{\circ} \mathrm{F}\right)$.

While the integrity failure time was recorded as $43 \mathrm{~min}$, the test was continued until 63 min. An average residual thickness of $63 \mathrm{~mm}$ was manually measured (Figure 3.30), resulting in an effective charring rate of $0.67 \mathrm{~mm} / \mathrm{min}$. It can also be seen that the surface spline was not close to being reached.

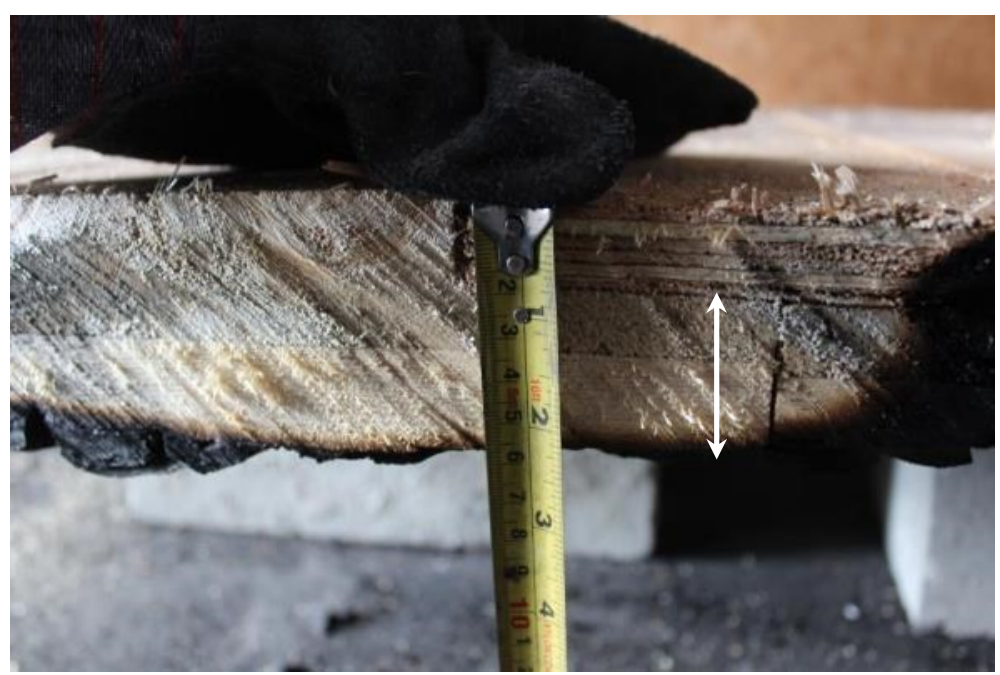

Figure 3.30 - Fire Test 4 residual cross-section after testing

\subsection{Fire Test 5 - 5-ply with internal spline}

The 5-ply CLT floor panels assembly with an internal spline was the fifth of the fire test series (Figure 3.31). The fire test was conducted on January 30, 2015. The ambient conditions inside the unheated laboratory were unknown, but the outdoor temperature was $-13^{\circ} \mathrm{C}$. The CLT specimens were not conditioned prior to fire testing. Additional information and results are presented in Appendix V. 


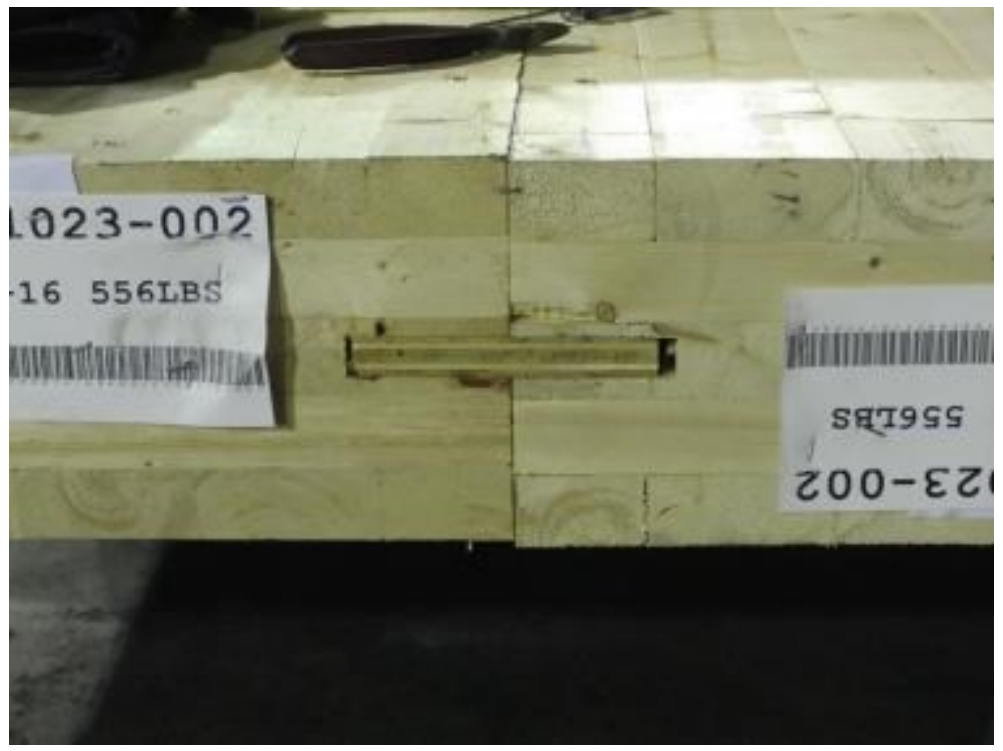

Figure 3.31 - Fire Test 5 specimen prior to testing

During this fire test 5 , the furnace temperature closely followed the standard timetemperature curve, while being slightly lower. Based on an initial deflection of $20 \mathrm{~mm}$, a load of $42 \mathrm{kN}$ was applied from the hydraulic jack throughout the test duration, representing $55 \%$ of the factored bending moment resistance.

Fire integrity failure occurred after $76 \mathrm{~min}$ into the test when glowing was observed at the unexposed surface, between the loading points, between the CLT panels (Figure 3.32). The glowing occurred at mid-span, where the plywood splines abut to each other (i.e. butt-jointed). The test was stopped after $90 \mathrm{~min}$ of fire exposure. According to the Canadian CLT calculation method, a structural time to failure of 104 min was predicted, while the European model would predict a fire integrity failure time of $107 \mathrm{~min}$. 


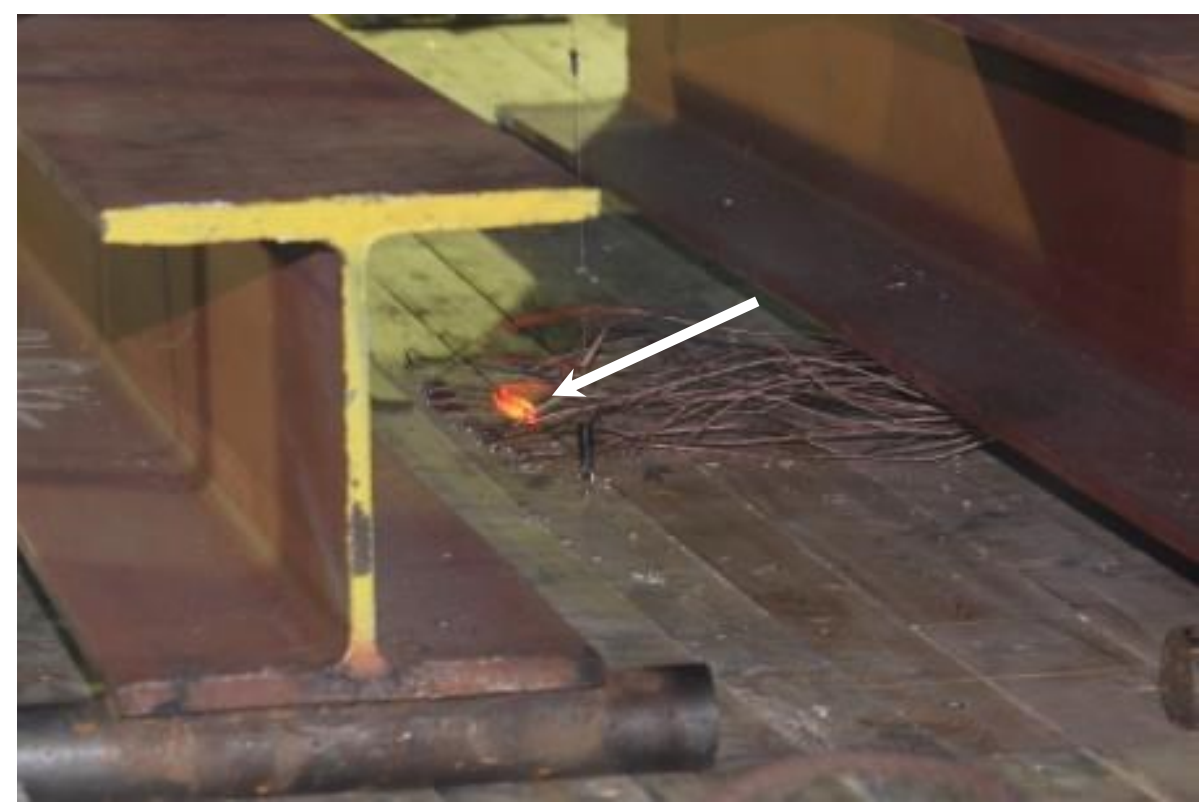

Figure 3.32 - Fire Test 5 failure (fire integrity) at 76 min

The char front was reached at 17.5, 35 and $70 \mathrm{~mm}$ after 29, 61 and $85 \mathrm{~min}$, resulting in charring rates of $0.60,0.57$ and $0.82 \mathrm{~mm} / \mathrm{min}$ respectively. The bottom and the top of the internal plywood spline reached $300^{\circ} \mathrm{C}$ shortly after 75 and $81 \mathrm{~min}$.

The self-tapping screws slowly heated during the fire test. The tips reached the critical temperature of $538^{\circ} \mathrm{C}\left(1000^{\circ} \mathrm{F}\right)$ shortly after $79 \mathrm{~min}$ into the test, while the middle of the screws never reached this limit.

A residual CLT thickness of $114 \mathrm{~mm}$ was manually measured after removing the char layer (Figure 3.33), resulting in an average charring rate of $0.68 \mathrm{~mm} / \mathrm{min}$. A thin $12-\mathrm{mm}$ layer of CLT remained underneath the internal plywood spline. 


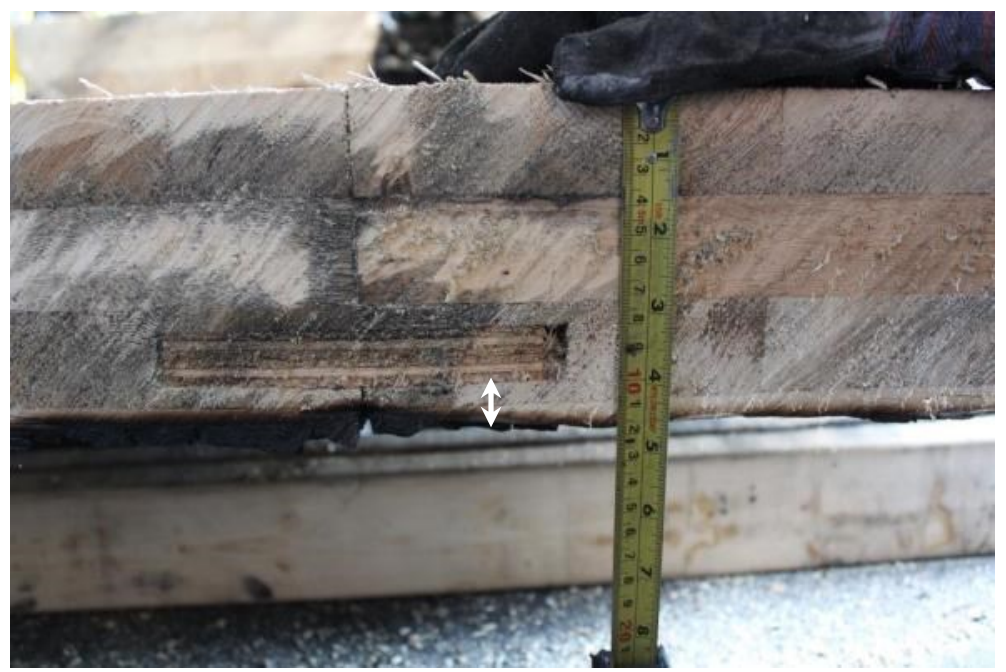

Figure 3.33 - Fire Test 5 residual cross-section after testing

\subsection{Fire Test 6 - 5-ply with half-lapped joint}

Fire test 6 with 5-ply CLT panels was with the half-lapped joint detail (Figure 3.34). The fire test was conducted on February 6, 2015. The ambient conditions inside the unheated laboratory were $-7^{\circ} \mathrm{C}$ and $43 \%$ relative humidity and the outdoor temperature was $-7^{\circ} \mathrm{C}$. The specimens were not conditioned prior to fire testing. Additional information and results are presented in Appendix VI.

During this fire test, the furnace temperature closely followed the standard timetemperature curve, while being slightly lower. As with the Fire Test 5, a load of $42 \mathrm{kN}$ was tentatively applied manually from the hydraulic jack throughout the test duration, representing $55 \%$ of the factored bending moment resistance. An initial deflection of 19 mm was recorded. 


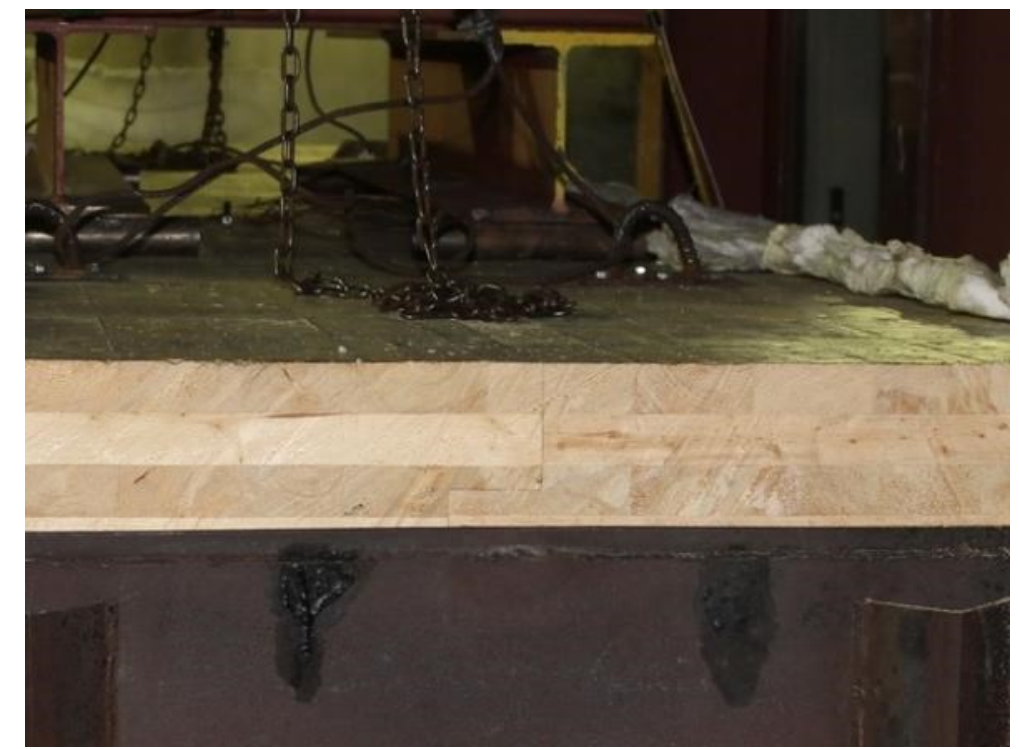

Figure 3.34 - Fire Test 6 specimen installed inside the furnace frame

Fire integrity failure was recorded at $98 \mathrm{~min}$. At that time, differential deflection was observed between the adjacent CLT panels, allowing the passage of flames through the assembly, as shown in Figure 3.35. As explained in subsection 3.3.1, some differential loading conditions may have been induced during the fire tests, which may explain the observed failure mode. When using the Canadian CLT calculation method, structural and fire integrity failures are predicted to occur at 104 and 94 min respectively, suggesting that fire integrity failure would occur first.

The char front was reached at 17.5 and $35 \mathrm{~mm}$ after 51 and $74 \mathrm{~min}$, which results in a charring rate of 0.34 and $0.47 \mathrm{~mm} / \mathrm{min}$ respectively. There was no significant temperature rise recorded at the $2^{\text {nd }}$ glueline $(70 \mathrm{~mm})$. Moreover, there was no significant temperature rise recorded at the half-lapped joint interface. 


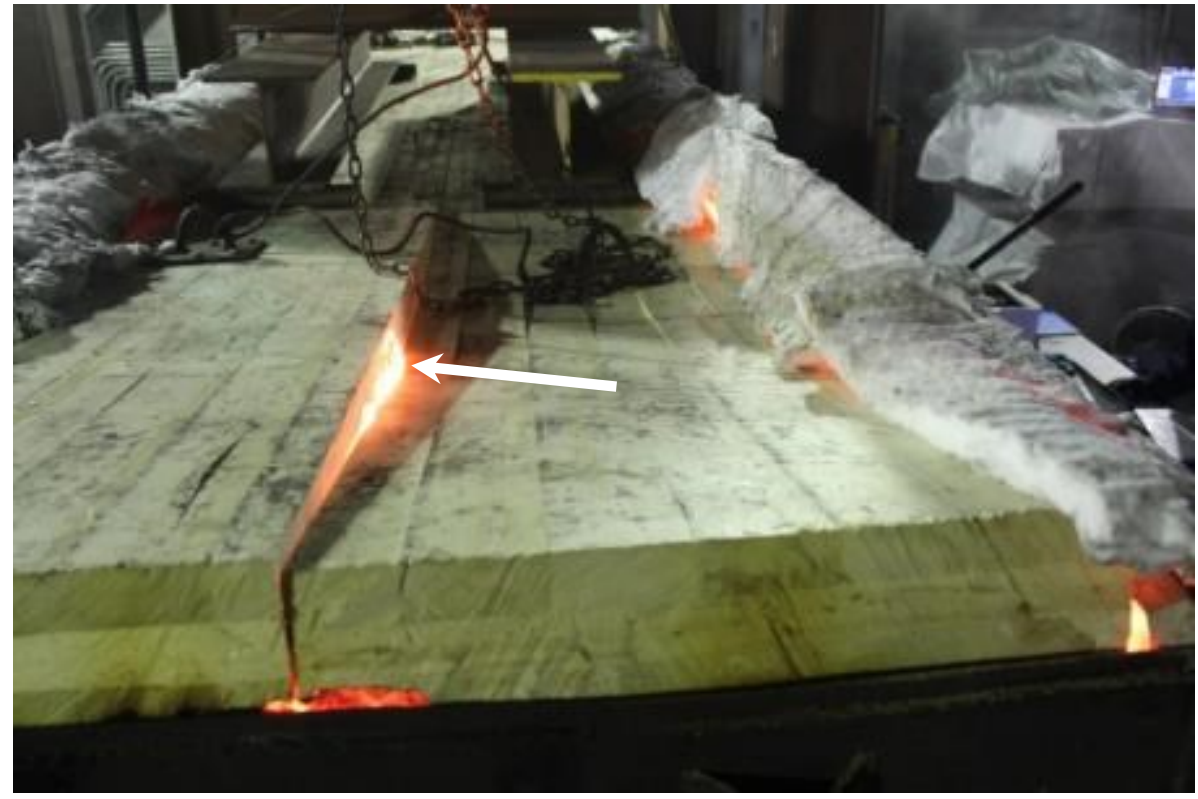

Figure 3.35 - Fire Test 6 failure (fire integrity) at $98 \mathrm{~min}$

The self-tapping screws slowly heated during the fire test. The tips reached the critical temperature of $538^{\circ} \mathrm{C}\left(1000^{\circ} \mathrm{F}\right)$ shortly after $95 \mathrm{~min}$ into the test, while the middle of the screws never reached this limit.

After manually removing the char layer, a residual CLT thickness of $110 \mathrm{~mm}$ was measured (Figure 3.36), resulting in an effective charring rate of $0.66 \mathrm{~mm} / \mathrm{min}$. Moreover, it can be seen that the half-lapped joint was not close to being reached by the char front as roughly $29 \mathrm{~mm}$ of wood was measured between the half-lapped joint interface and the underside of the charred CLT panels. 


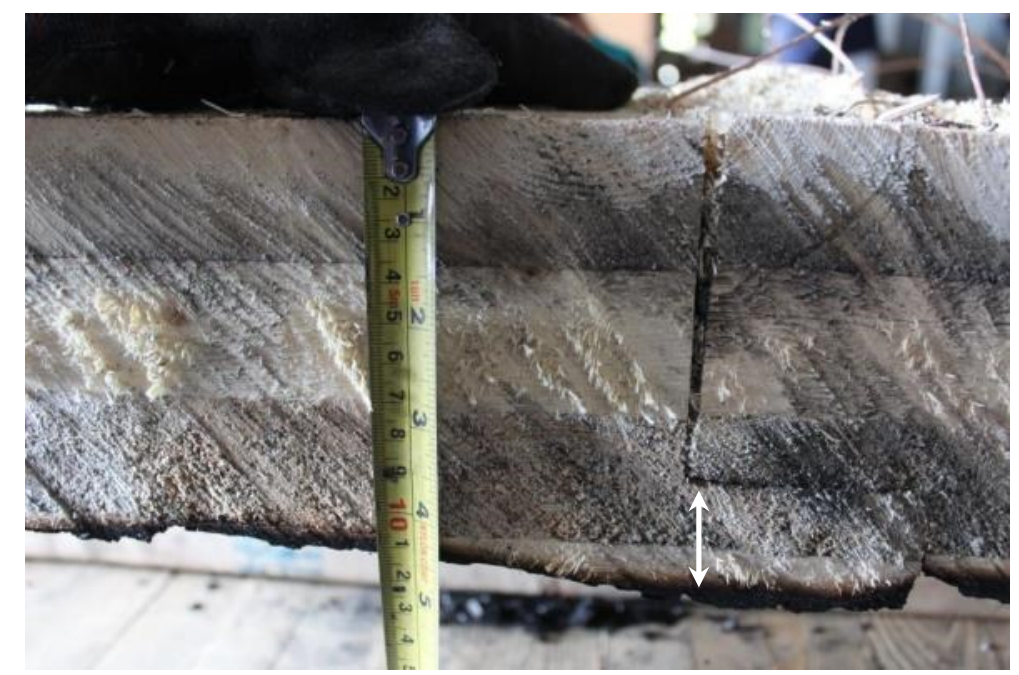

Figure 3.36 - Fire Test 6 residual cross-section after testing

\subsection{Fire Test 7 - 5-ply with single surface spline}

Fire test 7 with 5-ply CLT panels was with the single surface plywood spline joint detail and was conducted on February 17, 2015 (Figure 3.37). The ambient conditions inside the unheated laboratory were $-11^{\circ} \mathrm{C}$ and $29 \%$ relative humidity and the outdoor temperature was $-12^{\circ} \mathrm{C}$. The specimens were not conditioned prior to fire testing. Additional information and results are presented in Appendix VII.

The temperature recorded inside the furnace throughout the test closely followed the standard time-temperature curve. As with Fire Test 5, a load of $42 \mathrm{kN}$ was manually applied from the hydraulic jack throughout the test duration, representing 55\% of the factored bending moment resistance. An initial deflection of $20 \mathrm{~mm}$ was recorded. 


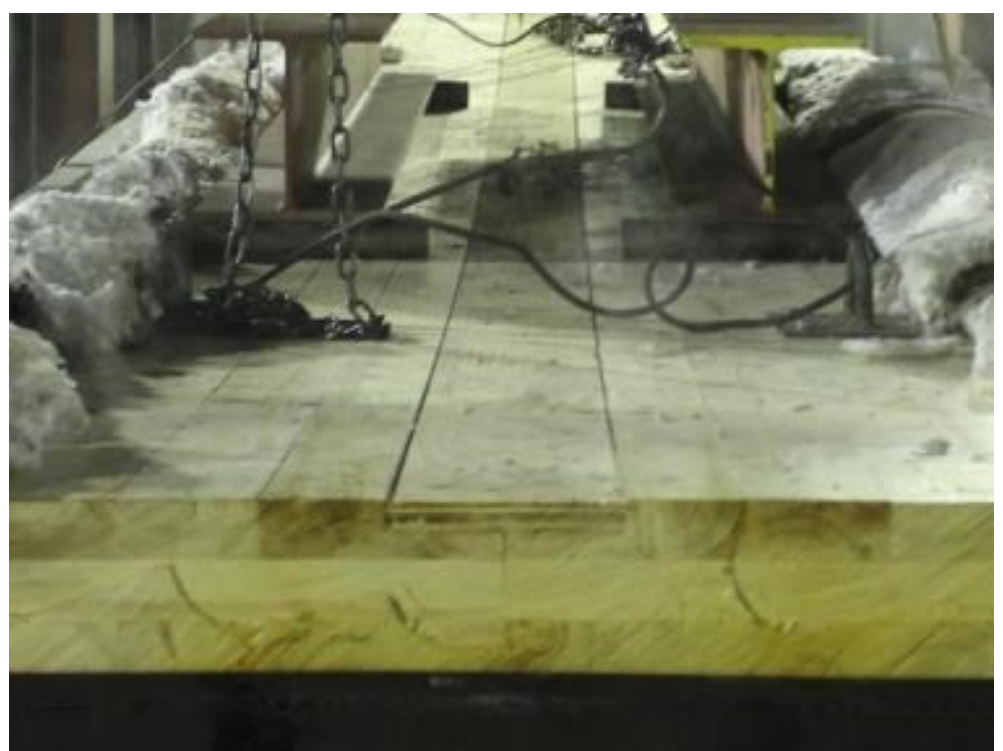

Figure 3.37 - Fire Test 7 specimen installed inside the furnace frame

After 98 min into the test, it was decided to end the fire test due to laboratory equipment safety concerns. Several burn-throughs were observed along the sides of the CLT specimens (Figure 3.38) and it was difficult to properly seal these gaps using Fiberfrax ${ }^{\circledR}$ ceramic fiber blanket. As such, no failure time was recorded for this test. However, given that the Canadian CLT calculation method predicted structural failure to occur around 104 min, the CLT specimen may have actually failed structurally shortly after deciding to shut down the burners, but it was not recorded nor observed. Nevertheless, this would explain the rapid increase in deflection and reduction in the applied load shown in Appendix VII. The European model would predict a fire integrity failure at $107 \mathrm{~min}$. 


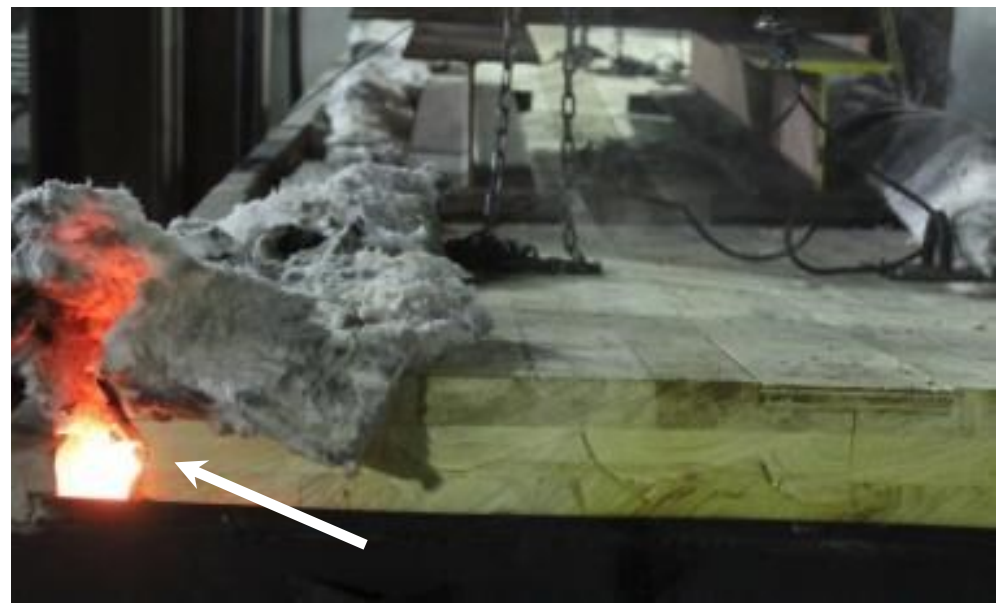

Figure 3.38 - Fire Test 7 with several burn-throughs along its perimeter

The char front was reached at 17.5 and $35 \mathrm{~mm}$ after 45 and $78 \mathrm{~min}$, which results in a charring rate of 0.39 and $0.45 \mathrm{~mm} / \mathrm{min}$ respectively. There was no significant temperature rise recorded at the $2^{\text {nd }}$ glueline $(70 \mathrm{~mm})$ and beyond. Moreover, no significant temperature rises were recorded at the surface plywood spline interface and along the self-tapping screws.

After scraping off the char layer, an average residual thickness of $116 \mathrm{~mm}$ was measured (Figure 3.27), resulting in an effective charring rate of $0.60 \mathrm{~mm} / \mathrm{min}$. Moreover, it can be seen that the surface spline was not close to being reached. 


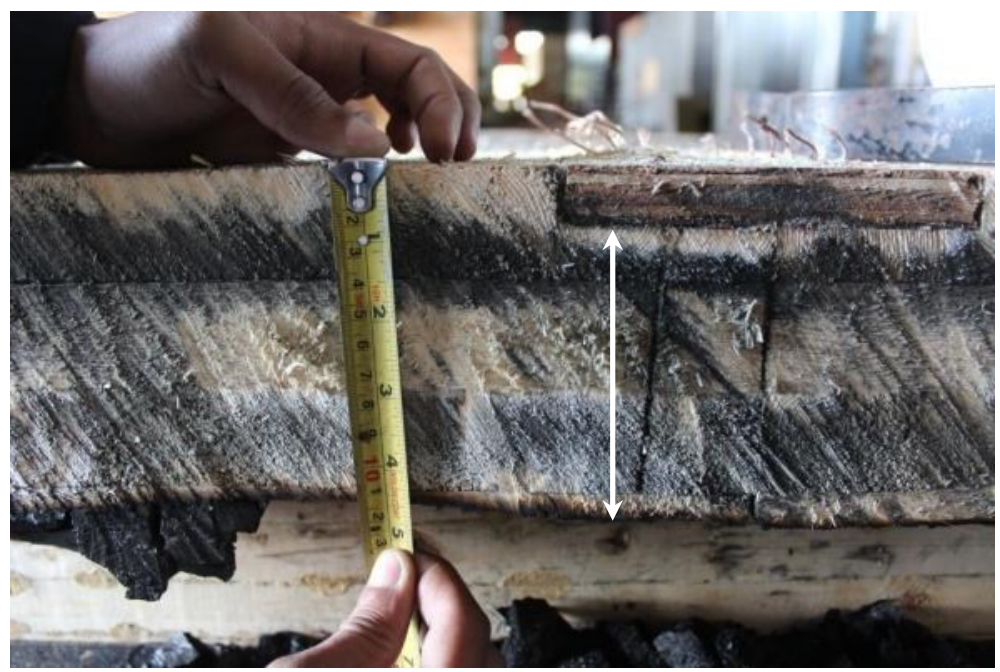

Figure 3.39 - Fire Test 7 residual cross-section after testing

\subsection{Fire Test 8 - 5-ply with double surface splines}

Fire test 8 with 5-ply CLT panels was with the double surface plywood splines joint detail, as shown in Figure 3.40. The fire test was conducted on February 11, 2015. The ambient conditions inside the unheated laboratory were $-5^{\circ} \mathrm{C}$ and $30 \%$ relative humidity and the outdoor temperature was $-14^{\circ} \mathrm{C}$. The specimens were not conditioned prior to fire testing. Additional information and results are presented in Appendix VIII.

The temperature recorded inside the furnace throughout the test closely followed the standard time-temperature curve, while being slightly lower for the first 45 minutes of burning. As with the previous fire tests conducted with 5-ply CLT specimens, a load of $42 \mathrm{kN}$ was applied from the hydraulic jack throughout the test duration, representing 55\% of the factored bending moment resistance. An initial deflection of $17 \mathrm{~mm}$ was recorded. 


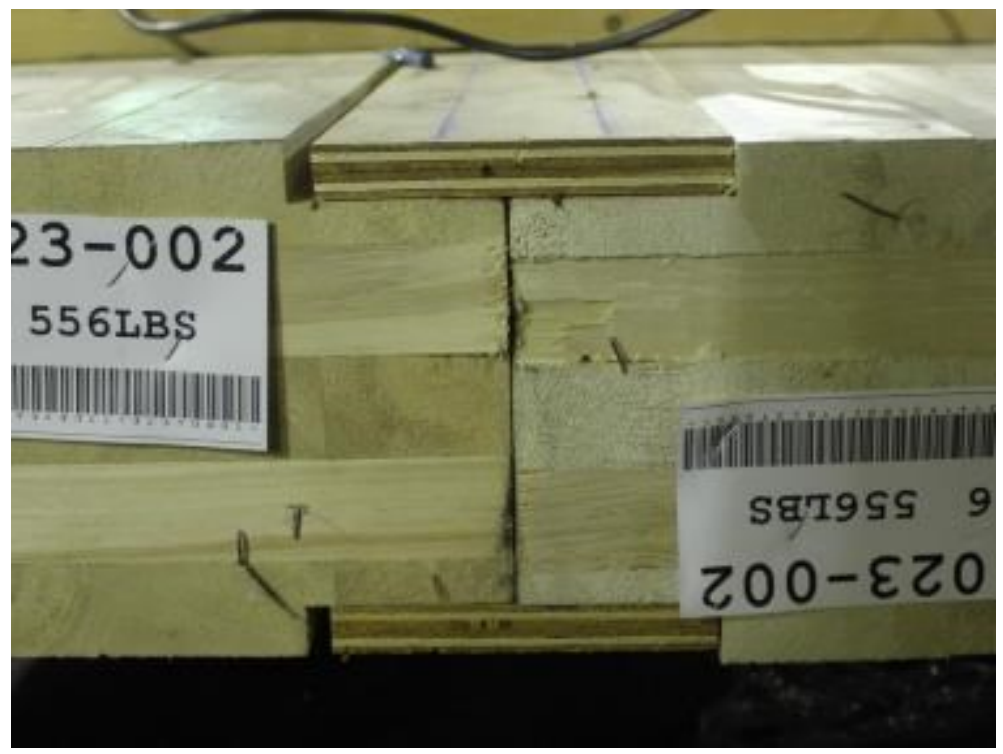

Figure 3.40 - Fire Test 8 prior to testing

After $82 \mathrm{~min}$, a small glowing was observed near one support and at about $90 \mathrm{~mm}$ from the surface plywood spline (Figure 3.41). However, it was felt that this would not be represents a fire integrity failure as it was most likely due to an opening from to a loosen knot in the outer CLT lamination. A few minutes later (at $90 \mathrm{~min}$ ), it was decided to end the fire test due to laboratory equipment safety concerns. As such, no failure time was recorded for this test. As with Fire Test 7, several burn-throughs were observed along the sides of the CLT specimens and at one end joint and it was difficult to properly seal these gaps. When using the Canadian CLT calculation method, structural failure is predicted to occur around $104 \mathrm{~min}$. The European model predicts a fire integrity failure of $161 \mathrm{~min}$, suggesting that structural failure would occur first. 


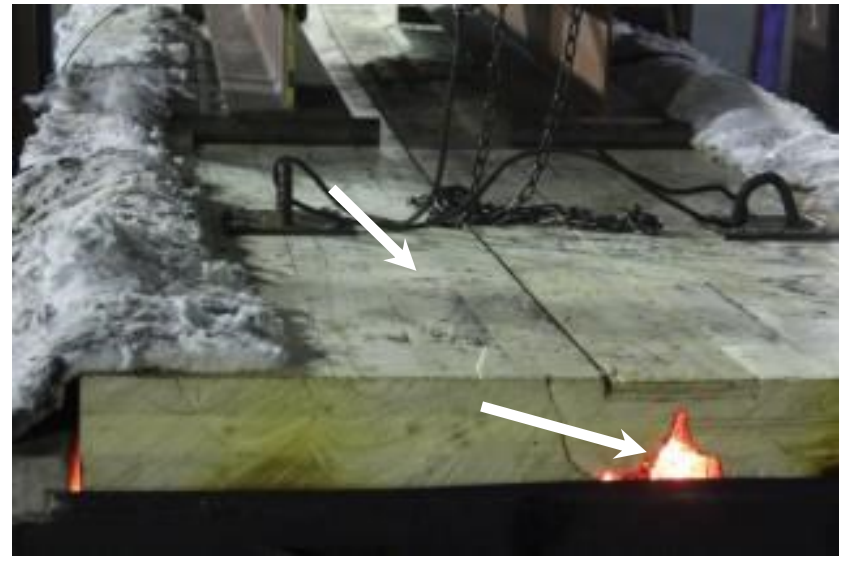

a) Burn-through the extremities and at one specific location

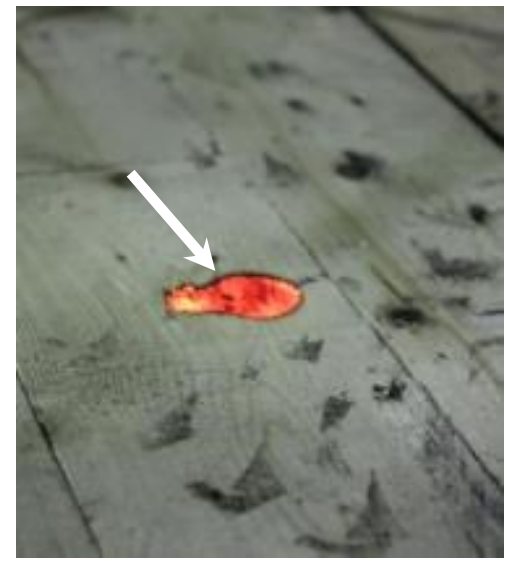

b) Close-up of the burn-through hole

Figure 3.41 - Fire Test 8 burn-through along the perimeter and at one location

The char front was reached at 17.5, 35 and $70 \mathrm{~mm}$ after 32,43 and $89 \mathrm{~min}$, which results in charring rates of $0.55,0.81$ and $0.79 \mathrm{~mm} / \mathrm{min}$ respectively. There was no significant temperature rise recorded at the $3^{\text {rd }}$ glueline $(105 \mathrm{~mm})$ and beyond. The thermocouple located at the bottom spline interface reached $300^{\circ} \mathrm{C}$ after 25 min into the test, resulting in a charring rate of $0.74 \mathrm{~mm} / \mathrm{min}$ for the plywood spline.

As observed with Fire Test 4 (3-ply specimens), heat was being rapidly conducted to the bottom self-tapping screws, which are directly exposed to fire. Very little difference in the temperature profile is observed between the middle and the tip of the bottom selftapping screws. The critical temperature of $538^{\circ} \mathrm{C}\left(1000^{\circ} \mathrm{F}\right)$ was reached within 2 min into the test.

Given that the char front did not pass by much the $2^{\text {nd }}$ glueline $(70 \mathrm{~mm})$ and that CLT has a very low thermal conductivity, no significant temperature rise was recorded from the self-tapping screws used for the top surface spline throughout the test. 
An average residual thickness of $115 \mathrm{~mm}$ was manually measured (Figure 3.42), resulting in an effective charring rate of $0.67 \mathrm{~mm} / \mathrm{min}$. It can also be seen that the surface spline was not close to being reached.

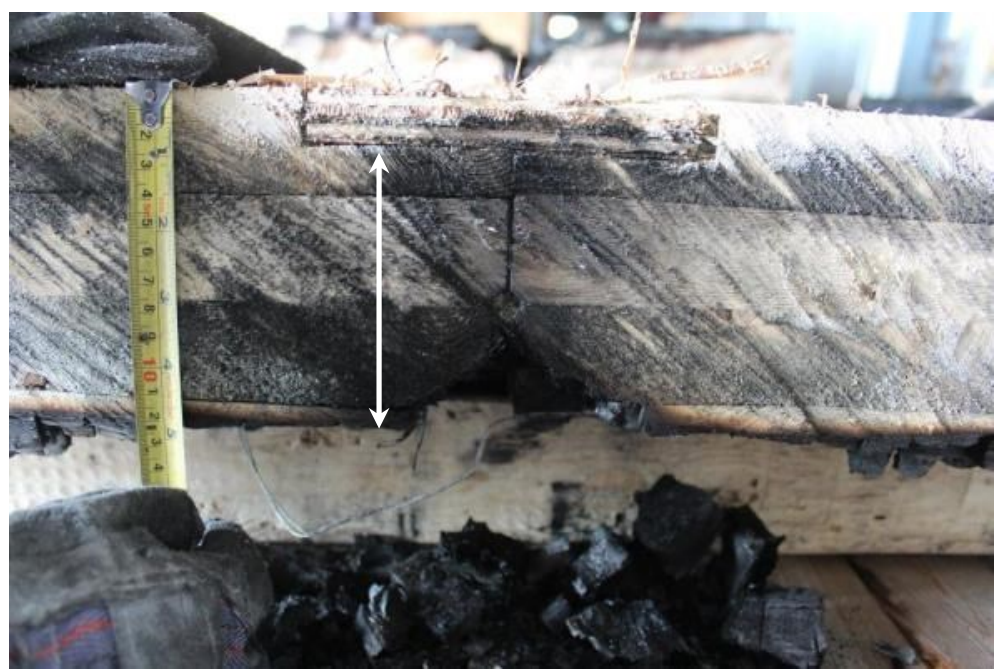

Figure 3.42 - Fire Test 8 residual cross-section after testing

\subsection{Fire Test 9 - 7-ply with half-lapped joint}

Fire test 9 was on 7-ply CLT panels with the half-lapped joint detail (Figure 3.43). It was conducted on March 12, 2015. The ambient conditions inside the unheated laboratory were not recorded, but the outdoor temperature was $-6^{\circ} \mathrm{C}$. The specimens were not conditioned prior to fire testing. Additional information and results are presented in Appendix IX. 


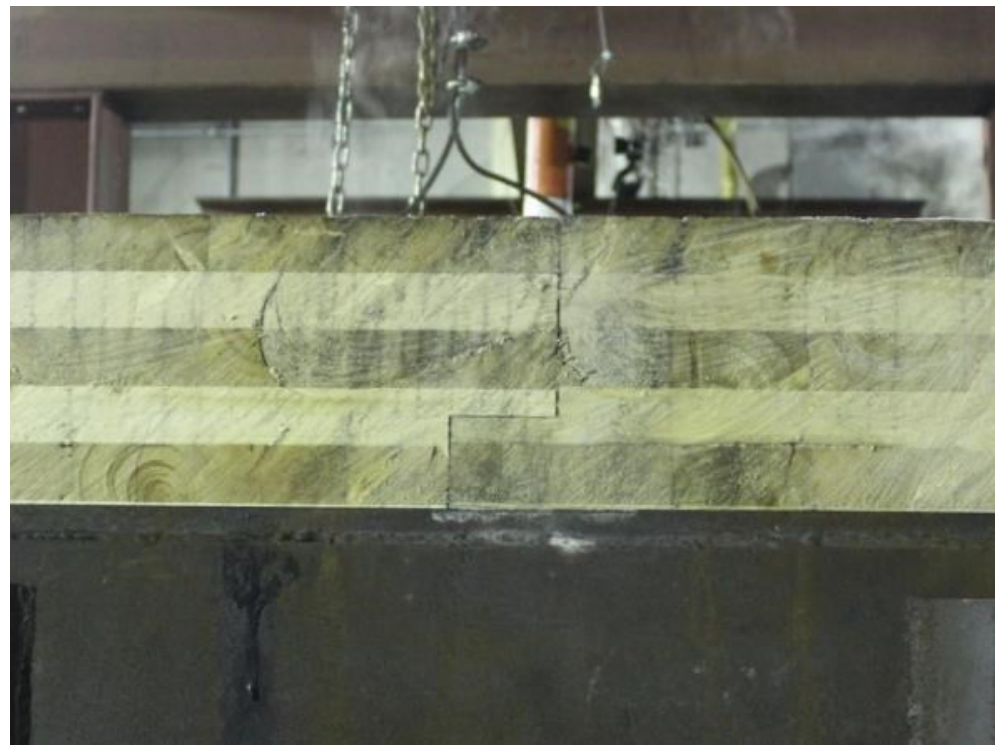

Figure 3.43 - Fire Test 9 specimen installed inside the furnace frame

The temperature curve throughout the test closely followed that of the standard timetemperature curve. Due to limitations in the hydraulic jack, a load of $50 \mathrm{kN}$ was applied during the fire test, representing $40 \%$ of the factored bending moment resistance.

Fire integrity failure was recorded at $140 \mathrm{~min}$. At that time and similarly to Fire Test 6 , differential deflection was observed between the adjacent CLT panels (Figure 3.44), allowing for the passage of flames through the assembly, as shown in Figure 3.45. The test was terminated only after $151 \mathrm{~min}$ of fire exposure. According to the Canadian CLT calculation method, structural and fire integrity failures are predicted to occur around 187 and 132 min respectively, suggesting that fire integrity failure would occur first. 


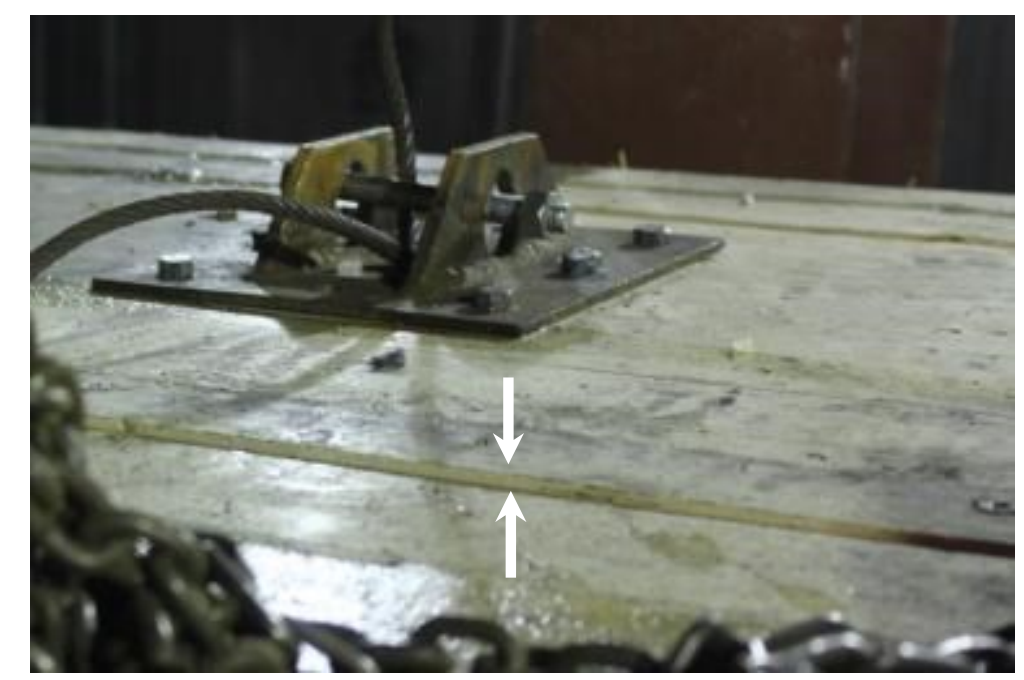

Figure 3.44 - Fire Test 9 experiencing differential displacement between CLT panels

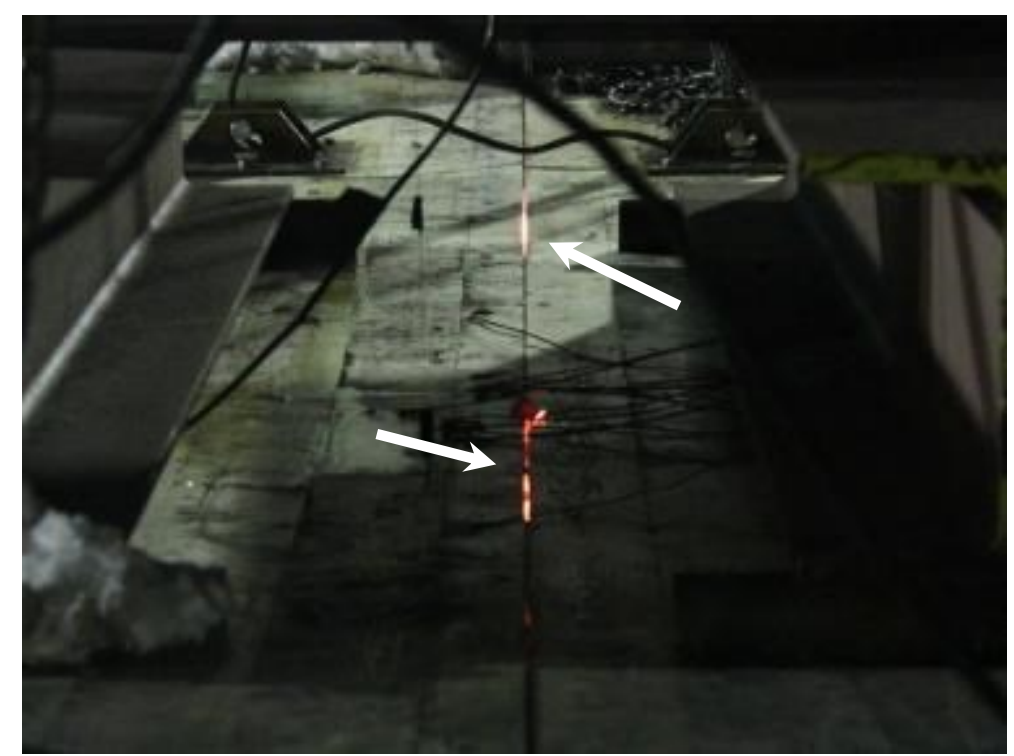

Figure 3.45 - Fire Test 9 fire integrity failure at $140 \mathrm{~min}$

The char front was reached at 17.5, 35, 70 and $105 \mathrm{~mm}$ after 47, 74, 117 and $144 \mathrm{~min}$, which results in charring rates of $0.37,0.47,0.60$ and $0.73 \mathrm{~mm} / \mathrm{min}$ respectively. The thermocouples located at the half-lapped joint interface reached $300^{\circ} \mathrm{C}$ at $96 \mathrm{~min}$. 
The tips reached the critical temperature of $538^{\circ} \mathrm{C}\left(1000^{\circ} \mathrm{F}\right)$ shortly after $80 \mathrm{~min}$ into the test, while the middle of the screws was still far from reaching this limit.

A residual CLT thickness of $141 \mathrm{~mm}$ was manually measured after removing the char layer (Figure 3.46), resulting in an average charring rate of $0.69 \mathrm{~mm} / \mathrm{min}$. Only $17 \mathrm{~mm}$ of CLT remained underneath the half-lapped interface.

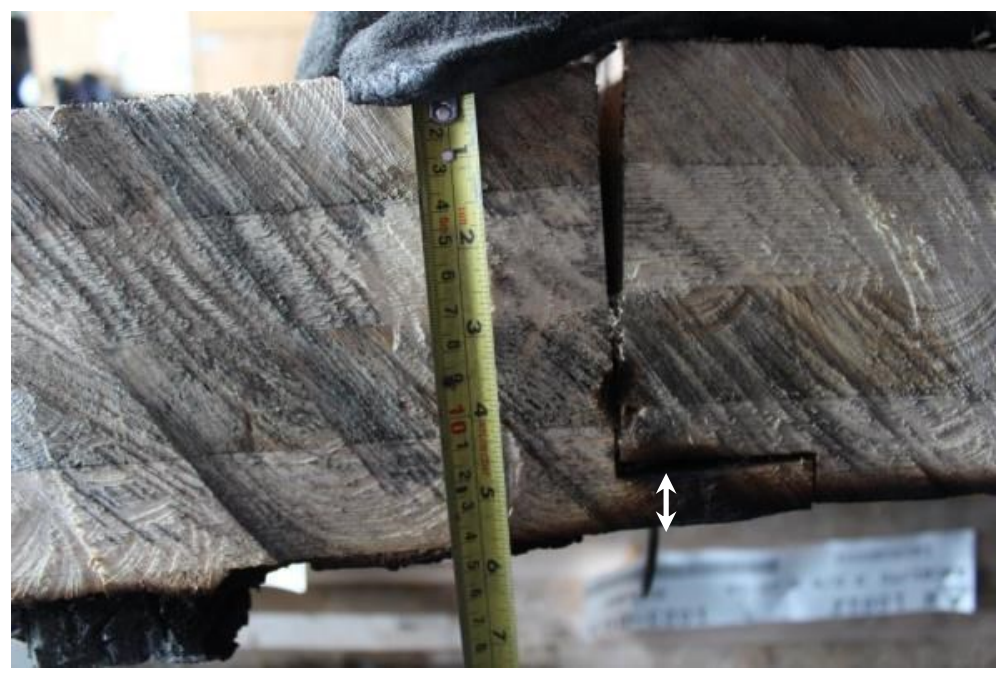

Figure 3.46 - Fire Test 9 residual cross-section after testing

\subsection{Fire Test 10 - 7-ply with double surface splines}

Fire test 10 with 7-ply CLT panels was with the double surface plywood splines joint detail, as shown in Figure 3.47. The fire test was conducted on February 27, 2015. The ambient conditions inside the unheated laboratory were $-7^{\circ} \mathrm{C}$ and $27 \%$ relative humidity and the outdoor temperature was $-16^{\circ} \mathrm{C}$. The specimens were not conditioned prior to fire testing. Additional information and results are presented in Appendix X. 


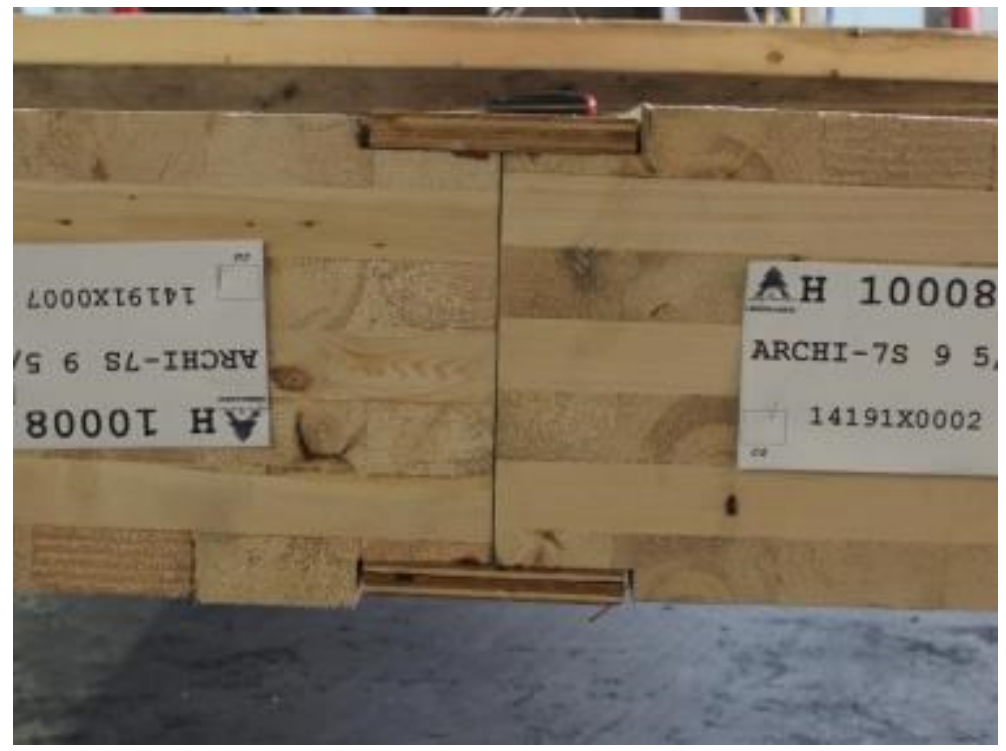

Figure 3.47 - Fire Test 10 specimen prior to testing

The furnace temperature closely followed the standard time-temperature curve, while being slightly lower in the first 40 minutes of fire exposure. As with fire test 9 conducted with 7-ply CLT specimens, a load of $50 \mathrm{kN}$ was applied from the hydraulic jack throughout the test duration, representing $40 \%$ of the factored bending moment resistance. An initial deflection of $11 \mathrm{~mm}$ was recorded.

The test was terminated shortly after 184 min into the test, after a loud sound being heard, most likely related to structural failure of the CLT panels. The sharp increase in the deflection after $180 \mathrm{~min}$ also supports the assumption of a structural failure. When using the Canadian CLT calculation method, structural failure is predicted to occur around 187 min. The European model predicts a fire integrity failure of $226 \mathrm{~min}$, suggesting that structural failure would occur first. 
Similarly to Fire Test 8 and as shown in Figure 3.48, several burn-throughs were observed along the sides and the ends of the CLT specimens and it was very difficult to properly seal these gaps using Fiberfrax ${ }^{\circledR}$ ceramic fiber blanket.

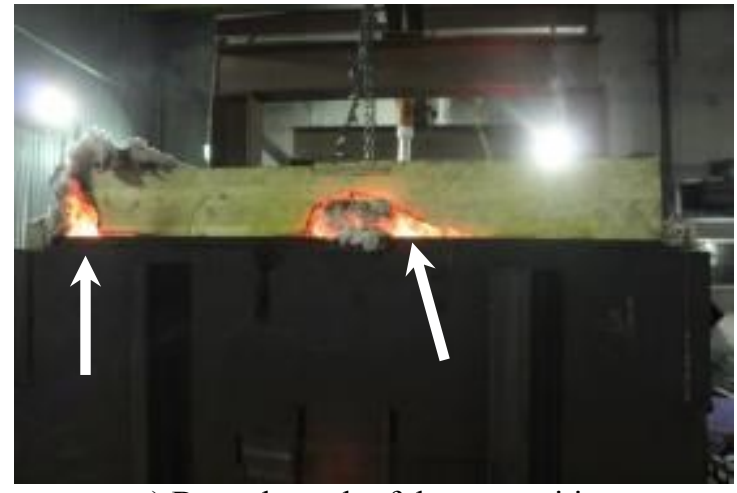

a) Burn-through of the extremities

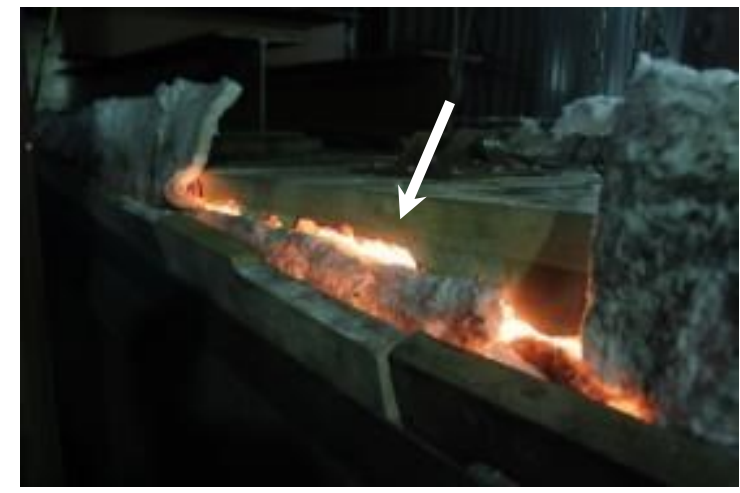

b) Burn-through of the sides

Figure 3.48 - Fire Test 10 burn-through along the CLT specimen perimeter

The char front was reached at 17.5, 35, 70 and $105 \mathrm{~mm}$ after 52, 51, 114 and $167 \mathrm{~min}$, which results in charring rates of $0.34,0.69,0.61$ and $0.63 \mathrm{~mm} / \mathrm{min}$ respectively. There was no significant temperature rise recorded beyond the $3^{\text {rd }}$ glueline (beyond $105 \mathrm{~mm}$ ) and at the top spline interface. The char front $\left(300^{\circ} \mathrm{C}\right)$ was first reached at $31 \mathrm{~min}$ at the bottom spline interface, resulting in a charring rate of $0.60 \mathrm{~mm} / \mathrm{min}$ for the plywood spline.

Similarly to Fire Tests 4 and 8 , heat was being rapidly conducted to the bottom selftapping screws, which are directly exposed to the fire. Moreover, very little difference in the temperature profile is observed between the middle and the tip of the bottom selftapping screws. The bottom screws reached the critical temperature of $538^{\circ} \mathrm{C}\left(1000^{\circ} \mathrm{F}\right)$ 
within 2 min into the test. No significant temperature rise was recorded from the selftapping screws used for the top surface spline throughout the test.

An average residual thickness of $118 \mathrm{~mm}$ was manually measured (Figure 3.49), resulting in an effective charring rate of $0.69 \mathrm{~mm} / \mathrm{min}$. It can also be seen that the surface spline was not close to being reached.

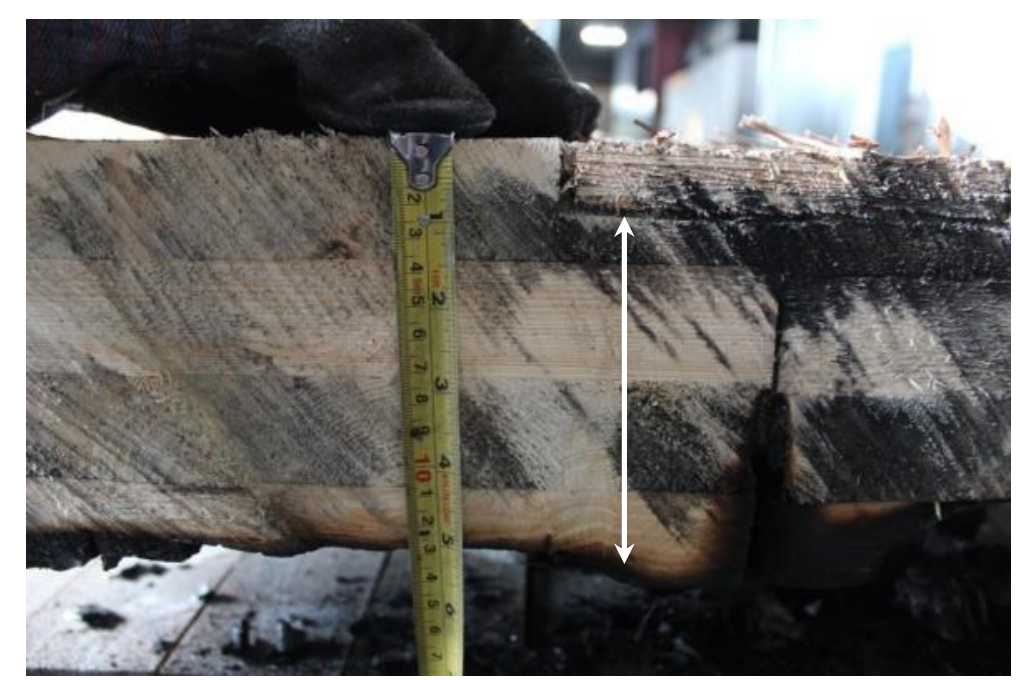

Figure 3.49 - Fire Test 10 residual cross-section after testing

\subsection{Analysis and Discussion}

The text matrix shown in Table 3.1 is used to compare the fire integrity failure of four CLT panel-to-panel joints for CLT specimens ranging from 3 to 7-plies in thickness. The following is an analysis and discussion of the test results obtained during this test series, summarized in Table 3.6. 
Table 3.6 - Summary of CLT panel-to-panel joint fire test results

Time to fire integrity failure (min)

CLT Assembly [predictions from Table 3.2]

\begin{tabular}{ccccc}
\cline { 2 - 5 } CLT Assembly & Half-Lapped & Internal Spline & $\begin{array}{c}\text { Single Surface } \\
\text { Spline }\end{array}$ & $\begin{array}{c}\text { Double Surface } \\
\text { Spline }\end{array}$ \\
\hline \multirow{2}{*}{ 3-ply $(105 \mathrm{~mm})$} & 45 & 35 & $>54^{(1)}$ & 43 \\
& {$[48]$} & {$[64]$} & {$[64]$} & {$[96]$} \\
\hline \multirow{2}{*}{5 -ply $(175 \mathrm{~mm})$} & 98 & 76 & $>98^{(1)}$ & $>90^{(1)}$ \\
& {$[80]$} & {$[107]$} & {$[107]$} & {$[161]$} \\
\hline \multirow{2}{*}{ 7-ply $(245 \mathrm{~mm})$} & 140 & n.a. & n.a. & $>180^{(2)}$ \\
& {$[113]$} & {$[150]$} & {$[150]$} & {$[226]$} \\
\hline
\end{tabular}

${ }^{(1)}$ Test was stopped, no failure was reached.

(2) Test was stopped due to structural failure occurring before fire integrity failure. n.a. $=$ not available as no test was conducted.

\subsubsection{Effect of Joint Configuration}

As one would predict, positioning the joint interface away from the fire-exposed surface would provide greater fire integrity resistance. In a similar manner, using splines also improves the fire integrity resistance by providing obstruction paths to smoke and flames. The test results shown in Table 3.6 somewhat reflect these assumptions.

Given that the location of the half-lapped joint is somewhat at a similar position as the internal spline, it was expected that similar failure times would be achieved based on the time for the char front to reach that location. However, the results suggest that an internal spline seems less efficient than the half-lapped joint in preventing fire integrity failure. In fact, the failure times for the internal spline specimens were observed at mid-span, where the internal plywood splines were butt-jointed (Figure 3.20 and Figure 3.32). This suggests that the spline may have not been properly tight-fitted together and a gap between the splines allowed for a premature flow-through. It is critical that internal 
splines be properly installed in an attempt to limit premature fire integrity failure. Such gaps are not possible when using half-lapped joints, eliminating potential field installation errors that may occur on a job site.

When comparing the half-lapped joint to the single and double surface spline details, one may assume that the configurations providing a spline the furthest from the fire-exposed surface would provide a better fire integrity resistance. The results obtained in this fire test series support this assumption. The single and double surface spline specimens provided longer fire integrity failure times when compared to the half-lapped joint specimens, except for Fire Test 4 (3-ply double surface spline) which resulted in a similar failure time to that of the 3-ply half-lapped joint. A potential reason for such early failure time may be attributed to the manufacturing process of CLT. According to ANSI/APA PRG-320, edge-gluing the narrow face of adjacent laminations within a CLT layer is optional. It is unclear from the remaining of the Fire Test 4 panels whether or not there was a significant gap between the laminations in the $2^{\text {nd }}$ layer (cross-layer), which would have led to early flame-through, as observed during the test. When comparing the 5-ply specimens, the results suggest that using single or double surface splines do enhance the fire integrity resistance of CLT panel-to-panel joints when compared to the half-lapped joints.

During this fire test series, the CLT panel-to-panel joints were tightly assembled; that is there was no gap between the CLT panels that would have allowed flame or smoke to 
easily flow through. It is anticipated that lower fire integrity time to failure would be observed should an air gap exist between the CLT panels.

\subsubsection{Effect of CLT Loading Ratio}

The primary intent of this study is to verify the fire integrity of CLT slabs acting as floor systems during a fire occurring on a floor below. Fasteners and splines connecting CLT panels together have the sole mandate of transferring horizontal shear forces resulting from a floor diaphragm action (i.e. in-plane loading).

During this fire test series, the CLT specimens were subjected to different stress ratios. The 3-ply, 5-ply and 7-ply specimens were respectively subjected to $100 \%, 55 \%$ and $40 \%$ of their factored bending resistance.

Except for Fire Test 1, all other CLT specimens were structurally loaded symmetrically; that is that the two adjacent CLT panels were subjected to the same applied load. From the testing procedure used in this fire test series, it is difficult to properly analyze the effect of CLT load ratio on the fire integrity resistance. The fasteners were not installed in a way to transfer in-plane and out-of-plane forces from one CLT to the other. The objective of this test series was to evaluate the influence of the presence of metal fasteners and splines on the integrity fire-resistance of CLT floor elements (i.e. flamethrough the joints). It was not intended to evaluate the structural fire-resistance of the connections. 


\subsubsection{Charring Rate and Effect of Adhesive Heat Delamination}

Table 2.9 summarized the design charring rates commonly used for most wood products. These charring rates are derived with the assumptions that glued structural products behave similarly to solid (non-glued) wood when exposed to fire and that the structural adhesive used in the manufacturing process does not exhibit heat delamination characteristics. If the adhesive is not able to maintain its bonding capacity at temperatures associated with charring of wood $\left(300^{\circ} \mathrm{C}\right)$, thus not able to prevent the premature fall-off of layers, then considerations should be given to the impact on the charring rate.

Table 3.7 summarizes the charring rates measured during this fire test series. It can be observed that, in most of the times, the average charring rates are similar to that typically assumed for softwood lumber (i.e. $0.65 \mathrm{~mm} / \mathrm{min}$ ). However, the overall charring increases when more than the $1^{\text {st }}$ lamination is charred (beyond $35 \mathrm{~mm}$ ), reaching approximately $0.70 \mathrm{~mm} / \mathrm{min}$ for a charring depth up to $105 \mathrm{~mm}$.

Moreover, when determining the charring rate for each respective layer, an increase in charring rate is also observed after the $1^{\text {st }}$ lamination is consumed. On average, the times to reach the $1^{\text {st }}$ and $2^{\text {nd }}$ gluelines are 61 and $101 \mathrm{~min}$, which result in charring rates of 0.57 and $0.88 \mathrm{~mm} / \mathrm{min}$ for the $1^{\text {st }}$ and $2^{\text {nd }}$ laminations, respectively.

The resulting charring rate of the $2^{\text {nd }}$ lamination is significantly greater than the traditional $0.65 \mathrm{~mm} / \mathrm{min}$ used for most wood products, which is due to heat delamination of the structural adhesive at elevated temperatures observed in all ten (10) fire tests 
(Figure 3.50). Such effect significantly impacts the charring rate of CLT and needs to be considered in calculation models.

Table 3.7-Time to 300 isotherm and resulting charring rate from test data

\begin{tabular}{|c|c|c|c|c|c|c|c|c|}
\hline \multirow{2}{*}{ Specimen } & \multicolumn{6}{|c|}{$\begin{array}{c}\text { Time to } 300^{\circ} \mathrm{C}(\mathrm{min}) \\
\text { (charring rate, } \mathrm{mm} / \mathrm{min})\end{array}$} & \multirow{2}{*}{$\begin{array}{l}\text { Average } \\
\text { Charing } \\
\text { Rate } \\
(\mathrm{mm} / \mathrm{min}) \\
\end{array}$} & \multirow{2}{*}{$\begin{array}{l}\text { Measured } \\
\text { Charring } \\
\text { Rate }^{(2)} \\
(\mathrm{mm} / \mathrm{min})\end{array}$} \\
\hline & $\begin{array}{l}17.5 \\
\mathbf{m m}\end{array}$ & $35 \mathrm{~mm}$ & $\begin{array}{l}52.5 \\
\mathrm{~mm}\end{array}$ & $70 \mathrm{~mm}$ & $105 \mathrm{~mm}$ & $\begin{array}{c}122.5 \\
\mathrm{~mm}\end{array}$ & & \\
\hline Test 1 & - & - & - & - & - & - & - & 0.94 \\
\hline Test 2 & $\begin{array}{c}28 \\
(0.63)\end{array}$ & - & $\begin{array}{c}53 \\
(0.99)\end{array}$ & - & - & - & 0.81 & 0.66 \\
\hline Test 3 & $\begin{array}{c}30 \\
(0.58)\end{array}$ & $\begin{array}{c}52 \\
(0.67)\end{array}$ & - & - & - & - & 0.63 & 0.71 \\
\hline Test 4 & $\begin{array}{c}46 \\
(0.38)\end{array}$ & $\begin{array}{c}60 \\
(0.58) \\
\end{array}$ & - & - & - & - & 0.48 & 0.67 \\
\hline Test 5 & $\begin{array}{c}29 \\
(0.60)\end{array}$ & $\begin{array}{c}61 \\
(0.57) \\
\end{array}$ & - & $\begin{array}{c}85 \\
(0.82) \\
\end{array}$ & - & - & 0.67 & 0.68 \\
\hline Test 6 & $\begin{array}{c}51 \\
(0.34) \\
\end{array}$ & $\begin{array}{c}74 \\
(0.47) \\
\end{array}$ & - & - & - & - & 0.41 & 0.66 \\
\hline Test 7 & $\begin{array}{c}45 \\
(0.39)\end{array}$ & $\begin{array}{c}78 \\
(0.45)\end{array}$ & - & - & - & - & 0.42 & 0.60 \\
\hline Test 8 & $\begin{array}{c}32 \\
(0.55)\end{array}$ & $\begin{array}{c}43 \\
(0.81) \\
\end{array}$ & - & $\begin{array}{c}89 \\
(0.79) \\
\end{array}$ & - & - & 0.72 & 0.67 \\
\hline Test 9 & $\begin{array}{c}47 \\
(0.37) \\
\end{array}$ & $\begin{array}{c}74 \\
(0.47) \\
\end{array}$ & - & $\begin{array}{c}117 \\
(0.60) \\
\end{array}$ & $\begin{array}{c}144 \\
(0.73) \\
\end{array}$ & $\begin{array}{c}96 \\
(1.28) \\
\end{array}$ & 0.69 & 0.69 \\
\hline Test 10 & $\begin{array}{c}52 \\
(0.34)\end{array}$ & $\begin{array}{c}51 \\
(0.69)\end{array}$ & - & $\begin{array}{c}114 \\
(0.61)\end{array}$ & $\begin{array}{c}167 \\
(0.63) \\
\end{array}$ & - & 0.57 & 0.69 \\
\hline Average & $\begin{array}{c}40 \\
(0.44)\end{array}$ & $\begin{array}{c}61 \\
(0.57)\end{array}$ & $\begin{array}{c}53 \\
(0.99)\end{array}$ & $\begin{array}{c}101 \\
(0.69)\end{array}$ & $\begin{array}{c}155 \\
(0.68)\end{array}$ & $\begin{array}{c}96 \\
(1.28)\end{array}$ & 0.60 & 0.70 \\
\hline \multirow{3}{*}{\multicolumn{2}{|c|}{$\begin{array}{c}\text { Average charring rate } \\
\text { between consecutive } \\
\text { readings }\end{array}$}} & \multicolumn{2}{|c|}{0 to $35 \mathrm{~mm}$} & \multicolumn{2}{|c|}{$0.57 \mathrm{~mm} / \mathrm{min}$} & & & \\
\hline & & \multicolumn{2}{|c|}{35 to $70 \mathrm{~mm}$} & \multicolumn{2}{|c|}{$0.88 \mathrm{~mm} / \mathrm{min}$} & - & - & - \\
\hline & & \multicolumn{2}{|c|}{70 to $105 \mathrm{~mm}$} & \multicolumn{2}{|c|}{$0.65 \mathrm{~mm} / \mathrm{min}$} & & & \\
\hline \multicolumn{9}{|c|}{$\begin{array}{l}\text { (1) Taken as the average of all charring rates within the same specimen. Rates within a specimen } \\
\text { are determined from thermocouple readings at } 300^{\circ} \mathrm{C} \text {. } \\
\text { (2) Taken as the initial thickness minus the residual thickness (from manual measurements), } \\
\text { divided by the time to failure (or end of test). }\end{array}$} \\
\hline
\end{tabular}




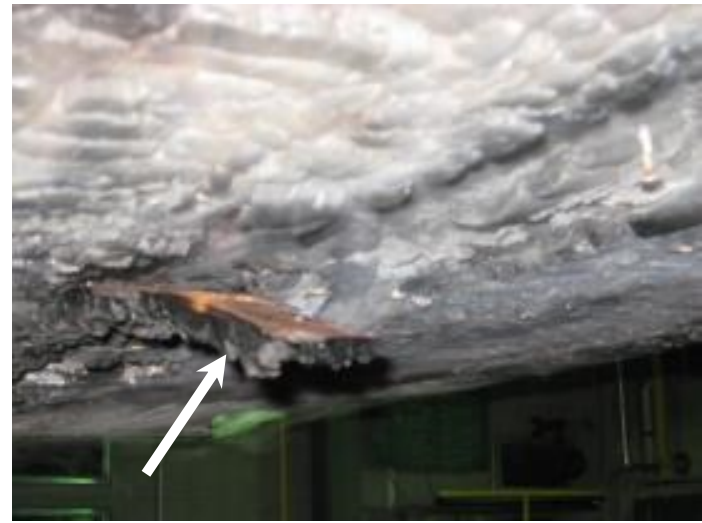

a) Hanging lamella after Fire Test 4

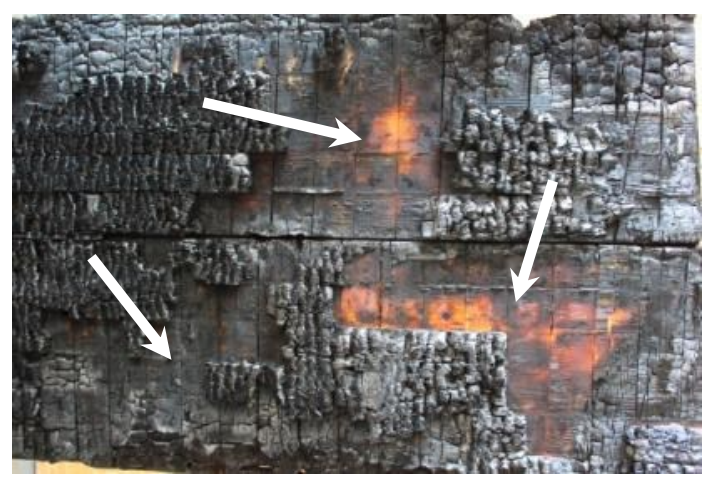

c) Localized delamination during Fire Test 3

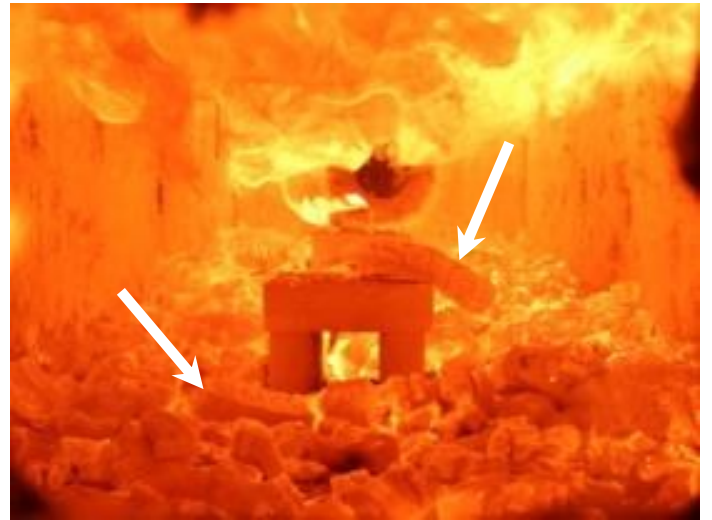

b) Fall-off during Fire Test 10

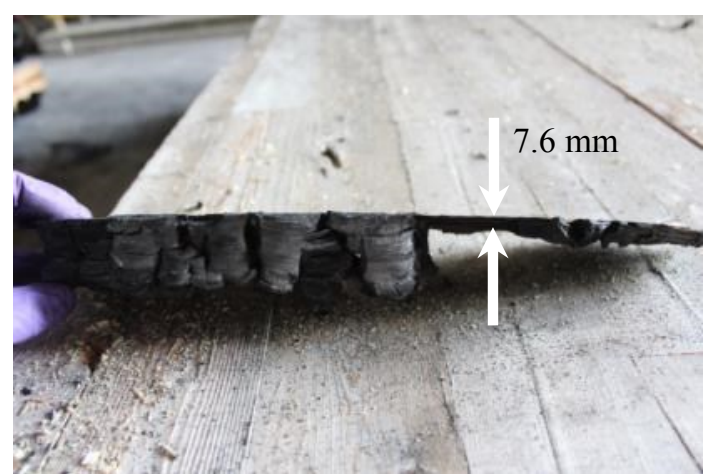

d) Lamella after Fire Test 7

Figure 3.50 - Heat delamination observed during fire testing

The reason for a charring rate of $0.65 \mathrm{~mm} / \mathrm{min}$ from the depth of 70 to $105 \mathrm{~mm}$ is unclear. Air gaps within the CLT panel and between lumber boards would typically not impact the lumber charring rate, but may lead to premature flame-through failure. In this test series, thermocouples were precisely embedded into the CLT panels at various locations and into solid lumber (not in gaps). If a thermocouple would have been placed in air gap, significant temperature rise would have been recorded during the tests, which was not observed. As such, one potential reason for such reduction is that the $2^{\text {nd }}$ and $3^{\text {rd }}$ laminations consist of a visually-graded SPF No.2 and MSR 1950f $\mathrm{f}_{\mathrm{b}}$ lumber grades, 
respectively. While CSA O86 publishes a relative density of $420 \mathrm{~kg} / \mathrm{m}^{3}$ for both $\mathrm{SPF}$ visually-graded and MSR lumber grades, the CLT manufacturer claims a value of 515 to $520 \mathrm{~kg} / \mathrm{m}^{3}$, thus a much denser wood than assumed in CSA O86. As explained in subsection 2.5.1.2, a decrease in charring rate is observed with an increase of the density, which may explain the observed reduction. When using Equation (2.16) with 12\% moisture content, a charring rate of $0.66 \mathrm{~mm} / \mathrm{min}$ is obtained for a wood density of 420 $\mathrm{kg} / \mathrm{m}^{3}$ while it reduces to $0.56 \mathrm{~mm} / \mathrm{min}$ for a density of 515 to $520 \mathrm{~kg} / \mathrm{m}^{3}$, which is consistent with the rate measured for the $1^{\text {st }}$ laminations of MSR lumber. When considering the adhesive heat delamination for subsequent laminations ( $2^{\text {nd }}$ and beyond), a $15 \%$ increase of the charring rate is observed $(0.65 \mathrm{~mm} / \mathrm{min} \div 0.57 \mathrm{~mm} / \mathrm{min} \approx 1.15)$.

When the adhesive reaches a temperature of approximately $220^{\circ} \mathrm{C}$, it loses its bonding capacity and fall-off of the lamination occurs, resulting in a sudden exposure of the next lamination that has not yet fully heated and initiated pyrolysis. As such, when the $1^{\text {st }}$ glueline exhibits heat delamination, the $2^{\text {nd }}$ lamination becomes suddenly exposed to fire and chars at an increased rate, when compared to the $1^{\text {st }}$ lamination, until the charred layer is formed. At that time, the rate reduces to the typical value of $0.65 \mathrm{~mm} / \mathrm{min}$ until the next glueline is reached. The thermal gradient within a wood slab is steep and the latter is considered to be acting as a thermally-thick solid when its thickness is at least 35 mm. When the thickness becomes less than $35 \mathrm{~mm}$, the unexposed surface starts experiencing an increase in temperature. According to the thermal model developed by Janssens \& White [35], detailed in Equation (2.3), a residual thickness of $7 \mathrm{~mm}$ would maintain the temperature at the glueline at slightly below $220^{\circ} \mathrm{C}$. Figure $3.50(\mathrm{~d})$ shows a 
piece of a lamella gently removed from the underside of the CLT panels after Fire Test 7. A thickness of $7.6 \mathrm{~mm}$ was measured with a digital caliper, which is consistent with the 7 mm provided from Equation (2.3). Therefore, for a lamination of $35 \mathrm{~mm}$ in thickness, only $28 \mathrm{~mm}$ is actually converted into char before fall-off may occur. At a rate of 0.65 $\mathrm{mm} / \mathrm{min}$, fall-off would then occur shortly after $43 \mathrm{~min}$ as opposed to $54 \mathrm{~min}$ for an adhesive that could maintain its bonding capacity at temperatures associated with charring of wood (i.e. at least $300^{\circ} \mathrm{C}$ ). The time to fall-off of $43 \mathrm{~min}$ is also consistent with that suggested in the 2014 revised Chapter 8 of the Canadian CLT Handbook [24], while shorter than most times observed in this fire test series.

As such, should one try to evaluate the time for the char front to reach the half-lapped joint or the spline interface, an increase in the charring rate should be considered to reflect the heat delamination behaviour of currently used structural adhesives in CLT. For example, assuming a charring rate of $0.65 \mathrm{~mm} / \mathrm{min}$ and a half-lapped joint located at middepth of a 3-ply, 5-ply and 7ply (105, 175 and $245 \mathrm{~mm})$ CLT panels, the char front would be predicted to reach the joint interface at 81, 135 and 188 min respectively. During Fire Tests 2 and 9 conducted on 3-ply and 7-ply CLT specimens, the char front was recorded to reach the joint interface at 53 and $96 \mathrm{~min}$, which was significantly faster.

Another option for considering this delamination effect is by adapting the joint coefficient, similarly to the model provided in the CLT Handbook, 2014 edition [24]. Theoretically, the half-lapped joint is located at mid-depth and therefore, the time to reach the joint would be based on half of the CLT thickness, which would result in a joint 
coefficient of 0.50 in Equation (2.2). However, the Canadian model, as described in subsection 2.2.3, suggests a joint coefficient of 0.35 and a constant charring rate of 0.65 $\mathrm{mm} / \mathrm{min}$. This reduced joint coefficient results in an increased "effective" charring rate of $0.93 \mathrm{~mm} / \mathrm{min}$, which is much closer to the actual charring rate of CLT panels, as well as those observed in this study.

\subsubsection{Effect from heating of the self-tapping screws}

One of the assumptions for fire integrity failure in CLT panel-to-panel connections is related to localized heat transfer and charring of the wood surrounding the fasteners. Due to its high thermal conductivity, metallic fasteners would absorb heat quicker and conduct heat faster than that would exhibit the wood around its perimeter. Such potential heating and heat transfer may result in premature charring of the wood and reduction in the embedment and withdrawal strengths, resulting in connections no longer capable to securely join CLT panel together and potentially allowing the passage of flames or hot gases.

In the half-lapped joint configuration, the tips of the self-tapping screws reached their critical temperature of $538^{\circ} \mathrm{C}$ after 35,95 and $66 \mathrm{~min}$ for the 3-ply, 5-ply and 7-ply, respectively. The mid-length of the fasteners never reached temperatures greater than the char front $\left(300^{\circ} \mathrm{C}\right)$.

Only one test result is available for the internal spline configuration (Test 5). During this fire test, the tips of the self-tapping screws reached their critical temperature of $538^{\circ} \mathrm{C}$ 
after $79 \mathrm{~min}$. The mid-length of the fasteners never reached temperatures greater than the char front $\left(300^{\circ} \mathrm{C}\right)$.

For the single surface spline panel-to-panel joint detail, the tips of the self-tapping screws used in the 3-ply specimen reached their critical temperature at $52 \mathrm{~min}$, while the middle was still far from reaching $300^{\circ} \mathrm{C}$. There was no significant temperature rise measured with the 5-ply specimen, suggesting that no temperature rise would be recorded for a 7 ply.

Lastly, no temperature rise was recorded for the fasteners located at the top spline of the double surface spline configurations.

From the temperature profiles measured along the self-tapping screws in these fire tests, it appears that heat conduction within such small diameter fasteners is negligible and may not be a source of potential failure mode in CLT panel-to-panel joints.

\subsection{Summary}

To evaluate the fire integrity resistance of four (4) types of CLT panel-to-panel joint details, a series of ten (10) fire tests has been conducted on 3-ply, 5-ply and 7-ply CLT specimens.

The test results suggest that using an internal spline seems the least efficient joint detail when compared to the other joint configurations. Flame-through of the internal splines occurred where the plywood splines abut to each other. This demonstrates that if one chooses to use this configuration, it is of high importance that proper field installation of 
the internal splines be made so that fire integrity between the CLT panels is maintained. Another possibility would be to use tongue-and-grooved panel joints or scarf joints.

The half-lapped joint provided better fire integrity performance when compared to the internal spline detail. This kind of configuration requires little machining at the plant, as opposed to the internal spline while providing high in-plane resistance to lateral loads [47]. It is also rapid to install at the job site and does not require another product or system for connecting the CLT panels together (i.e. spline). Moreover, half-lapped joints may also be less sensitive to field installation and moisture shrinkage (i.e. gaps between CLT panels) when compared to other joint details. From its test results and ease of assembly, the use of half-lapped joint is recommended in CLT construction.

Although limited fire integrity failures were actually reached for the assemblies using surface splines, they seem to be the best CLT panel-to-panel joint detail, provided the panels are tightly fitted together (i.e. no gaps). The spline positioned away from the fireexposed side allows for an efficient "last line of defense" for limiting flames and hot gases to flow through.

Lastly, the test results suggest that small diameter fasteners such as the self-tapping screws used in this study are a negligible source of heat conduction within CLT panels and may be neglected in calculation models. 


\section{Finite Element Heat Transfer Model}

Among the objectives of this study, two of them were to develop a finite element heat transfer model (FEM) and a coupled thermal-structural model to predict the integrity fireresistance of CLT assemblies based on a numerical approach. Being able to predict the fire integrity resistance of CLT panel-to-panel joints provides benchmarking as to what panel-to-panel joint configuration provides better fire-resistance and optimizing the joint detail to achieve the best balance between structural resistance, ease of assembly and fireresistance.

Various options are available for developing such models. Commercially available finite element software packages can be used, where the heat transfer and structural capacity are conducted using various parameters and sub-routines. These software packages are typically quite accurate, but may also be quite challenging in regards to convergence of models and somewhat cumbersome for designers due to long computational time. Werther et al. [82] recently conducted a parametric study on modeling structural timber using different finite element software packages. The authors studied various parameters of three software packages (ANSYS, SAFIR and ABAQUS), including the effects of one-dimensional and two-dimensional heat transfer analysis, mesh sizes, time steps and thermal properties. The authors concluded that the programs give comparable results to each other.

Figure 4.1 illustrates the various steps that need to be considered when assessing the structural response of an element exposed to fire. As detailed by Buchanan [37], this 
process involves three fundamental components: 1) a fire model, 2) a heat transfer model and 3) a structural model. The first two components are detailed in this Chapter, while the structural model is detailed in Chapter 5.

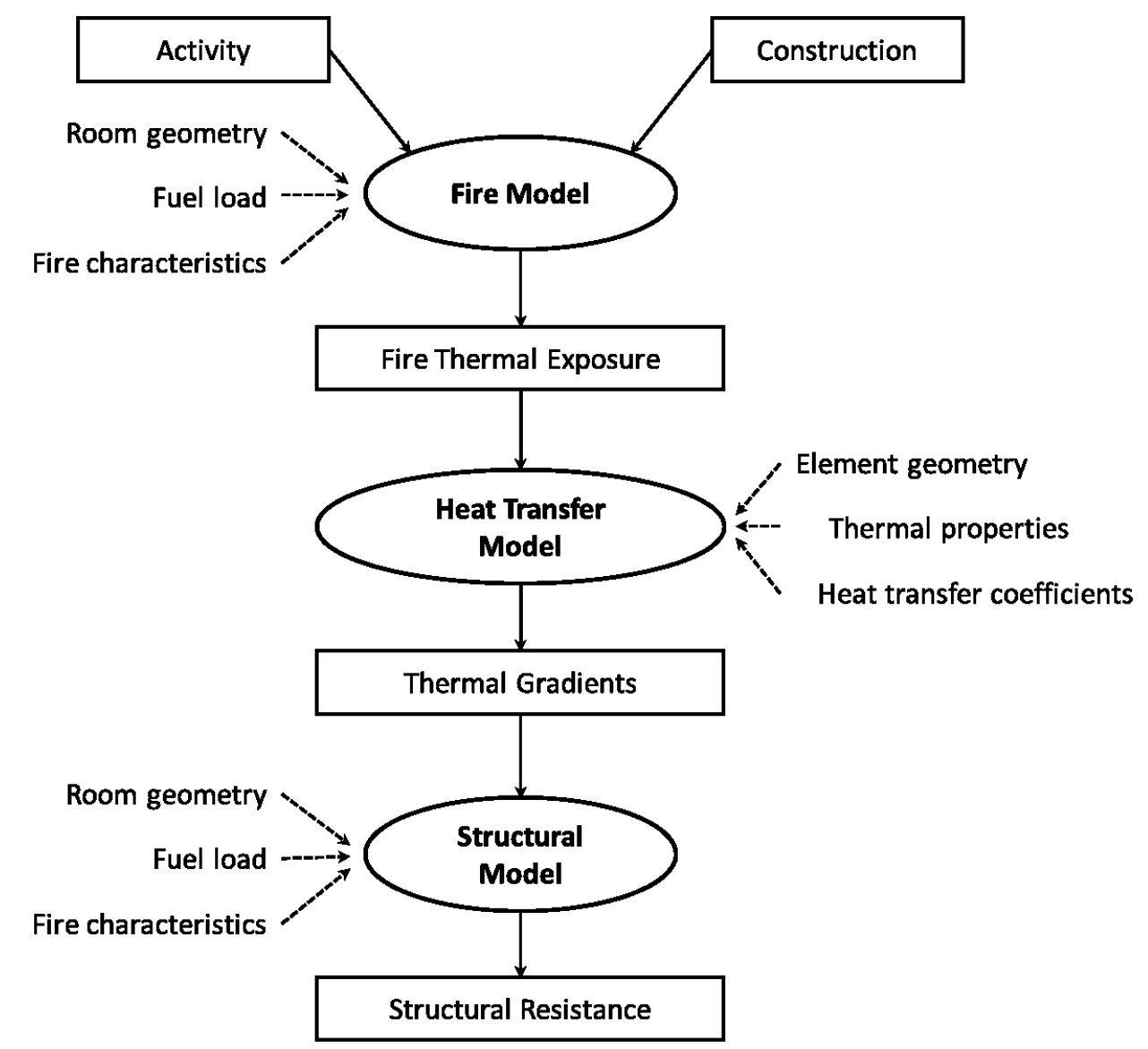

Figure 4.1 - Flow chart for calculation structural fire-resistance (adapted from [37])

\subsection{Fire Model}

The fire model may consist of a selected time-temperature curve such as a standard fire test, a measured time-temperature curve from real fire or a parametric fire curve. 
The standard CAN/ULC S101 time-temperature curve, as defined in Equation (2.1), is used in the FEM.

\subsection{Transient Heat Transfer Model}

After selecting the fire model, a heat transfer analysis needs to be done to evaluate a single maximum temperature or a temperature profile within a given heated element, at any given time of the fire exposure. As explained by Incropera et al. [83], heat transfer is a thermal energy in transit due to a spatial temperature difference. As such, whenever a temperature difference exists in a medium, heat transfer will occur.

In this study, a finite element model was developed in ANSYS version 15.0 [84] to replicate a transient thermal regime as that found in a standard fire-resistance test. The Transient Thermal Analysis System model from ANSYS was used. The software package allows for solving various types of applications, namely structural, thermal and fluid dynamics. Typically, when conducting a thermal and a structural finite element analysis, all material properties and heat transfer conditions are to be provided by the user. These properties may be temperature-dependent, but may also be directional-dependent (as with timber, an anisotropic material).

For this study, a three-dimensional (3D) heat transfer model was developed that considered heat transfer within and between the different materials, namely the CLT, the self-tapping screws and, when applicable, the plywood splines. 
Conduction is the primary heat transfer mode occurring across a medium and satisfies Fourier's law of heat conduction. Transient heat transfer within a solid material can be numerically expressed by the 3D partial differential equation shown in Equation (4.1).

$$
\frac{\partial}{\partial x}\left(k_{x} \frac{\partial T}{\partial x}\right)+\frac{\partial}{\partial y}\left(k_{y} \frac{\partial T}{\partial y}\right)+\frac{\partial}{\partial z}\left(k_{z} \frac{\partial T}{\partial z}\right)+\dot{Q}=\rho c \frac{\partial T}{\partial t}
$$

where $T$ is the temperature $(\mathrm{K}), k_{x, y, z}$ are thermal conductivities in $\mathrm{x}, \mathrm{y}, \mathrm{z}$ directions $\left(\mathrm{W} \cdot \mathrm{m}^{-1} \cdot \mathrm{K}^{-1}\right), \dot{Q}$ is the internally generated heat by the rate of heat consumption per unit volume due to chemical reaction (pyrolysis of wood) and the heat to evaporate water per unit volume $\left(\mathrm{W} / \mathrm{m}^{3}\right), \rho$ is the density $\left(\mathrm{kg} / \mathrm{m}^{3}\right), c$ is the specific heat $\left(\mathrm{J} \cdot \mathrm{kg}^{-1} \cdot \mathrm{K}^{-1}\right)$, and $t$ is the time (sec). König \& Walleij [67] reported that the heat of reaction during pyrolysis can be neglected in heat transfer calculations. In an attempt to lower computational time, the internally generated heat $(\dot{Q})$ from Equation (4.1) has therefore been neglected in this research. Steel is a non-combustible and isotropic material $\left(k_{x}=k_{y}=k_{z}\right)$ and thus cannot generate heat at elevated temperatures (but can conduct heat to other surrounding elements). Steel contribution to $\dot{Q}$ has thereby also been ignored.

In the case of surfaces exposed to fire, heat is transferred from the emitting source through convection and thermal radiation. Convection typically refers to heat transfer occurring between a surface and a moving fluid when they are at different temperatures. Thermal radiation occurs when surfaces of finite temperatures emit energy in the form of electromagnetic waves. 
The net emitted heat flux impinging on a surface exposed to fire is the sum of the emitted heat fluxes by convection and thermal radiation, as per Equation (4.2).

$$
q^{\prime \prime}=q_{c o n v}^{\prime \prime}+q_{\text {rad }}^{\prime \prime}=\alpha_{c}\left(T_{g}-T_{S}\right)+\Phi \varepsilon_{m} \varepsilon_{f} \sigma\left(T_{g}^{4}-T_{S}^{4}\right)
$$

Where $\alpha_{c}$ is the convection heat transfer coefficient, $T_{g}$ is the heating gas temperature as per Equation (2.1), $T_{s}$ is the receiving surface temperature, $\Phi$ is the view factor, $\varepsilon_{\mathrm{m}}$ is the surface material emissivity, $\varepsilon_{\mathrm{f}}$ is the fire source emissivity $\left(\varepsilon_{\mathrm{m}}\right.$ and $\varepsilon_{\mathrm{f}}$ are no greater than unity) and $\sigma$ is the Stefan-Boltzmann constant $\left(5.67 \times 10^{-8} \mathrm{~W} \cdot \mathrm{m}^{-2} \cdot \mathrm{K}^{-4}\right)$. Eurocode 1: Part 1-2 and Eurocode 5: Part 1-2 suggest that, in the case of a standard time-temperature curve exposure, the convective heat transfer coefficient, view factor, wood surface emissivity and fire emissivity be taken as $25 \mathrm{~W} \cdot \mathrm{m}^{-2} \cdot \mathrm{K}^{-1}, 1.0,0.8$ and 1.0 respectively, which have been used in this study.

The temperature gradient generated by the heat transfer model depends on the convective and radiative heat transfer coefficients at the exposed surface as well as the heat conduction within the element. Therefore, should a material have temperature-dependent thermal and mechanical properties, the heat transfer model needs to be accurate in predicting the temperature profile within the element by considering the proper properties.

\subsection{Thermal Properties}

Peng [85] reported that modeling fire behaviour of a connection involved three heat transfer processes: 1) heat conduction within the specimen, 2) convective and radiative 
heat transfer from the fire to the specimen boundary and 3) heat exchange between members. A three-dimensional heat transfer model can therefore be challenging due to the non-homogeneity of the connection, temperature-dependent material properties, different materials (char is considered as a different material to wood), and potential air gaps between connecting members.

Lastly, thermal properties available from various sources may provide overly conservative or unsafe design predictions if they are not calibrated such that the predictions fit well to the test data to test data [67]. Such calibration is of greater importance when computer models do not consider mass transfer, internal energy released due to pyrolysis and degradation of material (e.g. cracking of the charred wood increasing heat transfer on the charred layer).

Table 4.1 lists the thermal properties used in this research study, which accounts for heat delamination of the adhesive. They have been adjusted from those of Eurocode 5: part 12, listed in Table 2.10, which assumes heat transfer through solid lumber and no effect due to heat delamination of adhesive. For the panel-to-panel joints requiring a plywood spline, its thermal properties were taken from Benichou et al. [66]. Validation of the heat transfer model is presented in subsection 4.6.

The thermal properties used for the carbon-steel self-tapping screws as those given in Eurocode 3: Part 1-2, as detailed in subsection 2.5.2.2. 
Table 4.1 - Thermal properties used in FEM for E1 Stress Grade CLT panels

\begin{tabular}{|c|c|c|c|c|}
\hline \multirow[b]{2}{*}{$\begin{array}{c}\text { Temperature } \\
\left({ }^{\circ} \mathrm{C}\right)\end{array}$} & \multicolumn{2}{|c|}{ Density $\left(\mathrm{kg} \mathrm{m}^{-3}\right)$ at $12 \% \mathrm{RH}$} & \multirow{2}{*}{$\begin{array}{c}\text { Thermal } \\
\text { Conductivity } \\
\left(\mathbf{W} \mathbf{~ m}^{-1} \mathbf{K}^{-1}\right)\end{array}$} & \multirow{2}{*}{$\begin{array}{c}\text { Specific } \\
\text { Heat } \\
\left(\mathrm{J} \mathrm{kg}^{-1} \mathrm{~K}^{-1}\right)\end{array}$} \\
\hline & MSR 1950fb & SPF No.3 & & \\
\hline 20 & 582 & 470 & 0.12 & 1530 \\
\hline 99 & 582 & 470 & - & 1770 \\
\hline 100 & 582 & 470 & - & 13600 \\
\hline 120 & 520 & 420 & - & 13500 \\
\hline 121 & 520 & 420 & - & 2120 \\
\hline 200 & 520 & 420 & 0.15 & 2000 \\
\hline 250 & 484 & 391 & - & 1620 \\
\hline 300 & 395 & 319 & - & 710 \\
\hline 350 & 270 & 218 & 0.07 & 850 \\
\hline 400 & 198 & 160 & - & 1000 \\
\hline 500 & - & - & 0.12 & 1200 \\
\hline 600 & 146 & 118 & - & 1400 \\
\hline 800 & 135 & 109 & 0.15 & 1650 \\
\hline 1000 & - & - & 3.5 & 1650 \\
\hline 1200 & 0.01 & 0.01 & 5.0 & 1650 \\
\hline
\end{tabular}

\subsection{Geometry}

The geometries used in this study were those found in an area in the vicinity to the fasteners driven into solid elements replicating those found in an E1 stress grade CLT. Figure 4.2 shows an example of a geometry used to model 3-ply CLT elements and a self-tapping screw. The CLT sample geometry consisted of a $50 \mathrm{~mm}$ diameter cylinder composed of wood laminations of $35 \mathrm{~mm}$ in thickness. The dimensions of the ASSY® 3.0 Ecofast self-tapping screw were as detailed in Table 2.7. In order to reduce computational time, the entire geometry was reduced to one-fourth (quarter) due to symmetry of the geometry. 


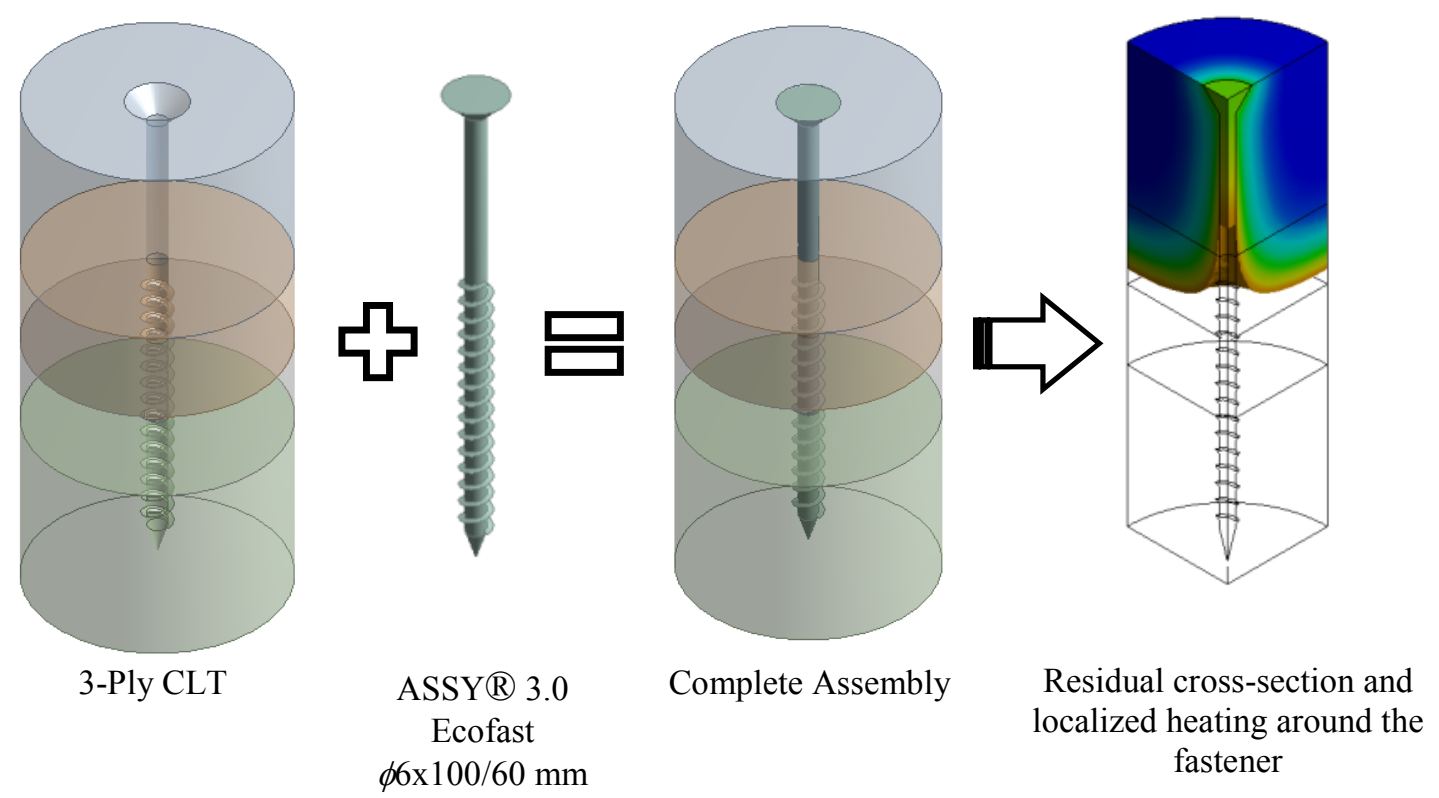

Figure 4.2 - Example of the geometry used in the FEM

\subsection{Meshing}

Meshing is a very important aspect in finite element modeling. Meshing serves two (2) functions: 1) representing the geometry of the model and 2) approximating the solution over each element of the mesh in attempt to provide a good representation of the solution over the entire model [86].

Moreover, shared topologies were used throughout the process to harmonize meshing and facilitate convergence within the various parts of the FEM. 


\subsection{Validation of Heat Transfer FEM}

\subsubsection{Intermediate-Scale Fire-Resistance Tests}

The heat transfer model is compared to the temperature data recorded during this fire test series. Figure 4.3 to Figure 4.5 illustrate a comparison between the intermediate-scale fire tests and the FEM at the $1^{\text {st }}, 2^{\text {nd }}$ and $3^{\text {rd }}$ gluelines $(35,70$ and $105 \mathrm{~mm})$. While the curves show variances in temperatures above $300^{\circ} \mathrm{C}$, the most important range is from 0 to $300^{\circ} \mathrm{C}$ (up to the char front, typically determined at the $300^{\circ} \mathrm{C}$ isotherm), especially from a structural fire engineering point of view. It can be observed that, while the overall trends are reasonable, there are large variations in the times to reach the gluelines.

During the fire tests, the $1^{\text {st }}$ glueline was reached between 43 and 79 min, a 36 min time interval. The $2^{\text {nd }}$ glueline was recorded to be reached between 86 and $115 \mathrm{~min}$, representing a 29 min interval. Lastly, the $3^{\text {rd }}$ glueline was reached between 143 and 167 min, an interval of $24 \mathrm{~min}$. The significant interval at the $1^{\text {st }}$ glueline may be due to the large variability in the furnace temperature during the beginning of the tests. As was described in Subsections 3.4 to 3.13, the furnace temperature was much closer to the standard time-temperature curve after 60 min into the tests. The $\mathrm{FEM}$ predicts the $300^{\circ} \mathrm{C}$ isotherm to reach the gluelines at 63,111 and $166 \mathrm{~min}$, which all fall within the intervals recorded in this study. 


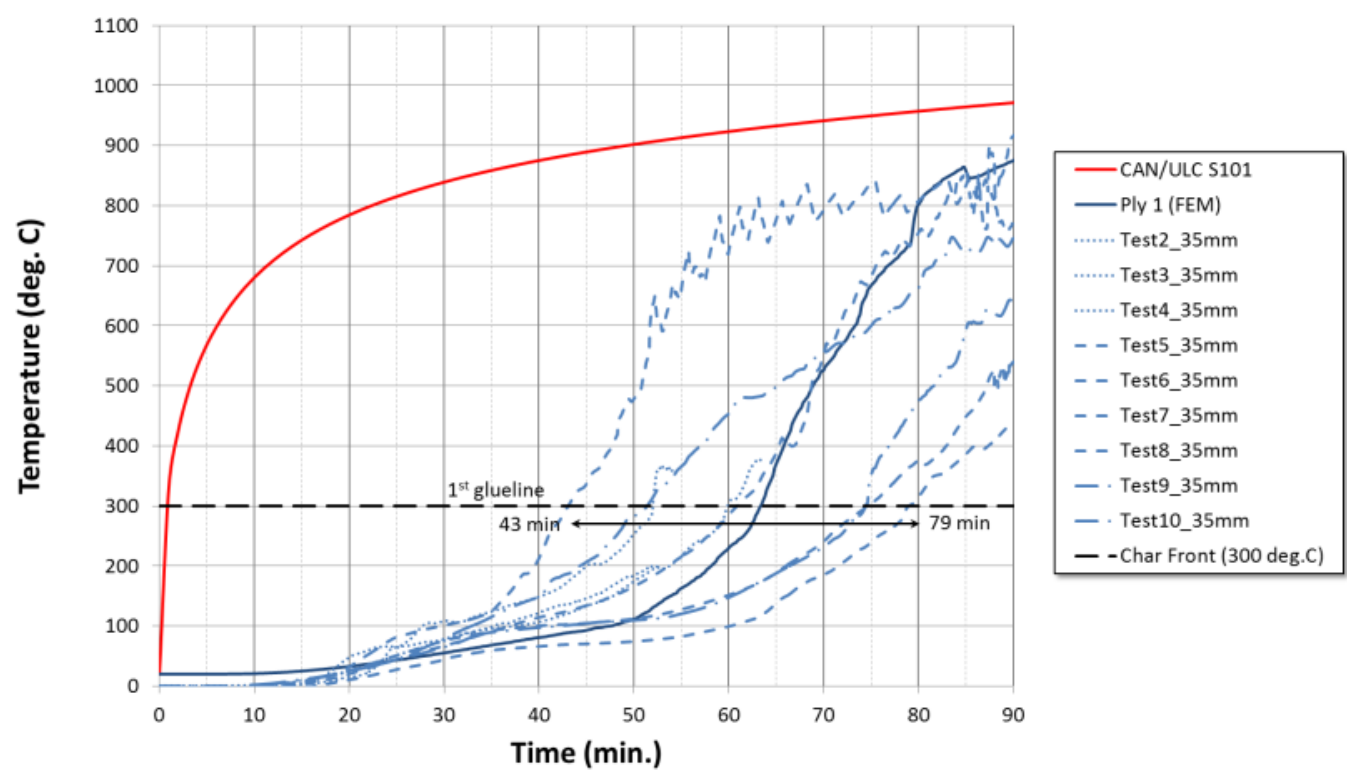

Figure 4.3 - Temperature profile - FEM compared to fire tests (at $35 \mathrm{~mm}$ )

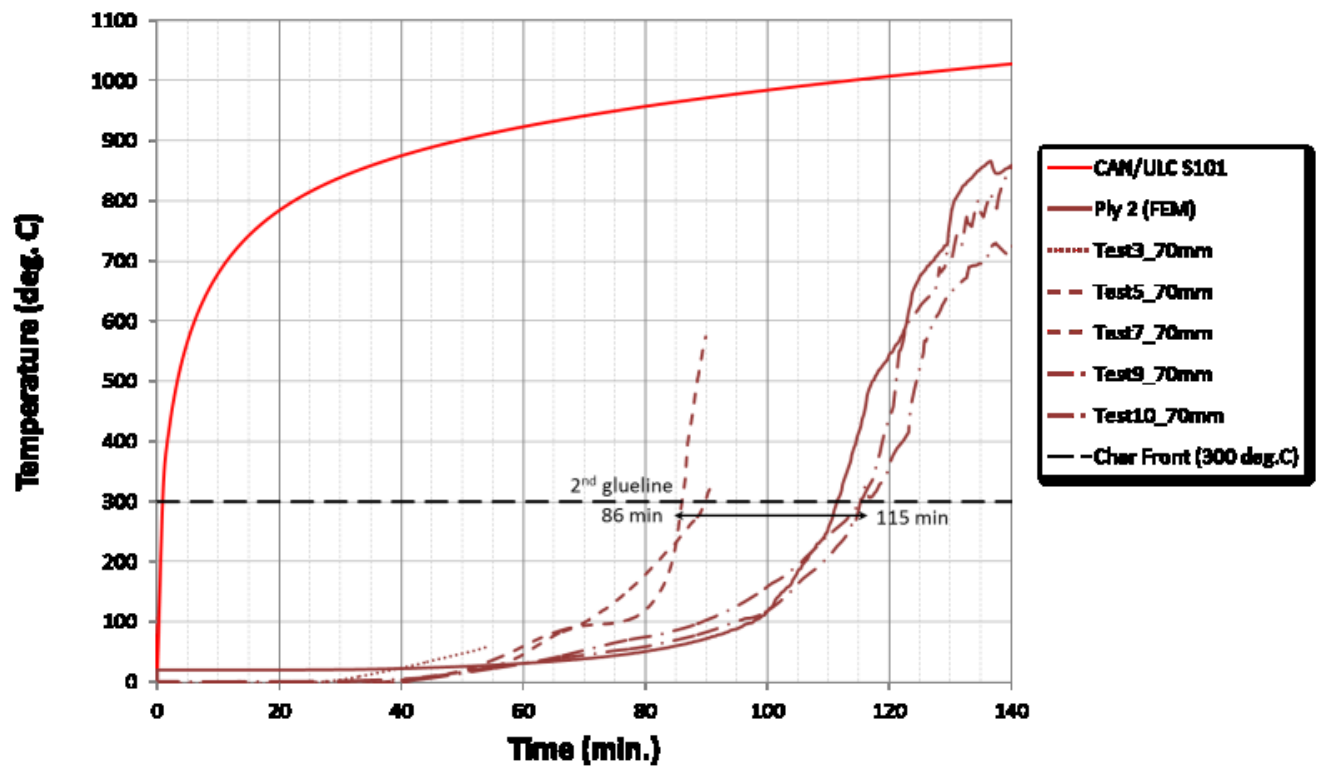

Figure 4.4 - Temperature profile - FEM compared to fire tests (at $70 \mathrm{~mm}$ ) 


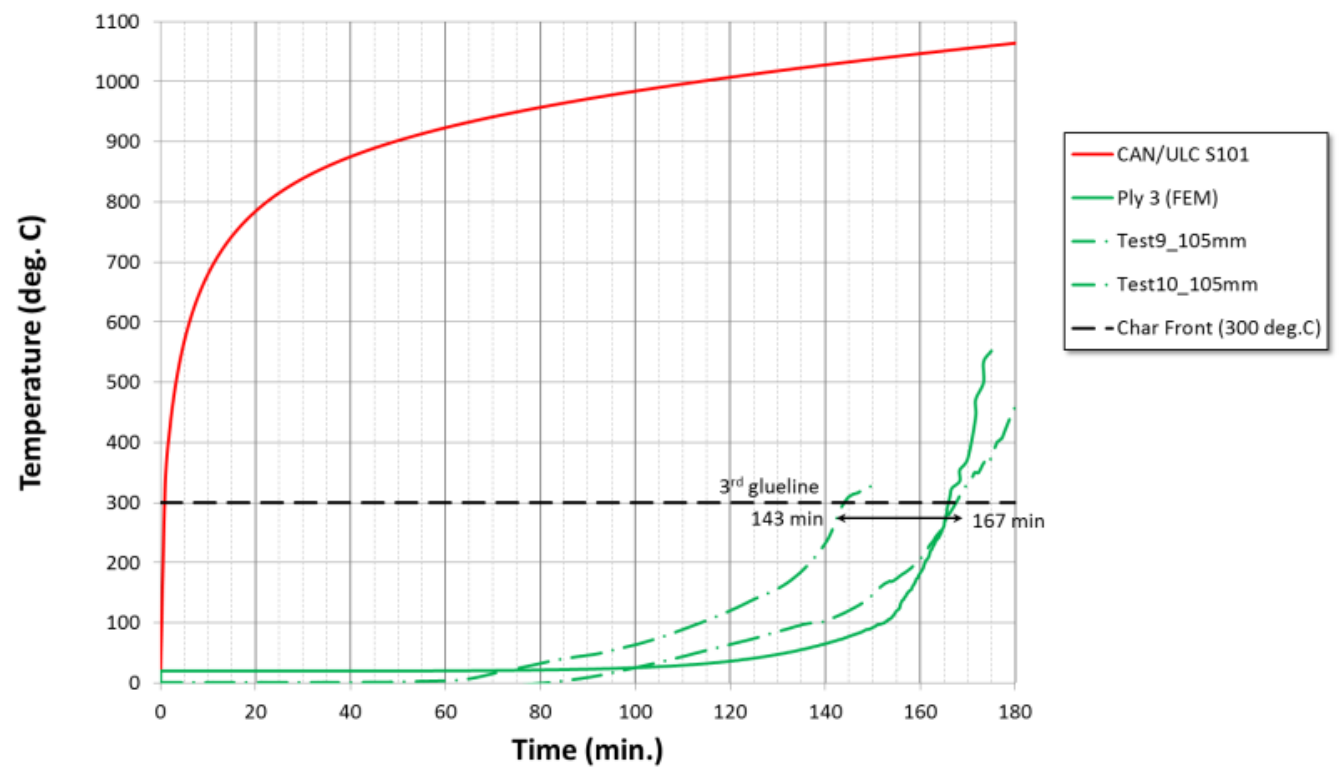

Figure 4.5 - Temperature profile - FEM compared to fire tests (at $105 \mathrm{~mm}$ )

\subsubsection{Full-Scale Fire-Resistance Tests}

Figure 4.6 illustrates the temperature profiles predicted from the heat transfer FEM compared to full-scale fire-resistance tests on CLT assemblies [10, 87]. Figure 4.7 shows the graphic visualization of the residual cross-section at various time steps.

It can be observed that the FEM accurately predicts temperature profiles for standard fire exposure up to $180 \mathrm{~min}$ (3 hours). According to test data from Osborne et al. [10] on CLT fully exposed to the standard fire time-temperature curve, the $300^{\circ} \mathrm{C}$ isotherm reaches gluelines located at 35, 70 and $105 \mathrm{~mm}$ in 62 to $64 \mathrm{~min}$ (Tests $1 \mathrm{~F}$ and $5 \mathrm{~F}$ respectively), at $106 \mathrm{~min}$ (Test 5F) and $161 \mathrm{~min}$ (Test 5F) respectively. During a recent fire-resistance test on a composite CLT-concrete floor assembly, Osborne [87] reported that gluelines 
located at 35,70 and $105 \mathrm{~mm}$ reached $300^{\circ} \mathrm{C}$ at 67,106 and $154 \mathrm{~min}$. The FEM predicts the $300^{\circ} \mathrm{C}$ isotherm to reach the gluelines at 63,111 and $166 \mathrm{~min}$.

The FEM predictions are within $7.5 \%$ accuracy when compared to full-scale test data and fire exposure up to 3 hours. The furnace temperature in these full-scale fire-resistance tests were much closer to the standard time-temperature curve throughout the entire duration of the tests, allowing for a much more accurate comparison and validation of the FEM.

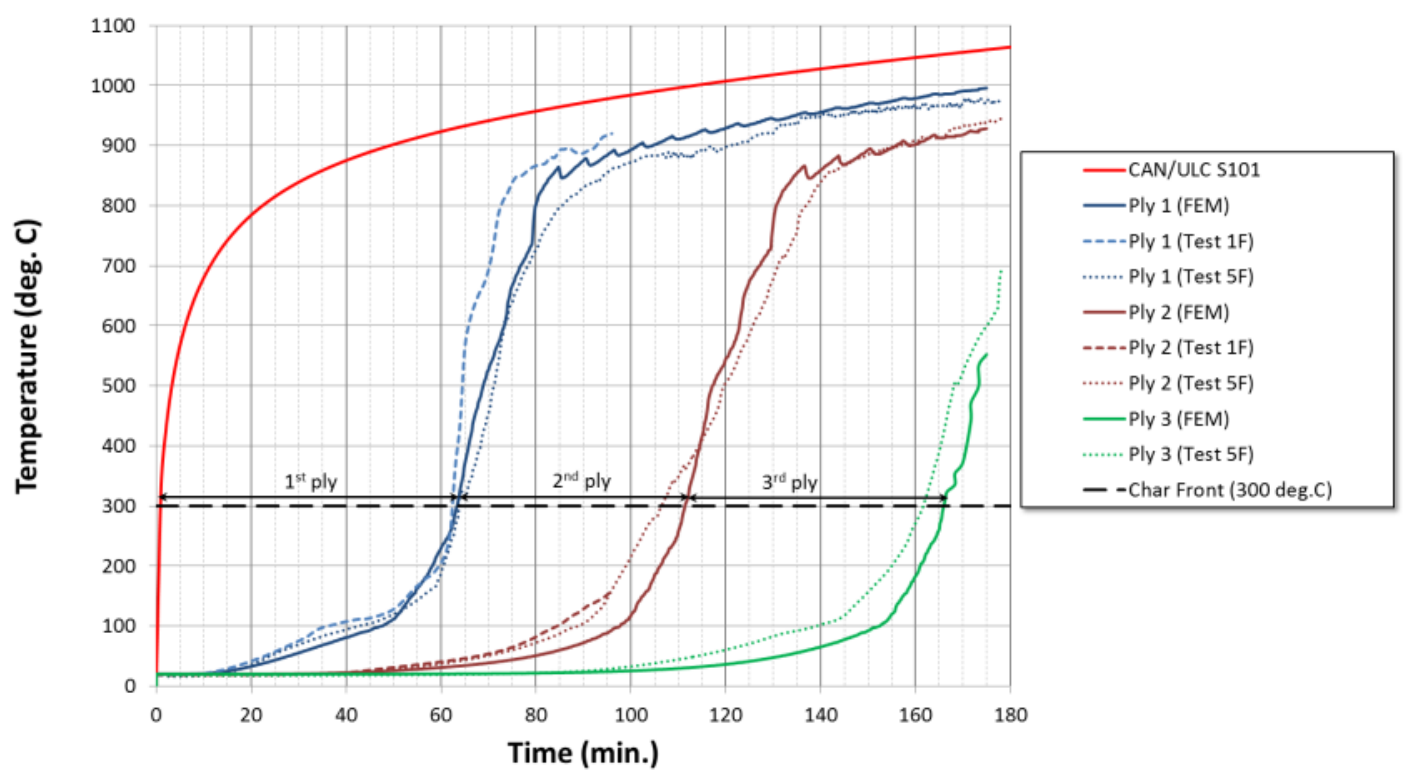

Figure 4.6 - Temperature profile - Comparison between FEM and test data from [10] 


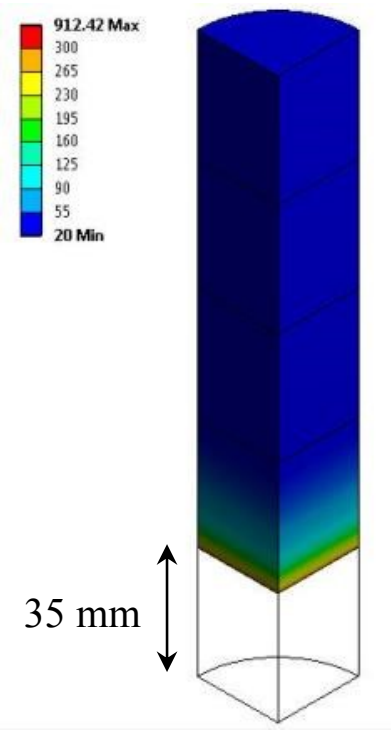

a) FEM at $63 \mathrm{~min}$

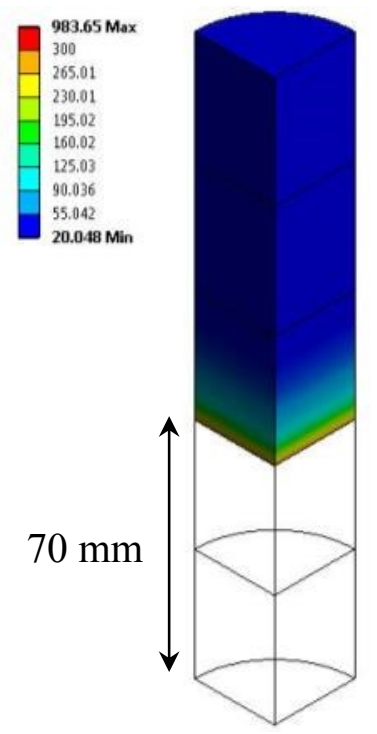

b) FEM at $111 \mathrm{~min}$

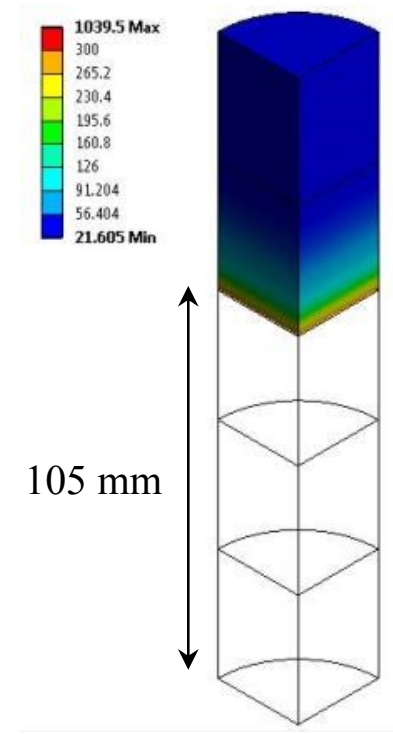

c) FEM at $166 \mathrm{~min}$

Figure 4.7-Visualization of the FEM temperature profiles

\subsubsection{Charring Rate from FEM}

The charring rates measured in this fire test series, as detailed in subsection 3.14.3, are $0.57,0.88$ and $0.65 \mathrm{~mm} / \mathrm{min}$, for the $1^{\text {st }}, 2^{\text {nd }}$ and $3^{\text {rd }}$ layers respectively.

The charring rates measured from Osborne et al. [10], as detailed in subsection 4.6.2, are $0.56,0.81$ and $0.64 \mathrm{~mm} / \mathrm{min}$, for the $1^{\text {st }}, 2^{\text {nd }}$ and $3^{\text {rd }}$ layers respectively and the average charring rates from the $1^{\text {st }}$ to the $3^{\text {rd }}$ glueline is $0.71 \mathrm{~mm} / \mathrm{min}$. Similar results were obtained from Osborne [87] on a CLT-concrete composite floor assembly, that is 0.52 , 0.90 and $0.73 \mathrm{~mm} / \mathrm{min}$ for the $1^{\text {st }}, 2^{\text {nd }}$ and $3^{\text {rd }}$ lamination, respectively.

The FEM predicts that the $300^{\circ} \mathrm{C}$ isotherm to reach the gluelines at 63,111 and $166 \mathrm{~min}$. The resulting charring rates for the $1^{\text {st }}, 2^{\text {nd }}$ and $3^{\text {rd }}$ laminations are $0.56,0.73$ and 0.64 
$\mathrm{mm} / \mathrm{min}$, respectively, which is somewhat close to those measured during the intermediate- and full-scale fire tests. Table 4.2 summarizes the resulting charring rates.

Table 4.2 - Charring rates from FEM compared to test data

\begin{tabular}{|c|c|c|c|c|c|}
\hline \multirow{3}{*}{$\begin{array}{c}\text { Layer } \\
\text { (35 mm } \\
\text { thickness) }\end{array}$} & \multirow{3}{*}{$\begin{array}{c}\text { Lumber } \\
\text { board }\end{array}$} & \multicolumn{4}{|c|}{ Charring Rate (mm/min) } \\
\hline & & \multirow{2}{*}{$\begin{array}{c}\text { Intermediate-Scale } \\
\text { Fire Tests }\end{array}$} & \multicolumn{2}{|c|}{ Full-Scale Fire Tests } & \multirow{2}{*}{ FEM } \\
\hline & & & [10] & [87] & \\
\hline $1^{\mathrm{st}}$ & MSR $1950 f_{b}$ & 0.57 & 0.56 & 0.52 & 0.56 \\
\hline $2^{\text {nd }}$ & SPF No. 3 & 0.88 & 0.81 & 0.90 & 0.73 \\
\hline $3^{\text {rd }}$ & MSR $1950 \mathrm{f}_{\mathrm{b}}$ & 0.65 & 0.64 & 0.73 & 0.64 \\
\hline
\end{tabular}

\subsection{Sensitivity Analysis of the FEM}

As with every computer model, a sensitivity analysis of the main variables and conditions needs to be performed to assess its accuracy, measures of errors and convergence of the solutions. The following subsections provide some discussion on the potential impacts on the heat transfer profiles by using various meshing and with simplifying the contact region between the self-tapping screw and the CLT (i.e. neglecting the threaded portion of the shank). It also discusses the effects of the wood thermal properties and the net emitted heat flux on the progression of the char front as function of time.

\subsubsection{Meshing}

Proper meshing of the geometry is fundamental for solving numerical problems using finite element method. To evaluate the level of accuracy, facilitate convergence and reduce computational time, three (3) meshing were evaluated: 1) fine, 2) medium, and 3) coarse. The "multizone" mesh method was used to generate the maximum of 
hexahedrons, as shown in Figure 4.8. This method provides automatic decomposition of geometry into mapped regions, of which all regions are meshed with a pure hexahedral mesh, when possible.

29427 nodes / 6300 elements

CPU Time: $6725 \mathrm{sec}$.

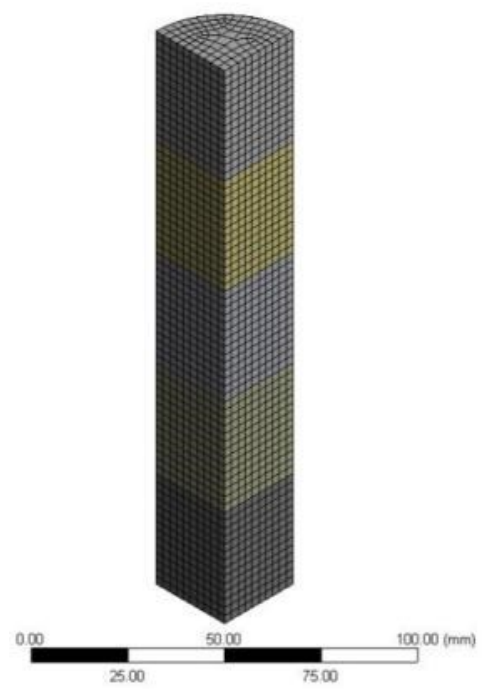

a) Fine Meshing
6639 nodes / 1280 elements

CPU Time: $1581 \mathrm{sec}$.

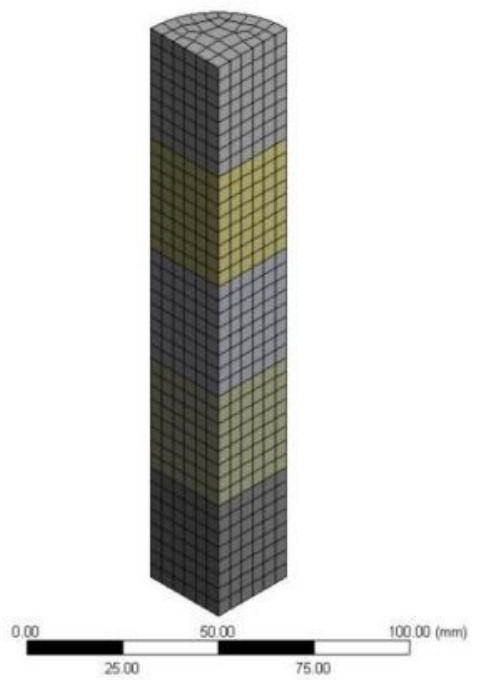

b) Medium Meshing
1326 nodes / 220 elements

CPU Tine: $772 \mathrm{sec}$.

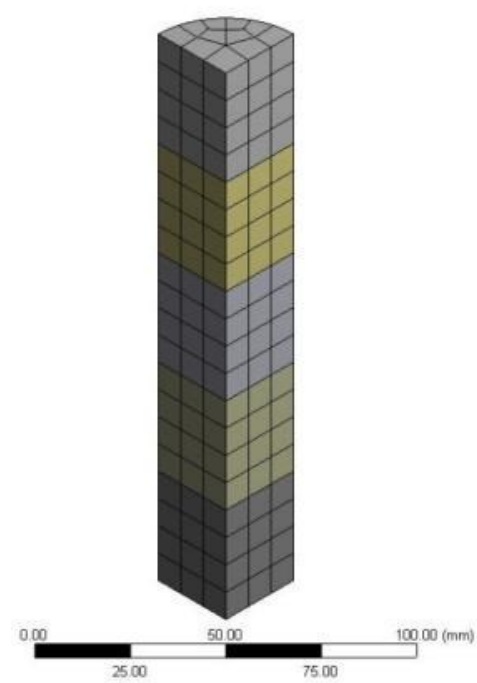

c) Coarse Meshing

Figure 4.8 - Various meshing evaluated for sensitivity analysis

It can be seen from the temperature profiles in Figure 4.9 that both the fine and medium meshing resulted in very close profiles, while the coarse meshing was significantly offset when compared to the other two meshing. Moreover, using the medium meshing significantly reduced the computational time when compared to the fine meshing. As it was previously shown in Figure 4.6, the FEM developed in this study used medium meshing. 


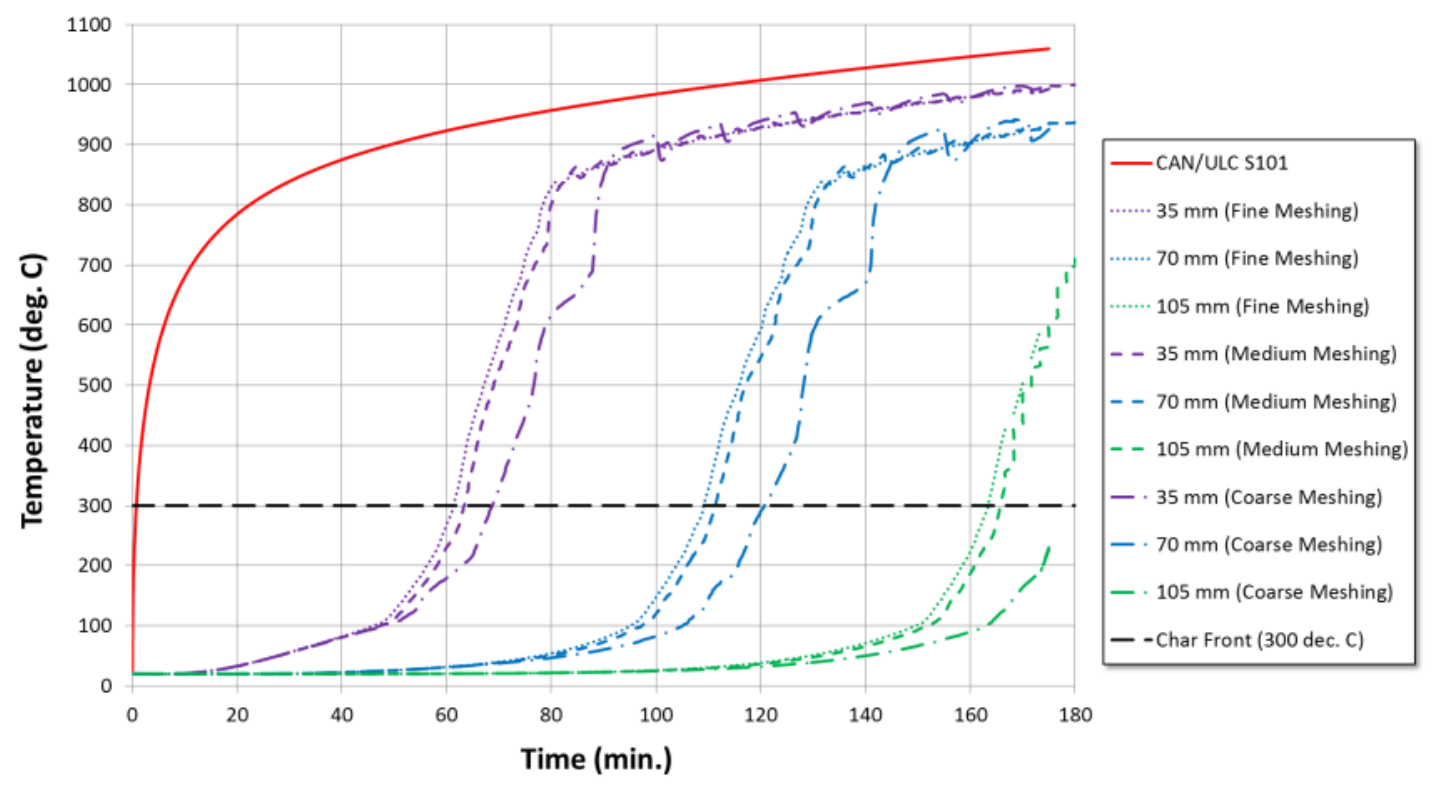

Figure 4.9 - Temperature profiles using 3 various meshing sizes

\subsubsection{Self-Tapping Screw Threaded Shank}

Due to the threaded portion of the self-tapping screw, it was difficult to have a complete meshing with hexahedrons throughout the elements (Figure 4.10). When neglecting the threaded portion of the shank (i.e. modeling a cylindrical shank only), the model resulted in fewer elements and nodes to solve, which significantly reduced the computational time due the greater quantity of hexahedrons.

It was found that the FEM predicted insignificant differences between the temperatures profiles considering the threaded portion of the self-tapping screw to those neglecting the threaded portion (Figure 4.11). 
Since the computational time was significantly reduced when neglecting the threaded portion of the shank (see Figure 4.10 for an example of computational time), it was decided to indeed neglect them during the meshing process.

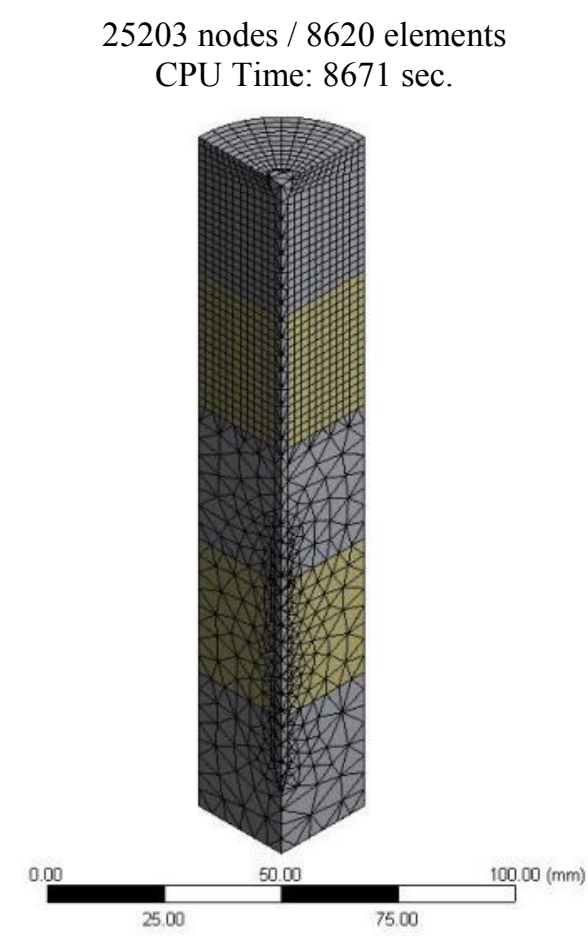

a) With threaded shank

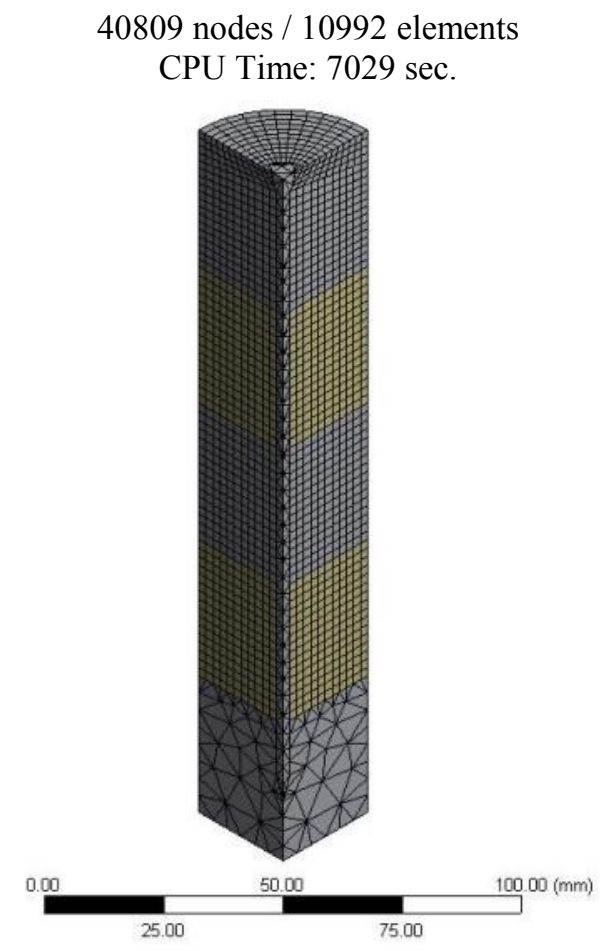

b) Without threaded shank

Figure 4.10 - Meshing of the self-tapping screw (with and without threaded shank) 


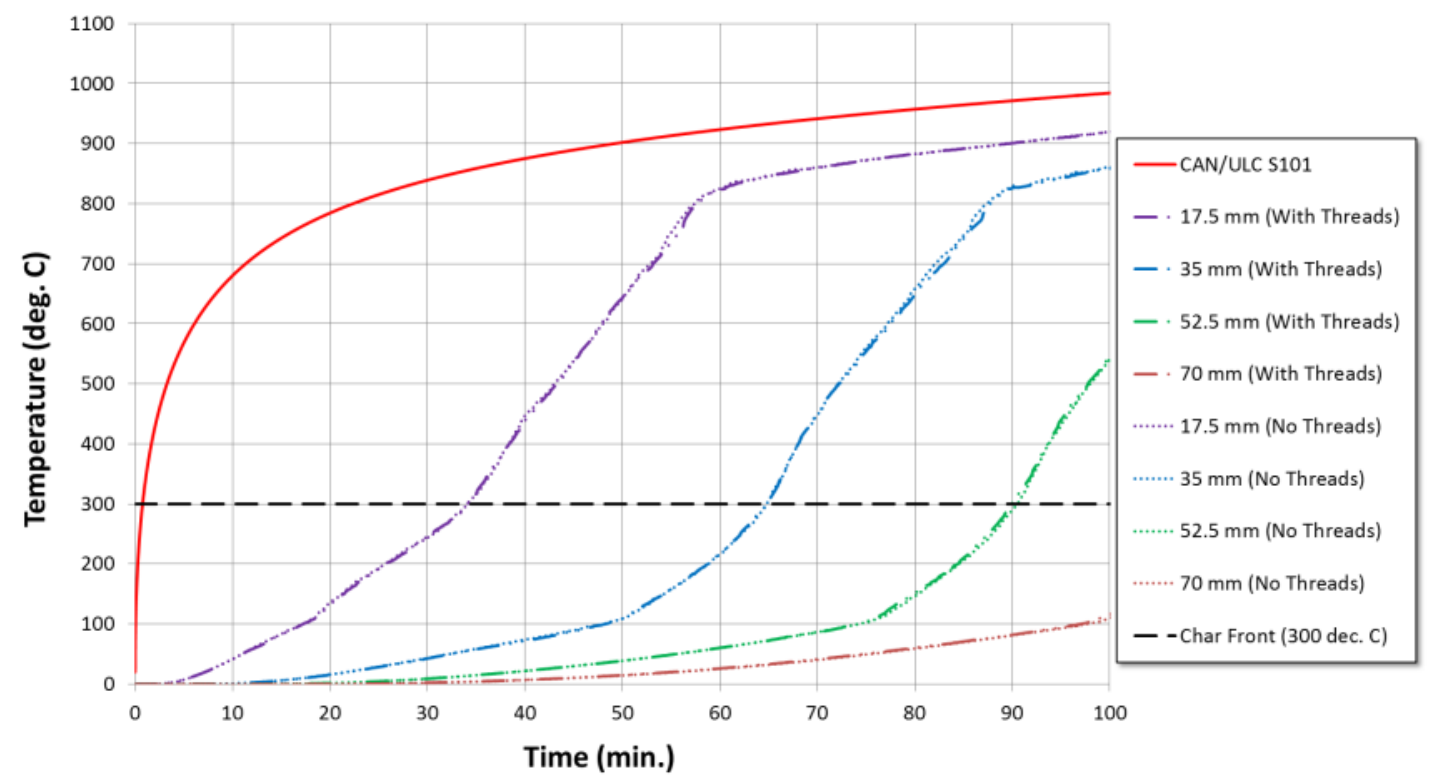

Figure 4.11 - Temperature profiles with and without the threaded shank

\subsubsection{Wood Thermal Properties}

As discussed in subsection 2.5, numerical models used to assess heat transfer through materials require thermal properties to be calibrated such that the predictions are fitted to the test data. Table 2.10 listed some of the thermal properties, including those provided in one of the most recognized and used wood standards: Eurocode 5: Part 1-2 [27]. The properties from these models are derived and calibrated for solid wood and glued wood products in which the adhesive does not exhibit heat delamination.

Due to the observations of heat delamination in CLT fire-resistance tests, resulting in an increased charring rate when compared to solid wood, it seemed obvious to evaluate the predicted temperature profiles obtained from other models for their suitability and accuracy when compared to test data. Figure 4.12 illustrates the temperature profiles 
generated from the FEM using various sources of thermal properties, namely those from Table 2.10, and those from Table 4.1. The FEM using the thermal properties from Table 4.1 has already been demonstrated as accurate when compared to intermediate- and fullscale fire-resistance test data (refer to subsection 4.6).

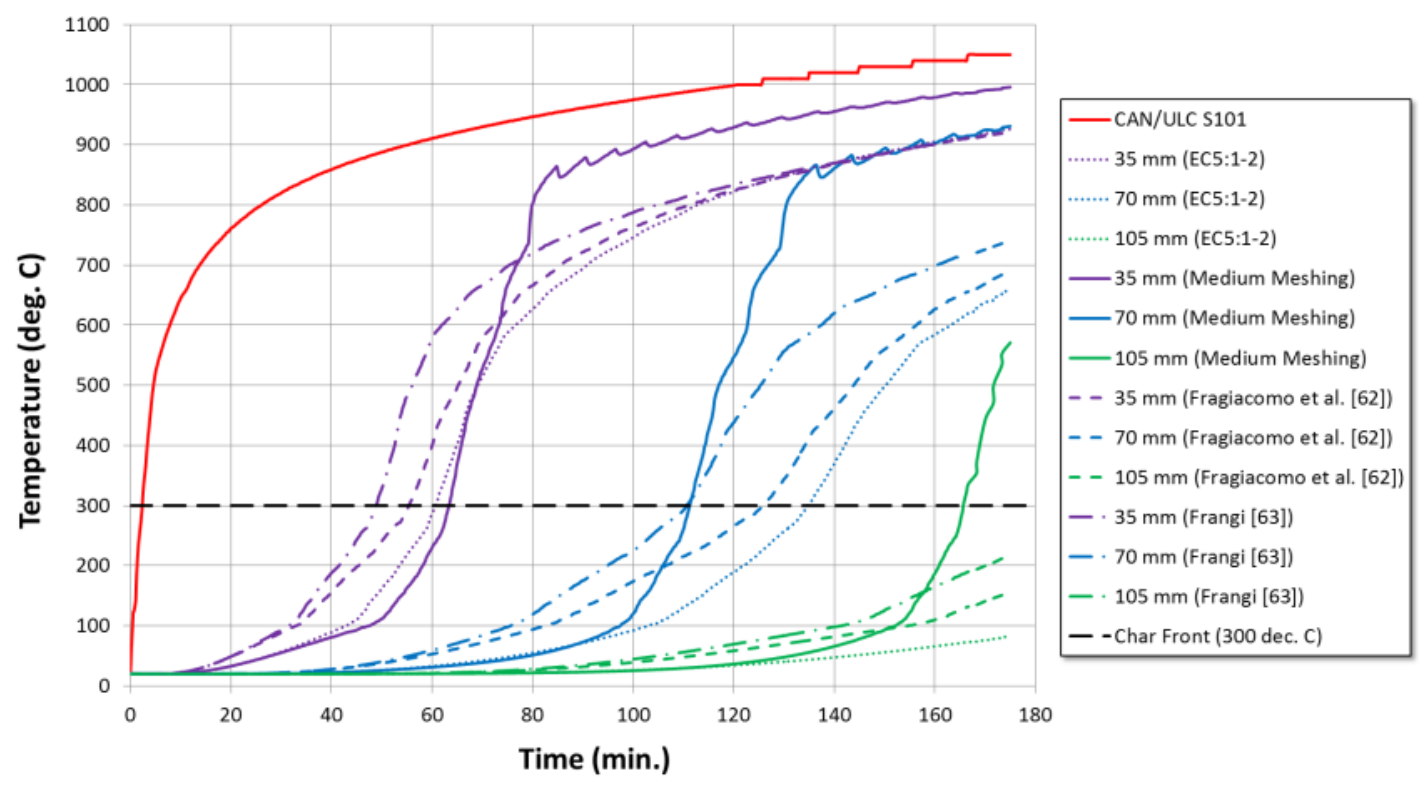

Figure 4.12 - Temperature profiles with various sources for wood thermal properties

From the plots shown in Figure 4.12, the $1^{\text {st }}$ glueline $(35 \mathrm{~mm})$ would be reached between 48 and $61 \mathrm{~min}$, of which the upper limit is close to the 63 min predicted from the current FEM and full-scale fire-resistance test data $(62,64$ and $67 \mathrm{~min})$. The $2^{\text {nd }}$ glueline $(70 \mathrm{~mm})$ is predicted to be reached between 110 and $134 \mathrm{~min}$. The lower limit is close to the 111 min predicted by the current FEM, while greater than the 106 min of the full-scale fireresistance tests. Lastly, none of the other models predicted the $3^{\text {rd }}$ glueline to be reached, 
while the current FEM predicted a time of $166 \mathrm{~min}$, which is close to that observed during full-scale fire-resistance tests (161 and $154 \mathrm{~min})$.

Moreover, it can be seen that the overall trend of the heat transfer is not quite similar. The temperature profiles from the current FEM significantly increase when the glueline approaches more or less $220^{\circ} \mathrm{C}$, while the other models follow relatively smoother slopes which result in significant differences in the charring rates. The observed increase is due to the adhesive heat delamination, which is captured from using the calibrated thermal properties.

Interestingly, a similar phenomenon was observed during a full-scale fire-resistance of timber-concrete composite floor assemblies [87], as shown in Figure 4.13. The CLT profiles showed a sharp increase when temperature at the gluelines approached $220^{\circ} \mathrm{C}$, similarly to the profiles observed in this study and predicted from the FEM. The profiles from the laminated nailed $2 \times 8$ floor slab (i.e. a solid thick wood slab) remained fairly increasing during the test duration, somewhat similar to those predicted from the FEM using Eurocode 5: Part 1-2 thermal properties, supporting the assumption that the latter do not address adhesive heat delamination. 


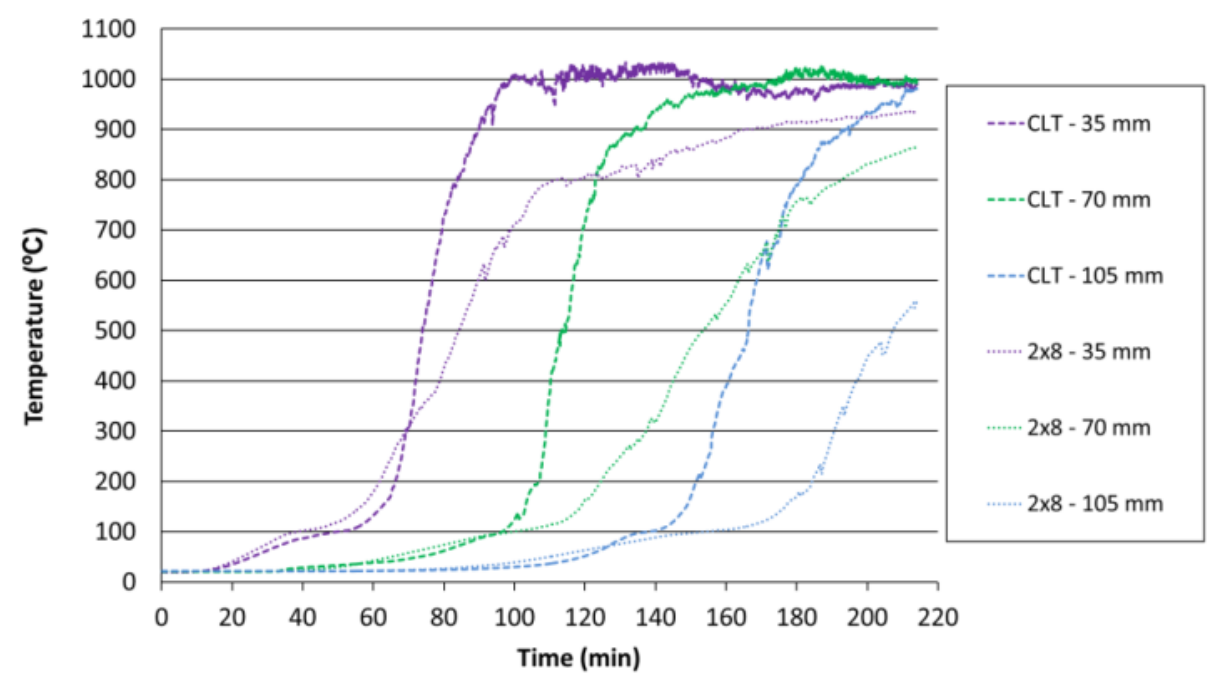

Figure 4.13 - Temperature profiles of CLT compared to solid nailed 2x8 slab [87]

\subsubsection{Emitted heat flux}

As shown in Equation (4.2), the net emitted heat flux impinging on a surface exposed to fire is composed of 2 heat fluxes: 1) convection and 2) thermal radiation. The heat flux emitted from convection is a function of the convection heat transfer coefficient and, depending on the application, may be set as low as $10 \mathrm{~W} \cdot \mathrm{m}^{-2} \cdot \mathrm{K}^{-1}$.

The thermal radiation depends on the product of three factors (view factor, surface material emissivity and fire source emissivity). A black body radiant source $\left(\varepsilon_{\mathrm{f}}\right)$ is assigned an emissivity of 1.0. A black body is a form that entirely absorbs electromagnetic radiation impinging on it and would have a surface emissivity $\left(\varepsilon_{\mathrm{m}}\right)$ of 1.0 .

Figure 4.14 shows the temperature profiles from 4 different net heat flux scenarios, using a convection heat transfer coefficient of 10 or $25 \mathrm{~W} \cdot \mathrm{m}^{-2} \cdot \mathrm{K}^{-1}$ and a surface emissivity of 
0.8 or 1.0 . It can be seen that the differences in time to reach $300^{\circ} \mathrm{C}$ (char front) at the gluelines are insignificant. Such insignificant differences support the assumptions of the transient heat transfer model detailed in subsection 4.2.

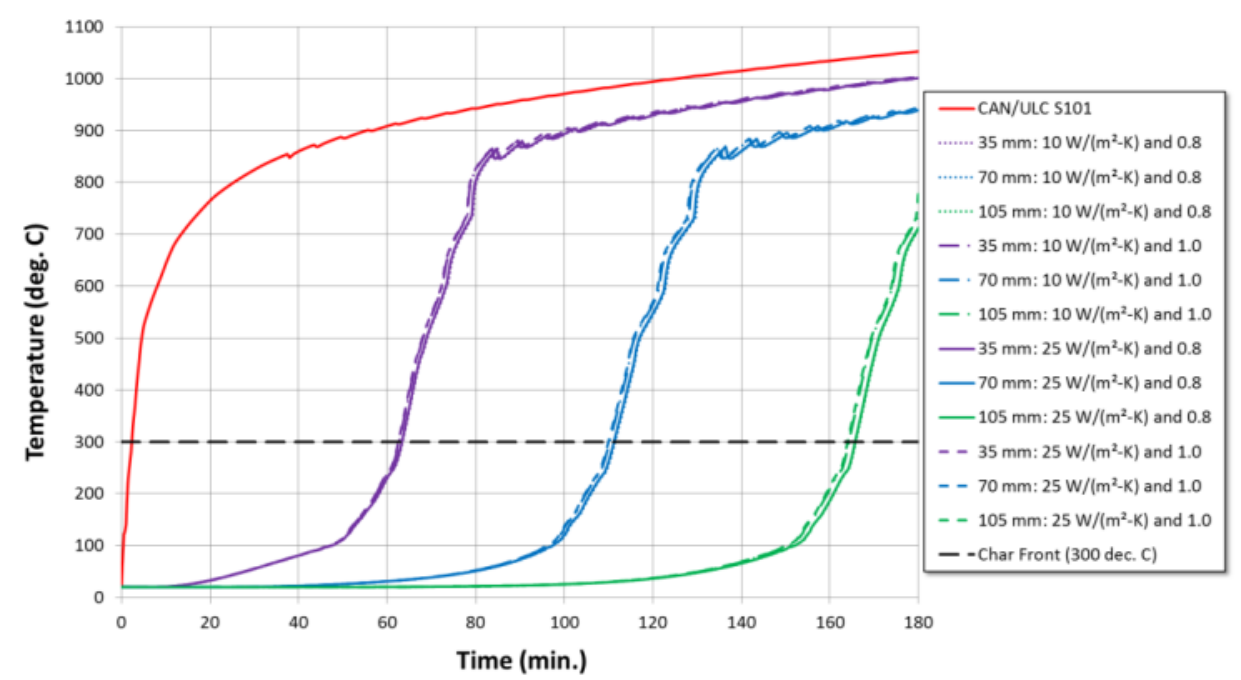

Figure 4.14 - Temperature profiles of CLT from various net emitted heat fluxes

\subsection{Summary}

To predict the temperature profiles within the CLT floor assemblies exposed to the standard CAN/ULC-S101 time-temperature curve, a finite element heat transfer model was developed in ANSYS version 15.0. Being able to predict the position of the char front $\left(300^{\circ} \mathrm{C}\right.$ isotherm $)$ and fire integrity resistance of CLT panel-to-panel joints provide benchmarking as to what panel-to-panel joint configuration provides better fire-resistance and optimizing the joint detail to achieve the best balance between structural resistance, ease of assembly and fire-resistance. 
The three-dimensional (3D) heat transfer model considered heat transfer within and between the different materials, namely the CLT, the self-tapping screws and, when applicable, the plywood splines.

Calibration of the thermal properties is an important aspect, especially for computer models that do not consider mass transfer, internal energy released due to pyrolysis and degradation of material (e.g. cracking of the charred wood increasing heat transfer on the charred layer), which is the case for the FEM developed in this study.

As such, thermal properties of the wood laminations were calibrated to test data, based on those given in Eurocode 5: Part 1-2 [27], to replicate the typical behaviour of CLT exposed to fire: adhesive heat delamination. The thermal properties used for the carbonsteel self-tapping screws were those given in Eurocode 3: Part 1-2 [71] and those for the plywood spline for the panel-to-panel joints requiring a spline were taken from Benichou et al. [66]. The CLT specimens evaluated in this study were tightly assembled together, leaving no air gaps in between the CLT panels. The FEM detailed in this subsection does not account for potential air gaps in the panel-to-panel joints.

The FEM predicts the $300^{\circ} \mathrm{C}$ isotherm to reach the gluelines at 63,111 and $166 \mathrm{~min}$, which all fall within the intervals recorded in this study. Moreover, the FEM predicts temperature profiles for standard fire exposure up to $180 \mathrm{~min}$ ( 3 hours) when compared to data from full-scale fire-resistance tests on CLT floor assemblies [10, 87], within a 7.5\% accuracy. The resulting charring rates for the $1^{\text {st }}, 2^{\text {nd }}$ and $3^{\text {rd }}$ laminations are $0.56,0.73$ 
and $0.64 \mathrm{~mm} / \mathrm{min}$, respectively, which is somewhat close to those measured during the intermediate- and full-scale fire tests.

From the FEM, one can determine the charring rate for each lamination and the time for the char front to reach a given depth within the CLT joint, thus predicting the fire integrity resistance of tightly fit CLT panel-to-panel joint configurations without air gaps. 


\section{Coupled Thermal-Structural Modeling}

This Chapter provides a methodology and assumptions used to model and predict the fire integrity resistance of CLT panel-to-panel joint details as a function of time and charring of the CLT panels. It also compares the predicted fire integrity times to those observed during this fire test series and provides recommendations for improving the fire integrity resistance of panel-to-panel joints in CLT floor applications.

\subsection{Methodology and Assumptions}

The coupled thermal-structural model is not developed to assess the CLT load-bearing function. The latter is to be assessed from other models such as those detailed in subsection 2.2 of this thesis. The proposed coupled thermal-structural model aims at predicting the fire integrity failure time of the four types of CLT panel-to-panel joints evaluated in this study based on a set of failure criteria detailed below.

The design provisions given in CSA O86 provide information with respect to minimum penetration length for wood-to-wood connections. For self-tapping screws designed in accordance with the provisions for lag screws loaded laterally, a minimum penetration length of 5 times the fastener shank diameter $\left(d_{F}\right)$ is required, regardless of the wood species. According to CSA O86, the shank diameter $\left(d_{F}\right)$ of a lag screw is taken as the

nominal diameter. There is currently no provision with respect to self-tapping screws in CSA O86. As a conservative approach, the maximum char depth that can be reached 
needs to respect the minimum penetration length for assuming that fasteners will continue to exhibit sufficient strength and that CLT panels remain connected together.

During this test series, self-tapping screws of outside diameter of $6 \mathrm{~mm}$ were used (shank diameter of $4.4 \mathrm{~mm}$, refer to Table 2.7), resulting in a minimum penetration depth of 22 $\mathrm{mm}$. It can be assumed at a residual thickness greater than $22 \mathrm{~mm}$, any air gap at the unexposed surface, as shown in Figure 5.1, would not lead to an insulation failure. At a thickness of $22 \mathrm{~mm}$, Equation (2.3) would estimate a temperature of $77^{\circ} \mathrm{C}$, which is below the insulation criteria stipulated in subsection 2.1.3.

Moreover, as detailed in subection 2.2.3, a fixed residual thickness of at least $12 \mathrm{~mm}$ would prevent an insulation failure and would most likely be more appropriate in the context of this study. This minimum residual thickness of $12 \mathrm{~mm}$ corresponds to $2.7 d_{F}$ of a $6 \mathrm{~mm}$ outside diameter self-tapping screw (4.4 mm shank diameter, per Table 2.7), which is not compliant with CSA O86 minimum penetration depth of $5 d_{F}$ (which would be $22 \mathrm{~mm}$ ). A minimum depth of $12 \mathrm{~mm}$ would however be similar to the arbitrary minimum residual tickness of $15 \mathrm{~mm}$ suggested by O'Neil [41]. As such, it was decided to evaluate two (2) different sets of minimum penetration depth: 1) a fixed minimum of $12 \mathrm{~mm}$ based on temperature rise limit and 2) a minimum of $22 \mathrm{~mm}$ based on $5 d_{F}$ rule given in CSA O86. 


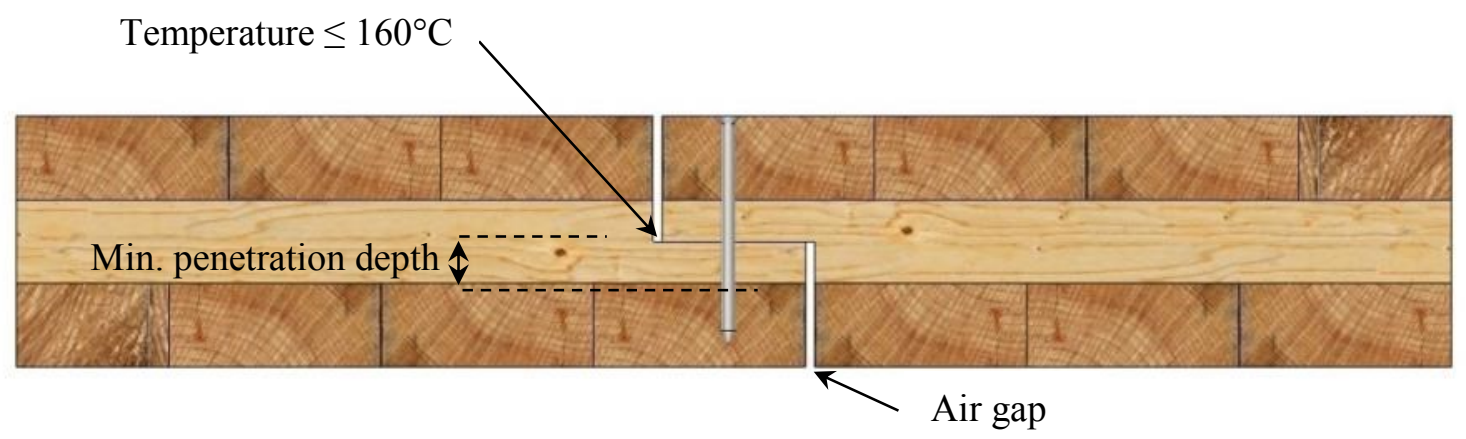

Figure 5.1 - Example of half-lapped joint with air gap (not thightly fit)

Furthermore, Peng [85] reported that the ratio between the CSA O86 factored resistance of connections and their ultimate values is estimated between 0.31 and 0.32 , thus a onethird $(1 / 3)$ ratio, which represents the typical level of safety afforded in timber connections [88]. While this fire test series does not specifically aim at evaluating the structural fire-resistance of the fasteners, it is assumed that connection between CLT panels will no longer be capable to maintain the joint securely and tightly fitted when a loss of $67 \%$ of the initial strength resistance is reached.

Also, Chapter 4 detailed a FEM heat transfer model that can reasonably predict temperature profiles within a CLT element exposed to the standard CAN/ULC-S101 time-temperature curve. The resulting charring rates for the $1^{\text {st }}, 2^{\text {nd }}$ and $3^{\text {rd }}$ laminations are $0.56,0.73$ and $0.64 \mathrm{~mm} / \mathrm{min}$, respectively. The average charring rate for the $18.5 \mathrm{~mm}$ plywood spline was calculated as $0.67 \mathrm{~mm} / \mathrm{min}$. For simplification and conservatism in the coupled thermal-structural model, the charring rates are rounded to the nearest 0.05 $\mathrm{mm} / \mathrm{min}$. As such, the charring rate becomes $0.65 \mathrm{~mm} / \mathrm{min}$ for the longitudinal 
laminations of MSR $1950 \mathrm{f}_{\mathrm{b}}$ lumber, of which heat delamination of the adhesive is considered. For the transverse layers of visually-graded SPF No.2 lumber, a charring rate of $0.75 \mathrm{~mm} / \mathrm{min}$ is used and incorporates heat delamination of the adhesive. A rate of $0.70 \mathrm{~mm} / \mathrm{min}$ is assumed for the plywood spline.

The "thermal" portion of the coupled thermal-structural model uses the rounded charring rates from the FEM, allowing one to determine the char front location and the residual cross-section at any given time. It is assumed that the embedment strengths are neglected in the charred layer (wood at temperature of $300^{\circ} \mathrm{C}$ and beyond).

Moreover, since the test results suggest that heat conduction within self-tapping screws may be considered as negligible and may not be a source of potential failure mode in CLT panel-to-panel joints, the steel bending yield strength $\left(f_{y}\right)$ is kept constant throughout the modeling. The bending yield strength of the ASSY ${ }^{\circledR} 3.0$ Ecofast partially-threaded self-tapping screws used in this study is taken as $969 \mathrm{MPa}$ [52].

Furthermore, a factor for reduced penetration $\left(J_{P L}\right)$ is used in Equations (2.9) and (2.10) when calculating the lateral resistance of lag screws, which is to be taken as 0.625 for penetration of $5 d_{F}$ and 1.0 for $8 d_{F}$. Linear interpolation is allowed for penetration between 5 and $8 d_{F}$, suggesting that it should be taken a zero when the penetration is less than $5 d_{F}$. As such, it is obvious that as soon as the penetration reaches $5 d_{F}(22 \mathrm{~mm}$ in this study), the factor $J_{P L}$ drops to zero and the lateral resistance becomes zero ( 0 $\mathrm{kN} / \mathrm{screw}$ ) and the $67 \%$ strength loss criterion would most likely always be the limiting factor, especially in the case where a fixed residual thickness of $12 \mathrm{~mm}$ is assumed. 
Therefore, the coupled thermal-structural model assumes that linear interpolation may be done at penetration less than $5 d_{F}$.

Combining the temperature profiles and the residual cross-section in Equation (2.9) (thermal portion) as well as yielding modes shown in Figure 2.26 (structural portion) would allow predicting the connection lateral resistance and its strength reduction as well as failure mode as a function of time, until a specific failure criterion is reached. The duration of load factor $\left(K_{D}\right)$ is also taken as 1.15 (short-term) for fire-resistance design, as prescribed in Annex B of CSA O86. Figure 5.2 illustrates the coupled thermal-structural model and its variables (embedment strengths, $f_{1}$ and $f_{2}$ ) changing as a function of time $(t)$ and temperature $(T)$.

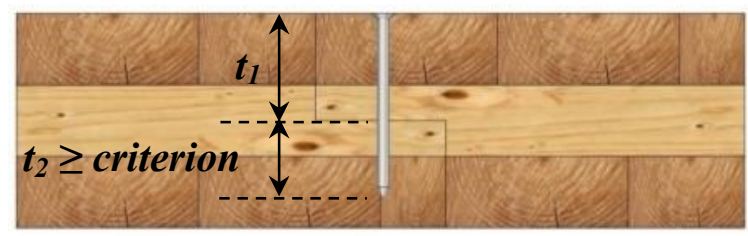

a) CLT à $t=0 \mathrm{sec}$

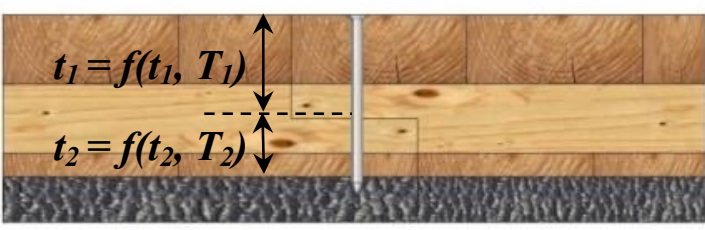

b) CLT à $t=x \mathrm{sec}$.

Figure 5.2 - Schematic of the coupled thermal-structural model

The coupled thermal-structural model has been developed with the actual fire test joint configurations (e.g. CLT thicknesses and laminations, plywood spline thickness, selftapping screws and actual location of the joint along the CLT thickness). In all tested CLT panel-to-panel joint details, the self-tapping screws were always shorter than the CLT thickness. The wood covering the tip of the self-tapping screw afforded certain duration where the main member thickness $\left(t_{2}\right)$ is kept constant to the actual length of the 
threaded shank embedded into the CLT and the lateral resistance is thus not impacted. At the time where the char front reaches the tip of the self-tapping screw, the main member thickness becomes reduced and the lateral resistance of the connection starts decreasing until a $67 \%$ capacity loss is calculated or until the minimum penetration depth of 12 or 22 $\mathrm{mm}$ is reached, whichever occurs first. A calculation example is presented in Appendix XI.

\subsection{Predictions from the Coupled Thermal-Structural Model}

\subsubsection{Half-Lapped Joint}

During the fire test series, all 3 specimens reached an integrity failure at the half-lapped interface. Failures occurred at 45, 98 and 140 min respectively for the 3-ply, 5-ply and 7ply CLT specimens.

When computing the connection capacity as a function of time and a minimum penetration depth of $12 \mathrm{~mm}$, the coupled thermal-structural model would predict a failure time of 54, 101 and 155 min for the 3-ply, 5-ply and 7-ply CLT specimens, respectively. For all three scenarios, the failure time occurs when $67 \%$ strength loss is reached and when a main member penetration thickness of $4.0 d_{F}, 3.9 d_{F}$ and $4.0 d_{F}( \pm 17 \mathrm{~mm})$ is reached for the 3-ply, 5ply and 7-ply, respectively.

Interestingly, the minimum required thickness of $17 \mathrm{~mm}$ is consistent with the remaining thickness measured underneath the half-lapped joint interface in this fire test series. Thicknesses of 23, 29 and $17 \mathrm{~mm}$ were measured for the 3-ply, 5-ply and 7-ply CLT 
specimens (average thickness of $23 \mathrm{~mm}$ ), suggesting that $17 \mathrm{~mm}$ may be a valid lower limit, but perhaps too liberal.

By setting the minimum penetration to $22 \mathrm{~mm}$, the model predictions reduce to 46,94 and $147 \mathrm{~min}$. This value of $22 \mathrm{~mm}$ is actually more consistent with the average value of 23 measured in this fire test series and coincides with the $5 d_{F}$ penetration depth required in CSA O86. These failure times are governed by the minimum thickness criterion as opposed to the connection strength loss criterion. These new predictions suggest that 22 mm may be a more suitable minimum thickness failure criterion, while respecting CSA O86 minimum penetration depth requirement of $5 d_{F}$, as previously presented in Table 2.6. Table 5.1 provides a summary of the predicted failure time for each criterion. Figure 5.3 shows that the predicted failure times are close to those observed during the fire tests, while slightly over-predicting the failure time. When plotting a linear regression having an intercept set to zero, the coefficients of correlation from the linear regression of all four models are $0.938,0.941,0.944$ and 0.989 for the Canadian, European, American and the proposed coupled thermal-structural models, respectively.

Table 5.1 - Coupled Thermal-Structural Failure Times - Half-lapped Joint

\begin{tabular}{|c|c|c|c|c|c|}
\hline \multirow[b]{2}{*}{$\begin{array}{c}\text { CLT } \\
\text { Assembly }\end{array}$} & \multicolumn{5}{|c|}{ Time to fire integrity failure (min) } \\
\hline & $\begin{array}{c}\text { Criterion 1: } \\
\text { 67\% strength } \\
\text { loss } \\
\end{array}$ & $\begin{array}{l}\text { Criterion 2: } \\
12 \mathrm{~mm}\end{array}$ & $\begin{array}{l}\text { Criterion 3: } \\
22 \mathrm{~mm}\end{array}$ & $\begin{array}{c}\text { Assigned } \\
\text { Failure Time }\end{array}$ & $\begin{array}{c}\text { Test Failure } \\
\text { Time }\end{array}$ \\
\hline $\begin{array}{c}\text { 3-ply } \\
(105 \mathrm{~mm})\end{array}$ & 54 & 61 & 46 & 46 & 45 \\
\hline $\begin{array}{c}\text { 5-ply } \\
(175 \mathrm{~mm})\end{array}$ & 101 & 108 & 94 & 94 & 98 \\
\hline $\begin{array}{c}7-\text { ply } \\
(245 \mathrm{~mm})\end{array}$ & 155 & 161 & 147 & 147 & 140 \\
\hline
\end{tabular}




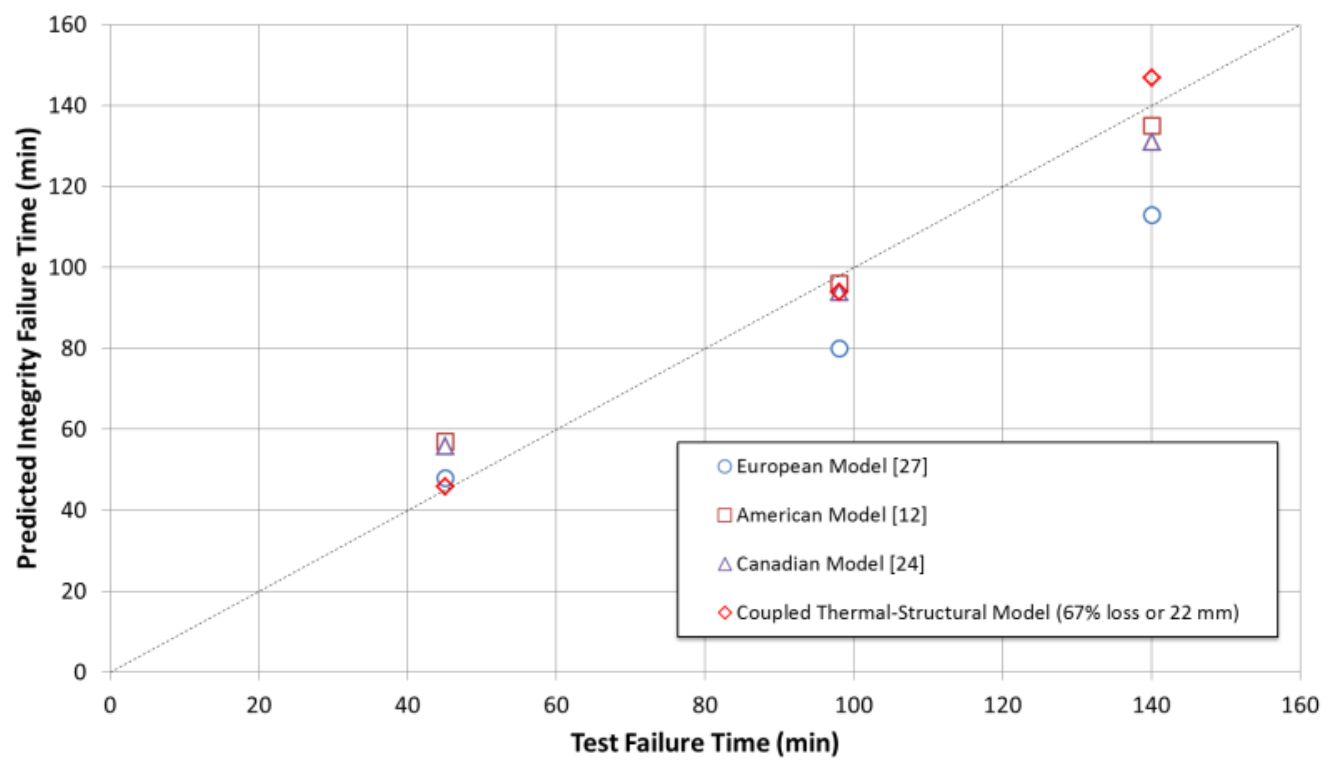

Figure 5.3 - Failure time comparisons - Half-lapped joint

The coupled thermal-structural model also allows for assessing the fastener yield mode as a function of any given time. Figure 5.4 shows the model predictions for the 5-ply halflapped joint configuration using self-tapping screws of $\phi 6-160 / 70 \mathrm{~mm}$. It can be observed that the connection capacity is not experiencing any reduction until $66 \mathrm{~min}$, time at which the fasteners went from yielding mode $\mathrm{f}$ ) to mode $\mathrm{d}$ ), until failure is reached. The main member residual thickness at failure is $22 \mathrm{~mm}$. A yielding mode f) occurs when a fastener yields in bending at 2 plastic hinge points per shear plane and with limited localized crushing of wood fibers near the shear plane. A yield mode d) occurs when a fastener yields in bending at one plastic hinge point per shear plane and with bearing-dominated yield of wood fibers in contact with the fastener in the main member. Figure 5.5 shows the fastener yield mode d) observed during fire tests 6 and 9 (5- and 7-ply specimens). 


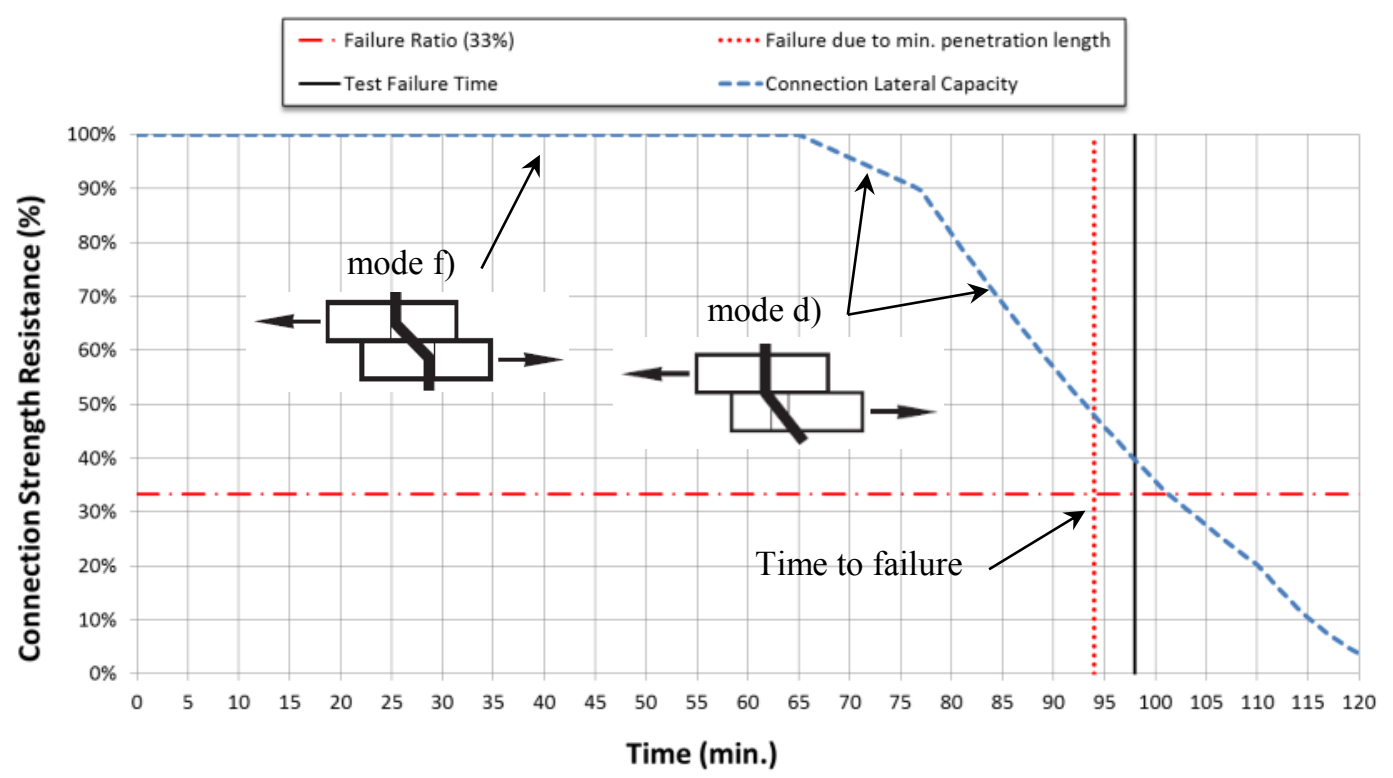

Figure 5.4-Coupled thermal-structural model prediction for the 5-ply half-lapped joint

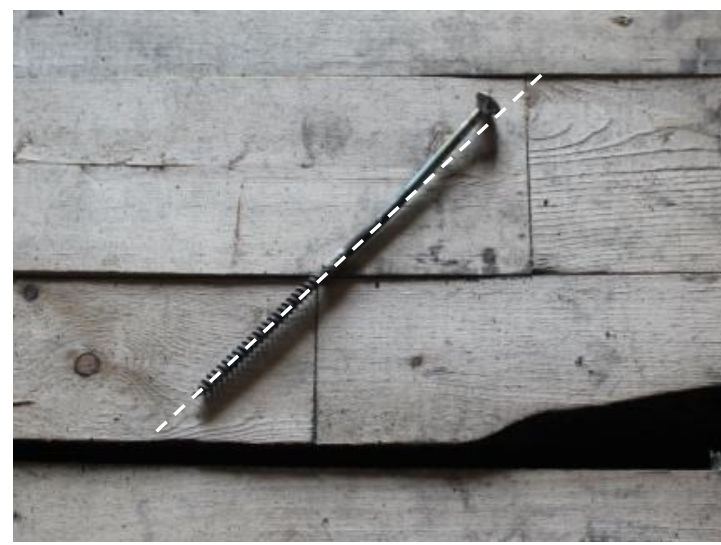

a) Fire Test 6

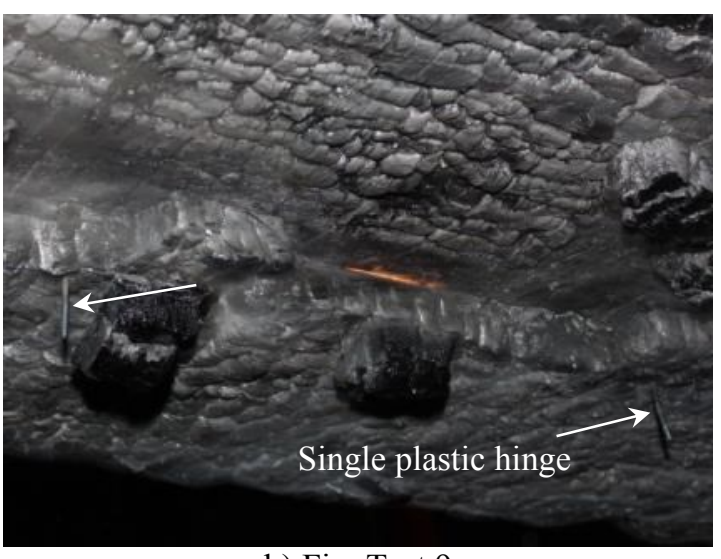

b) Fire Test 9

Figure 5.5 - Observed fastener yield mode with half-lapped joints

Furthermore, such model allows for improving the fire integrity performance and the lateral (in-plane) resistance of CLT slabs by quickly evaluating the capacity assuming the lapped joint is located at various depths along the CLT thickness. For example, moving 
the lapped joint upward at $30 \%$ or $40 \%$ of the thickness (vs. $50 \%$ for the half-lapped joint) of a 5-ply (175 mm) CLT increases respectively the predicted failure time to 147 and 120 min (Figure 5.6). Shifting the lapped joint interface at these 2 locations is also not influencing the lateral resistance of the self-tapping screws. In fact, the factored resistance remains unchanged $(1.1 \mathrm{kN} / \mathrm{screw})$ until the main member thickness reaches a thickness of $44 \mathrm{~mm}$, times at which yield mode shifts from mode f) to d) (occurring at 66 $\mathrm{mm})$.

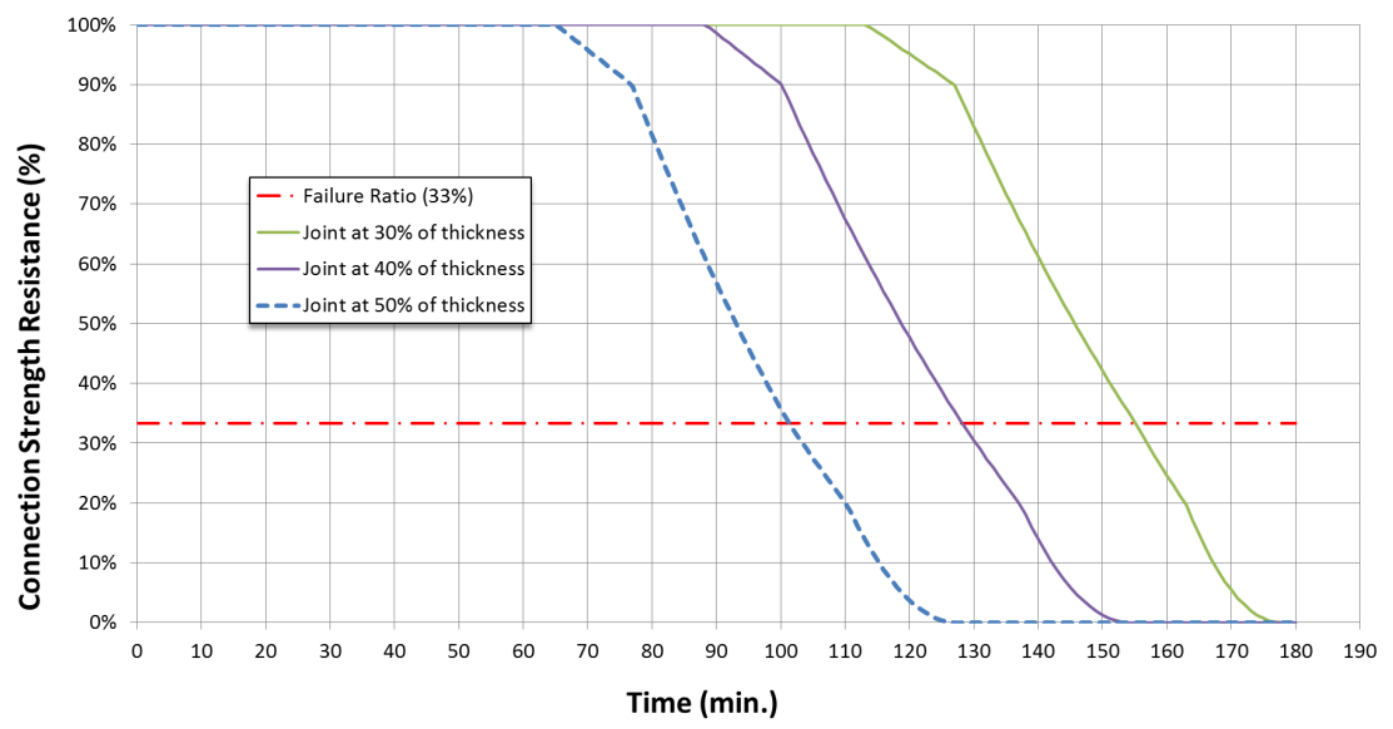

Figure 5.6-Effect of moving the lapped joint interface on the predicted failure time

As such, by moving the joint interface furthest from the fire-exposed surface would allow for a much better fire integrity resistance while not significantly impacting the lateral resistance of the CLT panel-to-panel connection. 


\subsubsection{Internal spline}

Given that the internal spline is located at mid-depth across the CLT panels, it would appear, at first, reasonable that this joint detail would perform similarly to the half-lapped joint. However, from the time to failure shown in Table 3.6, it actually afforded shorter time to failure than that of the half-lapped joint. The reason for such differences was explained in subsection 3.14 .

Moreover, the plywood used as spline material was $18.5 \mathrm{~mm}$ thick, which is much thinner than the required thickness required in CSA O86 for fasteners acting in double shear. Due to the fact that the plywood spline was much thinner, the probability that a self-tapping screw would exhibit two (2) plastic hinge points (failure mode g) in Figure 2.23) seems unrealistic. It is thereby assumed that the fasteners used to connect the internal spline would behave in single shear. Single plastic hinges were observed during the fire test series with internal spline joints, supporting the assumption that self-tapping screws were indeed solicited in single shear action (Figure 5.7). Moreover, given that field installation may lead to premature flow-through the butt-joints of the splines, it is assumed that the side member thickness $\left(t_{1}\right)$ is comprised of the upper portion of the CLT and the plywood spline. The shear plane is then located at the lower interface of the CLT and the plywood spline. 


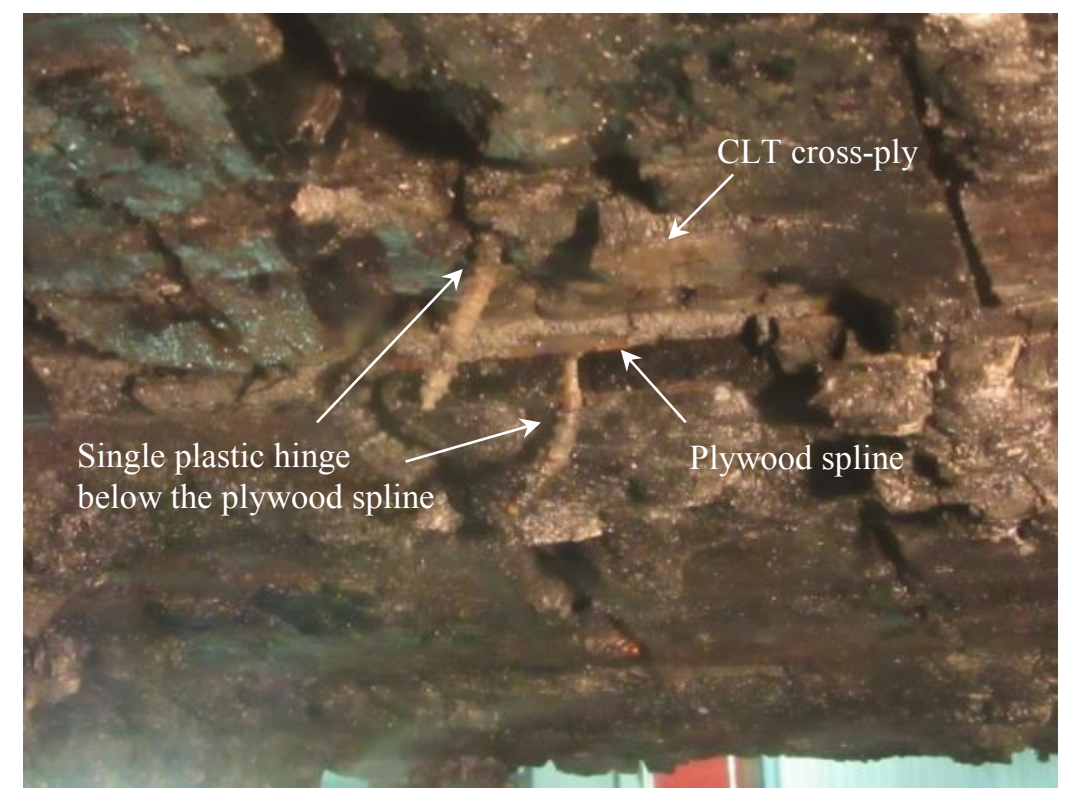

Figure 5.7 - Observed fastener yield mode with internal spline joint (Test 1)

When assuming failure criteria of $12 \mathrm{~mm}$ and a $67 \%$ strength loss, the failure times of all three scenarios are achieved at 41, 88 and 140 min for the 3-ply, 5ply and 7-ply, respectively. At these times, the penetration depth into the main member is $3.8 d_{F}, 4.0 d_{F}$ and $4.0 d_{F}( \pm 17 \mathrm{~mm})$ for the 3-ply, 5ply and 7-ply, respectively. When changing the failure criterion to $22 \mathrm{~mm}$ and $67 \%$ strength loss, all failures occur when the minimum penetration depth criterion is first reached as opposed to the connection strength loss criterion. From these new failure criteria, the model predictions reduce to 32,82 and 133 min for the 3-ply, 5ply and 7-ply, respectively. During the fire test series, failures occurred at 35 and 76 min respectively for the 3-ply and 5-ply CLT specimens. Table 5.2 provides the model predictions from the coupled thermal-structural model. Figure 5.8 shows that the predicted failure times are quite accurate when compared to those 
observed during the fire tests, suggesting that $22 \mathrm{~mm}$ may be a more suitable minimum thickness failure criterion, while fulfilling CSA O86 minimum penetration depth requirement of $5 d_{F}$. When plotting a linear regression having an intercept set to zero, the coefficient of correlation of the proposed coupled thermal-structural model is 0.978 .

Table 5.2 - Coupled Thermal-Structural Failure Times - Internal Spline Joint

\begin{tabular}{cccccc}
\hline CLT & \multicolumn{5}{c}{ Time to fire integrity failure (min) } \\
\cline { 2 - 6 } Assembly & $\begin{array}{c}\text { Criterion 1: } \\
\text { 67\% strength } \\
\text { loss }\end{array}$ & $\begin{array}{c}\text { Criterion 2: } \\
\mathbf{1 2} \mathbf{~ m m}\end{array}$ & $\begin{array}{c}\text { Criterion 3: } \\
\mathbf{2 2} \mathbf{~ m m}\end{array}$ & $\begin{array}{c}\text { Assigned } \\
\text { Failure Time }\end{array}$ & $\begin{array}{c}\text { Test Failure } \\
\text { Time }\end{array}$ \\
\hline $\begin{array}{c}\text { 3-ply } \\
(105 \mathrm{~mm})\end{array}$ & 41 & 48 & 32 & 32 & 35 \\
\hline $\begin{array}{c}5 \text {-ply } \\
(175 \mathrm{~mm})\end{array}$ & 88 & 95 & 82 & 82 & 76 \\
\hline $\begin{array}{c}7-\mathrm{ply} \\
(245 \mathrm{~mm})\end{array}$ & 140 & 148 & 133 & 133 & n.a. \\
\hline (1) Assigned failure time is taken as the minimum value from either Criteria 1 and 2, or Criteria 1 and 3.
\end{tabular}

In all three scenarios, yielding mode d) is predicted when failure occurs (Figure 5.9), meaning that the failure is caused by the fastener yielding in bending at one plastic hinge point per shear plane and from bearing-dominated yield of wood fibers in contact with the fastener in the main member. Such failure mode is consistent with that observed during the fire tests using internal spline joint details. 


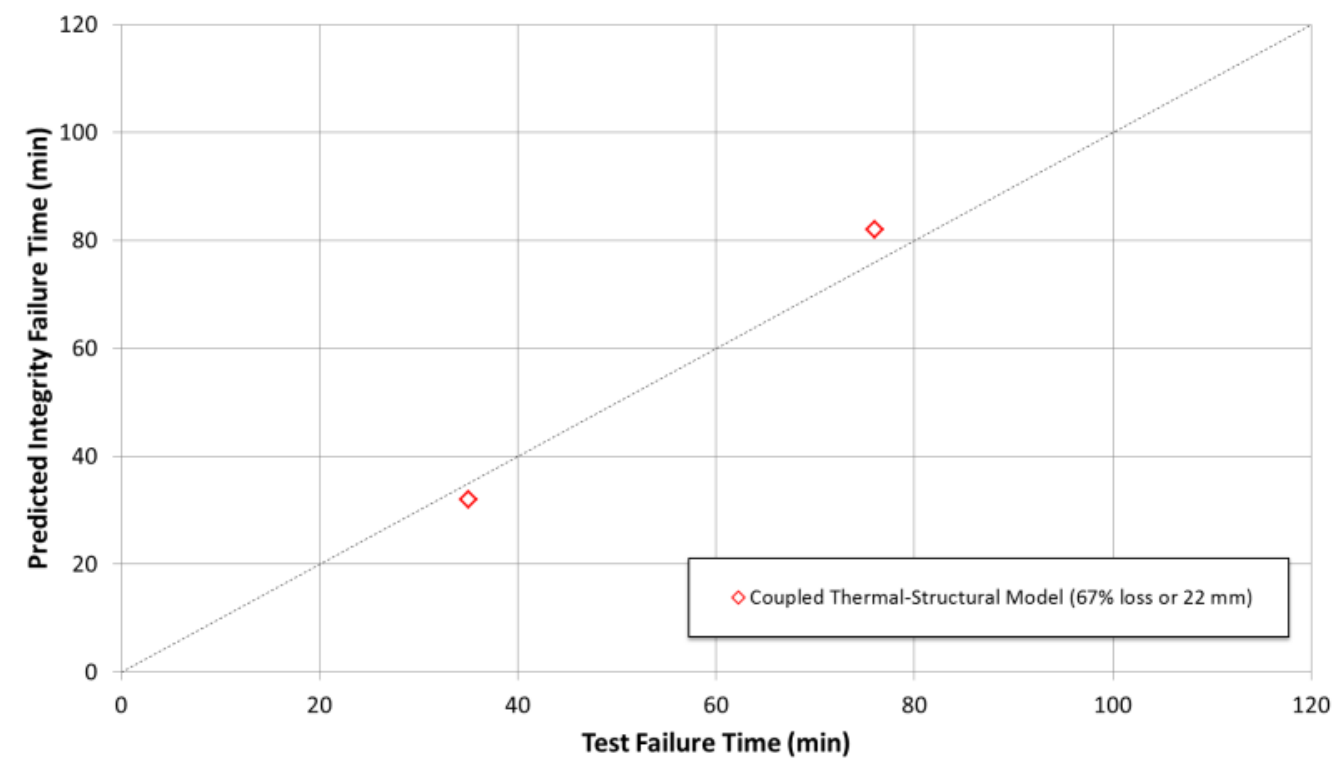

Figure 5.8 - Failure time comparisons - Internal spline joint

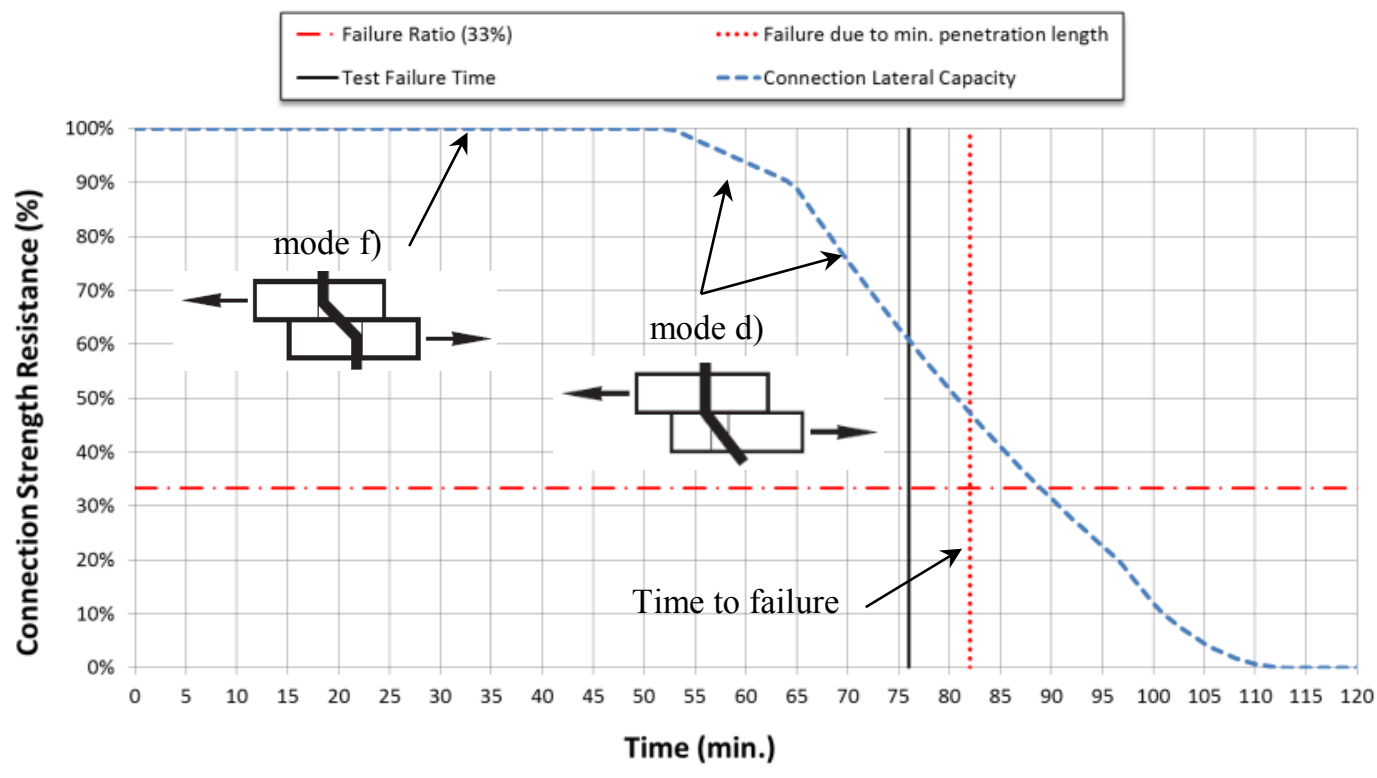

Figure 5.9-Coupled thermal-structural model prediction for the 5-ply internal spline 
As with the half-lapped joint, the model assists in improving the fire integrity performance and the lateral (in-plane) resistance of CLT slabs by quickly evaluating the capacity assuming the internal spline is located at various depths along the CLT thickness. For example, moving the internal spline upward at $30 \%$ or $40 \%$ of the thickness (vs. 50\% for the typical internal spline) of a 5-ply (175 mm) CLT increases respectively the predicted failure time to 138 and $109 \mathrm{~min}$, both governed by the minimum thickness of $22 \mathrm{~mm}$ criterion. Shifting the internal spline interface at these 2 locations is not influencing the lateral resistance of the self-tapping screws. It also allows for assessing the fastener yield mode as a function of time.

Again, by moving the joint interface furthest from the fire-exposed surface would allow for a much better fire integrity resistance while not significantly impacting the lateral resistance of the CLT panel-to-panel connection. However, as observed during this fire test series, proper installation of the splines is to be ensured to limit premature fire integrity failure (i.e. premature air flow penetrating potential gaps between the splines).

\subsubsection{Single surface spline}

The CLT panel-to-panel joint using a single surface spline is modeled following the same principles and assumptions as the previous two joint details. However, the validation of the model cannot be fully performed as none of the fire test assemblies reached an actual failure. The 3-ply and 5-ply CLT specimens were stopped after 54 and $98 \mathrm{~min}$ respectively and no failure was reached. As such, it can only be argued that they would 
last more than the recorded test durations and the proposed model is only being discussed based on engineering judgment.

As opposed to the half-lapped and internal spline joint details where different self-tapping screw length was used, the surface spline joints used self-tapping screws of $\phi 6-80 / 50 \mathrm{~mm}$ for all CLT specimens and thicknesses. It seems somewhat obvious that thicker CLT panels would exhibit longer fire integrity resistance due to the fact that they afford more wood to be consumed before the minimum fastener penetration depth is reached or a $67 \%$ capacity reduction is calculated.

According to the proposed coupled thermal-structural model and the $22 \mathrm{~mm}$ minimum penetration depth criterion, fire integrity failure is deemed to occur at 93 min and 193 min for a 3-ply and 5-ply CLT, which is beyond the times at which the fire tests were stopped (almost twice as much). A time of $287 \mathrm{~min}$ is predicted for a 7-ply CLT, which would most likely trigger a structural failure to occur prior to reaching a fire integrity failure. When reducing the minimum penetration depth to $12 \mathrm{~mm}$, the $67 \%$ strength loss criterion becomes the limiting factor and the predicted fire integrity failure times slightly increase to 96, 197 and $290 \mathrm{~min}$ for a 3-ply, 5-ply and 7-ply, respectively. The failure is deemed to occur when the penetration depth into the main member reduces to $4.5 d_{F}, 4.4$ $d_{F}$ and $4.5 d_{F}( \pm 19 \mathrm{~mm})$ for the 3-ply, 5ply and 7-ply, respectively. Table 5.3 provides the model predictions from the coupled thermal-structural model. 
In all three scenarios, yielding mode e) is predicted when failure occurs (Figure 5.10). In single shear connection, yielding mode e) involves pivoting of the fastener at the shear plane and localized crushing of wood fibers near the faces of the wood members.

Table 5.3 - Coupled Thermal-Structural Failure Times - Single Surface Spline Joint

\begin{tabular}{cccccc}
\hline \multirow{2}{*}{$\begin{array}{c}\text { CLT } \\
\text { Assembly }\end{array}$} & $\begin{array}{c}\text { Criterion 1: } \\
\text { 67\% strength } \\
\text { loss }\end{array}$ & $\begin{array}{c}\text { Criterion 2: } \\
\mathbf{1 2} \mathbf{~ m m}\end{array}$ & $\begin{array}{c}\text { Criterion 3: } \\
\text { 22 mm }\end{array}$ & $\begin{array}{c}\text { Assigned } \\
\text { Failure Time }\end{array}$ & $\begin{array}{c}\text { Test Failure } \\
\text { Time }\end{array}$ \\
\hline $\begin{array}{c}3-\mathrm{ply} \\
(105 \mathrm{~mm})\end{array}$ & 96 & 107 & 93 & 93 & $>54$ \\
\hline $\begin{array}{c}5-\mathrm{ply} \\
(175 \mathrm{~mm})\end{array}$ & 197 & 207 & 193 & 193 & $>98$ \\
\hline $\begin{array}{c}7-\mathrm{ply} \\
(245 \mathrm{~mm})\end{array}$ & 290 & 300 & 287 & 287 & n.a. \\
\hline$(1)$ Assime to fire integrity failure (min)
\end{tabular}

(1) Assigned failure time is taken as the minimum value from either Criteria 1 and 2 , or Criteria 1 and 3.

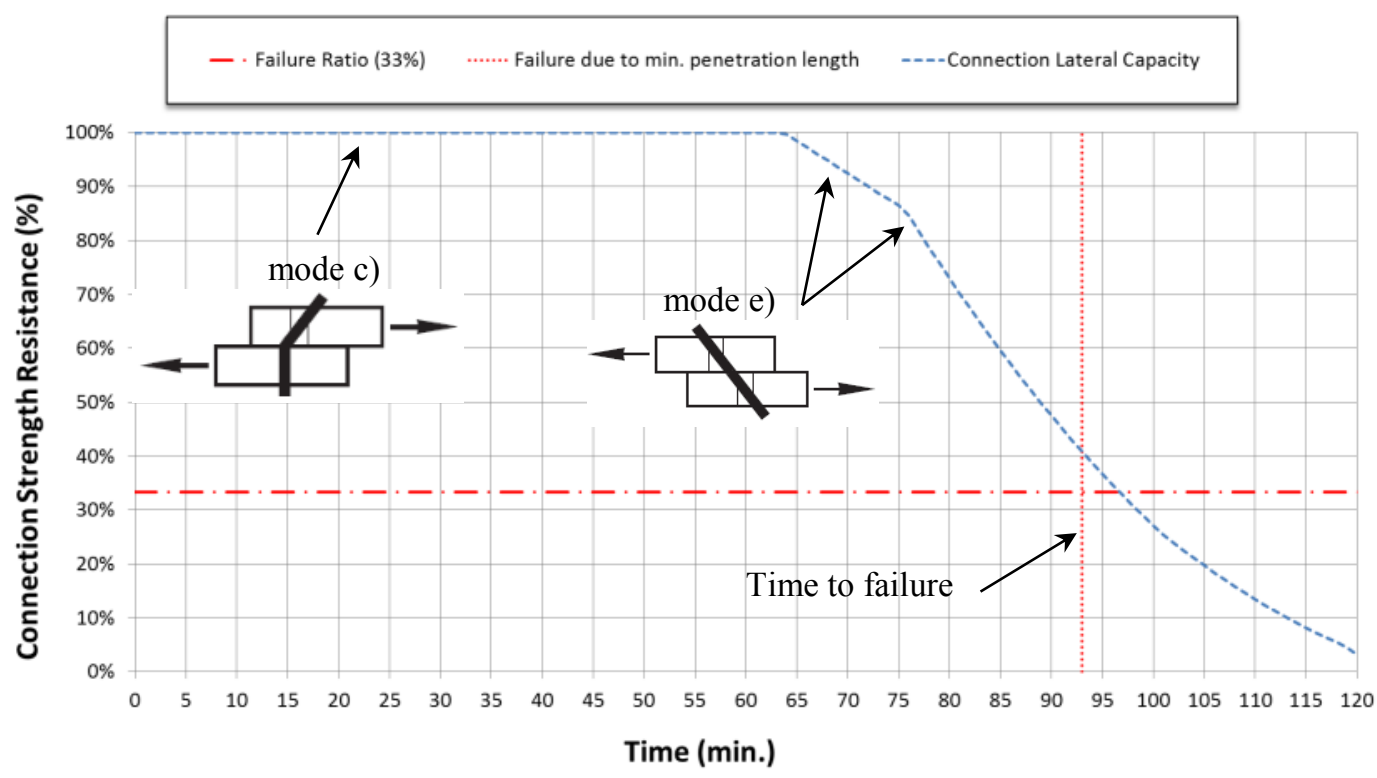

Figure 5.10 - Coupled thermal-structural model prediction for the 3-ply single surface spline 
The CLT panel-to-panel joint configuration using a single surface spline does not allow for moving upward or downward the joint interface, except to perhaps changing the thickness of the spline material. As such, there is not much improvement that can be made in attempt to balance the fire integrity resistance and the lateral (in-plane) resistance of CLT panels.

As with the internal spline, it is also critical that the surface splines are properly installed to limit premature fire integrity failure (i.e. premature air flow penetrating potential gaps between the splines). The CLT panels also need to be tightly fit together as to not create an air gap that would facilitate charring to occur between the panels and reach the surface spline prematurely.

\subsubsection{Double surface spline}

The double surface spline is analyzed from the same principles and assumptions as the single surface spline. The joint details used the same plywood spline and self-tapping screws as the single surface spline. The only difference between the single and double surface spline model is the charring rate of $0.70 \mathrm{~mm} / \mathrm{min}$ for the bottom spline as opposed to $0.65 \mathrm{~mm} / \mathrm{min}$ for the $1^{\text {st }}$ lamination, resulting in a faster displacement of the char front in the early stage of the fire exposure (i.e. for burning through the bottom plywood spline).

The validation of the model cannot be fully performed as only the 3-ply CLT specimen reached an actual fire integrity failure (at $43 \mathrm{~min}$ ). The 5-ply CLT specimen was stopped after $90 \mathrm{~min}$ and no failure was reached. The 7-ply CLT specimen was stopped at 180 
min when a structural failure occurred first. As with the single surface spline, the proposed model is thereby only being discussed based on engineering judgment.

According to the proposed coupled thermal-structural model and the $22 \mathrm{~mm}$ minimum penetration depth criterion, fire integrity failure is deemed to occur at 91, 197 and 305 min for a 3-ply, 5-ply and 7-ply CLT, respectively, which is beyond the times at which the fire tests were stopped (almost twice as much). When reducing the minimum penetration depth to $12 \mathrm{~mm}$, the $67 \%$ strength loss criterion becomes the limiting factor and the predicted fire integrity failure times slightly increase to 94, 201 and 309 min for a 3-ply, 5-ply and 7-ply, respectively. For all three scenarios, the failure is deemed to occur when the penetration depth into the main member reduces to $4.5 d_{F}( \pm 19 \mathrm{~mm})$. Table 5.4 provides the model predictions from the coupled thermal-structural model.

Table 5.4-Coupled Thermal-Structural Failure Times - Double Surface Spline Joint

\begin{tabular}{cccccc}
\hline \multirow{2}{*}{$\begin{array}{c}\text { CLT } \\
\text { Assembly }\end{array}$} & $\begin{array}{c}\text { Criterion 1: } \\
\text { 67\% strength } \\
\text { loss }\end{array}$ & $\begin{array}{c}\text { Criterion 2: } \\
\mathbf{1 2} \mathbf{~ m m}\end{array}$ & $\begin{array}{c}\text { Criterion 3: } \\
\mathbf{2 2} \mathbf{~ m m}\end{array}$ & $\begin{array}{c}\text { Assigned } \\
\text { Failure Time }\end{array}$ & $\begin{array}{c}\text { Test Failure } \\
\text { Time }\end{array}$ \\
\hline $\begin{array}{c}3-\mathrm{ply} \\
(105 \mathrm{~mm})\end{array}$ & 94 & 105 & 91 & 91 & 43 \\
\hline $\begin{array}{c}5-\mathrm{ply} \\
(175 \mathrm{~mm})\end{array}$ & 201 & 212 & 197 & 197 & $>90$ \\
\hline $\begin{array}{c}7-\mathrm{ply} \\
(245 \mathrm{~mm})\end{array}$ & 309 & 320 & 305 & 305 & $>180$ \\
\hline
\end{tabular}

(1) Assigned failure time is taken as the minimum value from either Criteria 1 and 2 , or Criteria 1 and 3.

As one would expect, the model predictions are very similar to those from the single surface spline model suggesting that there may not have significant benefits from using a double surface spline joint detail (from a fire performance perspective), except perhaps for increasing the in-plane lateral resistance of the panel-to-panel connection. Also 
similar with the single surface spline predictions, all three scenarios predicted a yielding mode e) when failure occurs.

The CLT panel-to-panel joint configuration using a double surface spline does not allow for moving upward or downward the joint interface, except to perhaps changing the thickness of the spline material. As such, there is not much improvement that can be made in attempt to balance the fire integrity resistance and the lateral (in-plane) resistance of CLT panels.

As with the internal and single surface spline joint details, it is also critical that the surface splines are properly installed to limit premature fire integrity failure (i.e. premature air flow penetrating potential gaps between the splines). As such, the top and bottom spline butt-joints should not be at the same location along the CLT length. The same principle applies to wood-frame assemblies protected by 2 layers of gypsum board. To limit potential leakage between gypsum board joints, they should typically be spaced by at least one framing member in the minor orientation and at least $610 \mathrm{~mm}$ in major orientation. As such, it is recommended that the spline butt-joints used in CLT panel-topanel joint details be longitudinally offset from each other by at least $610 \mathrm{~mm}$. In all cases, the CLT panels need to be tightly fit together as to not create an air gap that would facilitate charring to occur between the CLT panels and reach the surface spline prematurely. 


\subsection{Summary}

One of the objectives of this study was to develop a coupled thermal-structural model that could predict the fire integrity resistance of various CLT panel-to-panel joint details. Assessing the structural fire-resistance is outside the scope of this thesis. Understanding the fastener structural behaviour, yield modes and resistance provide benchmarking as to which panel-to-panel joint configuration offers better fire-resistance and optimizing the joint detail to achieve the best balance between structural resistance, ease of assembly and fire-resistance.

The coupled thermal-structural model consisted of combining the temperature profiles, evaluating the residual cross-section and fastener yielding modes as a function of time until one of the pre-determined failure criteria is reached. The coupled thermal-structural model has been developed for the actual fire test joint configurations and, in most parts, validated against the intermediate-scale fire tests of this study. The charring rates obtained from the test data and predicted from the FEM were used to determine the location of the char front at any given time. The rates incorporated the effect of adhesive heat delamination and were based on CLT manufactured with laminations of $35 \mathrm{~mm}$ thick. CLT with thinner laminations are expected to exhibit a faster "effective" charring rate and should be considered in a charring model $[24,89]$. The model did not consider the impact from air gaps between the CLT panels, which could lead to premature charring at the joint interface. 
According to Equation (2.3), a residual thickness of $12 \mathrm{~mm}$ would allow meeting the insulation criterion as described in subsection 2.1.3 of this thesis. By setting a minimum penetration depth into the main member to $12 \mathrm{~mm}$, all failure times predicted from the coupled thermal-structural model occur when the fastener experiences a $67 \%$ strength loss from its initial resistance. At these times to failure, the penetration depth into the main member is approximately $17 \mathrm{~mm}\left( \pm 4.0 d_{F}\right)$, which is slightly lower than CSA O86 requirement of $5 d_{F}$. Moreover, with this set of criteria, the coupled thermal-structural over-predicts the fire integrity resistance times for the half-lapped and the internal spline joint, when compared to fire test data.

When setting the minimum penetration depth criterion to $22 \mathrm{~mm}$, which coincides with the $5 d_{F}$ rule in CSA O86, all predicted failure times are governed by this minimum depth requirement as opposed to the connection strength loss criterion. Figure 5.11 summarizes the predicted fire integrity failure times from the coupled thermal-structural model, assuming a minimum penetration depth of $22 \mathrm{~mm}$.

Figure 5.12 shows that when compared to fire test data, the model predictions are in very strong agreement when a minimum penetration depth into the main member of $22 \mathrm{~mm}$ and a strength loss of $67 \%$ are used as the failure criteria. A high coefficient of correlation of 0.989 is obtained from the linear regression of these five data points. While the $22 \mathrm{~mm}$ criterion matches the $5 d_{F}$ rule set forth in CSA O86 for lag screws and provides reasonable predictions, further investigation is needed to confirm its validity for other types of fasteners and/or other diameters as well as other thickness of laminations. 


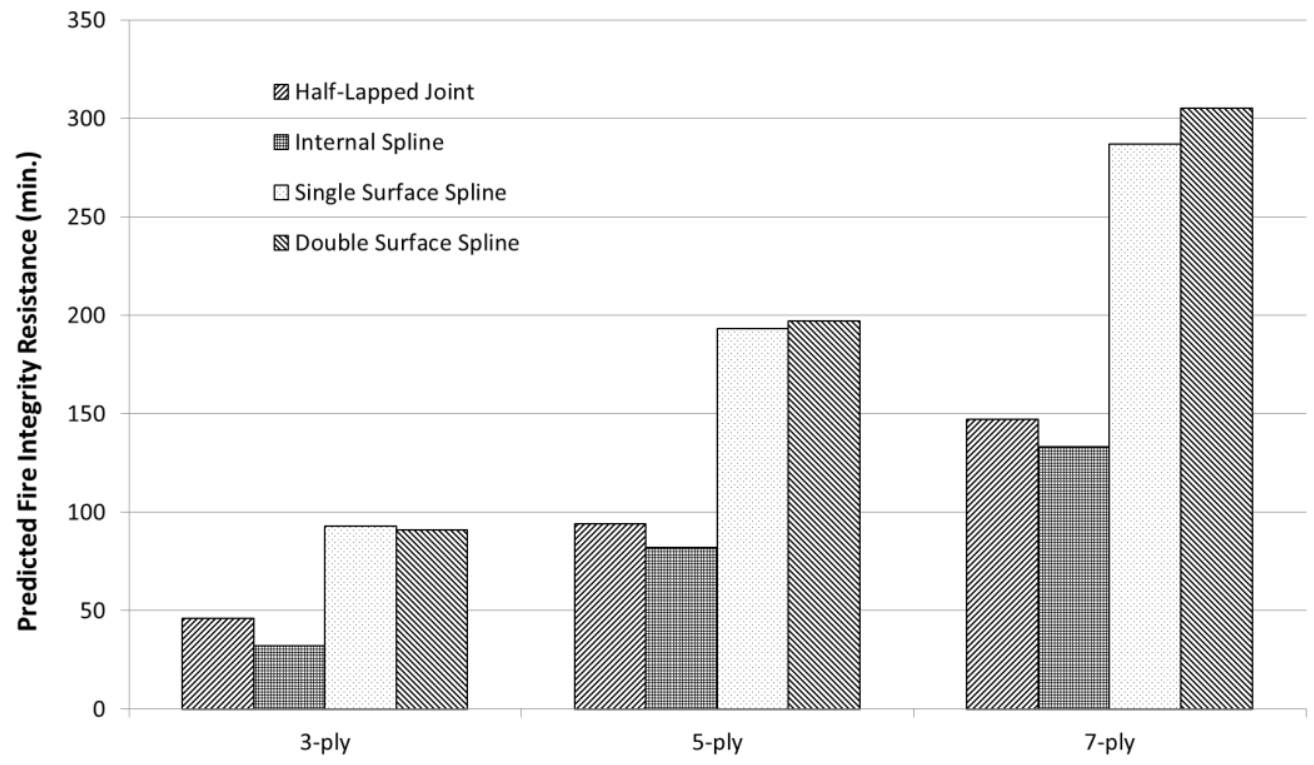

Figure 5.11 - Predicted failure time from the coupled thermal-structural model

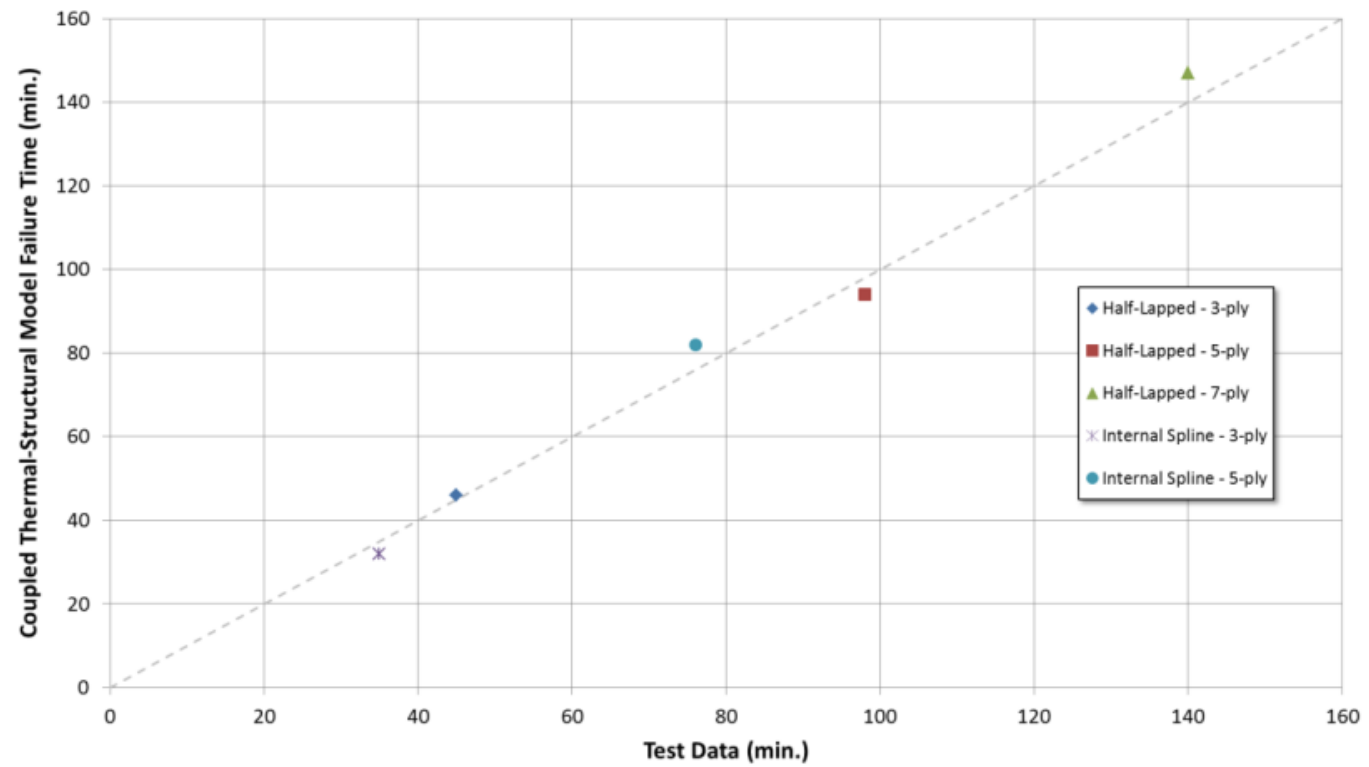

Figure 5.12 - Failure time from the coupled thermal-structural model compared to test data 
The model predictions also suggest that using a half-lapped joint would provide a better fire integrity resistance than that of an internal spline. Moreover, fire integrity failure from the internal spline joint details occurred at mid-span where the plywood splines abut to each other, suggesting that they may have not been adequately butt-jointed (i.e. no gaps). This raises the importance of proper field installation when an internal spline is being used to connect CLT panels together in an attempt to effectively provide the anticipated level of fire integrity performance.

There is very minimal difference observed in the predicted failure times between the single and double surface spline details. The predictions were however not fully validated against fire test data as only the 3-ply specimen with double surface spline reached an actual integrity failure, and it was much faster than the predicted failure time. While very limited test data was available for validating the single and double surface spline predictions, the accurate validation from the other two joint details suggest that the methodology and assumptions implemented in the coupled thermal-structural model are reasonable and may be valid for these surface spline joint details, provided the CLT panels are tightly fit together (i.e. no air gaps).

The minimal difference in predicted times suggests that except for improving the in-plane resistance of CLT panel-to-panel connections, there may not be a benefit from using the double surface spline in CLT floor applications. In CLT wall applications, a symmetrical joint detail would most likely be preferable as fire-resistance is to be assessed from fire 
occurring from either side. Assessment of CLT wall fire-resistance is however beyond the scope of the current thesis.

Lastly, the coupled thermal-structural model allows for rapidly evaluating the CLT connection capacity for half-lapped joints and internal splines located at other depths along the CLT thickness. Shifting the joint interface furthest from the fire-exposed surface would provide a significant increase in fire integrity resistance, while not significantly impacting the lateral resistance of the CLT panel-to-panel connection. 


\section{Simplified Design Model}

Chapter 6 describes the last stage of this study, which aims at developing the joint coefficient values $\left(K_{j}\right)$ for the four (4) types of CLT panel-to-panel joint details to be used in a simplified design model to predict the fire integrity resistance of CLT panel-to-panel joints.

\subsection{Methodology and Assumptions}

Simplified design methods have traditionally been shown to predict integrity and structural fire-resistance with an acceptable level of accuracy, while being efficient with respect to computational time. Simplified and user-friendly design models, such as those typically implemented into Codes and design standards, are usually preferred by the building design community.

The design provisions given in Eurocode 5: Part 1-2, the CLT Handbook and the Technical Report 10 [90] are examples, among others, of simple and efficient design models. Other examples of simplified models are the spreadsheet developed by O'Neil et al. [91] for predicting the fire-resistance of timber-concrete composite floor assemblies and the one-dimensional finite difference numerical model developed by Aguanno [89] for predicting the temperature profile and fire-resistance of CLT floor assemblies exposed to standard or design fire exposures.

Based on a similar approach to that detailed in [24] and assuming a constant onedimensional charring rate $\left(\beta_{0}\right)$ of $0.65 \mathrm{~mm} / \mathrm{min}$, which is applicable to most softwood 
products (Table 2.9), a joint coefficient value can be derived using Equation (2.2) in its general form. When solving for $K_{j}$, Equations (6.1) and (6.2) are obtained.

$$
\begin{gathered}
K_{j}=\frac{t_{\text {Test Data }} \cdot \beta_{0}}{D} \\
K_{j}=\frac{t_{\text {Model }} \cdot \beta_{0}}{D}
\end{gathered}
$$

Where $t_{\text {Test Data }}$ is the fire integrity failure times recorded during the fire test series (min.), $t_{\text {Model }}$ is the predicted failure time from the coupled thermal-structural model (min.), $\beta_{0}$ is a constant one-dimensional charring rate of $0.65 \mathrm{~mm} / \mathrm{min}$ and $D$ is the CLT initial thickness (mm).

\subsection{Predictions from the Simplified Design Model}

\subsubsection{Half-Lapped Joint}

As reported previously in this thesis, fire integrity failures occurred at 45, 98 and $140 \mathrm{~min}$ respectively for the 3-ply, 5-ply and 7-ply CLT specimens. The coupled thermalstructural model predicted a failure at 46, 94 and 147 min for the 3-ply, 5-ply and 7-ply CLT specimens, respectively. Table 6.1 provides the joint coefficients associated with the actual test data and predicted failure times for the half-lapped joint configuration. The joint coefficient value for the simplified model is taken as the average value from the test data and coupled thermal-structural model predictions. 
Table 6.1 - Joint coefficient $\left(K_{j}\right)$ from test data and model predictions - Half-lapped joint

\begin{tabular}{|c|c|c|c|c|c|}
\hline \multirow{2}{*}{ CLT Specimen } & \multicolumn{2}{|c|}{ Test Data } & \multicolumn{2}{|c|}{ Model Predictions } & \multirow{2}{*}{$\begin{array}{c}\text { Simplifie d Model } \\
\qquad\left(K_{j}=0.35\right)\end{array}$} \\
\hline & Time & $K_{j, \text { Test }}$ & Time & $\boldsymbol{K}_{j, \text { Model }}$ & \\
\hline 3-ply (105 mm) & $45 \mathrm{~min}$ & 0.28 & $46 \mathrm{~min}$ & 0.28 & $56 \mathrm{~min}$ \\
\hline 5-ply (175 mm) & $98 \mathrm{~min}$ & 0.36 & $94 \mathrm{~min}$ & 0.35 & $94 \mathrm{~min}$ \\
\hline \multirow[t]{2}{*}{ 7-ply (245 mm) } & $140 \mathrm{~min}$ & 0.37 & $147 \mathrm{~min}$ & 0.39 & $131 \mathrm{~min}$ \\
\hline & Average & 0.34 & & 0.34 & \\
\hline Standar & Deviation & 0.05 & & 0.05 & \\
\hline
\end{tabular}

As explained in subsection 3.14.3, it is not surprising to obtain a joint coefficient lower than the actual location of the half-lapped joint (mid-depth $=0.50$ ratio). This is attributed to the adhesive heat delamination which increases the "effective" charring rate of CLT exposed to fire. It also accounts for the fastener minimum penetration length requirements from CSA O86, which is captured in the coupled thermal-structural model.

On average, a joint coefficient of 0.34 is obtained for the half-lapped joint configuration, which is very close to that suggested in the CLT Handbook and slightly higher than that of Eurocode 5: Part 1-2 (Table 2.1). While this value of 0.34 provides a significant difference in the prediction for a 3-ply CLT, the predicted times are consistent with the full-scale fire-resistance tests data obtained from Osborne et al. [10]. As shown in Table 2.3, a 3-ply CLT assembly would achieve a fire integrity failure of $56 \mathrm{~min}$, which would result in a joint coefficient value of 0.35 .

As such, it is recommended to maintain the value of 0.35 currently prescribed in the CLT Handbooks (US and Canadian), resulting in predicted failure times of 56, 94 and $131 \mathrm{~min}$ respectively for a 3-ply, 5-ply and 7-ply CLT floor assembly. Figure 6.1 illustrates the 
fire integrity resistance times from the test data, the coupled thermal-structural model and the simplified design model using $K_{j}$ of 0.35 .

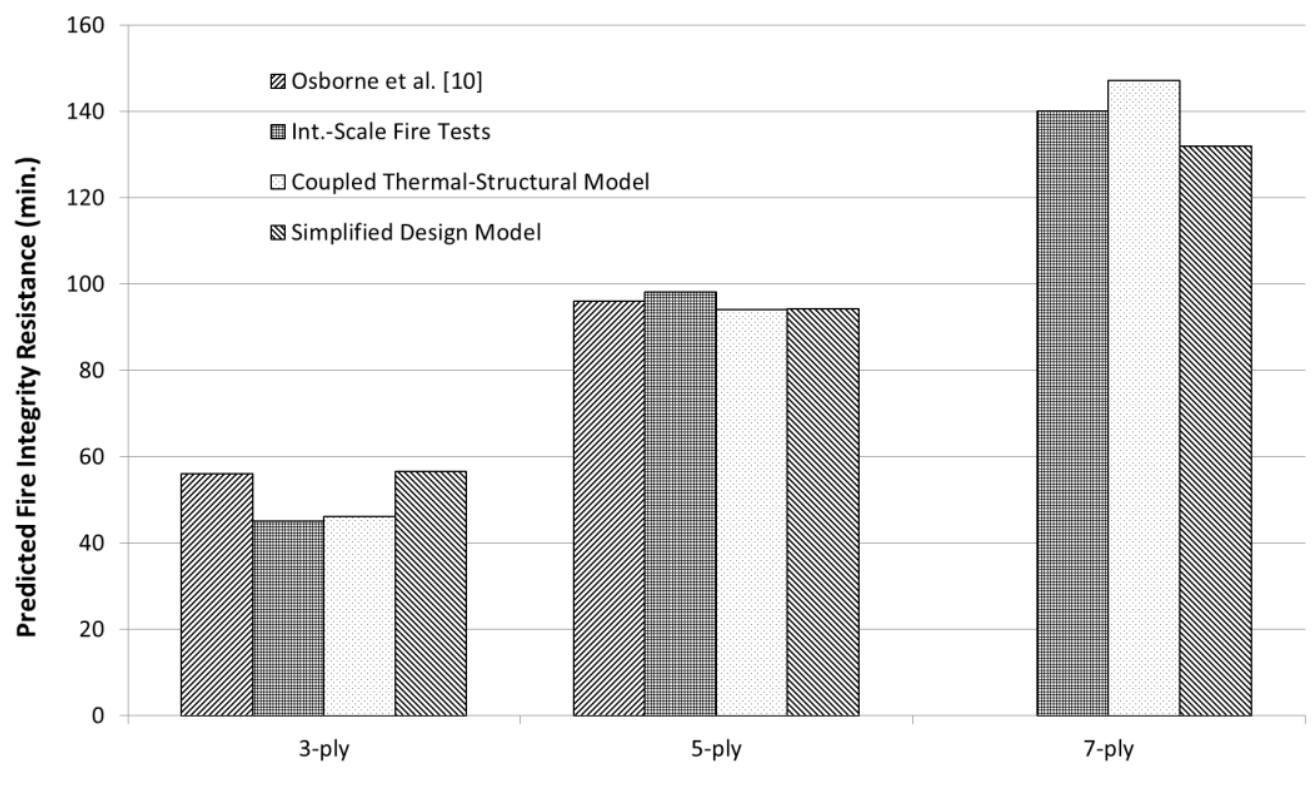

Figure 6.1 - Comparison of fire integrity failure time for the half-lapped joint

\subsubsection{Internal spline}

Similarly to the half-lapped joint, a joint coefficient can be calculated using Equations (6.1) and (6.2). Table 6.2 provides the joint coefficients associated with the actual test data and predicted failure times for an internal spline joint detail. The joint coefficient value for the simplified model is taken as the average value from the test data and coupled thermal-structural model predictions. 
Table 6.2 - Joint coefficient $\left(K_{j}\right)$ from test data and model predictions - Internal spline

\begin{tabular}{|c|c|c|c|c|c|}
\hline \multirow{2}{*}{ CLT Specimen } & \multicolumn{2}{|c|}{ Test Data } & \multicolumn{2}{|c|}{ Model Predictions } & \multirow{2}{*}{$\begin{array}{c}\text { Simplifie d Model } \\
\left(K_{j}=\mathbf{0 . 2 7}\right)\end{array}$} \\
\hline & Time & $K_{j, \text { Test }}$ & Time & $\boldsymbol{K}_{j, \text { Model }}$ & \\
\hline 3-ply (105 mm) & $35 \mathrm{~min}$ & 0.22 & $32 \mathrm{~min}$ & 0.20 & $43 \mathrm{~min}$ \\
\hline 5-ply (175 mm) & $76 \mathrm{~min}$ & 0.28 & $82 \mathrm{~min}$ & 0.30 & $72 \mathrm{~min}$ \\
\hline \multirow[t]{2}{*}{ 7-ply (245 mm) } & - & - & $133 \mathrm{~min}$ & 0.35 & $102 \mathrm{~min}$ \\
\hline & Average & 0.25 & & 0.29 & \\
\hline Standar & Deviation & 0.05 & & 0.08 & \\
\hline
\end{tabular}

On average, a joint coefficient of 0.27 is obtained for the internal spline joint detail, which is significantly lower than that of Eurocode 5: Part 1-2. The latter also assigns a greater joint coefficient value to the internal spline $\left(K_{j}=0.40\right)$ when compared to that of the half-lapped $\left(K_{j}=0.30\right)$, as assumed in Table 3.2. Interestingly, the fire test data from this study and the predictions from the coupled thermal-structural model suggest otherwise; the half-lapped joint seems to perform better. Furthermore, given the fact that the internal spline may be subject to inadequate field installation (butt-joints not being tightly fitted), it is recommended to assign a lower joint coefficient value to that of the half-lapped joint.

A joint coefficient of 0.30 for an internal spline CLT panel-to-panel joint is suggested, resulting in reasonable predicted failure times of 48,80 and 113 min respectively for a 3ply, 5-ply and 7-ply CLT floor assembly when compared to test data. Figure 6.2 illustrates the fire integrity resistance times from the test data, the coupled thermalstructural model and the simplified design model using $K_{j}$ of 0.30 . 


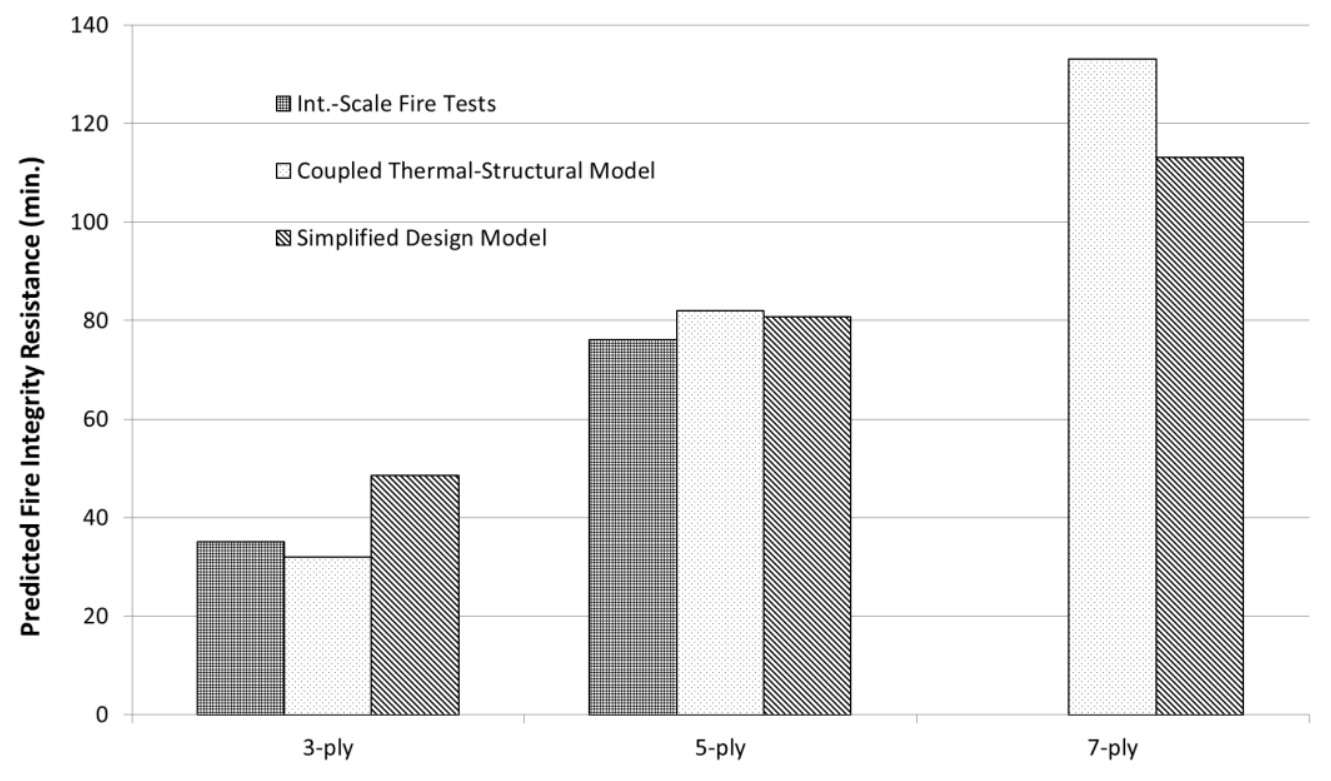

Figure 6.2 - Comparison of fire integrity failure time for the internal spline joint

\subsubsection{Single Surface Spline}

While no actual fire test data is available to fully validate the coupled thermal-structural and the simplified design models, the development of a joint coefficient for the CLT panel-to-panel joints using a single surface spline is only based on the same principles and assumptions detailed above, that is from the coupled model predictions and sound engineering judgment. Table 6.3 provides a summary of the various parameters used to evaluate the single surface spline joint detail. 
Table 6.3 - Joint coefficient $\left(K_{j}\right)$ from test data and model predictions - Single surface spline

\begin{tabular}{|c|c|c|c|c|c|}
\hline \multirow{2}{*}{ CLT Specimen } & \multicolumn{2}{|c|}{ Test Data } & \multicolumn{2}{|c|}{ Model Predictions } & \multirow{2}{*}{$\begin{array}{c}\text { Simplifie d Model } \\
\left(K_{j}=0.68\right)\end{array}$} \\
\hline & Time & $K_{j, \text { Test }}$ & Time & $\boldsymbol{K}_{j, \text { Model }}$ & \\
\hline 3-ply (105 mm) & $>54 \mathrm{~min}$ & $>0.33$ & $93 \mathrm{~min}$ & 0.58 & $110 \mathrm{~min}$ \\
\hline 5-ply (175 mm) & $>98 \mathrm{~min}$ & $>0.36$ & $193 \mathrm{~min}$ & 0.72 & $184 \mathrm{~min}$ \\
\hline \multirow[t]{2}{*}{ 7-ply (245 mm) } & - & - & $287 \mathrm{~min}$ & 0.76 & $258 \mathrm{~min}$ \\
\hline & Average & $>0.35$ & & 0.68 & \\
\hline Standar & Deviation & - & & 0.10 & \\
\hline
\end{tabular}

The intermediate-scale fire tests suggest that a joint coefficient value greater than 0.35 would seem appropriate. Based on the actual joint configuration and location of the joint interface across the CLT thickness (much further from the fire-exposed surface compared to the half-lapped and internal spline), it appears reasonable that indeed the joint coefficient value could be greater than 0.35 , as assumed in Table 3.2. From the coupled thermal-structural model, an average joint coefficient value of 0.68 is derived, supporting the assumption of a joint coefficient value greater than 0.35 . There is unfortunately no test data to validate further the simplified model predictions. Nevertheless, the predicted failure times are greater than the times from the fire tests of the 3-ply and 5-ply CLT specimens. They are also in agreement with the predicted times from the coupled thermal-structural model.

Currently, Eurocode 5: Part 1-2 (Table 2.1) assigns a value of 0.40 and 0.60 to a single and double tongue- $\&$-groove joint details, respectively. Given that the single surface spline is more similar, with respect to its configuration providing only one obstruction to air flow and flames, it would appear appropriate to assign a value of 0.40 . The resulting 
fire integrity failure times would then be 64, 107 and 150 min for a 3-ply, 5-ply and 7-ply CLT specimen respectively.

However, as mentioned in subsections 3.6 and 3.10 for the 3-ply and 5-ply specimens, respecrively, the char front was still far from reaching the plywood surface spline, suggesting that the CLT specimens could have lasted much longer.

As a result, a joint coefficient of 0.60 for a single surface spline CLT panel-to-panel joint is suggested, resulting in predicted failure times of 96, 161, $226 \mathrm{~min}$ respectively for a 3ply, 5-ply and 7-ply CLT floor assembly. Figure 6.3 illustrates the fire integrity resistance times from the test data, the coupled thermal-structural model and the simplified design model using $K_{j}$ of 0.60 .

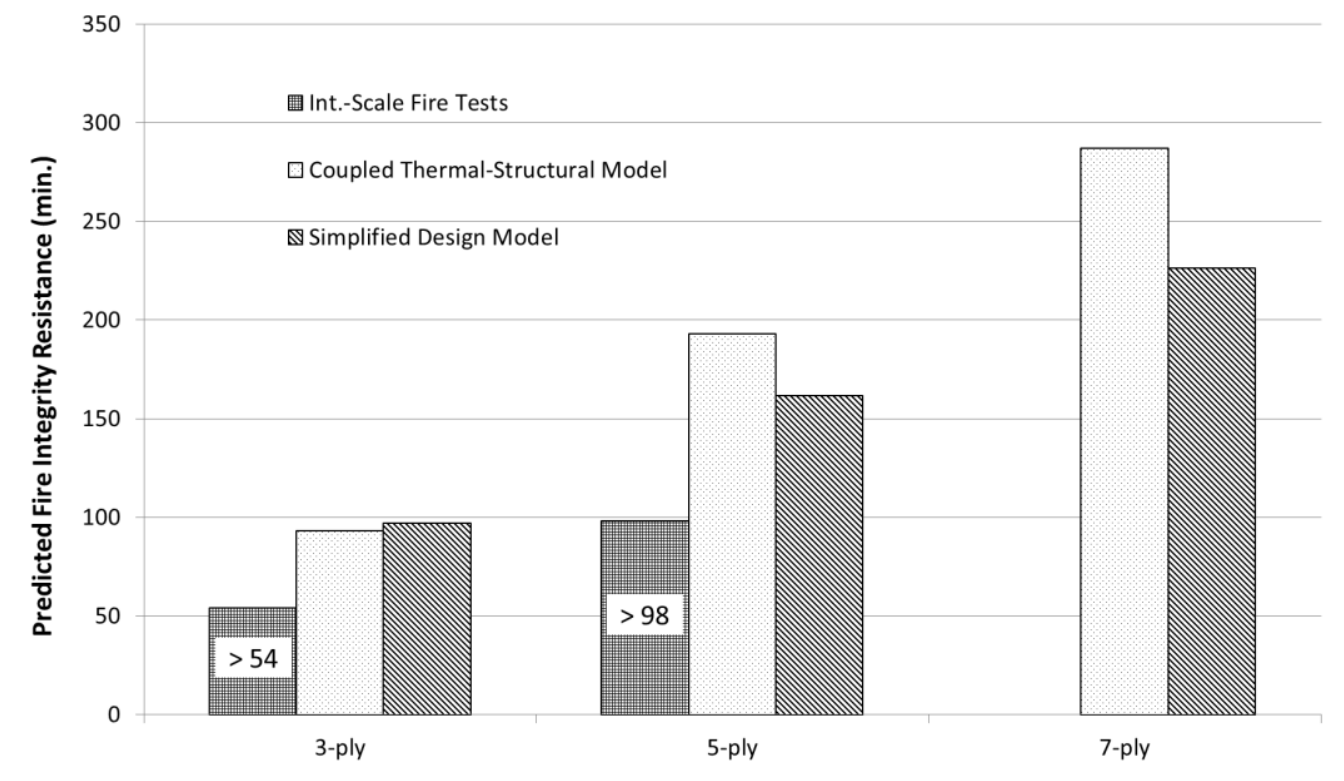

Figure 6.3 - Comparison of fire integrity failure time for the single surface spline joint 


\subsubsection{Double Surface Splines}

As with the single surface spline joint detail and as reported in subsection 5.2.4, very limited test data was available to validate the coupled thermal-structural model fire integrity failure time predictions (only the 3-ply specimen reached an actual fire integrity failure, at $43 \mathrm{~min}$ ). As such, the development of a joint coefficient for the CLT panel-topanel joints using a double surface spline is only based on the same principles and assumptions detailed for the single surface spline joint. Table 6.4 provides a summary of the various parameters used to evaluate the double surface spline joint detail. The joint coefficient value for the simplified model is taken as the average value from the test data and coupled thermal-structural model predictions.

Table 6.4 - Joint coefficient $\left(K_{j}\right)$ from test data and model predictions - Double surface spline

\begin{tabular}{|c|c|c|c|c|c|}
\hline \multirow{2}{*}{ CLT Specimen } & \multicolumn{2}{|c|}{ Test Data } & \multicolumn{2}{|c|}{ Model Predictions } & \multirow{2}{*}{$\begin{array}{c}\text { Simplified Model } \\
\left(K_{j}=0.59\right)\end{array}$} \\
\hline & Time & $K_{j, \text { Test }}$ & Time & $\boldsymbol{K}_{j, \text { Model }}$ & \\
\hline 3-ply (105 mm) & $43 \mathrm{~min}$ & 0.27 & $91 \mathrm{~min}$ & 0.56 & $95 \mathrm{~min}$ \\
\hline 5-ply (175 mm) & $>90 \mathrm{~min}$ & $>0.33$ & $197 \mathrm{~min}$ & 0.73 & $159 \mathrm{~min}$ \\
\hline \multirow[t]{2}{*}{ 7-ply (245 mm) } & $>180 \min ^{(1)}$ & $>0.48$ & $305 \mathrm{~min}$ & 0.81 & $223 \mathrm{~min}$ \\
\hline & Average & $>0.36$ & & 0.70 & \\
\hline Standar & d Deviation & - & & 0.13 & \\
\hline
\end{tabular}

(1) Test was stopped due to a structural failure. Fire integrity failure was not reached.

At first, it was expected that the double surface spline would afford longer fire integrity resistance when compared to that of the single surface spline, resulting in a greater joint coefficient value. Not much difference between the two configurations was however observed during the intermediate-scale fire tests. In fact, when comparing the 3-ply CLT specimens, the double surface spline failed quite early when compared to the single 
surface spline. As reported in subsection 3.11, the actual cause of such premature failure is unclear.

Moreover, as observed for the CLT specimens with the single surface spline joint detail (refer to subsections 3.6 and 3.10), the char front was still far from reaching the plywood surface spline, suggesting that the CLT specimens could have lasted much longer. This is especially relevant to the 3-ply CLT specimen which seems to have failed prematurely.

Nevertheless, the coupled thermal-structural model predictions would result in an average joint coefficient value of 0.59 , which is somewhat similar to that suggested for the single surface spline joint detail.

Given that the double surface spline is simply a symmetrical configuration of the single surface spline, it is recommended to use a joint coefficient of 0.60 for the double surface spline CLT panel-to-panel joint detail, which results in predicted failure times of 96, 161, 226 min for a 3-ply, 5-ply and 7-ply CLT floor assembly, respectively. Figure 6.4 illustrates the fire integrity resistance times from the test data, the coupled thermalstructural model and the simplified design model using $K_{j}$ of 0.60 . 


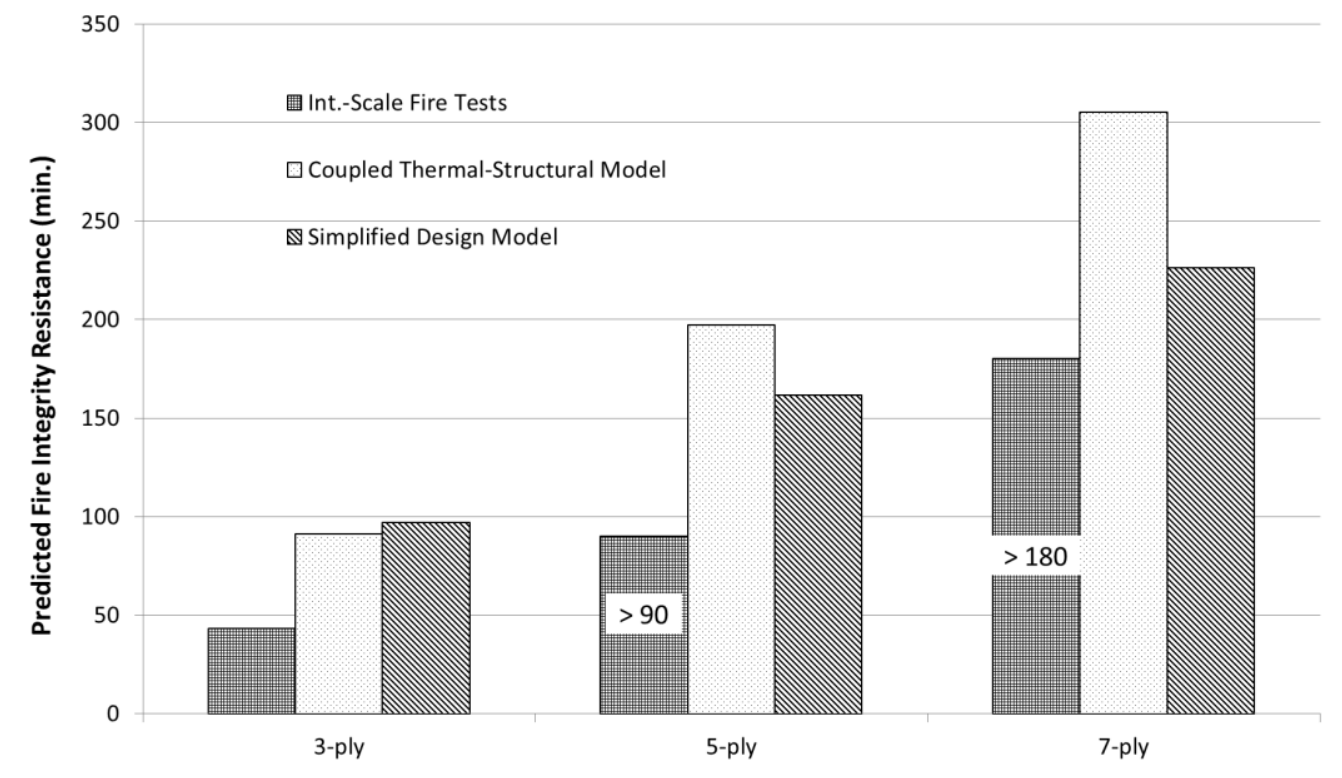

Figure 6.4 - Comparison of fire integrity failure time for the double surface spline joint

\subsection{Summary}

Chapter 6 aimed at developing a simplified design model for predicting the fire integrity resistance of the four CLT panel-to-panel joint details evaluated in this study. More precisely, the objective was to derive suitable joint coefficient $\left(K_{j}\right)$ values for use in Equation (2.2). The simplified model assumed a constant one-dimensional charring rate of $0.65 \mathrm{~mm} / \mathrm{min}$, which is typical of most softwood products, allowing to easily backcalculating a joint coefficient value.

The simplified design model has been shown to provide reasonable fire integrity failure times when compared to the intermediate-scale fire tests, when available, and to the predictions from the coupled thermal-structural model. Table 6.5 is a summary of the joint coefficient values derived from the results and predictions of this study as well as 
recommended values for potential Code implementation. It is noted that the simplified design model provides less conservative predictions for 3-ply CLT panels and more conservative values for 7-ply CLT panels, suggesting a non-linear effect potentially due to the load ratio, the resulting effective charring rate and/or the CLT thickness. This observation warrants further investigation and improvement of the model in the future research.

Table 6.5 - CLT panel-to-panel joint coefficients from test data and simplified design model

\begin{tabular}{|c|c|c|c|c|}
\hline \multirow{2}{*}{ CLT Assembly } & \multicolumn{4}{|c|}{$\begin{array}{c}\text { Joint Coefficient }\left(\boldsymbol{K}_{\boldsymbol{J}}\right) \text { for use in Equation (2.2) } \\
\text { (From Equation }(6.1) \text { / Equation }(6.2))\end{array}$} \\
\hline & Half-Lapped & Internal Spline & $\begin{array}{l}\text { Single Surface } \\
\text { Spline }\end{array}$ & $\begin{array}{l}\text { Double Surface } \\
\text { Spline }\end{array}$ \\
\hline 3-ply $(105 \mathrm{~mm})$ & $0.28 / 0.28$ & $0.22 / 0.20$ & $>0.33 / 0.58$ & $0.27 / 0.56$ \\
\hline 5-ply $(175 \mathrm{~mm})$ & $0.36 / 0.35$ & $0.28 / 0.30$ & $>0.36 / 0.72$ & $>0.33 / 0.83$ \\
\hline 7-ply $(245 \mathrm{~mm})$ & $0.37 / 0.39$ & $-\quad / 0.35$ & $-\quad / 0.76$ & $>0.48 / 0.81$ \\
\hline $\begin{array}{l}\text { Recommended } \\
\text { value }\end{array}$ & 0.35 & 0.30 & 0.60 & 0.60 \\
\hline
\end{tabular}

Designers should be capable to safely verify both the load-bearing and separating functions of CLT assemblies in wall and floor applications in accordance with fire-related provisions of the building codes. The simplified design model presented in this Chapter is an easy-to-use design procedure for evaluating the fire integrity resistance of four commonly-used CLT panel-to-panel joint details. The load-bearing function of CLT assemblies is beyond the scope of this thesis and may be evaluated from other exiting models such as those detailed in subsection 2.2 of this thesis. 


\section{Conclusions and Recommendations}

\subsection{Summary}

During the past few years, a relatively new technology has emerged in North America and changed the way professionals design and build wood structures: Cross-laminated Timber (CLT). While they have been shown to provide good fire-resistance, recent fullscale fire-resistance tests conducted by FPInnovations identified that fire integrity failure of CLT panel-to-panel connections in floor assemblies was one of the predominant failure modes when using a half-lapped joint detail. Such failure mode was not observed in CLT wall assemblies under load as they usually exhibit buckling due to increased second-order effects. Nevertheless, the panel-to-panel joint configuration can affect the fire integrity performance of CLT assemblies when panel-to-panel joints can no longer prevent the passage of flames and hot gases.

Typical panel-to-panel joint configurations of CLT assemblies may consist of internal spline(s), single or double surface splines or half-lapped joints. These tightly fitted joint profiles should provide sufficient fire-resistance, but have yet to be properly evaluated for fire-resistance in CLT assemblies.

The main objective of this study was to evaluate commonly used floor panel-to-panel connection details through fire tests and to develop a finite element heat transfer model, a coupled thermal-structural model and lastly a simplified design model that would predict the fire integrity resistance of CLT assemblies. 
The experimental portion of the study consisted of conducting ten (10) intermediate-scale fire-resistance tests of four (4) types of CLT panel-to-panel joint and three (3) CLT thicknesses. The CLT used in this study were of the E1 stress grade per the ANSI/APA PRG-320 standard and were manufactured with 35-mm thick laminations. The fasteners used to connect the CLT together were partially-threaded ASSY® 3.0 Ecofast selftapping screws. For the assemblies requiring a spline, strips of $18.5 \mathrm{~mm}$ (6-ply) plywood were used.

The fire tests generated valuable information with respect to the thermal and mechanical behaviour of the panel-to-panel joints. A three-dimensional finite element model (FEM) heat transfer model and a coupled thermal-structural model were analysed to predict the temperature profiles within the CLT panels, the charring rates of the $35 \mathrm{~mm}$ laminations and the mechanical behaviour of the panel-to-panel connection exposed to the standard CAN/ULC S101 time-temperature curve. While the fire test results were inconclusive for the single surface spline joints, the resulting information was used to determine joint coefficients to all four panel-to-panel joint configurations to easily and rapidly predict their fire integrity through a simplified design model.

The data generated from the intermediate-scale fire tests were used to validate a finite element heat transfer model, a coupled thermal-structural model and a simplified design model. The results show that the FEM accurately predicts temperature profiles for standard fire exposure up to 180 min (3 hours) when compared to data from full-scale 
fire-resistance tests on CLT floor assemblies found in the literature, within $7.5 \%$ accuracy.

The sensitivity analysis of the finite element heat transfer model showed that thermal properties and meshing are important factors impacting the heat transfer and temperature profiles, thus the resulting charring rates. However, it was demonstrated that meshing the actual geometry of the self-tapping screw threaded shank does not improve the accuracy of the heat transfer model, albeit significantly increasing the computational time.

The resulting charring rate of each lamination was then implemented into a coupled thermal-structural model. It was found that the coupled thermal-structural model provides reasonable fire integrity failure times when compared to the experimental results, where applicable. It also allows for an understanding of the mechanical behaviour of the connections (i.e. yield mode) and optimizing the joint configuration by moving the joint interface along the CLT thickness. Such optimization can significantly improve the fire integrity of the half-lapped and internal spline joint details while not impacting their lateral resistance to in-plane loading.

Lastly, the fire test data and failure times predicted from the coupled thermal-structural model allowed deriving joint coefficient for each joint configuration for use in a simplified design model. The simplified design model presented in this thesis is an easyto-use design procedure for evaluating the fire integrity resistance of four commonly-used CLT panel-to-panel joint details and could potentially be implemented into building codes and design standards. It is noted however that single surface spline and double 
surface splines fire tests were mostly inconclusive. As such, the simplified design model for these joint details could not be fully validated from test data.

\subsection{Main Conclusions}

From the results reported in this thesis, valuable and relevant conclusions can be drawn with respect to the fire integrity resistance of CLT panel-to-panel joint in floor applications. The following conclusions are however valid within the scope and limitations set forth in Subsection 1.3, and thus may not valid if there is significant loading across the screwed connection in in-plane or out-of-plane shear, especially if the CLT panels are loaded in two-way bending (accidentally or on purpose).

a) Using surface splines was found to be the best CLT panel-to-panel joint detail, provided the panels are tightly fitted together (i.e. no gaps) and the spline is installed on the surface opposite to the source of fire.

b) Using an internal spline was found to be the least efficient joint detail when compared to the other joint configurations due to potential gaps at the butt joint between the splines. It could be improved if tongue- and-groove or scarf joint is used between splines.

c) Half-lapped joints provided better fire integrity performance when compared to the internal spline joints.

d) In all fire tests, a 20\% increase in the charring rate is observed, due to adhesive heat delamination, for the $2^{\text {nd }}$ and subsequent laminations exposed to the standard fire and should be considered in calculation models. 
e) Small diameter fasteners such as the self-tapping screws used in this study have a negligible source of heat conduction within CLT panels and may be neglected in calculation models.

f) Wood thermal properties significantly impact the resulting charring rates in a FEM when not properly calibrated to account for heat delamination of adhesive.

g) Neglecting the threaded portion from the shank of self-tapping screws when meshing the contact regions in the FEM does not affect significantly the heat transfer model results, but significantly reduces the computational times.

h) FEM predicted charring rates of $0.56,0.73$ and $0.64 \mathrm{~mm} / \mathrm{min}$ for the $1^{\text {st }}, 2^{\text {nd }}$ and $3^{\text {rd }}$ laminations respectively, which is within $7.5 \%$ accuracy when compared to those measured during the intermediate- and full-scale fire tests.

i) Coupling the charring rates from the FEM with the fastener design provisions of CSA 086-14 allows understanding the mechanical behaviour, lateral capacity and failure mode of the connection as a function of time.

j) Coupling the charring rates from the FEM with the fastener design provisions of CSA O86-14 also allows optimizing joint configurations by moving the joint interface across the CLT thickness until the best balance between lateral capacity and fire integrity is achieved.

k) The simplified design model predicted reasonable fire integrity failure times when compared to the intermediate-scale fire tests and to the predictions from the coupled thermal-structural model for half-lapped and internal spline joint details. 
1) The simplified design model is an easy-to-use design procedure for evaluating the fire integrity resistance of four commonly-used CLT panel-to-panel joint details and could potentially be implemented into building codes and design standards.

\subsection{Contribution of this Study}

The information generated from this study allows for a better understanding of the behaviour of CLT floor assemblies with four (4) commonly used types of panel-to-panel joints exposed to the CAN/ULC S101 standard time-temperature curve in an intermediate-scale test furnace. Literature review did not find any research in this area, hence this is the first research aimed at evaluating the fire integrity performance of CLT panel-to-panel joints.

A three-dimensional (3D) finite element heat transfer model was developed for evaluating the temperature profiles in the CLT panel-to-panel joints. Due to adhesive heat delamination observed during the intermediate-scale fire-resistance tests, a calibration of the thermal properties of the $35-\mathrm{mm}$ thick wood laminations has also been made. The finite element heat transfer model has been validated against data from intermediate- and full-scale fire tests on CLT floor assemblies. It allows predicting accurately the temperature profiles of CLT floor elements exposed to a standard fire curve up to 180 $\min (3$ hours).

The resulting charring rate of each lamination was also implemented into a coupled thermal-structural model. The model allows predicting the mechanical behaviour of the 
connections (i.e. yield mode), predicting its fire integrity failure time and optimizing the joint configuration by moving the joint interface along the CLT thickness. The coupled thermal-structural model was shown to predict failure times accurately when compared to the intermediate-scale fire tests, namely with respect to the half-lapped and internal spline joint details which were validated from the fire tests.

Based on the test data and models developed in this study, joint coefficient values were derived for the four (4) types of CLT panel-to-panel joint details. Joint coefficients are required when assessing the fire integrity of joints using simple design models, such as Eurocode 5: Part 1-2.

In summary, the contribution of this study is to increase the knowledge of CLT exposed to fire and to facilitate its use in North America by complementing current fire-resistance design methodologies of CLT assemblies, namely with respect to the fire integrity criterion. When CLT is used as floor and wall assemblies, designers should be capable to verify both the load-bearing and separating functions of CLT assemblies in accordance with fire-related provisions of the building codes, which are now feasible based on the findings of this study.

\subsection{Recommendations for Future Research}

The research detailed in this thesis aimed at evaluating four commonly used CLT panelto-panel joints in floor applications. The joints were assembled in such a way to avoid any gaps between the adjacent CLT panels. 
Therefore, to expand the range of application of the findings from this study, further fire tests should be conducted with CLT specimens subjected to either one-way bending along the minor strength axis of the CLT panels or two-way bending to assess the impact of gaps that may open due to bending deflection.

Furthermore, there is a need for evaluating the fire performance of other joint configurations, CLT made from laminations of other thicknesses, CLT glued with other types of adhesives that may or may not exhibit heat delamination, CLT joints with other types of fasteners and other diameters as well as CLT joints with air gaps of various widths.

Moreover, given that this study evaluated panel-to-panel joints of CLT of three different thicknesses, various stress ratios were applied. As such, fire testing of a specific CLT panel-to-panel joint subjected to various stress ratios would be relevant and would allow analyzing the load ratio effect, which was beyond the scope of the current thesis.

The simplified design model presented in this study suggests a non-linear effect when predicting the fire integrity resistance of CLT panels. CLT from laminations of other thicknesses and CLT subjected to other stress ratios should be studied to verify this nonlinearity and potentially improve the model accordingly.

Lastly, it would also be beneficial that future research investigates the fire integrity performance of CLT walls connected with similar CLT panel-to-panel joints to those evaluated in this study. Full-scale fire-resistance tests by FPInnovations demonstrated 
that CLT walls exhibit different failure modes than CLT floors [10, 19], when joined together with a half-lapped joint.

\subsection{Final Remarks}

While the single and double surface splines provided better fire integrity performance than the other two joint configurations, it is recommended that the half-lapped joint be used in CLT construction. Such joint is easy to manufacture at the plant and to assemble at the job site. It was also found that such joint detail exhibits superior strength and ductility when compared to that of single surface spline joint detail [47], while limiting negative impacts on the mechanical behaviour of connections due to eccentricity. It can easily be optimized by moving the lapped joint at various locations along the CLT thickness in such a way to achieve the best balance between fire integrity performance and lateral capacity against in-plane loading (e.g. wind and seismic forces).

Half-lapped joint also eliminates potential field installation, resulting in gaps between adjoining panels as observed during some intermediate-scale fire tests with a spline joint configuration (either internal or surface). Such observation raises the importance of proper field installation when a spline is being used to connect CLT panels together in attempt to effectively provide the anticipated level of fire integrity performance.

In CLT wall applications, a symmetrical joint detail would most likely be preferable as fire-resistance is to be assessed from fire occurring from either side. Therefore, the single surface spline joint detail may not be appropriate. 


\section{References}

[1] J. Mayo, Solid Wood: Case Studies in Mass Timber Architecture, Technology and Design, New York (NY): Routledge, 2015.

[2] D. Moses and S. Gagnon, "The Advent of Cross-Laminated Timber," Construction Canada, vol. 53 (2), pp. 76-84, March 2011.

[3] FPInnovations, CLT Handbook (Cdn Edition): Chapter 1 - Introduction to CrossLaminated Timber, Quebec City (Qc): FPInnovations, 2011.

[4] SP Trätek, Multi-Storey Wooden Houses in Sweden - Technical Data, Stockholm (Sweden): SP Trätek (Swedish Institute for Wood Technology Research), 2009.

[5] S. Gagnon and C. Dagenais, "Rapport de voyage : Mission technique en Allemage et Autriche - 21 au 25 septembre 2009," FPInnovations, Quebec City (Qc), 2009.

[6] S. Gagnon and L. Hu, "Trip report: Sweden, Norway and France - November 1st to 11, 2007," FPInnovations, Quebec City (Qc), 2007. 
[7] NRCC, National Building Code - Canada (volume 2), Ottawa (Ont.): National Research Council Canada, 2010.

[8] NRCC, National Building Code - Canada (volume 1), Ottawa (Ont.): National Research Council Canada, 2010.

[9] C. Dagenais, M. Mohammad, R. Desjardins and N. Bénichou, Overview of FPInnovations CLT Fire Resistance Tests (TechNote 12-01E), Quebec City (Qc): FPInnovations, 2012.

[10] L. Osborne, C. Dagenais and N. Bénichou, Preliminary CLT Fire Resistance Testing Report (Project No. 301006155) - Final Report 2012/13, Ottawa (Ont.): FPInnovations, 2012.

[11] ISO, ISO 834-1: Fire-Resistance Test - Elements of Building Construction - Part 1: General Requirements, Geneva (Switzerland): International Standard Organization, 1999.

[12] C. Dagenais, R. H. White and K. Sumathipala, CLT Handbook (US Edition): Chapter 8 - Fire Performance of Cross-Laminated Timber Elements, Quebec City (Qc): FPInnovations, 2013. 
[13] L. Podesto, "The Coming of Cross-Laminated Timber," The Construction Specifier, vol. September 64 (9), pp. 46-55, 2001.

[14] ANSI, Standard for Performance-Rated Cross-Laminated Timber (ANSI/APA PRG 320-2012), New York, NY: American National Standards Institute, 2012.

[15] NRCC, "NBC 2010 - Intent Statements," National Research Council Canada, 2012. [Online]. Available: http://irccgonline2.irc.nrc.ca/IRC_CGONLINEUI/IA/10NBC/intentframe.html. [Accessed 2012].

[16] NFPA, NFPA 550: Guide to the Fire Safety Concepts Tree, Quincy, MA: National Fire Protection Association, 2012.

[17] ULC, Standard Method of Fire Endurance Tests of Building Construction Materials (ULC S101-07), Toronto (Ont.): Underwriters Laboratories of Canada, 2007.

[18] ISO, ISO 13943: Glossary of Fire Terms and Definitions, Geneva (Switzerland): International Organization for Standardization, 2008.

[19] C. Dagenais, L. Osborne and N. Benichou, "Full-Scale Fire Performance of Cross- 
Laminated Timber Walls and Floors," in 13th International Symposium Interflam, Royal Holloway College, UK, 2013.

[20] A. Frangi, M. Fontana, E. Hugi and R. Jöbstl, "Experimental analysis of crosslaminated timber panels in fire," Fire Safety J., vol. 44 (8), pp. 1078-1087, 2009.

[21] J. Schmid, J. König and J. Kohler, "Design Model for Fire Exposed CrossLaminated Timber," in Sixth International Conference on Structures in Fire, June 24, Michigan State University, East Lansing (MI), 2010.

[22] Trada, Guidance Document 10 (GD10): Cross-Laminated Timber (Eurocode 5) Design Guide for Project Feasibility, Buckinghamshire, UK: Trada Technology Ltd., 2009.

[23] SP Trätek, Fire Safety in Timber Buildings - Technical Guideline for Europe (SP Report 2010:19), Stockholm, Sweden: SP Trätek (Swedish Institute for Wood Technology Research), 2010.

[24] C. Dagenais, CLT Handbook (CDN Edition): Chapter 8 - Fire Performance of CrossLaminated Timber Elements, FPInnovations, 2014. 
[25] I. Hagiwara, Personnal Communication, Building Research Institute, 2015.

[26] A. Frangi, Personnal communication by email, ETH Institute of Structural Engineering, 2012.

[27] CEN, Eurocode 5 : Design of timber structures - Part 1-2 : General - Structural fire design, Brussels (Belgium): European Committee for Standardization, 2004.

[28] M. Klippel, C. Leyder, A. Frangi, M. Fontana, F. Lam and A. Ceccotti, "Fire Tests on Loaded Cross-laminated Timber Wall and Floor Elements," in Proceedings of the 11th International Symposium on Fire Safety Science IAFSS, University of Canterbury, New Zealand, 2014.

[29] J. Bodig and B. A. Jayne, Mechanics of Wood and Wood Composites, New York: Van Nostrand Reinhold Company Inc., 1993.

[30] CEN, Draft prEN 16351 Timber structures - Cross laminated timber - Requirements, London (UK): European Committee for Standardization, 2012.

[31] CEN, Eurocode 0 : Basis, Brussels, Belgium: European Committee for Standardization, 2003. 
[32] E. Karacabeyli and B. Douglas, "CLT Handbook: Cross-Laminated Timber (US Edition)," FPInnovations, 2013.

[33] AF\&PA, 2005 ASD/LRFD Manual for Engineered Wood Construction - M16: Fire Design, Washington, DC: American Forest \& Paper Association, 2006.

[34] S. Craft, CLT Handbook: Chapter 8 - Fire Performance of Cross-Laminated Timber, Quebec City (Qc): FPInnovations, 2011.

[35] M. L. Janssens and R. H. White, "Short Communication: Temperature Profiles in Wood Members Exposed to Fire," Fire \& Materials, vol. 18, pp. 263-265, 1994.

[36] R. H. White and M. A. Dietenberger, "Chapter 18: Fire Safety of Wood Construction," in Wood Handbook: Wood as an Engineering Material, Madison, WI, Forest Products Laboratory, 2010, pp. 18-1 - 18-22.

[37] A. H. Buchanan, Structural Design for Fire Safety, University of Canterbury, Nouvelle-Zélande: John Wiley \& Sons Ltd., 2002.

[38] FPL, Wood Handbook: Wood as an Engineering Material, Madison (WI): Forest Products Laboratory, 2010. 
[39] L. Richardson and M. Batista, "Fire resistance of timber decking for heavy timber construction," Fire and Materials, vol. 25, pp. 21-29, 2001.

[40] B. Kampmeir, "Innovationen im Mehrgeschossigen Holzbau," in Brunswick Fire Protection Day '09 - 23 symposium fire protection - Research and Practice, Technical University of Braunschweig, 2009.

[41] J. W. O'Neil, The Fire Performance of Timber Floors in Multi-Storey Buildigs (Doctoral Thesis), Christchurch (NZ): University of Canterbury, 2013.

[42] A. Medina, Fire Resistance of Partially Protected Cross-Laminated Timber Rooms (Master's Thesis), Ottawa (Ont.): Carleton University, 2014.

[43] A. Frangi, V. Schleifer and M. Fontana, "Design Model for the Verification of the Separating Function of Light Timber Frame Assemblies," Engineering Structures (32), pp. 1184-1195, 2010.

[44] M. Mohammad and W. Muñoz, CLT Handbook (Cdn Edition): Chapter 5 Connections in Cross-Laminated Timber Buildings, Quebec City (Qc): FPInnovations, 2011. 
[45] S. Gagnon and M. Popovski, CLT Handbook (Cdn Edition): Chapter 3 - Structural Design of Cross-Laminated Timber Elements, Quebec City (Qc): FPInnovations, 2011.

[46] BinderHolz, Cross Laminated Timber BBS Technical Documentation, 2010.

[47] M. S. Sheikhtabaghi, Draft Thesis: Continuity Connection for Cross-Laminated Timber (CLT) Floor Diaphragms, Fredericton (N.B.): University of New Brunswick, 2015.

[48] CSA, CSA O86-14: Engineering Design in Wood, Mississauga (Ont.): CSA Standards, 2014.

[49] R. R. Craig Jr., Mechanics of Materials, John Wiley \& Sons Inc., 1996.

[50] AWC, National Design Specifications for Wood Construction (ANSI/AWC NDS2015), Leesburg (VA): American Wood Council, 2015.

[51] MyTiCon, Canadian Lateral Load Resistance Design in Cross Laminated Timber (CLT) with SWG ASSY Structural Screws, Surrey (BC), 2014. 
[52] CCMC, "Evaluation Report CCMC 13677-R SWG Assy VG Plus and SWG ASSY 3.0 Self-Tapping Wood Screws," Canadian Construction Materials Centre, Ottawa (Ont.), 2013.

[53] MyTiCon, Canadian Lateral Load Resistance Design with ASSY Structural Screws, Surrey (BC), 2014.

[54] W. Muñoz, M. Mohammad and S. Gagnon, "Lateral and Withdrawal Resistance of Typical CLT Connections," in World Conference on Timber Engineering, Riva del Garda (Italy), 2010.

[55] S. Kennedy, A. Salenikovich, W. Muñoz and M. Mohammad, "Design Equations for Dowel Embedment Strength and Withdrawal Resistance for Threaded Fasteners in CLT," in World Conference on Timber Engineering, Quebec City (Canada), 2014.

[56] S. Kennedy, A. Salenikovich, W. Muñoz and M. Mohammad, "Design Equation for Withdrawal Resistance of Threaded Fasternes in the Canadian Timber Design Code," in World Conference on Timber Engineering, Quebec City (Canada), 2014.

[57] NLGA, Standard Grading Rules for Canadian Lumber, New Westminster (BC): National Lumber Grades Authority, 2003. 
[58] CSA, CSA O141-05: Softwood Lumber, Mississauga (Ontario): CSA Standards, 2010.

[59] NLGA, Special Products Standard for Machine Graded Lumber (SPS-2), New Westminster (BC): National Lumber Grades Authority, 2010.

[60] E. L. Schaffer, "Charring Rate of Selected Woods - Transverse to Grain (Research Paper FPL 69)," Forest Products Laboratory, Madison (WI), 1697.

[61] M. Janssens and B. Douglas, "Chapter 7: Wood and Wood Products," in Handbook of Building Materials for Fire Protection, McGraw-Hill, 2004, pp. 7.1 - 7.58.

[62] SFPE, Handbook of Building Materials for Fire Protection, Quincy (MA): Society of Fire Protection Engineers, 2004.

[63] SFPE, The SFPE Handbook of Fire Protection Engineering (4th Edition), Quincy (MA): Society of Fire Protection Engineers, 2008.

[64] S. V. Saidu, Fire Performance of Materials - Wood, Gypsum Board, Limestone, Concrete and Steel (Thesis), Ottawa (Ont.): Carleton University, 2011. 
[65] S. Craft, CUWoodFrame - A Heat and Mass Transfer Model for Light-Frame Wood Floors Exposed to Fire (Thesis), Ottawa (Ont.): Carleton University, 2009.

[66] N. Bénichou and M. A. Sultan, "Thermal Properties of Lightweight-Framed Construction Components at Elevated Temperatures," Fire and Materials, vol. 29, pp. 165-179, 2005.

[67] J. König and L. Walleij, "One-Dimensional Charring of Timber Exposed to Standard and Parametric Fires in Initially Unprotected and Postprotection Situations (Rapport I 9908029)," SP Trätek (Swedish Institute for Wood Technology Research), Stockholm (Sweden), 1999.

[68] M. Fragiacomo, A. Menis, P. J. Moss, A. H. Buchanan and I. Clemente, "Numerical and Experimental Evaluation of the Temperature Distribution Within Laminated Veneer Lumber (LVL) Exposed to Fire," J. Structural Fire Eng., vol. 1, no. 3, pp. 145-159, 2010.

[69] A. Frangi, "Brandverhalten von Holz-Beton-Verbunddecken (Thesis)," Institute of Structural Engineering ETH, Zurich (Switzerland), 2001.

[70] CSA, CSA S16-14: Design of Steel Structures, Mississauga (Ontario): CSA 
Standards, 2014.

[71] CEN, Eurocode 3: Design of Steel Structures - Part 1-2: General - Structural Fire Design, Brussels (Belgium): European Committee for Standardization, 2005.

[72] C. Dagenais, "Fire Performance of Cross-Laminated Timber Panel-to-Panel Joints (Project 301009649)," FPInnovations, Quebec City (Qc), 2015.

[73] APA, "Product Report PR-L306C - Nordic X-Lam," APA - The Engineered Wood Association, Tacoma (WA), 2012.

[74] Hilti, Product Data Sheet for FS-ONE Intumescent Firestop Sealant, Mississauga (Ont.): Hilti Canada Corp., 2015.

[75] P. Quenneville, Interviewee, Full loading of CLT floor during fire test. [Interview]. 26 March 2015.

[76] ASTM, ASTM D198-14 - Standard Test Methods of Static Tests of Lumber in Structural Sizes, West Conshohocken (PA), USA: ASTM International, 2014.

[77] ASTM, ASTM D2915-03: Standard Practice for Evaluating Allowable Properties for Grades of Structural Lumber, vol. 04.10, West Conshohocken, PA: ASTM 
International, 2003.

[78] TEW\&C, Product Data Sheet, Saddle Brook (NJ): TE Wire \& Cable LLC, 2015.

[79] ICC-ES, ESR-2442: RSS Rugged Structural Screws, RSS LPS Panel Screws, RSS LTF Timber Frame Screws, RSS PHEinox Stainless Steel Screws, RSS JTS Truss Screws and Climatek Coating, Whittier (CA): ICC Evaluation Service, 2014.

[80] NRCC, User's Guide - NBC 2010: Structural Commentaries (Part 4 of Division B), Ottawa (Ont.): National Research Council Canada, 2011.

[81] R. H. White, "Section 4 - Chapter 13: Analytical Methods for Determining Fire Resistance of Timber Members," in The SFPE Handbook of Fire Protection Engineering (4th Edition), Quincy (MA), Society of Fire Protection Engineers, 2008, pp. 4-346 - 4-366.

[82] N. Werther, J. O'Neil, P. M. Spellman, A. K. Abu, P. J. Moss, A. H. Buchanan and S. Winter, "Parametric Study of Modelling Structural Timber in Fire with Different Software Packages," in 7th International Conference on Structures in Fire, Zurich (Switzerland), 2012. 
[83] F. P. Incropera, D. P. Dewitt, T. L. Bergman and A. S. Lavine, Fundamentals of Heat and Mass Transfer (Sixth Edition), John Wiley \& Sons, 2006.

[84] ANSYS, ANSYS version15.0, Canonsburg (PA): ANSYS Inc., 2014.

[85] L. Peng, Performance of Heavy Timber Connections in Fire (Doctoral Thesis), Ottawa, Ontario: Carleton University, 2010.

[86] J. N. Reddy, An Introduction to the Finite Element Method (Second Edition), McGraw-Hill, 1993.

[87] L. Osborne, "Fire Resistance of Long Span Composite Wood-Concrete Floor Systems (Project No. 301009649)," FPInnovations, Quebec City (Qc), 2015.

[88] M. Mohammad, Personnal Communication, FPInnovations, 2014.

[89] M. Aguanno, Fire Resistance Tests on Cross-Laminated Timber Floor Panels: An Experimental and Numerical Analysis (Master's Thesis), Ottawa, Ontario: Carleton University, 2013.

[90] AWC, Calculating the fire resistance of exposed wood members - Technical report 
10, Leesburg (VA): American Wood Council, 2014.

[91] J. O'Neil, D. Carradine, P. J. Moss, M. Fragiacomo, R. Dhakal and A. H. Buchanan, "Design of Timber-Concrete Composite Floors for Fire Resistance," Journal of Structural Fire Engineering, vol. 2(3), pp. 231-242, 2001. 


\section{Appendix I - Fire Test 1 - 3-ply CLT with internal spline}

This appendix provides further test results from the fire test 1 on a CLT with an internal spline, as presented in subsection 3.4 of this thesis.

Significant differential deflection occurred on one side (Figure 3.19). Figure A. 1 shows the load and recorded deflection during the fire test. It can also be observed that it was difficult to maintain the required loading level throughout.

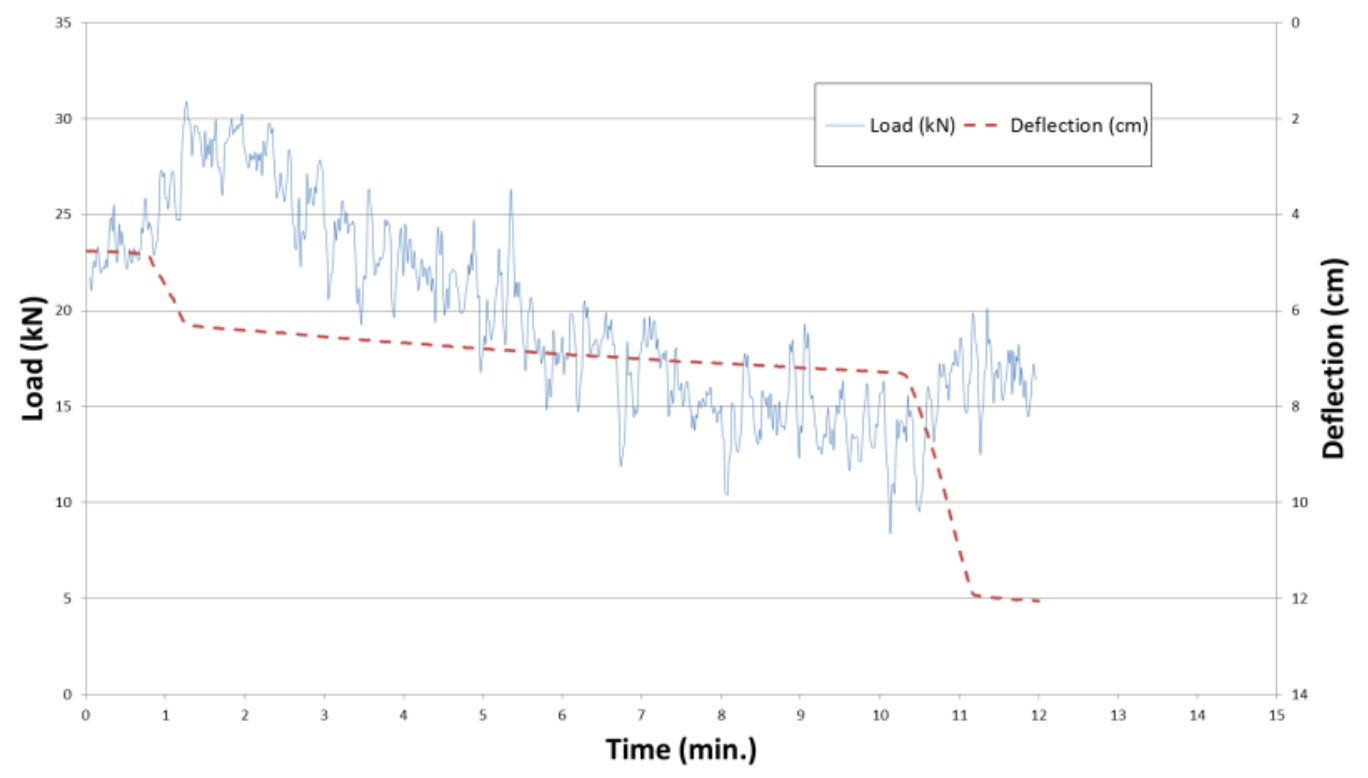

Figure A. 1 - Fire Test 1 load and deflection measurements 


\section{Appendix II - Fire Test 2 - 3-ply CLT with half-lapped joint}

This appendix provides further test results from the fire test 2 on a CLT with a halflapped joint, as presented in subsection 3.5 of this thesis.

It can be seen from Figure A. 2 that the furnace average temperature was not quite following the standard curve. As the CLT cross-section chars, its bending stiffness and capacity are reduced. The CLT deflection quickly increased and reached the maximum very early into the test (Figure A. 3).

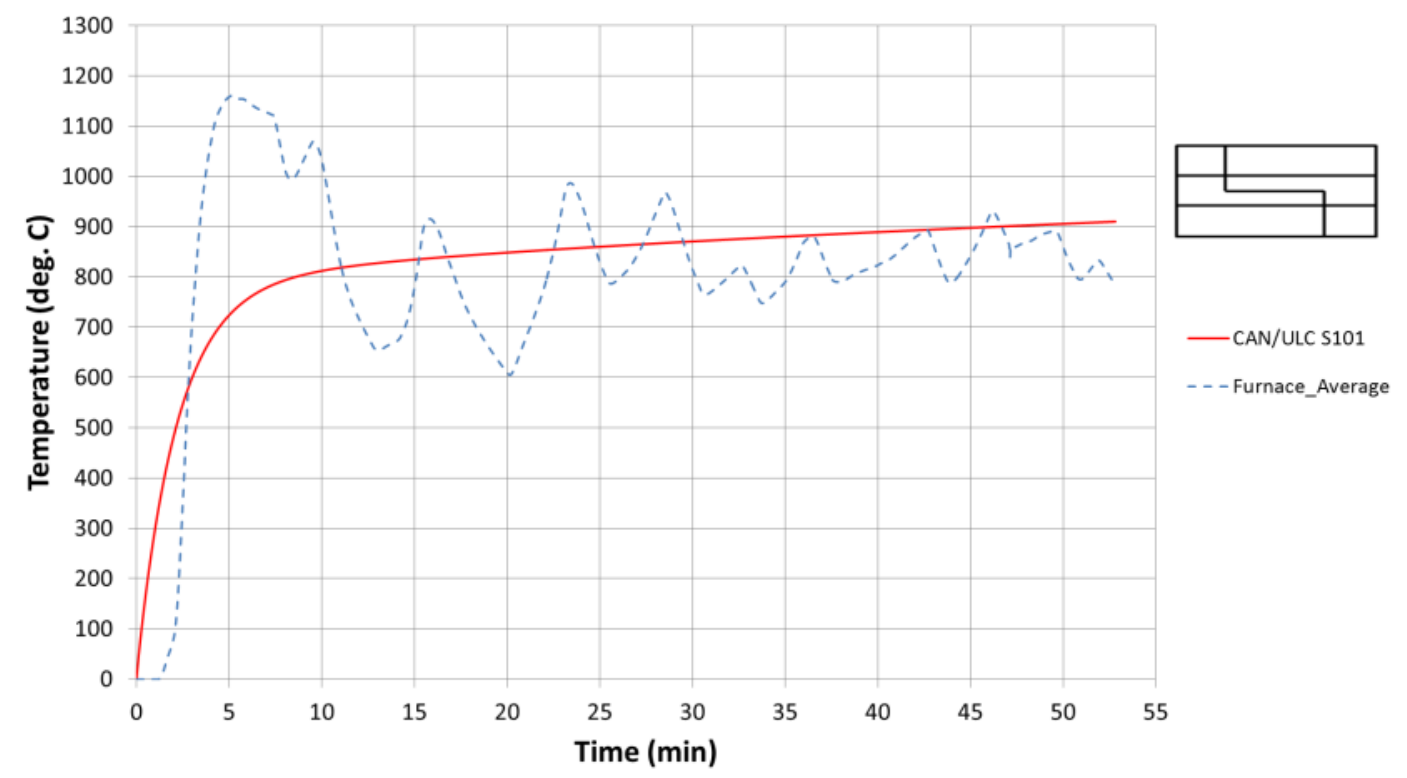

Figure A. 2 - Fire Test 2 furnace temperature (average) 


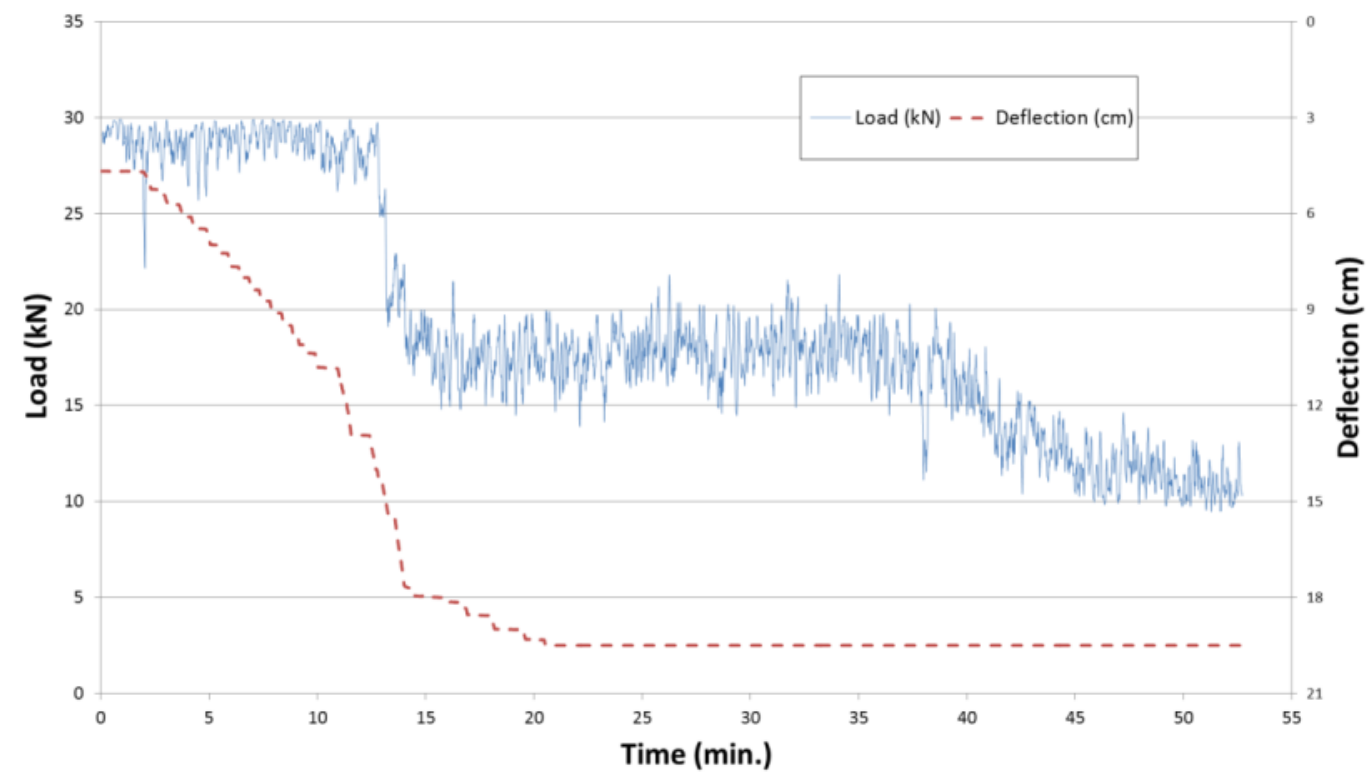

Figure A. 3 - Fire Test 2 load and deflection measurements

Figure A. 4 and Figure A. 5 show the temperature profiles measured across the CLT panels and at the half-lapped joint. The temperatures of the right side corner of the joint are indicated by "Joint_1" and "Joint_3" in Figure A. 5. It can be observed that heat seems to have penetrated through the CLT and the joints shortly after $15 \mathrm{~min}$. After reviewing the data and given that the other three (3) plots in Figure A. 5 are similar, it is difficult to explain the sharp increase from the thermocouple labelled "Joint_3" between 15 and 30 min when compared to the plot from "Joint_1". Similarly to Fire Test 1, the variances in the temperature measurements were most likely due to interference in the data acquisition system or bad thermocouple connections. 


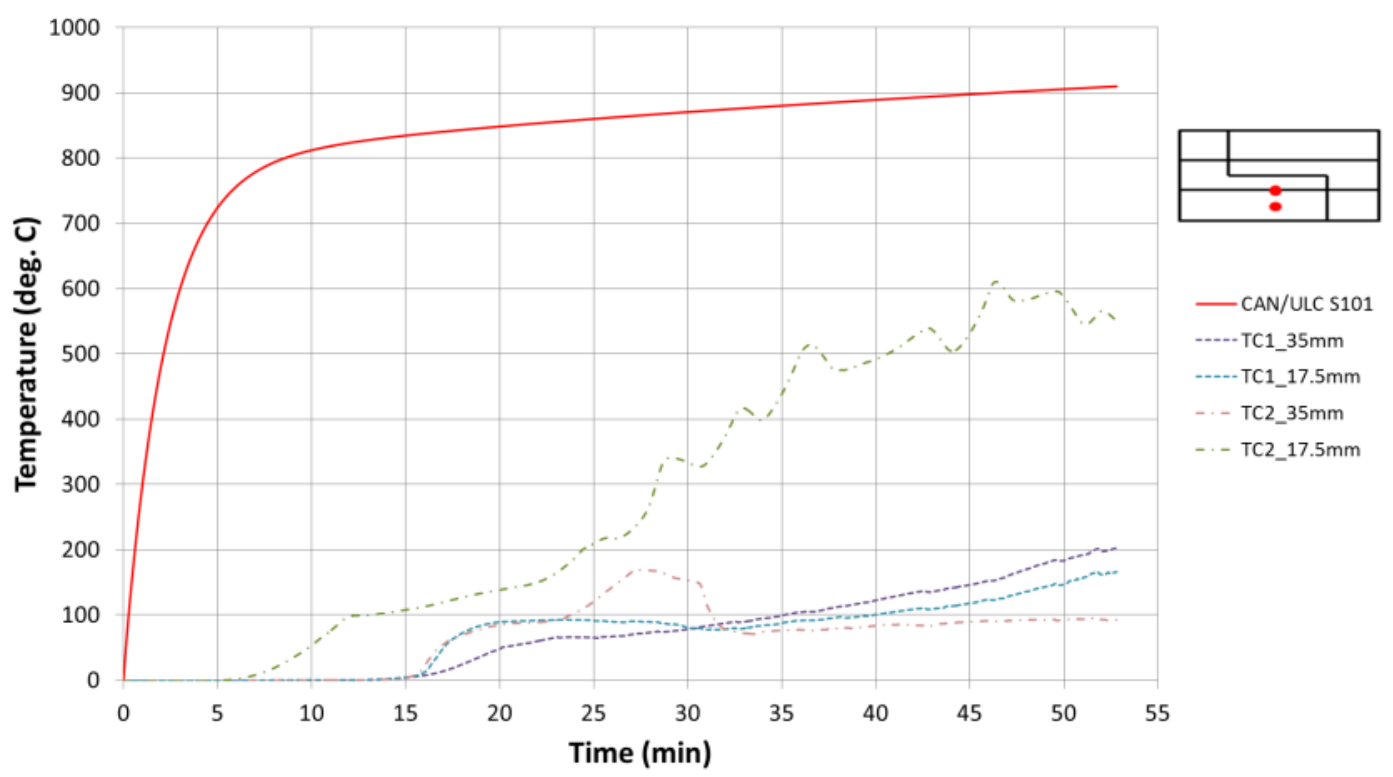

Figure A. 4 - Fire Test 2 temperature profiles across the CLT panels

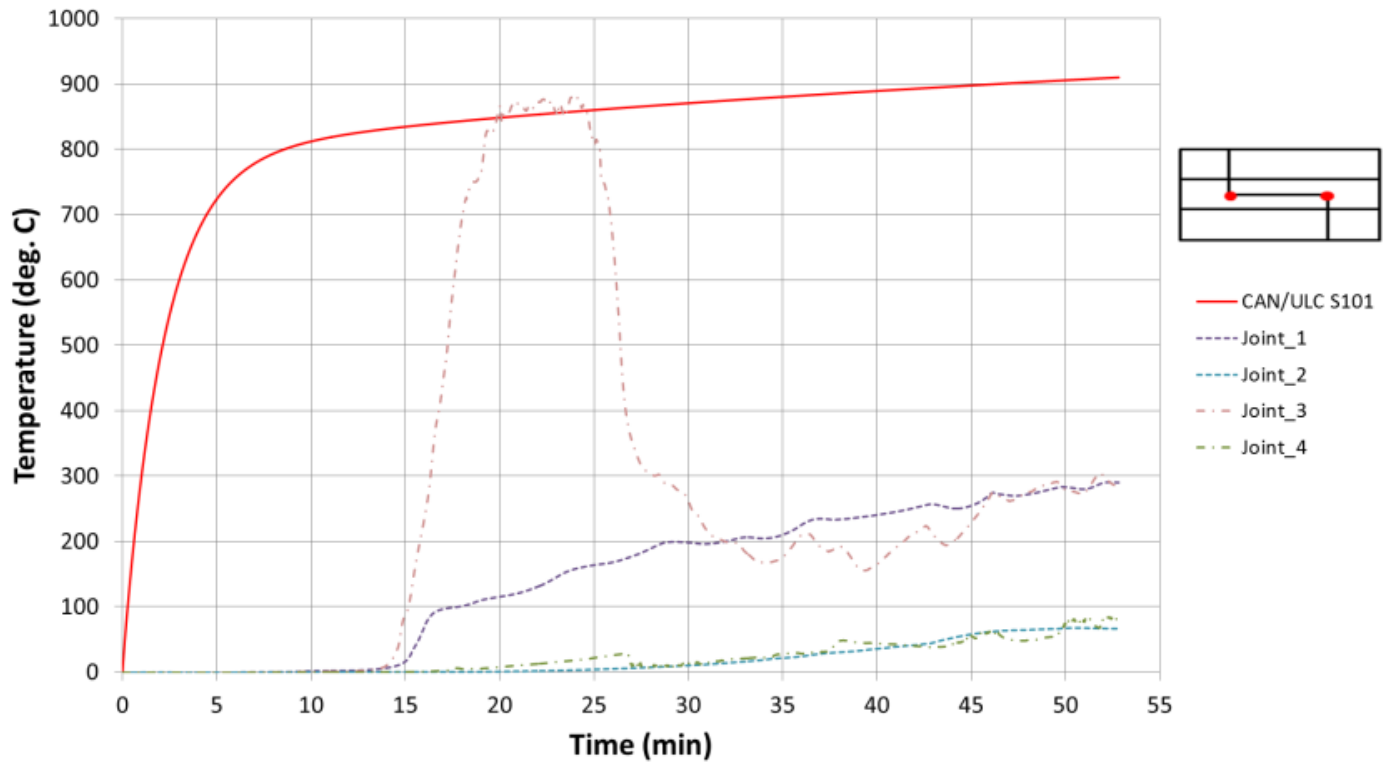

Figure A. 5 - Fire Test 2 temperature profiles at the half-lapped joint 
Figure A. 6 shows the temperature profiles generated from the thermocouples glued to two self-tapping screws. It can be seen that heat was conducted to the screw very rapidly during the test.

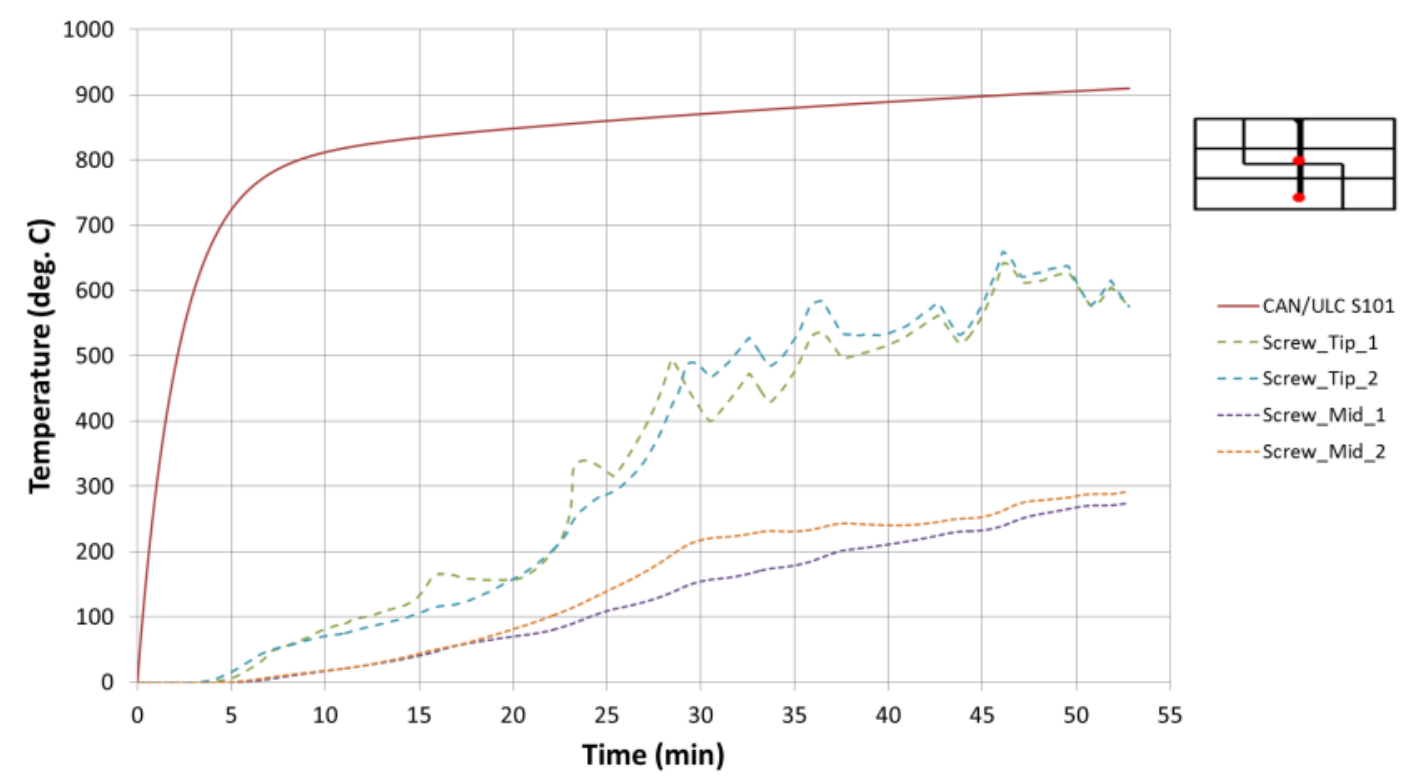

Figure A. 6 - Fire Test 2 temperature profiles of the self-tapping screws 


\section{Appendix III - Fire Test 3 - 3-ply CLT with single surface spline}

This appendix provides further test results from the fire test 3 on a CLT with a single surface spline, as presented in subsection 3.6 of this thesis.

It can be seen that the furnace average temperature was not quite following the standard curve, especially during the first 20 minutes and stayed mostly below the standard curve for the remaining of the test (Figure A. 7). Figure A. 8 shows that the CLT rapidly reached the maximum deflection due to the reduction of its cross-section. During the test, some of the readings were recorded as negative values due to potential sound interference between the data acquisition system and the thermocouples. All the negative values were removed from the graphs for clarity, while showing some empty spots.

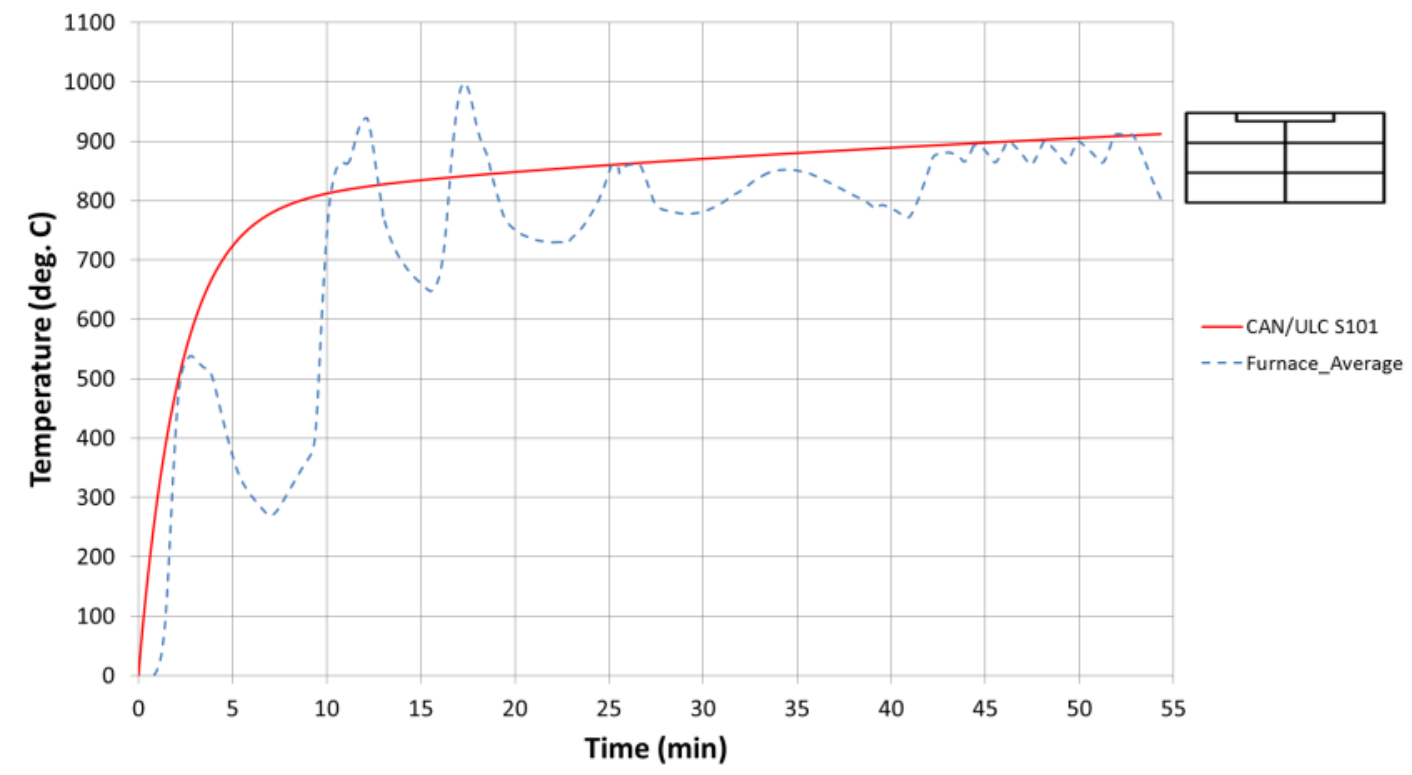

Figure A. 7- Fire Test 3 furnace temperature (average) 


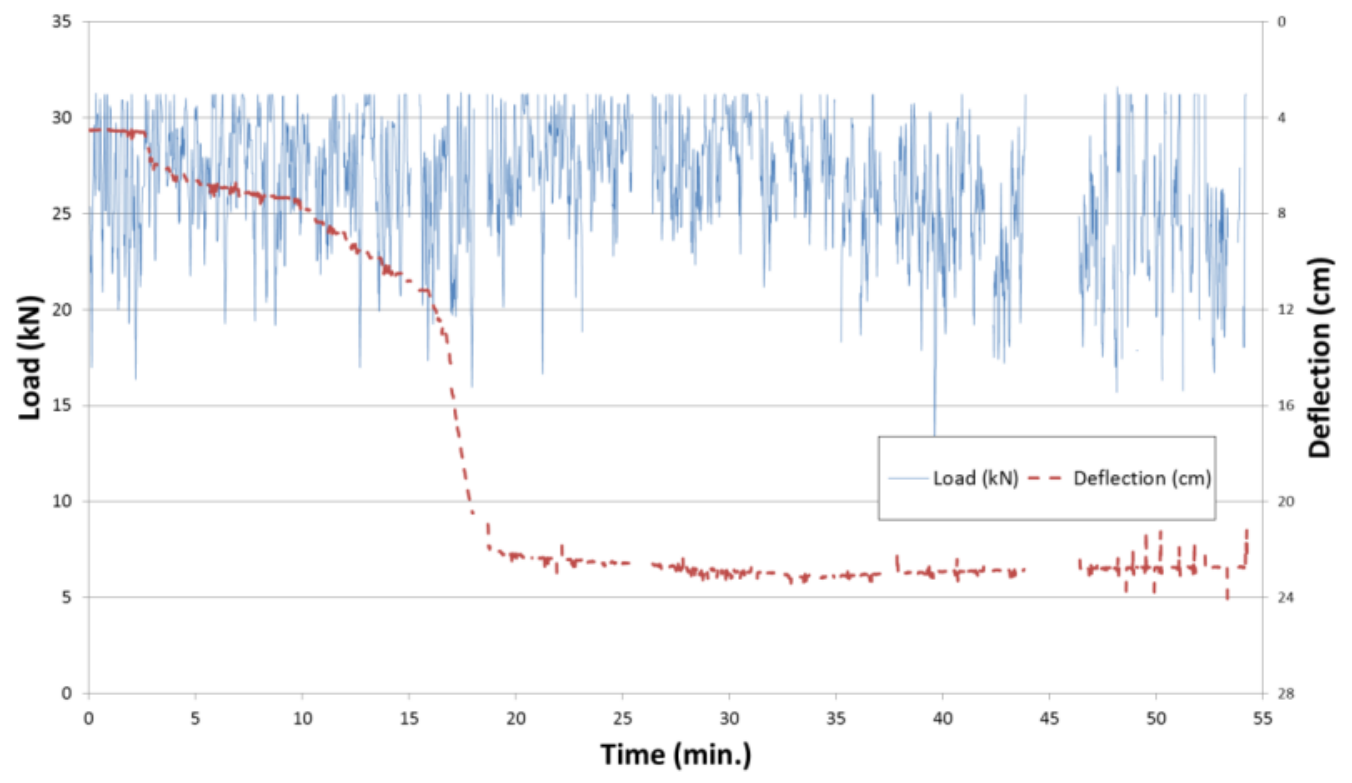

Figure A. 8 - Fire Test 3 load and deflection measurements

It can be observed from the thermocouple readings that no significant temperature rise was recorded passed the $2^{\text {nd }}$ glueline and at the surface spline interface (Figure A. 9). Figure A. 10 shows the temperature profiles measured across the CLT panels near the joint.

The temperatures recorded from the instrumented self-tapping screws are shown inFigure A. 11. It can be seen that heat was conducted to the screw very rapidly during the test. 


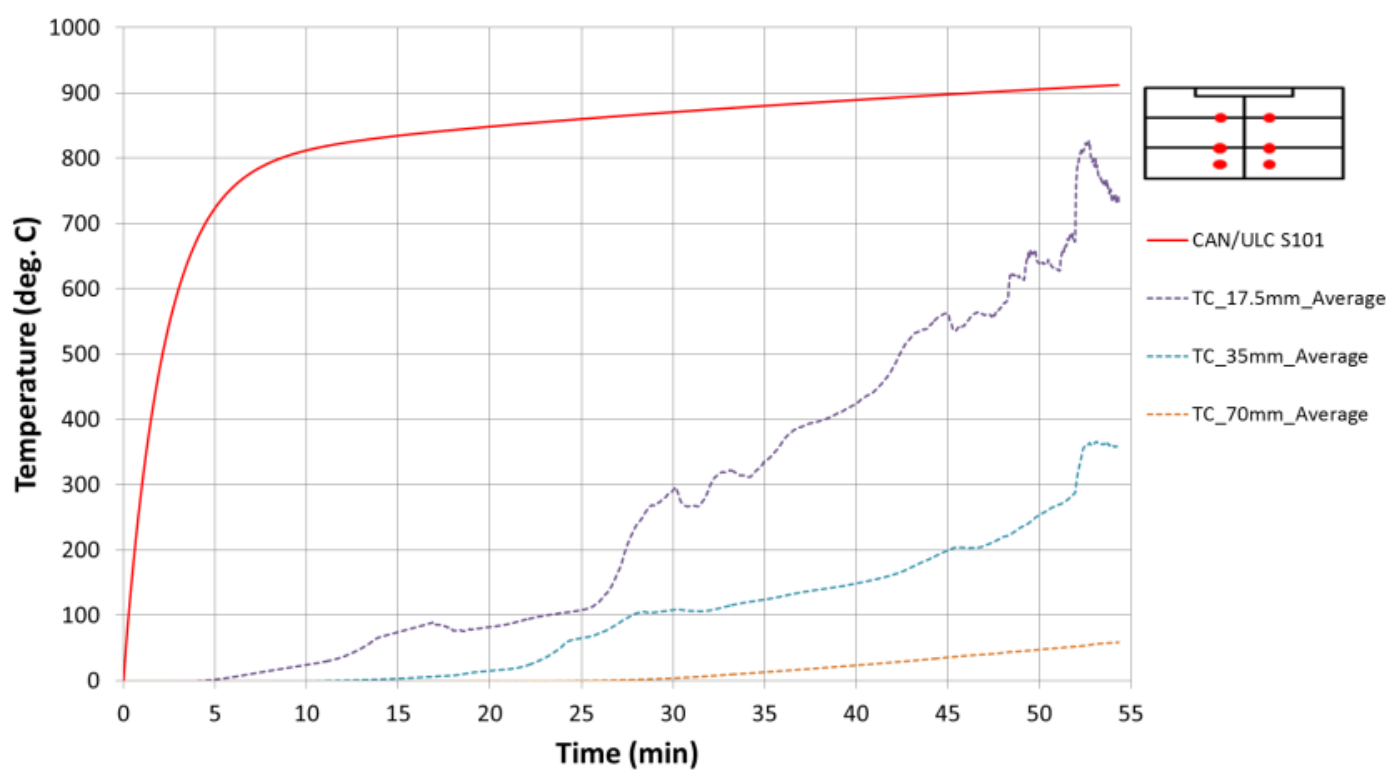

Figure A. 9 - Fire Test 3 temperature profiles across the CLT panels (average)

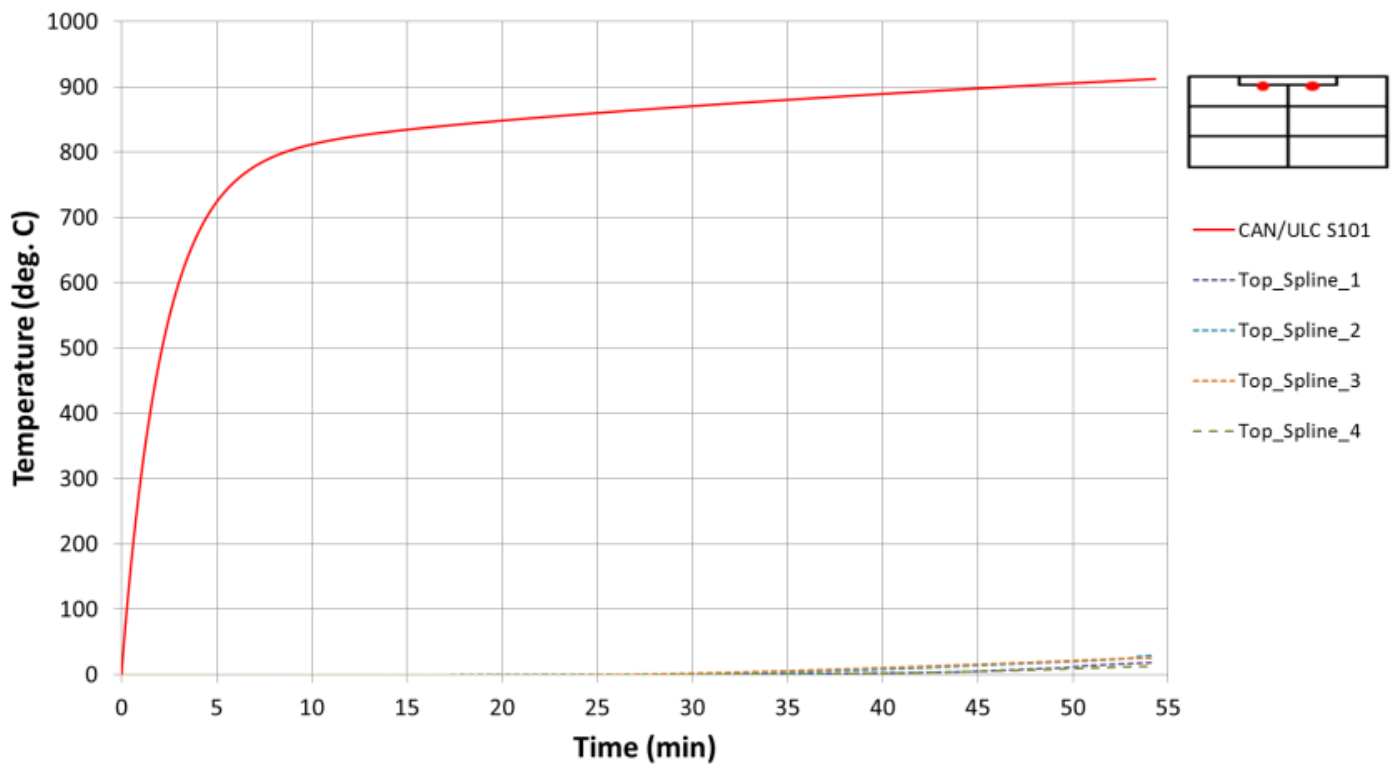

Figure A. 10 - Fire Test 3 temperature profiles at the single surface spline interface 


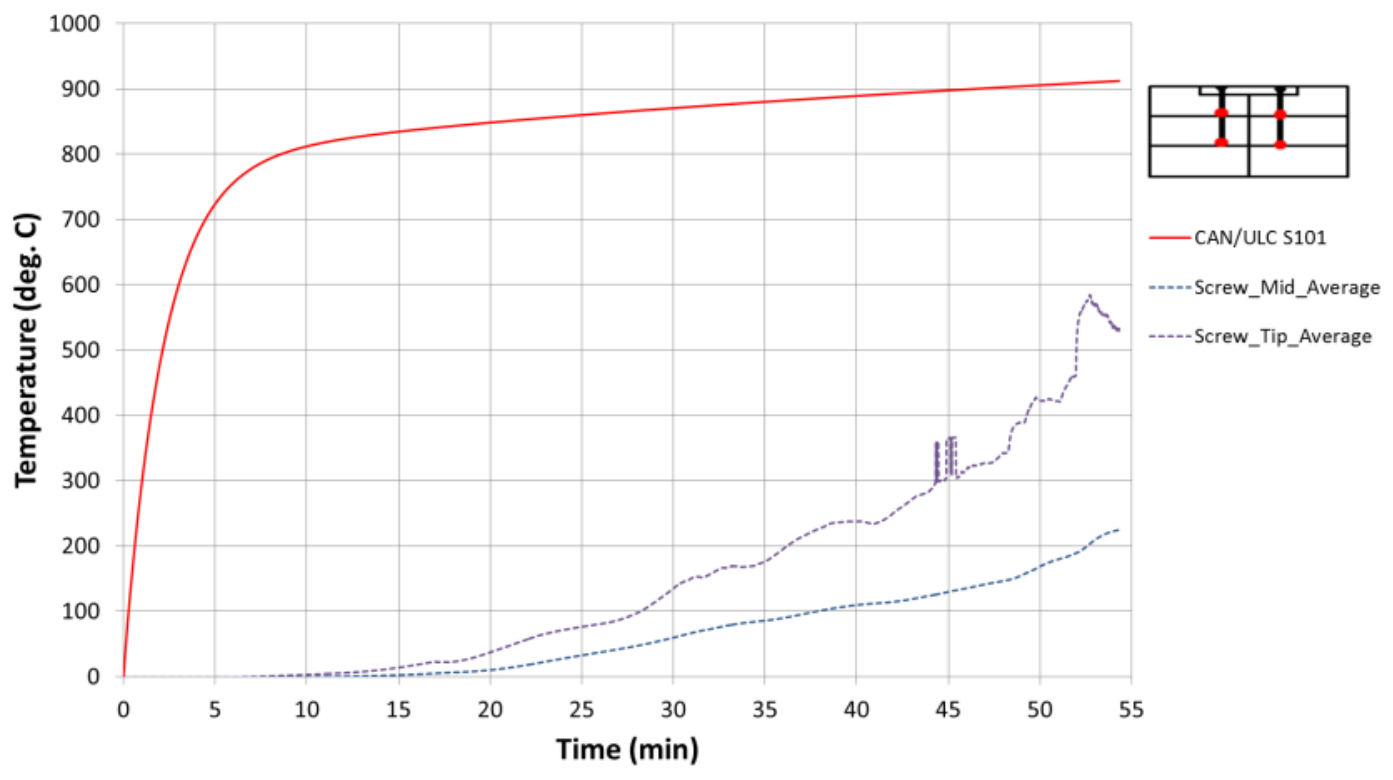

Figure A. 11 - Fire Test 3 temperature profiles of the self-tapping screws (average) 


\section{Appendix IV - Fire Test 4 - 3-ply CLT with double surface spline}

This appendix provides further test results from the fire test 4 on a CLT with double surface splines, as presented in subsection 3.7 of this thesis.

While there were still some difficulties in properly following the standard timetemperature curve, the variations were much less significant than in previous tests, as shown in Figure A. 12. Figure A. 13 shows that the CLT rapidly reached the maximum deflection due to the reduction of its cross-section. During this test, some of the readings were recorded as negative values due to potential sound interference between the data acquisition system and the thermocouples. All the negative values were removed from the graphs for clarity, while showing some empty spots.

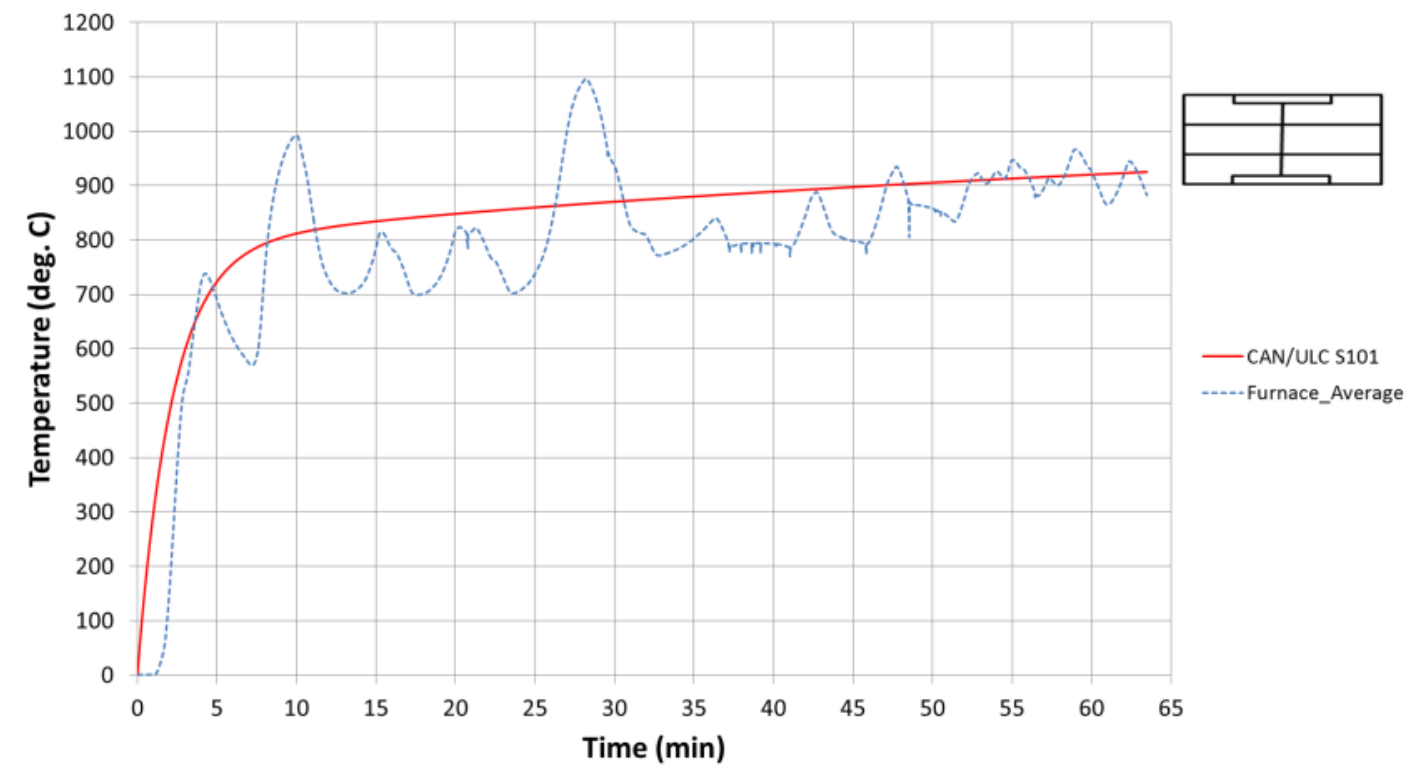

Figure A. 12 - Fire Test 4 furnace temperature (average) 


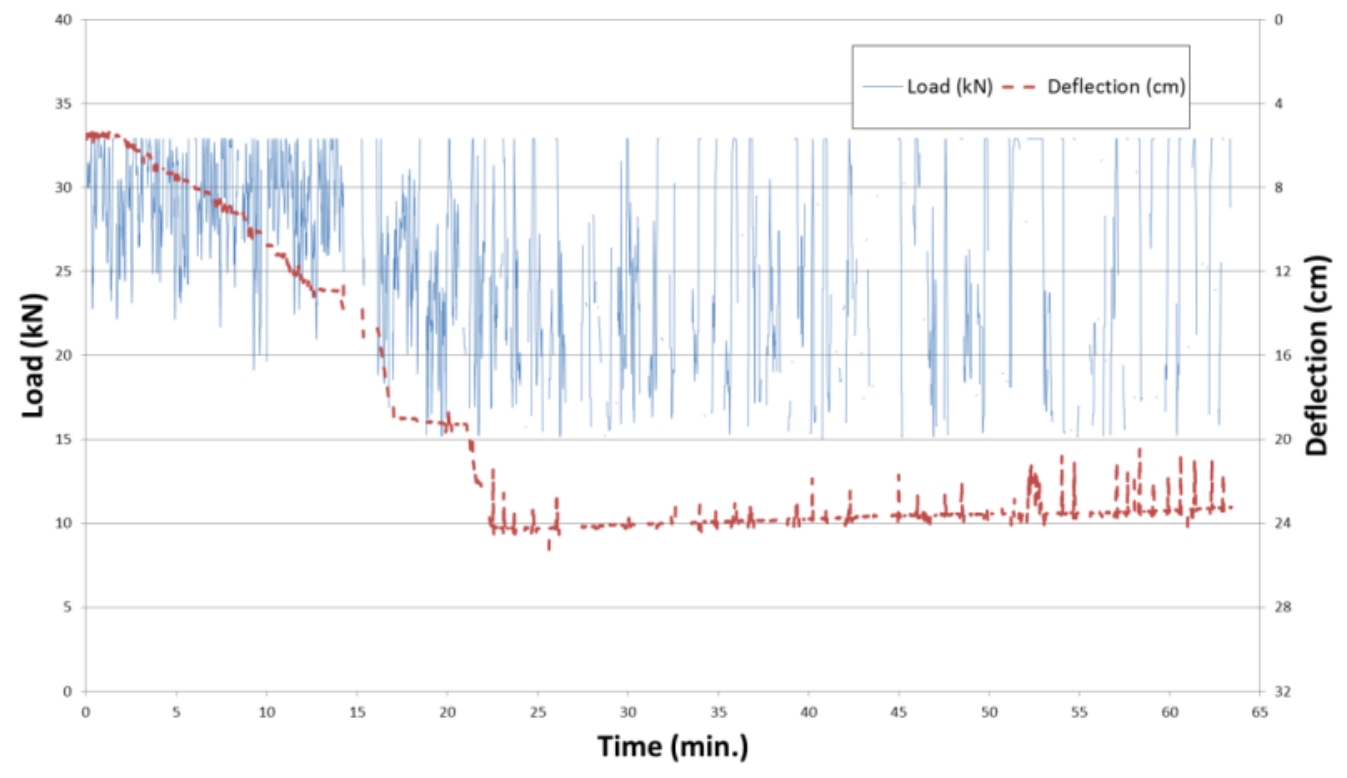

Figure A. 13 - Fire Test 4 load and deflection measurements

Figure A. 14 shows the temperature profiles measured across the CLT panels. Moreover, it can be observed from Figure A. 15 that the bottom surface plywood spline burned shortly after $28 \mathrm{~min}$, resulting in a charring rate of $0.66 \mathrm{~mm} / \mathrm{min}$ for the plywood spline.

The temperatures recorded from the instrumented self-tapping screws are shown in Figure A. 16. It can be seen that heat was rapidly conducted to the bottom self-tapping screws, which were directly exposed to the fire, and that they somewhat followed the furnace temperature throughout the test. Very little difference in the temperature profile was observed between the middle and the tip of the bottom self-tapping screws. 


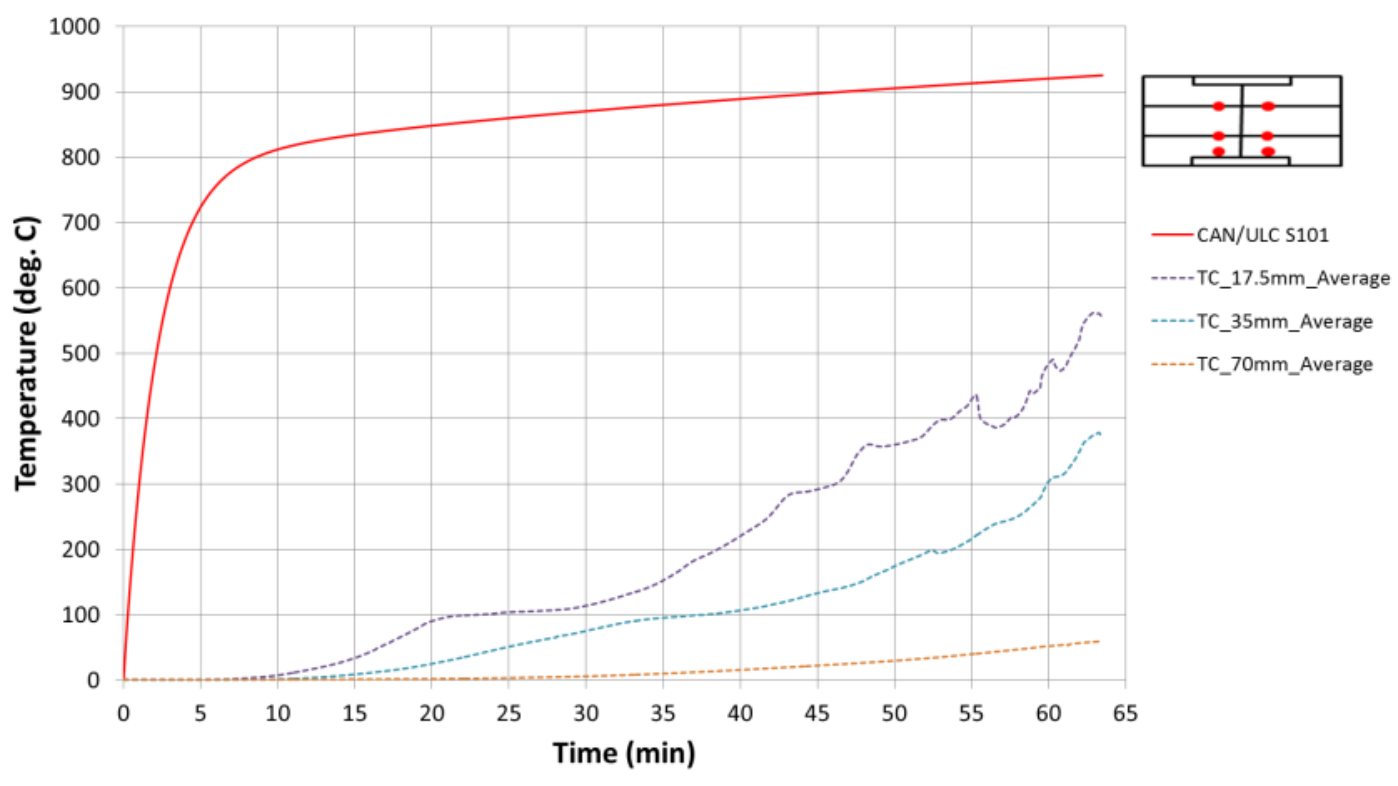

Figure A. 14 - Fire Test 4 temperature profiles across the CLT panels (average)

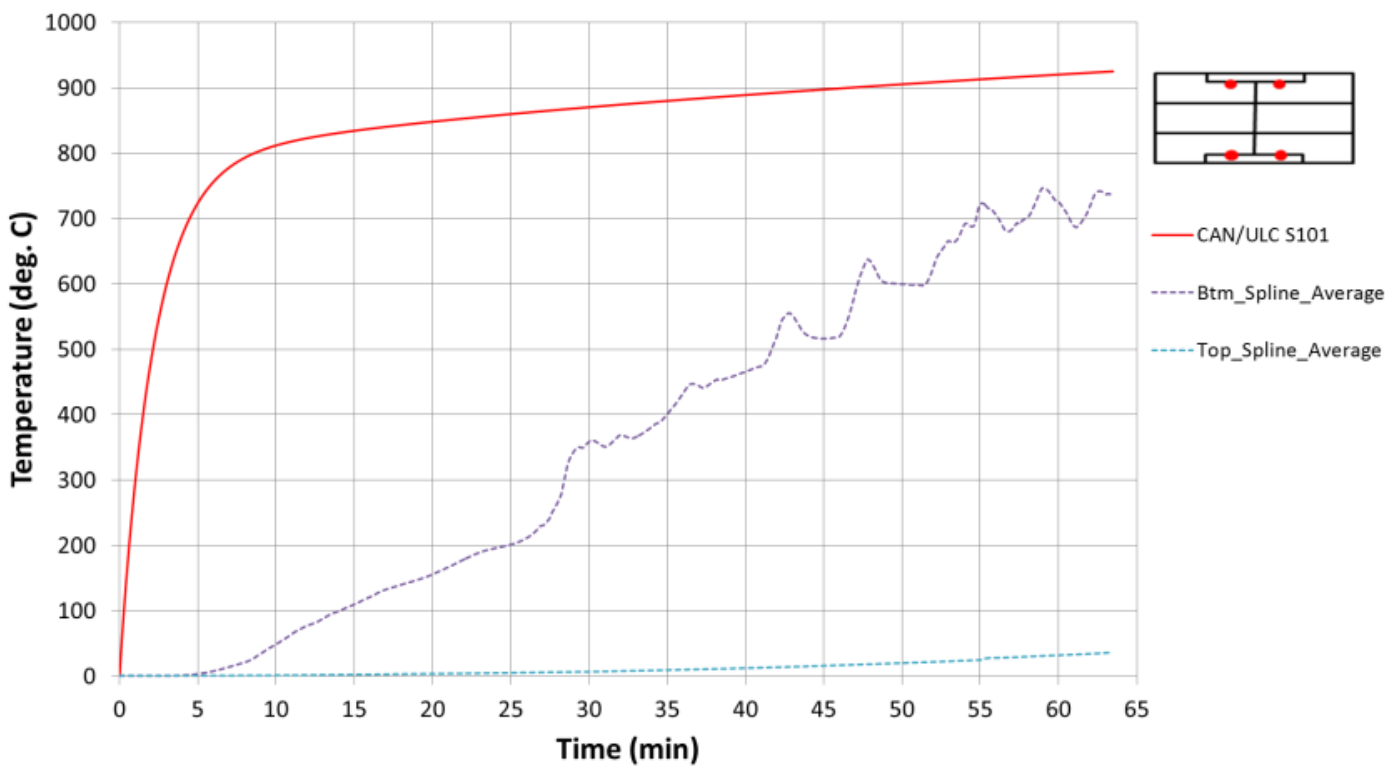

Figure A. 15 - Fire Test 4 temperature profiles at the surface spline interfaces (average) 


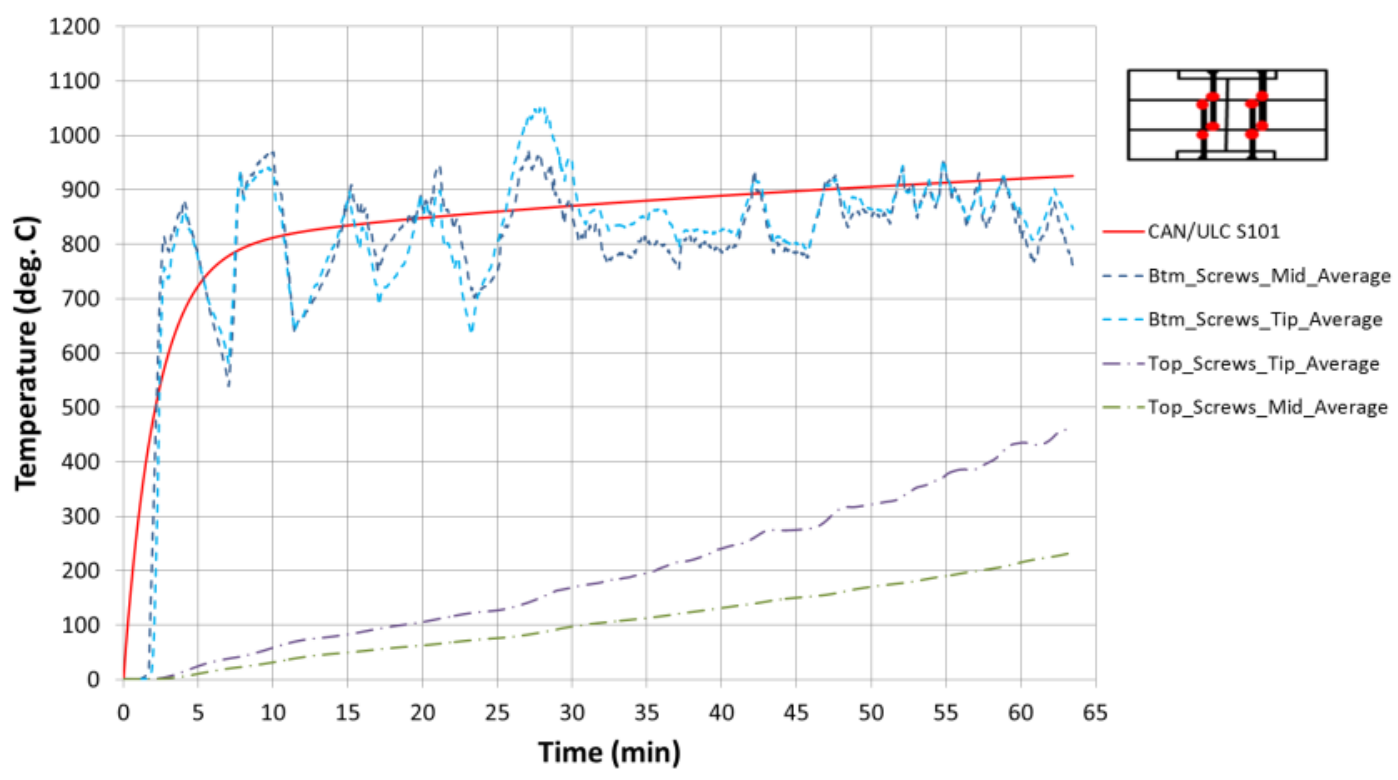

Figure A. 16 - Fire Test 4 temperature profiles of the self-tapping screws (average) 


\section{Appendix V - Fire Test 5 - 5-ply CLT with internal spline}

This appendix provides further test results from the fire test 5 on a CLT with an internal spline, as presented in subsection 3.8 of this thesis.

In this fire test 5 , the furnace temperature closely followed the standard time-temperature curve, while being slightly lower (Figure A. 17). Figure A. 18 shows the load and deflection measurements recorded during the test.

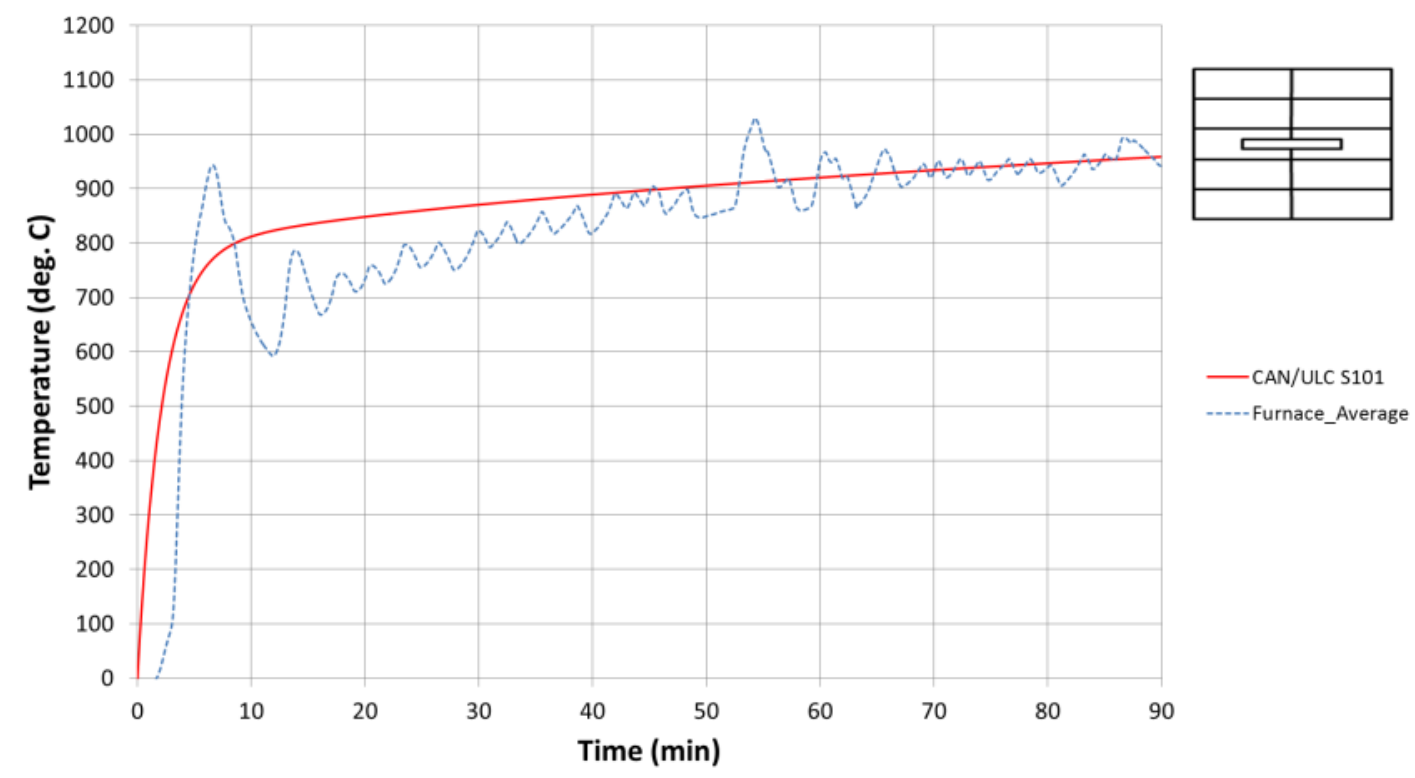

Figure A. 17 - Fire Test 5 furnace temperature (average) 


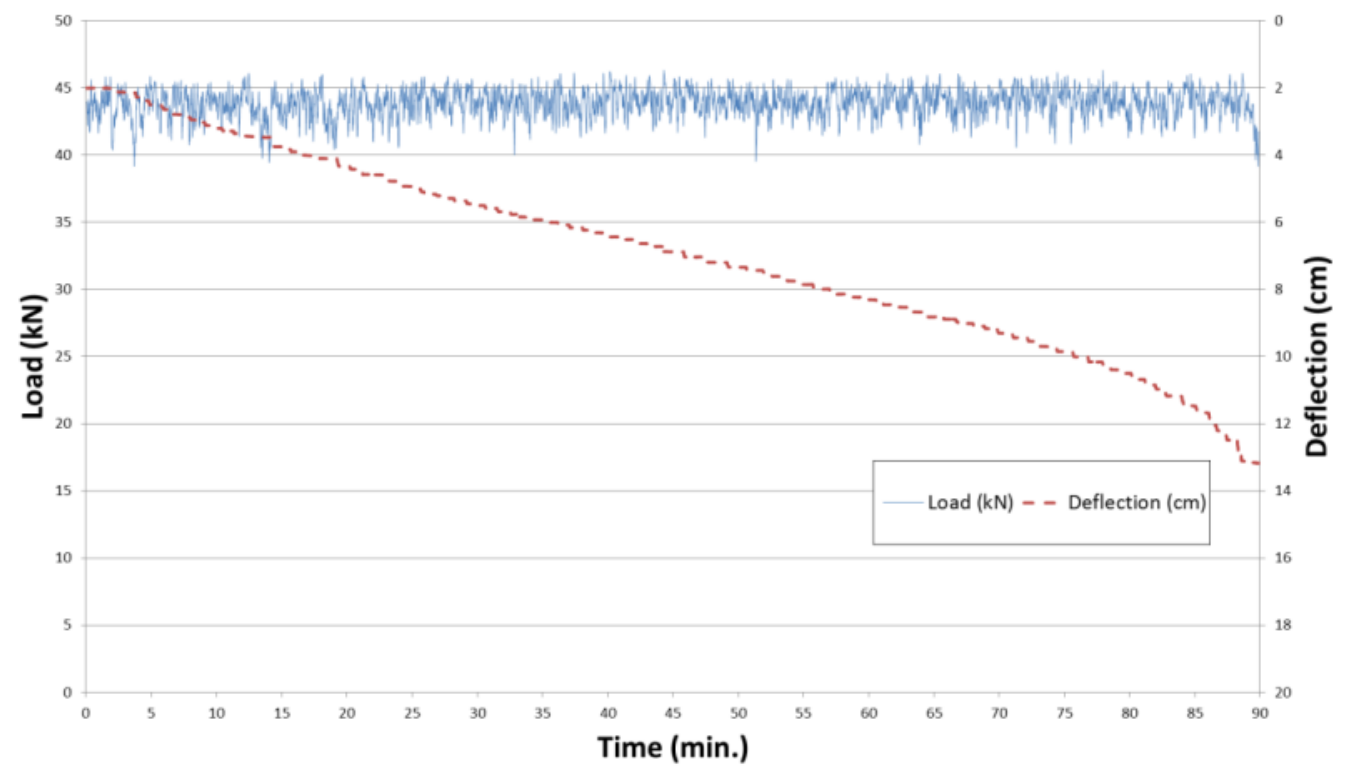

Figure A. 18 - Fire Test 5 load and deflection measurements

The temperature profiles measured across the CLT panels are shown in Figure A. 19. It can be observed from Figure A. 20 that the spline reached $300^{\circ} \mathrm{C}$ before the glueline located at $70 \mathrm{~mm}$, which is somewhat awkward. Given that the thermocouples embedded inside the CLT were not positioned at the exact same location as those for the internal spline, one possible reason for the bottom of the spline to reach $300^{\circ} \mathrm{C}$ before the $2^{\text {nd }}$ glueline may be due to the presence of air gaps between lumber boards of the same lamination.

It can also be observed from Figure A. 21 that the self-tapping screws slowly heated during the fire test. 


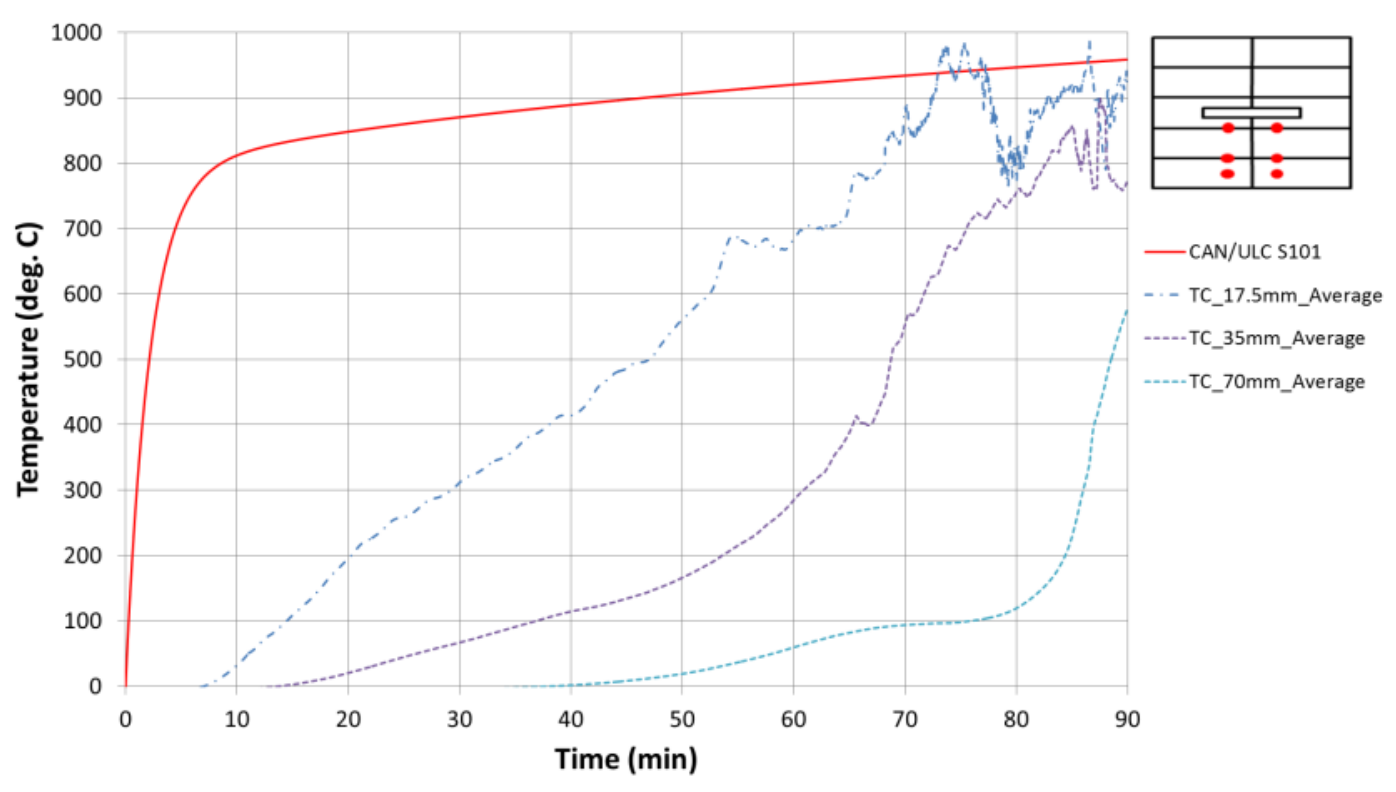

Figure A. 19 - Fire Test 5 temperature profiles across the CLT panels (average)

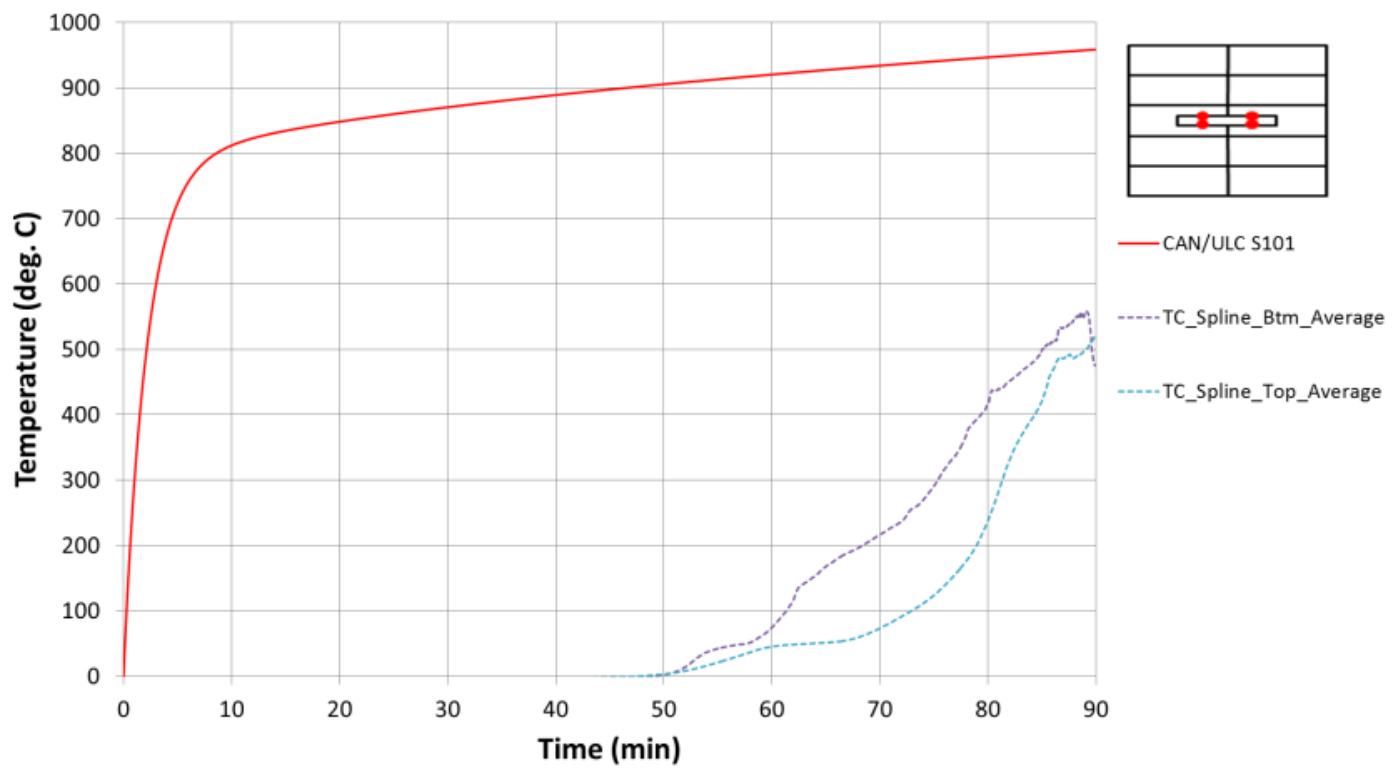

Figure A. 20 - Fire Test 5 temperature profiles at the internal spline interfaces (average) 


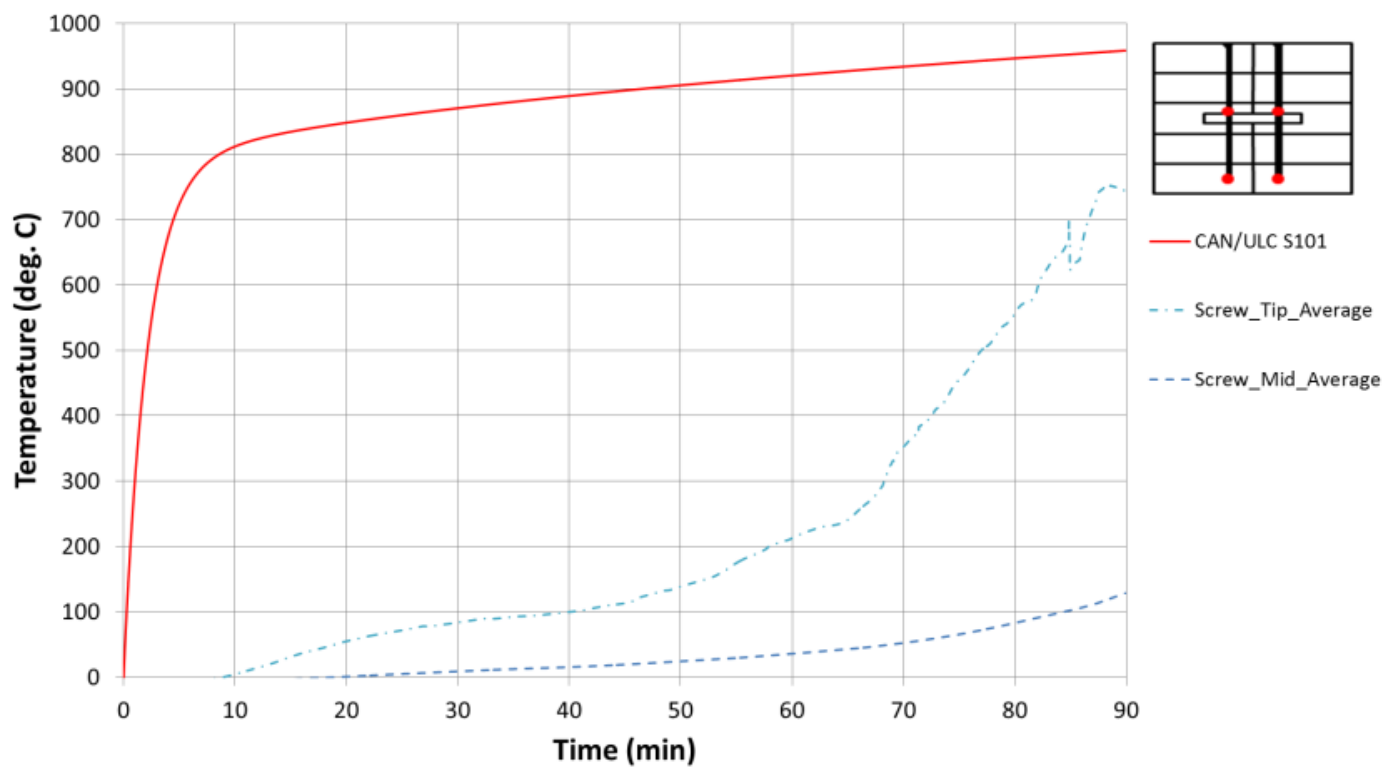

Figure A. 21 - Fire Test 5 temperature profiles of the self-tapping screws (average) 


\section{Appendix VI - Fire Test 6 - 5-ply CLT with half-lapped joint}

This appendix provides further test results from the fire test 6 on a CLT with a halflapped joint, as presented in subsection 3.9 of this thesis.

Figure A. 22 shows that the temperature recorded inside the furnace throughout the test closely followed the standard time-temperature curve, while being slightly lower. Figure A. 23 shows the load and deflection measurements recorded during the test. As with previous tests, some of the readings were recorded as negative values due to potential sound interference between the data acquisition system and the thermocouples. All the negative values were removed from the graphs for clarity, showing some empty spots on the graphs.

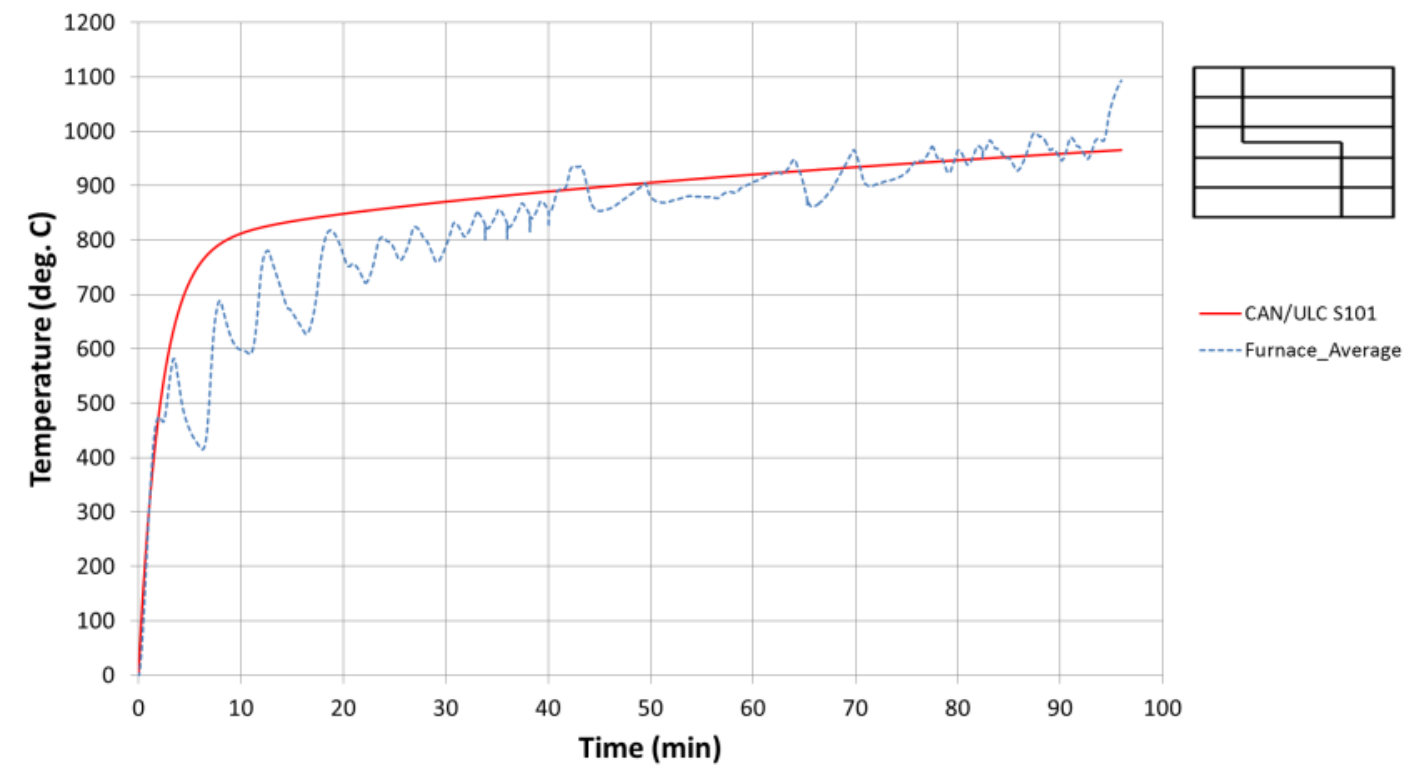

Figure A. 22 - Fire Test 6 furnace temperature (average) 


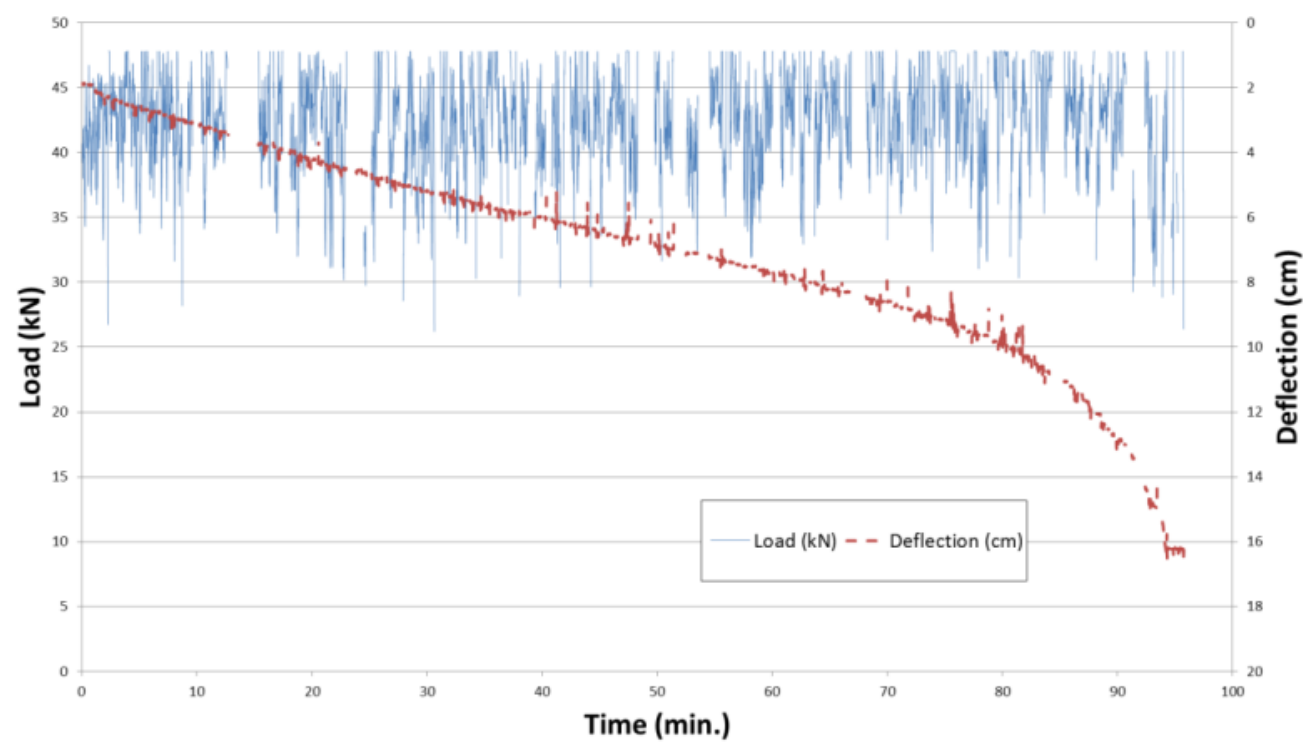

Figure A. 23 - Fire Test 6 load and deflection measurements

Figure A. 24 show the temperature profiles measured across the CLT panels. Moreover, it can be observed from Figure A. 25 that no significant temperature rise was recorded at the half-lapped joint interface. Lastly, Figure A. 26 shows that the self-tapping screws slowly heated during the fire test. 


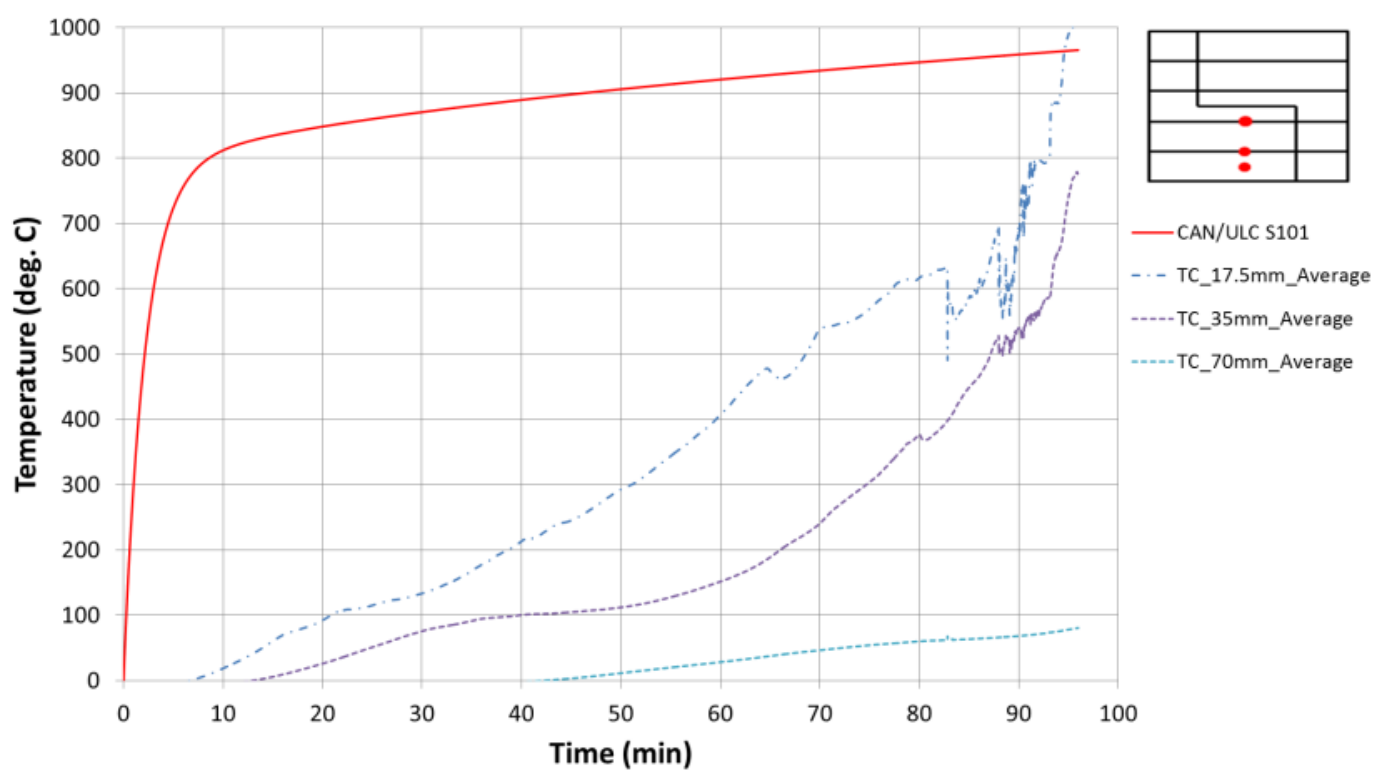

Figure A. 24 - Fire Test 6 temperature profiles across the CLT panels (average)

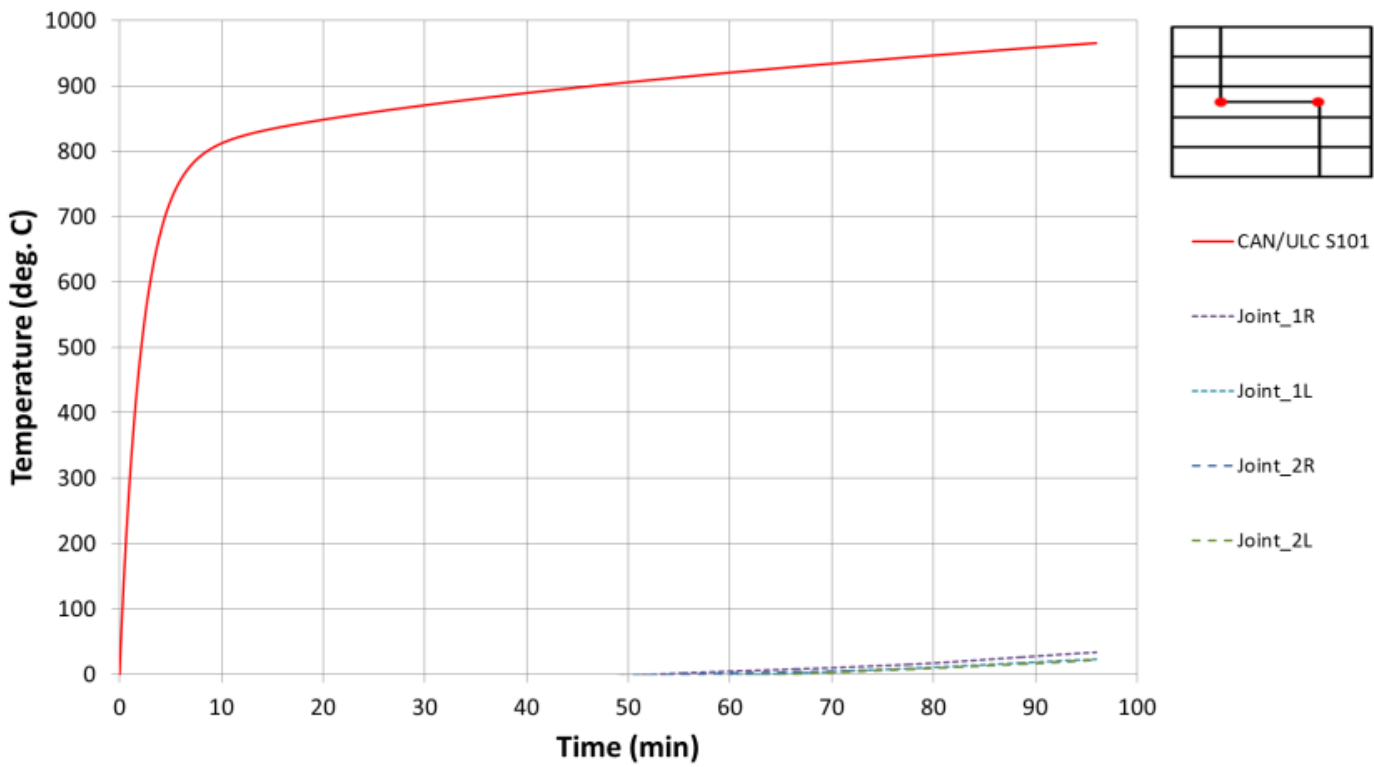

Figure A. 25 - Fire Test 6 temperature profiles at the half-lapped interface 


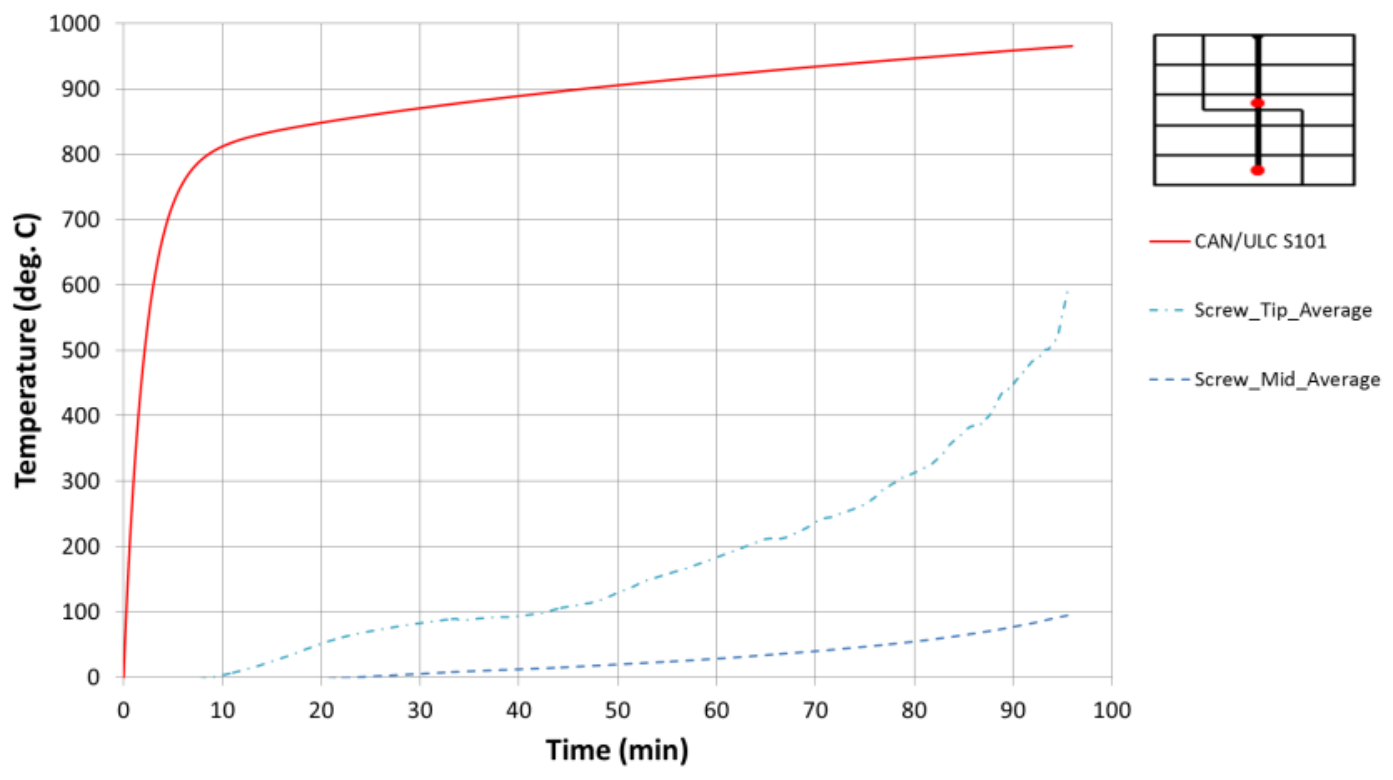

Figure A. 26 - Fire Test 6 temperature profiles of the self-tapping screws (average) 


\section{Appendix VII - Fire Test 7 - 5-ply CLT with single surface spline}

This appendix provides further test results from the fire test 7 on a CLT with a single surface spline, as presented in subsection 3.10 of this thesis.

Figure A. 27 shows that the temperature recorded inside the furnace throughout the test closely followed the standard time-temperature curve. Figure A. 28 shows the load and deflection measurements recorded during the test.

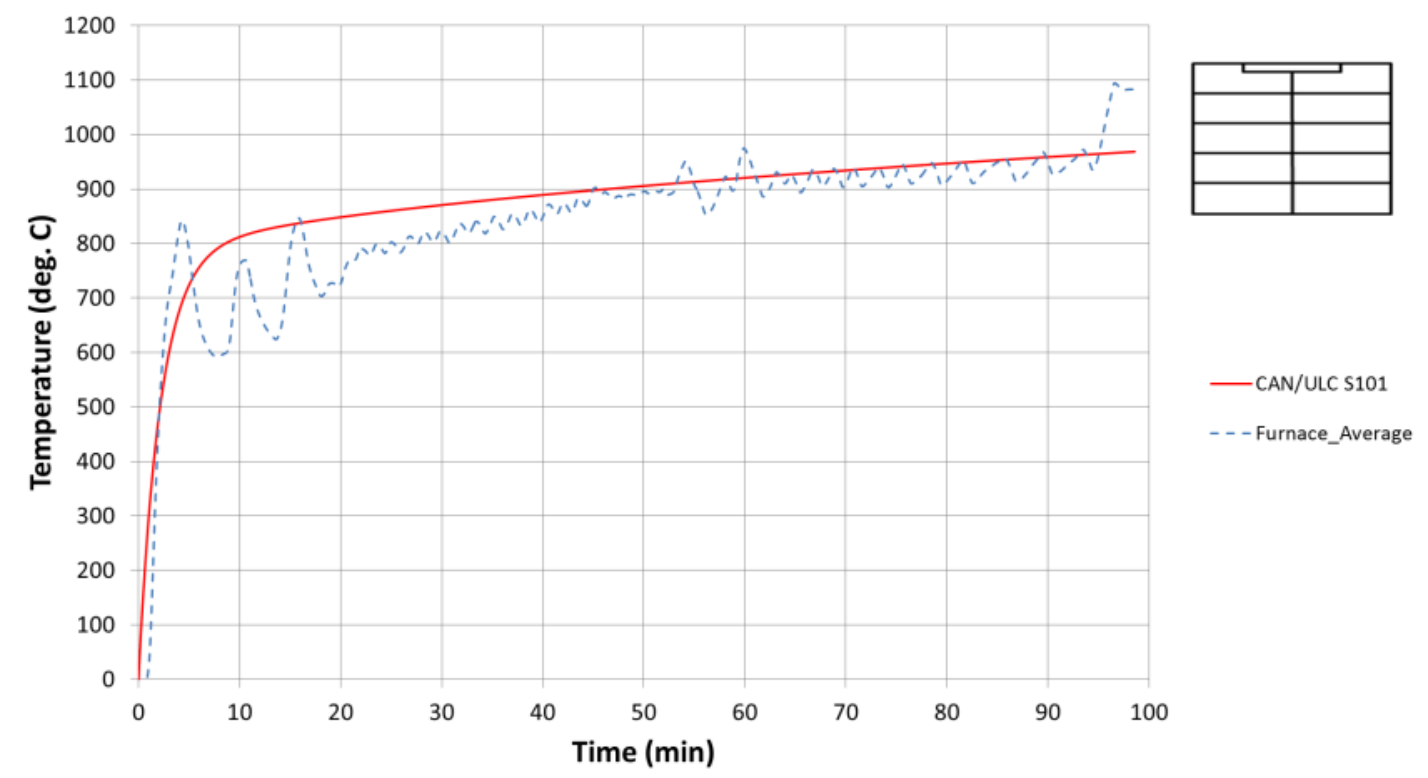

Figure A. 27 - Fire Test 7 furnace temperature (average) 


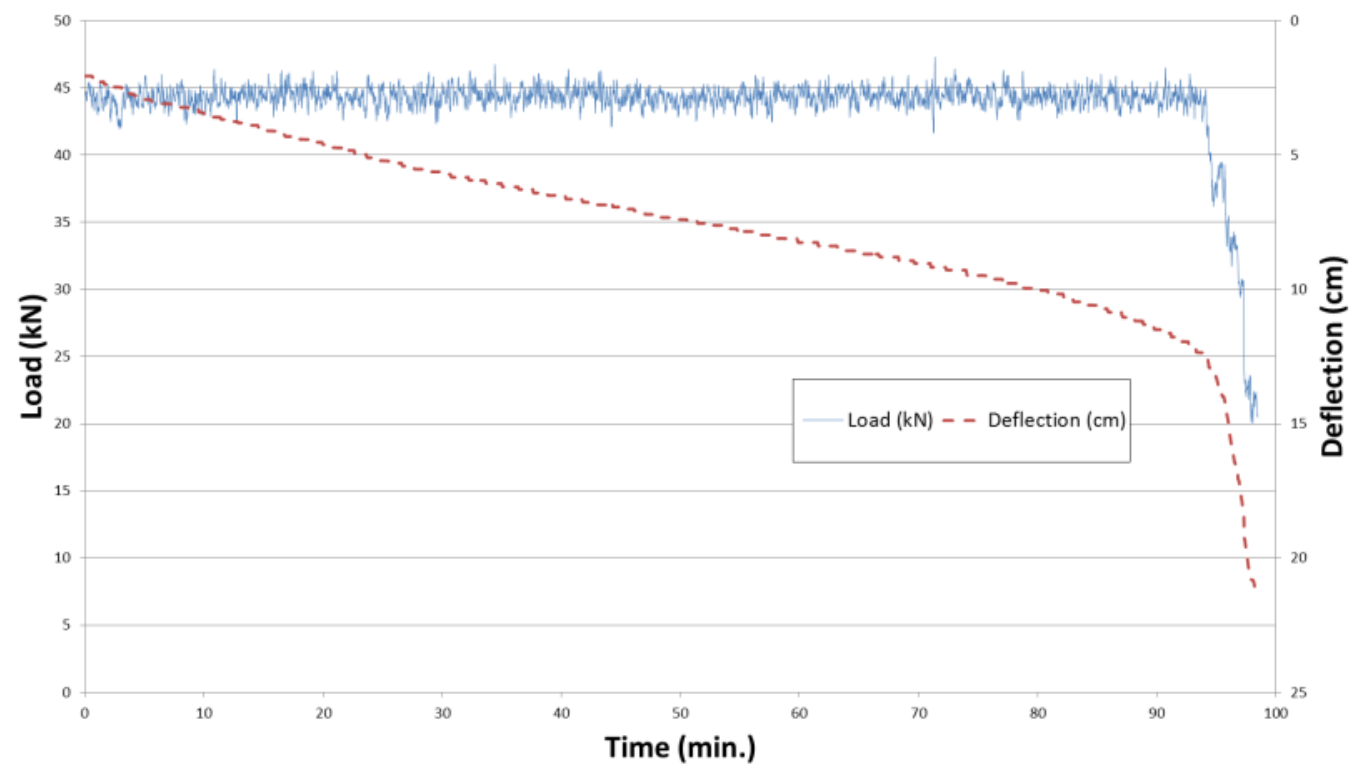

Figure A. 28 - Fire Test 7 load and deflection measurements

Figure A. 29 shows the temperature profiles measured across the CLT panels. It can be observed that two (2) sharp increases were recorded at 17.5 and $35 \mathrm{~mm}$ a few minutes before the end of the test. These increases coincide with the furnace rapid increased temperature shown in Figure A. 27 near the end of the test. At that time, thermocouples at 17.5 and $35 \mathrm{~mm}$ were most likely fully exposed due to complete charring of the CLT and recorded the furnace temperature as opposed to that of the CLT.

There was no significant temperature rise recorded at the $2^{\text {nd }}$ glueline $(70 \mathrm{~mm})$ and beyond. Moreover, no significant temperature rises were recorded at the surface plywood spline interface and along the self-tapping screws. 


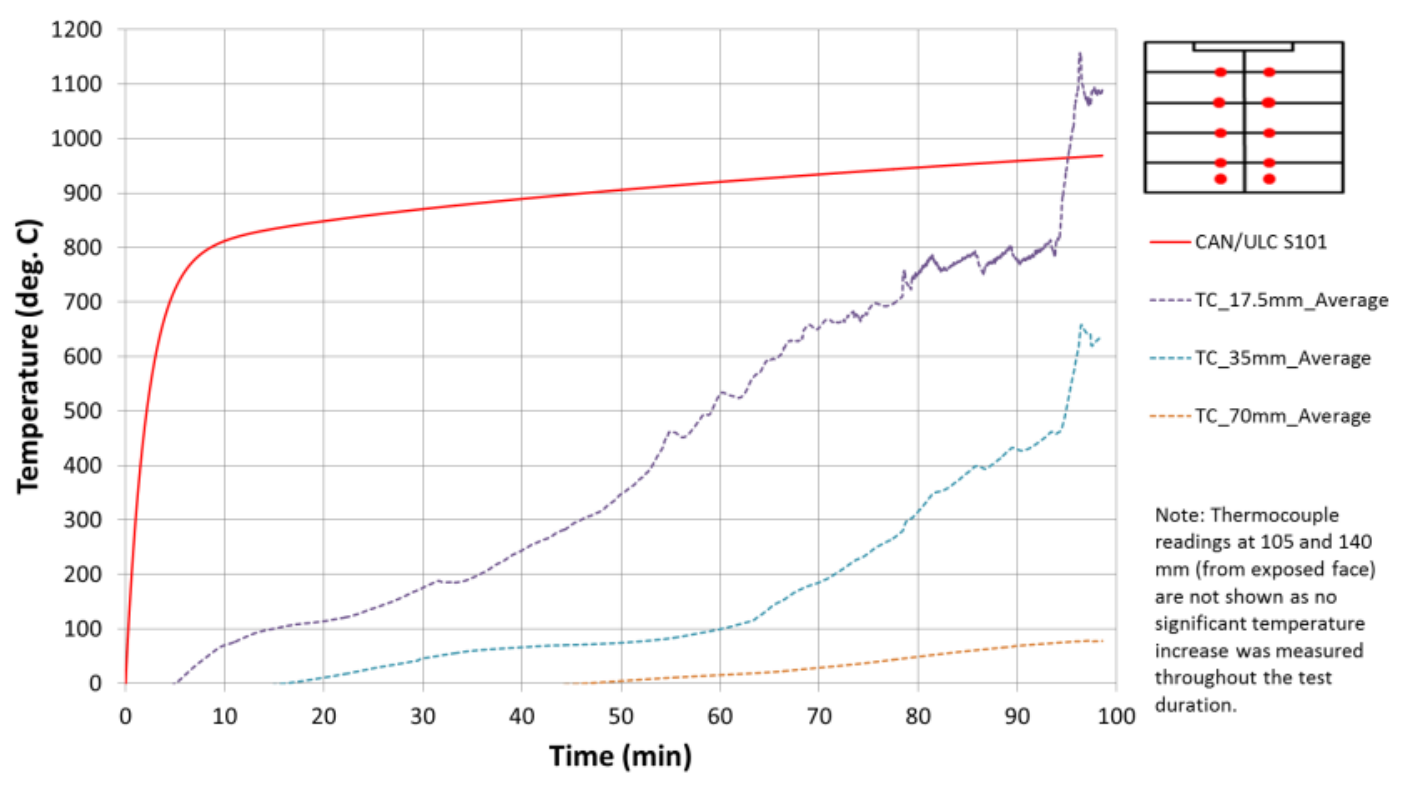

Figure A. 29 - Fire Test 7 temperature profiles across the CLT panels (average) 


\section{Appendix VIII - Fire Test 8 - 5-ply CLT with double surface spline}

This appendix provides further test results from the fire test 8 on a CLT with double surface splines, as presented in subsection 3.11 of this thesis.

Figure A. 30 shows that the temperature recorded inside the furnace throughout the test closely followed the standard time-temperature curve, while being slightly lower for the first 45 minutes of burning. Figure A. 31 shows the load and deflection measurements recorded during the test.

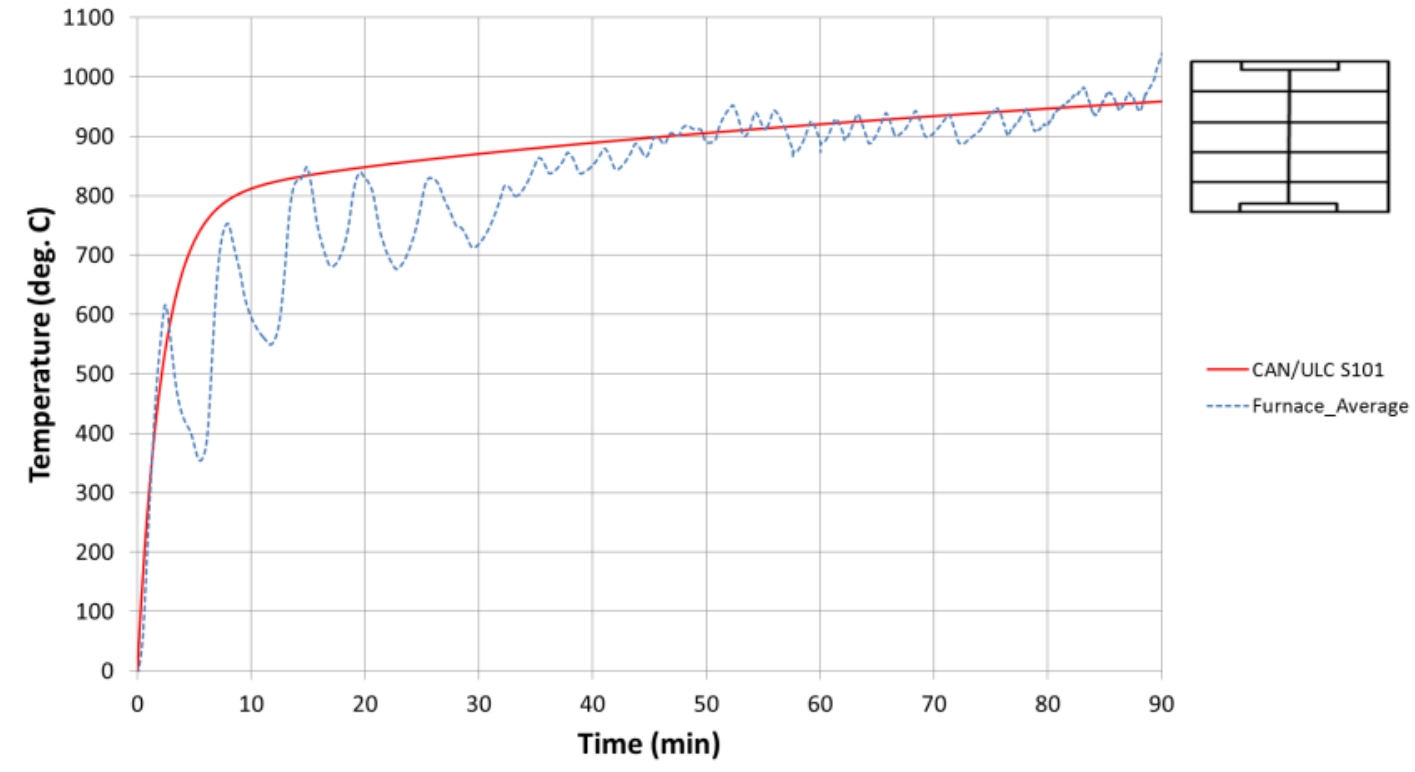

Figure A. 30 - Fire Test 8 furnace temperature (average) 


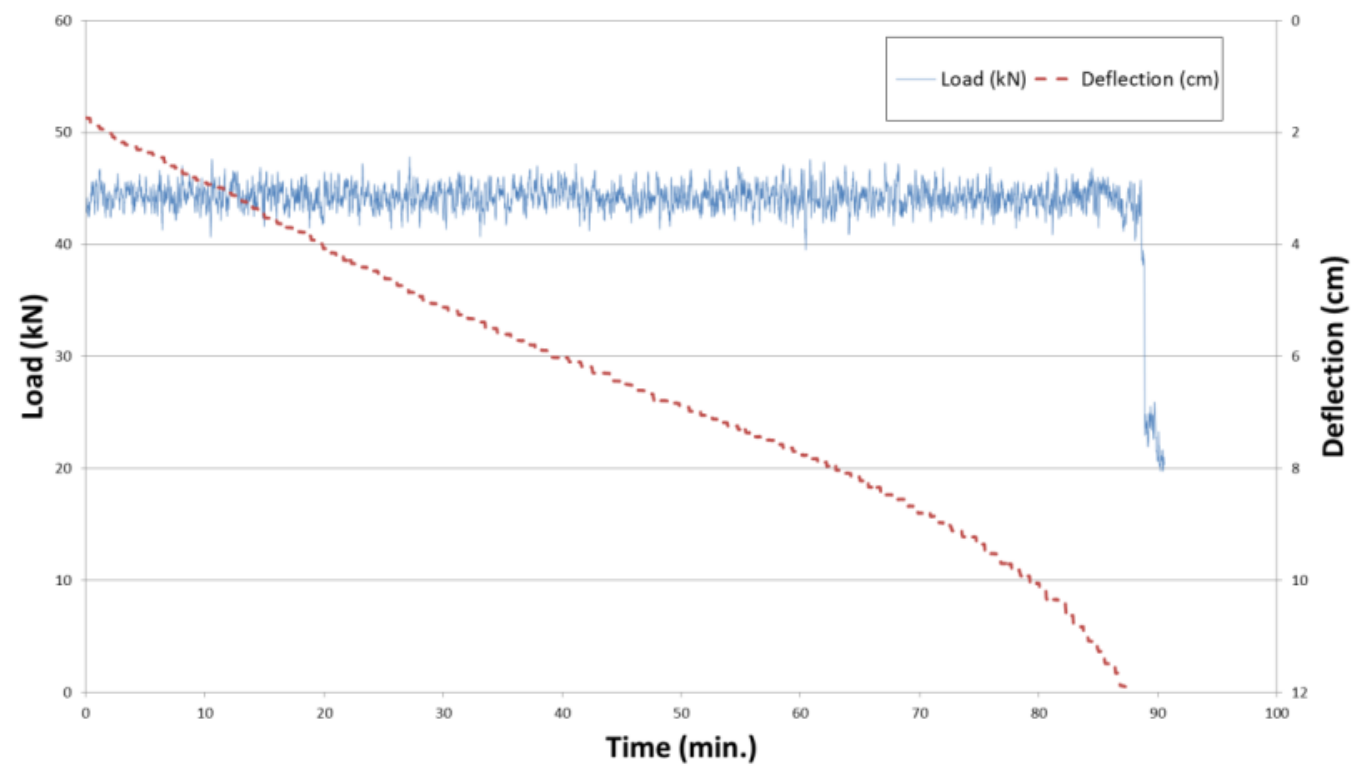

Figure A. 31 - Fire Test 8 load and deflection measurements

The temperature profiles measured across the CLT panels and at the spline interfaces are plotted in Figure A. 32 and Figure A. 33. There was no significant temperature rise recorded at the $3^{\text {rd }}$ glueline $(105 \mathrm{~mm})$ and beyond.

The temperatures recorded from the instrumented self-tapping screws are shown in Figure A. 34. It can be seen that heat is being rapidly conducted to the bottom selftapping screws, which are directly exposed to fire, and that they somewhat followed the furnace temperature throughout the test. Very little difference in the temperature profile is observed between the middle and the tip of the bottom self-tapping screws. 


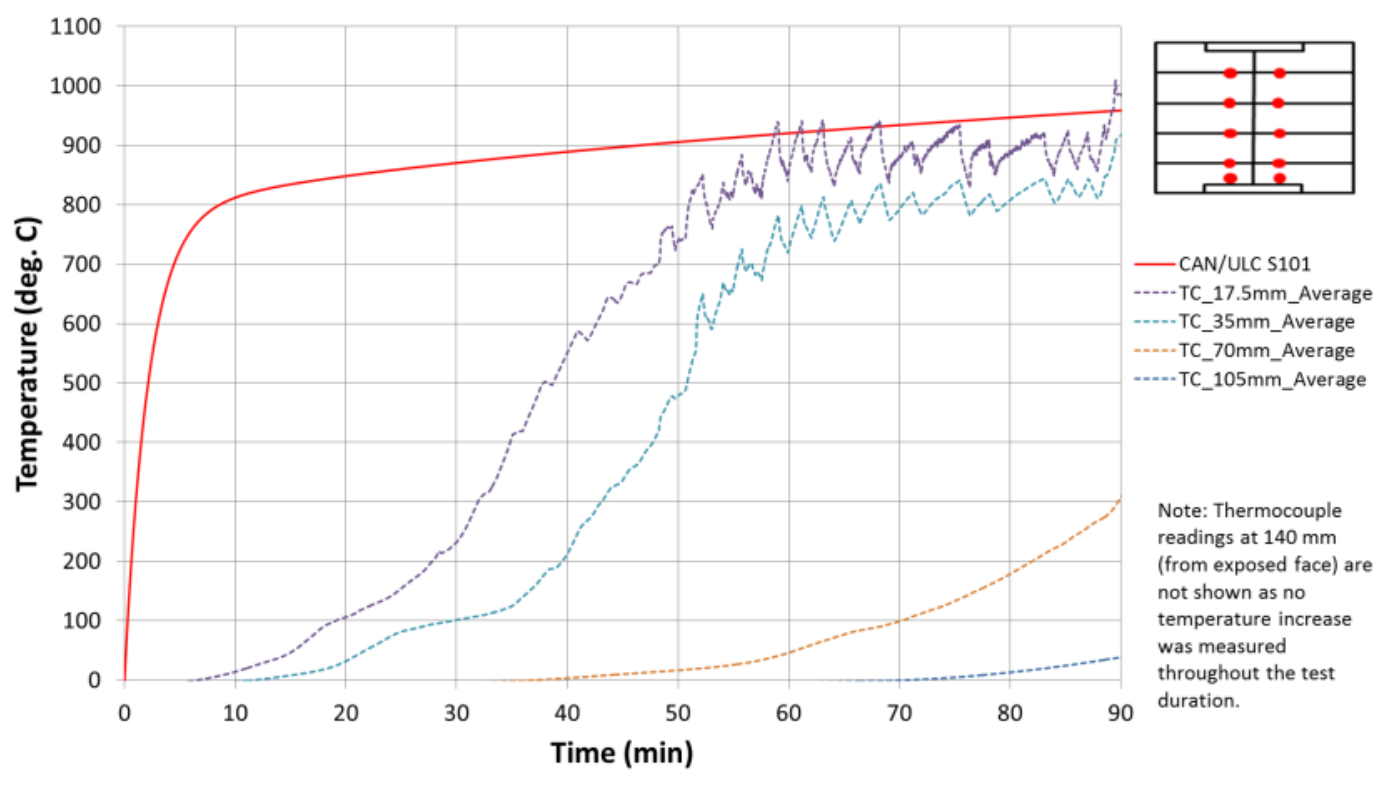

Figure A. 32 - Fire Test 8 temperature profiles across the CLT panels (average)

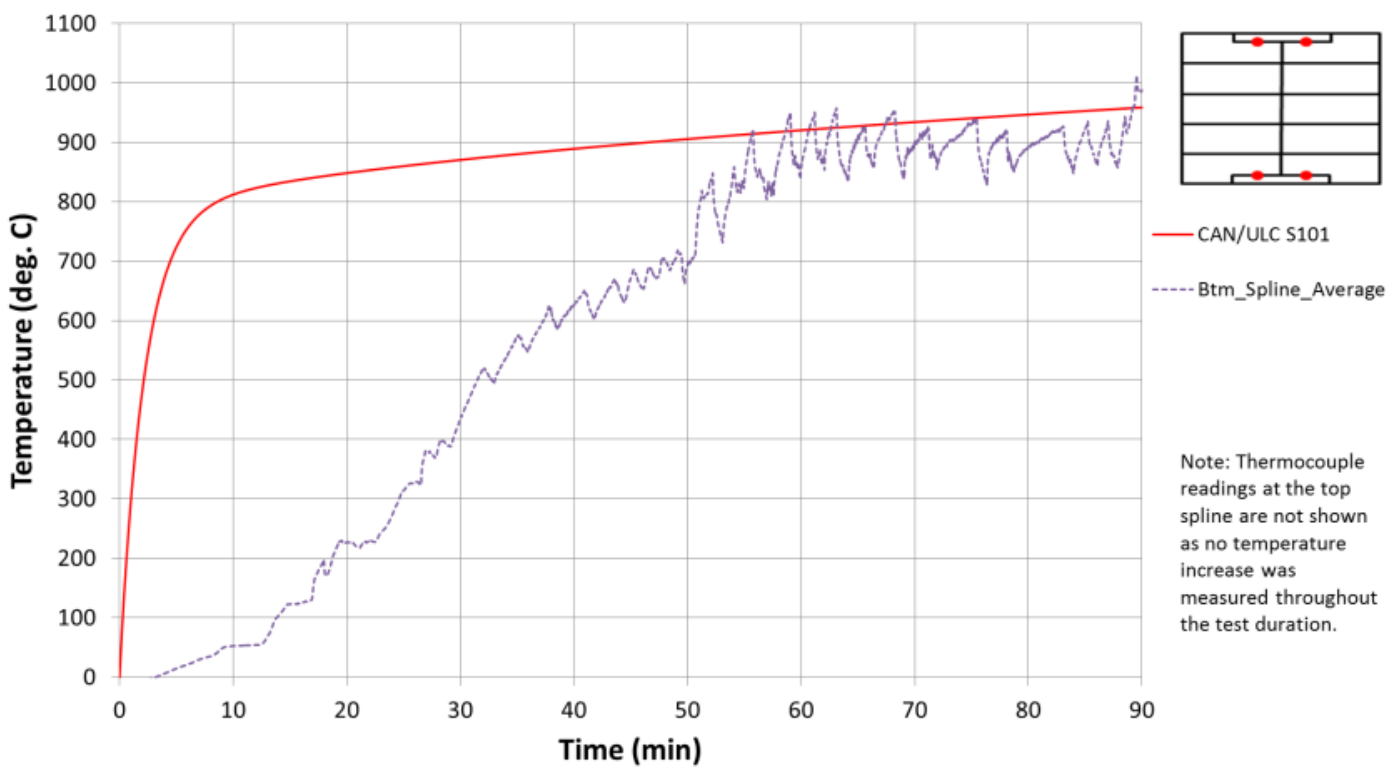

Figure A. 33 - Fire Test 8 temperature profiles at the surface splines interface 


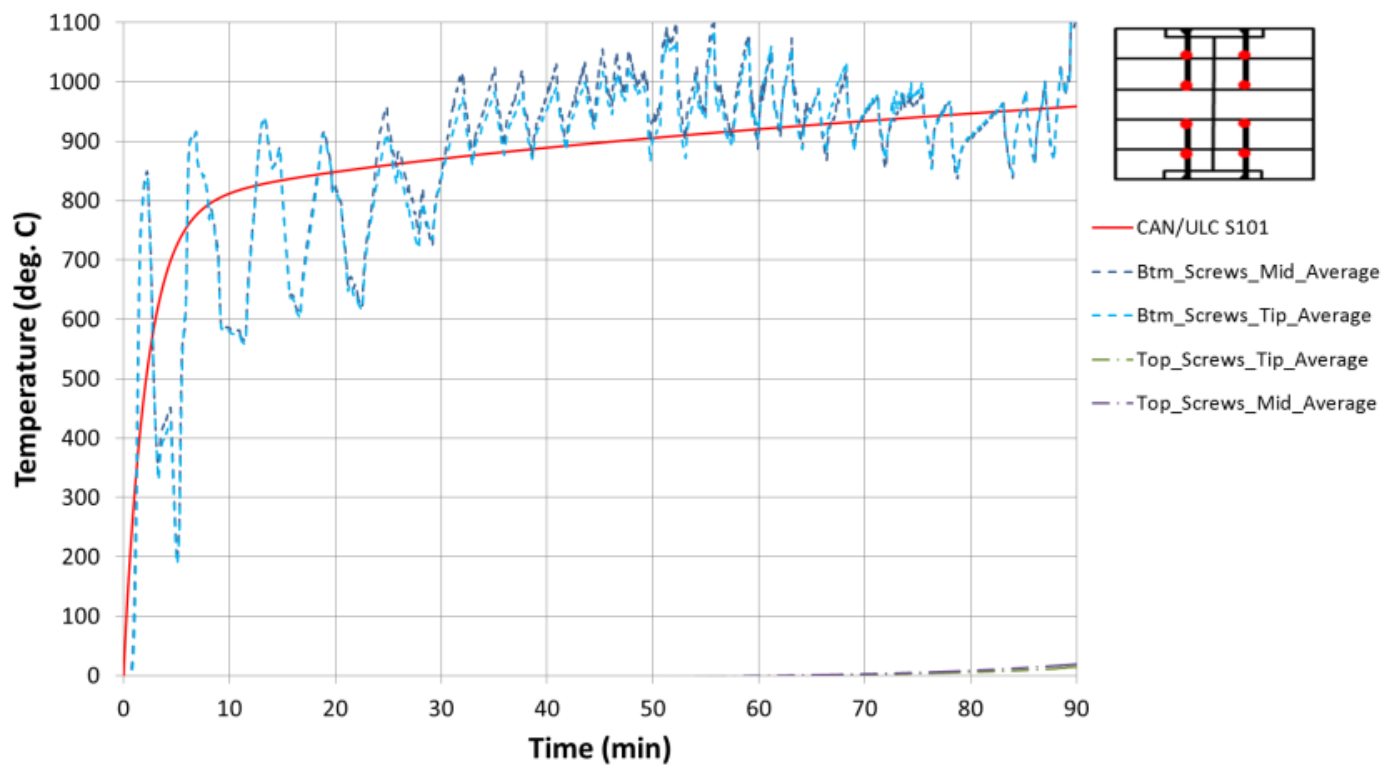

Figure A. 34 - Fire Test 8 temperature profiles of the self-tapping screws (average) 


\section{Appendix IX - Fire Test 9 - 7-ply CLT with half-lapped joint}

This appendix provides further test results from the fire test 9 on a CLT with a halflapped joint, as presented in subsection 3.12 of this thesis.

The temperature curve throughout the test closely followed that of the standard timetemperature curve (Figure A. 35). The load and deflection measurements recorded during the test are shown in Figure A. 36. During the fire test, a problem occurred in the voltage displacement acquisition system. As such, the only data points available with respect to the deflection are those taken from personal notes and pictures. The deflection curve shown in Figure A. 36 is a rough approximation from four (4) data points and does not accurately represent the actual deflection during the fire test.

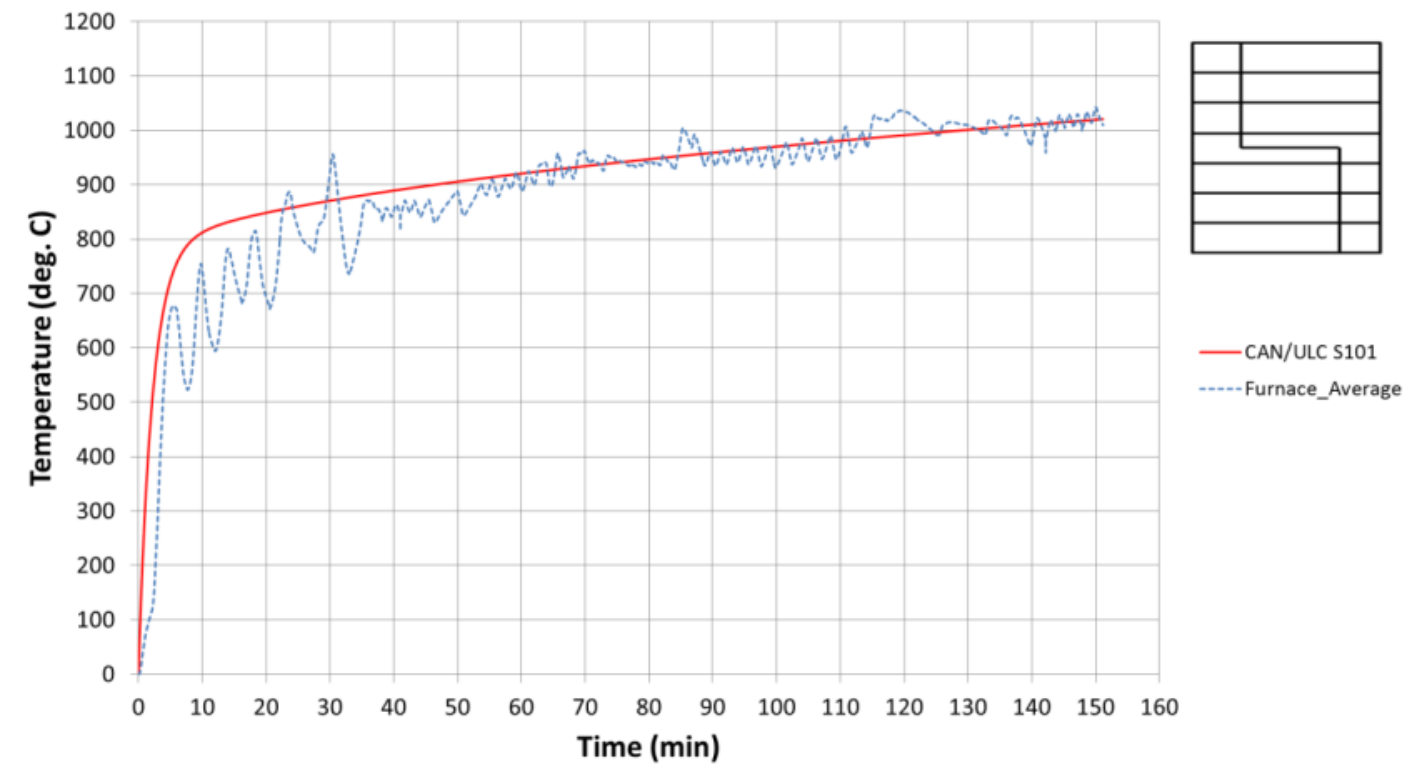

Figure A. 35 - Fire Test 9 furnace temperature (average) 


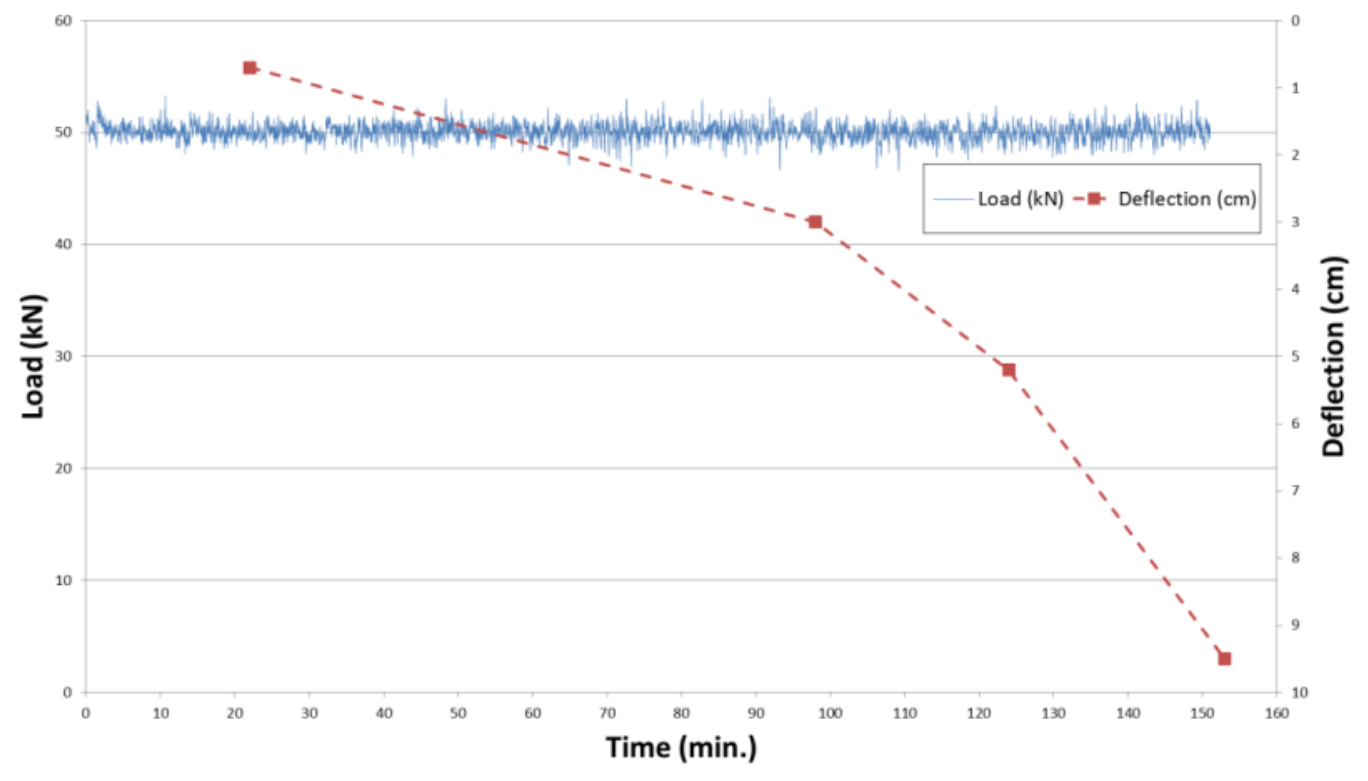

Figure A. 36 - Fire Test 9 load and deflection measurements

The temperature profiles measured across the CLT panels and at the joint interface are plotted in Figure A. 37 and Figure A. 38. As also observed in Fire Test 2, the heat seems to have penetrated through the CLT and the joints shortly after $70 \mathrm{~min}$. After reviewing the data and given that the other four (4) plots in Figure A. 37 are similar, it is difficult to explain the premature increase from the thermocouples in the joint between 80 and 100 min. Again, the possibility of air gaps between adjacent laminations may have led to heat flow through the joint and reached faster the spline at that location.

Lastly, it can be observed from Figure A. 39 that the self-tapping screws slowly heated during the fire test. 


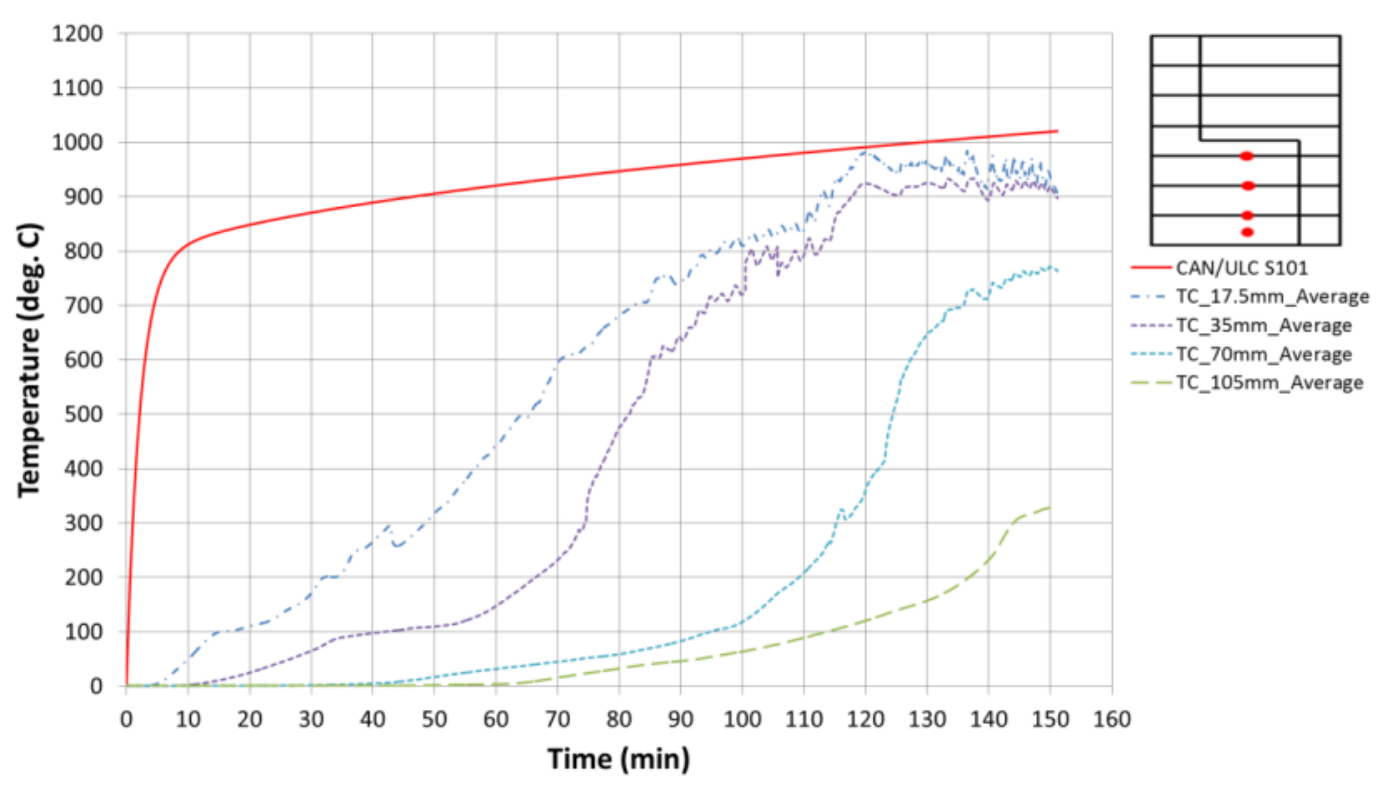

Figure A. 37 - Fire Test 9 temperature profiles across the CLT panels (average)

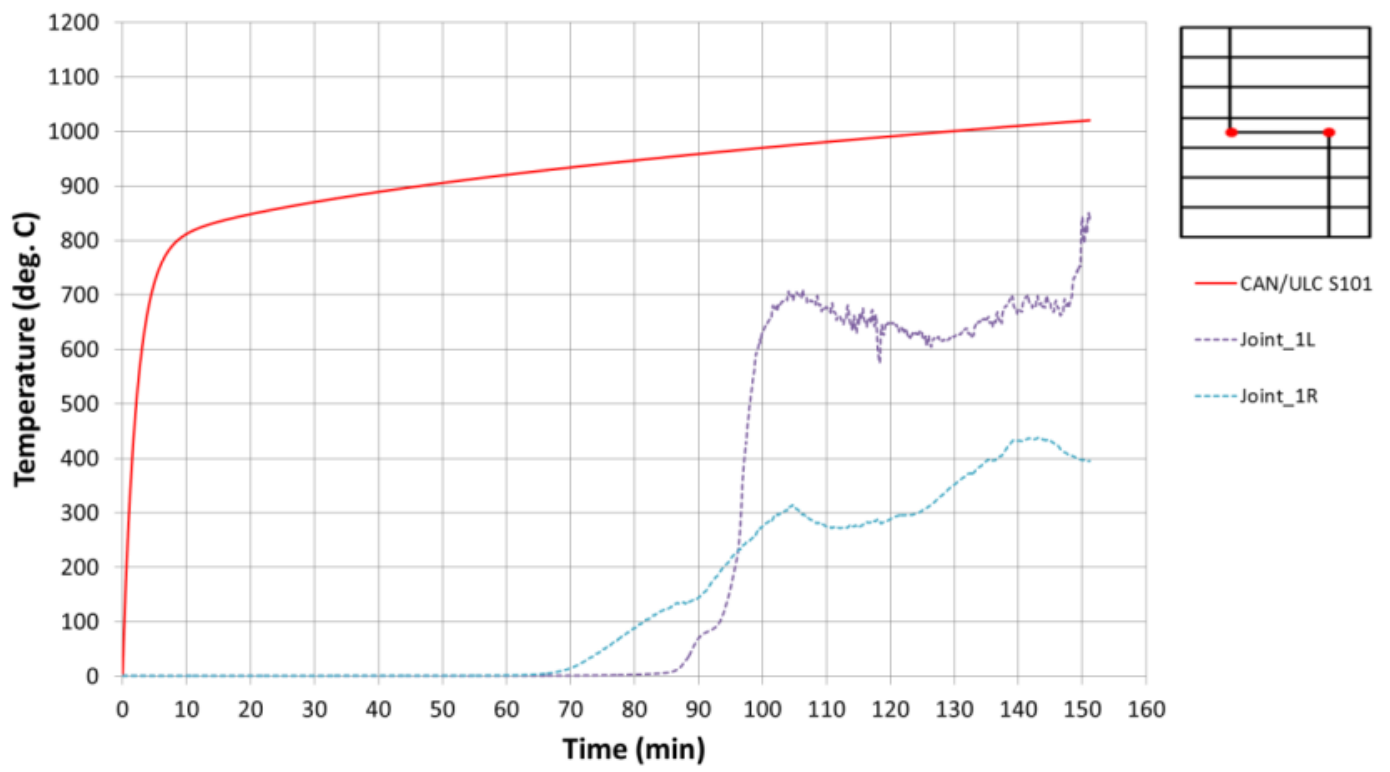

Figure A. 38 - Fire Test 9 temperature profiles at the half-lapped interface 


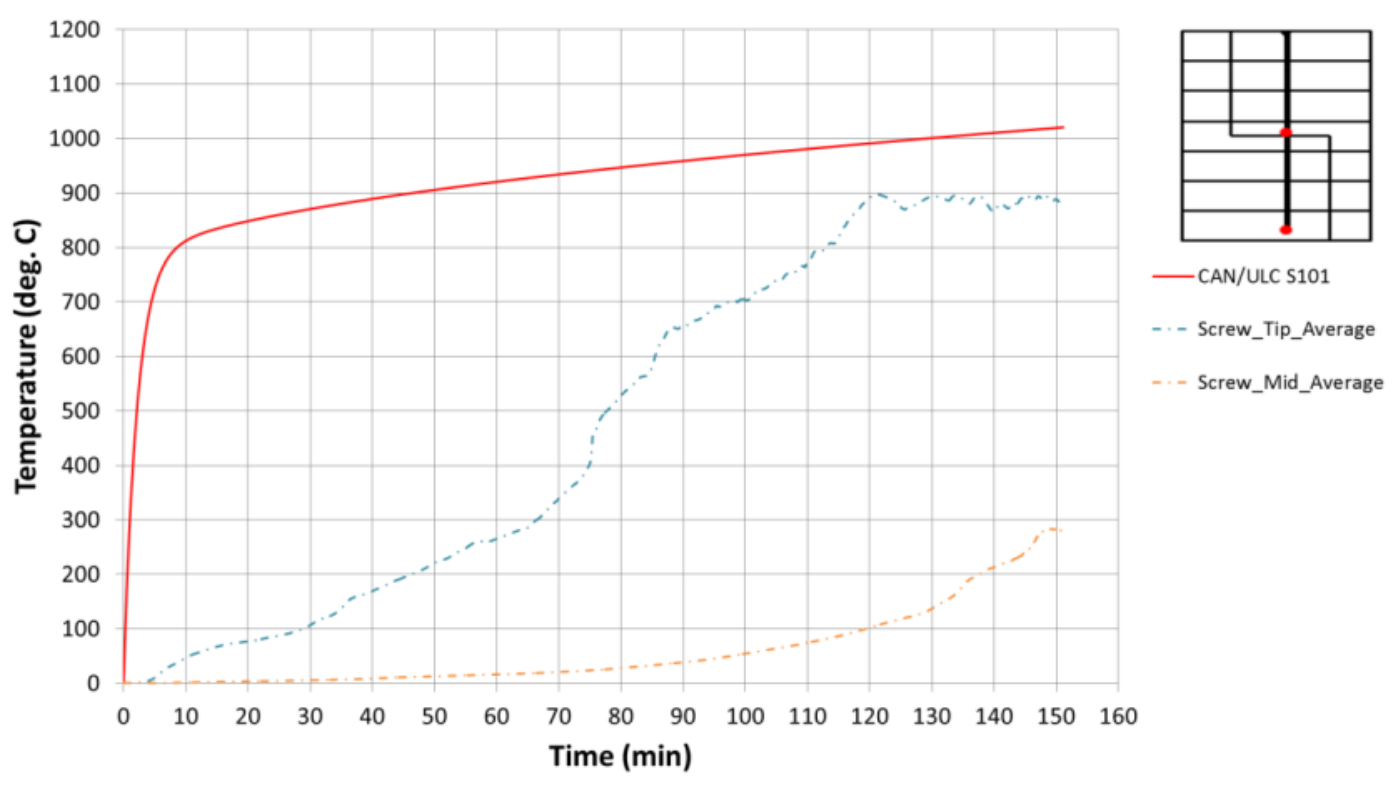

Figure A. 39 - Fire Test 9 temperature profiles of the self-tapping screws (average) 


\section{Appendix X - Fire Test 10 - 7-ply CLT with double surface spline}

This appendix provides further test results from the fire test 10 on a CLT with double surface splines, as presented in subsection 3.13 of this thesis.

It can be observed from Figure A. 40 that the furnace temperature closely followed the standard time-temperature curve, while being slightly lower in the first 40 minutes of fire exposure. The load and deflection measurements recorded during the test are shown in Figure A. 41.

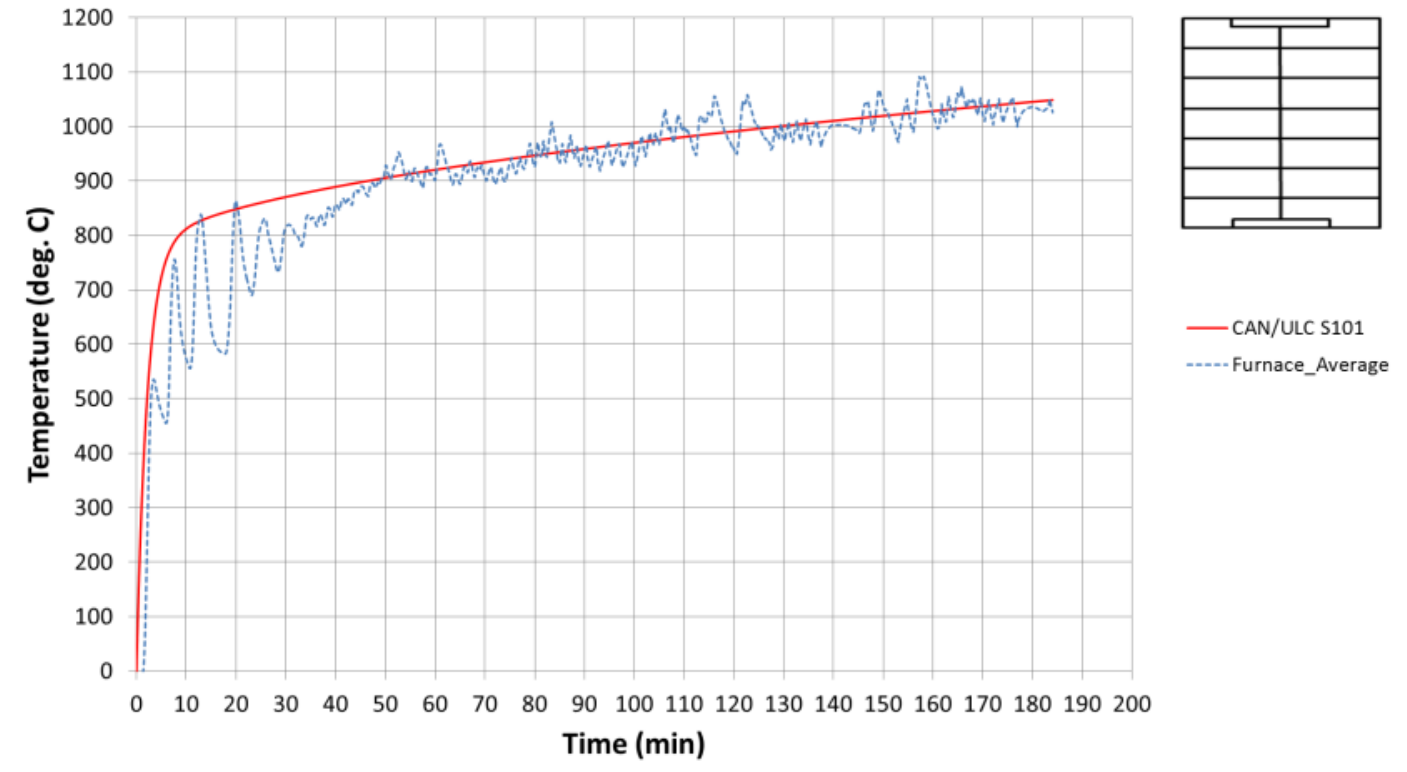

Figure A. 40 - Fire Test 10 furnace temperature (average) 


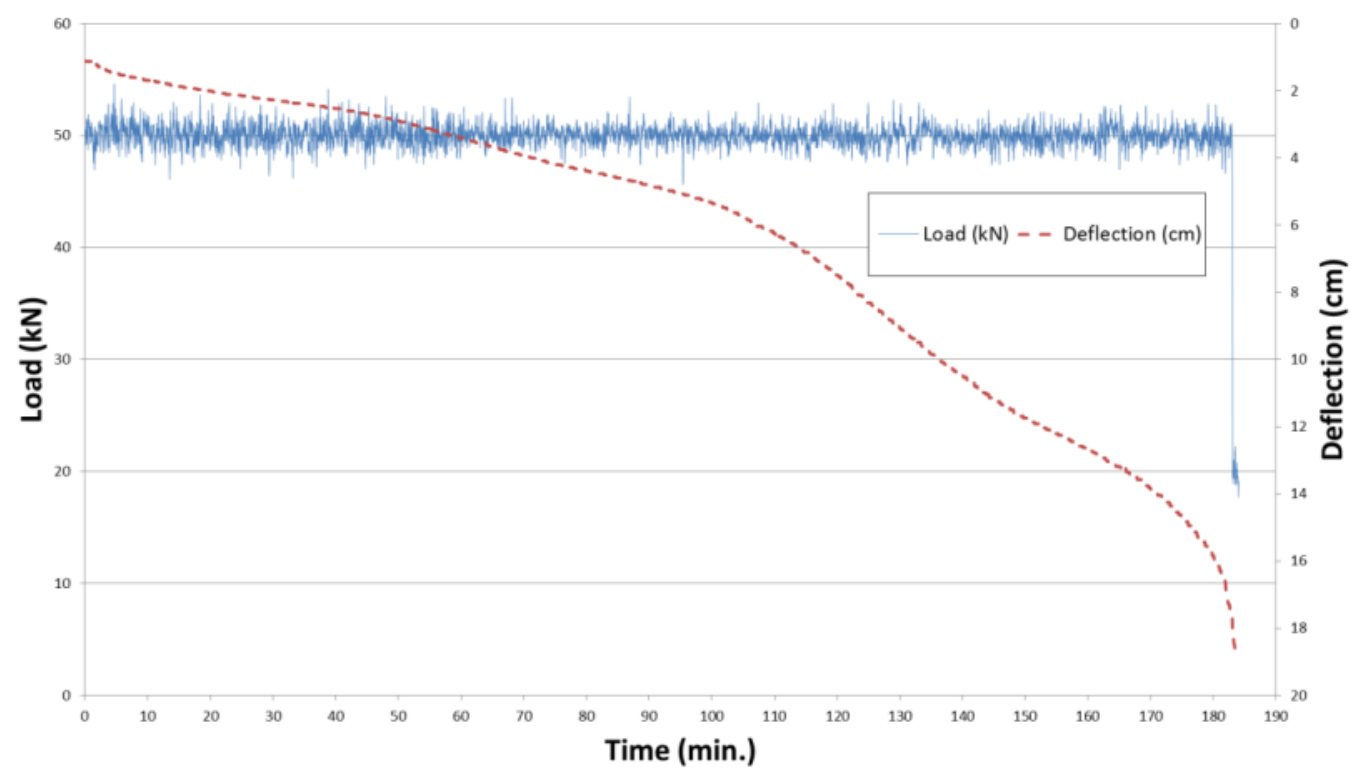

Figure A. 41 - Fire Test 10 load and deflection measurements

The temperature profiles measured across the CLT panels and at the spline interfaces are plotted in Figure A. 42 and Figure A. 43. For some reason, one of the four (4) thermocouples located at $17.5 \mathrm{~mm}$ recorded temperature below $600^{\circ} \mathrm{C}$ after $140 \mathrm{~min}$ into the test, resulting in a decreasing average temperature profile from 140 min until the end of the test. As such, the temperatures recorded from that particular thermocouple have been neglected when calculating the average profile at $17.5 \mathrm{~mm}$ shown in Figure A. 42 . There was no significant temperature rise recorded beyond the $3^{\text {rd }}$ glueline (beyond 105 $\mathrm{mm}$ ) and at the top spline interface, thus not shown in the figures for clarity.

Similarly to Fire Tests 4 and 8 , it can be observed that heat is being rapidly conducted to the bottom self-tapping screws, which are directly exposed to the fire, and that they somewhat followed the furnace temperature throughout the test (Figure A. 44). 
Moreover, very little difference in the temperature profile is observed between the middle and the tip of the bottom self-tapping screws. No significant temperature rise was recorded from the self-tapping screws used for the top surface spline throughout the test

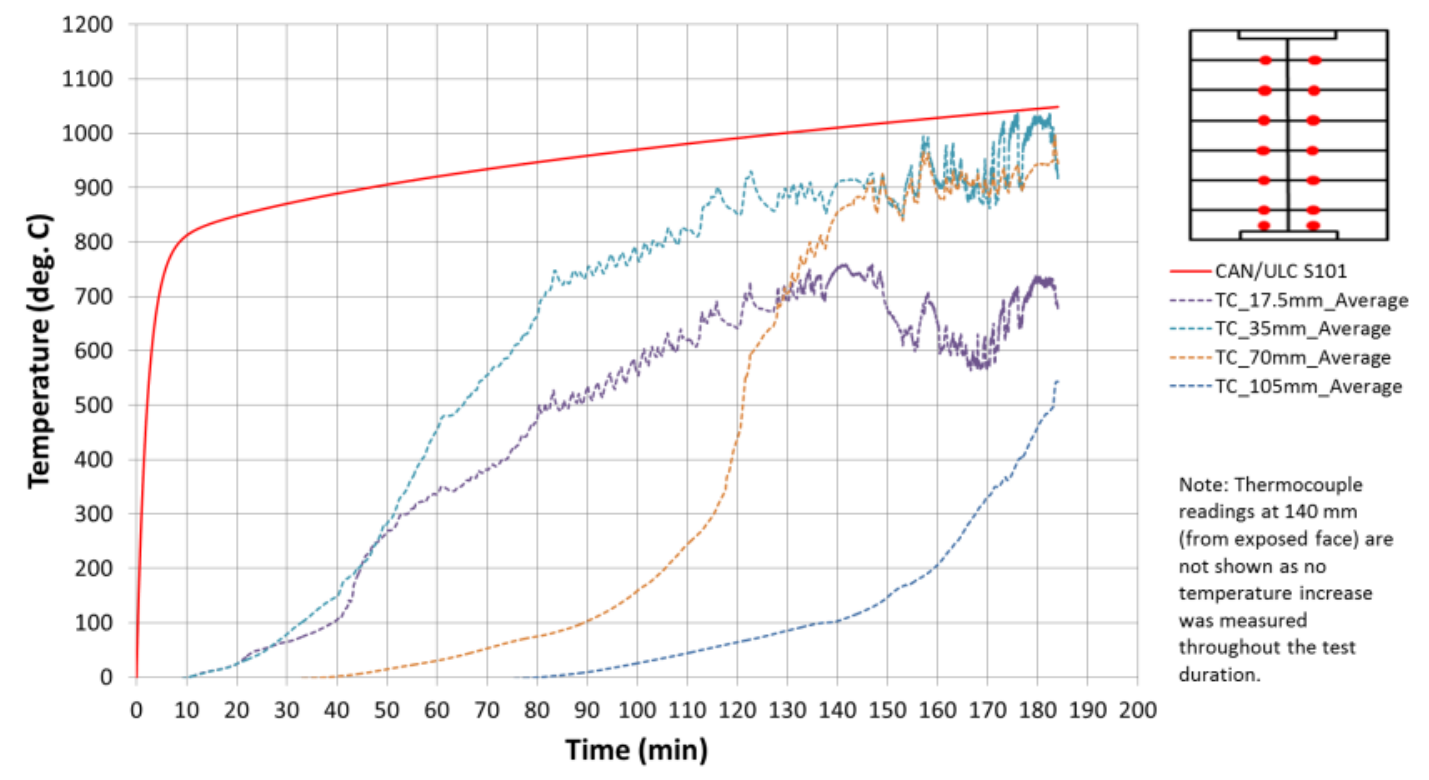

Figure A. 42 - Fire Test 10 temperature profiles across the CLT panels (average) 


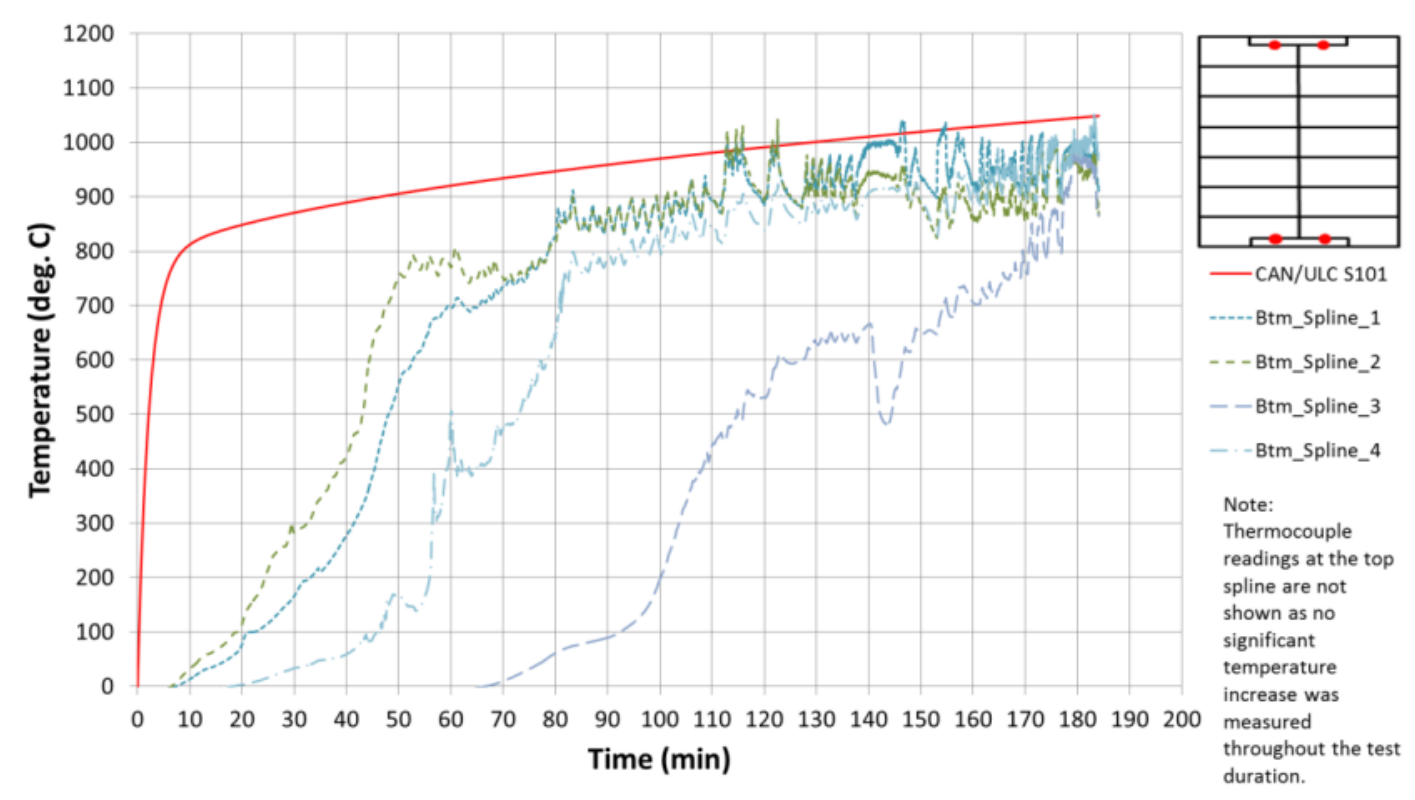

Figure A. 43 - Fire Test 10 temperature profiles at the surface splines interface

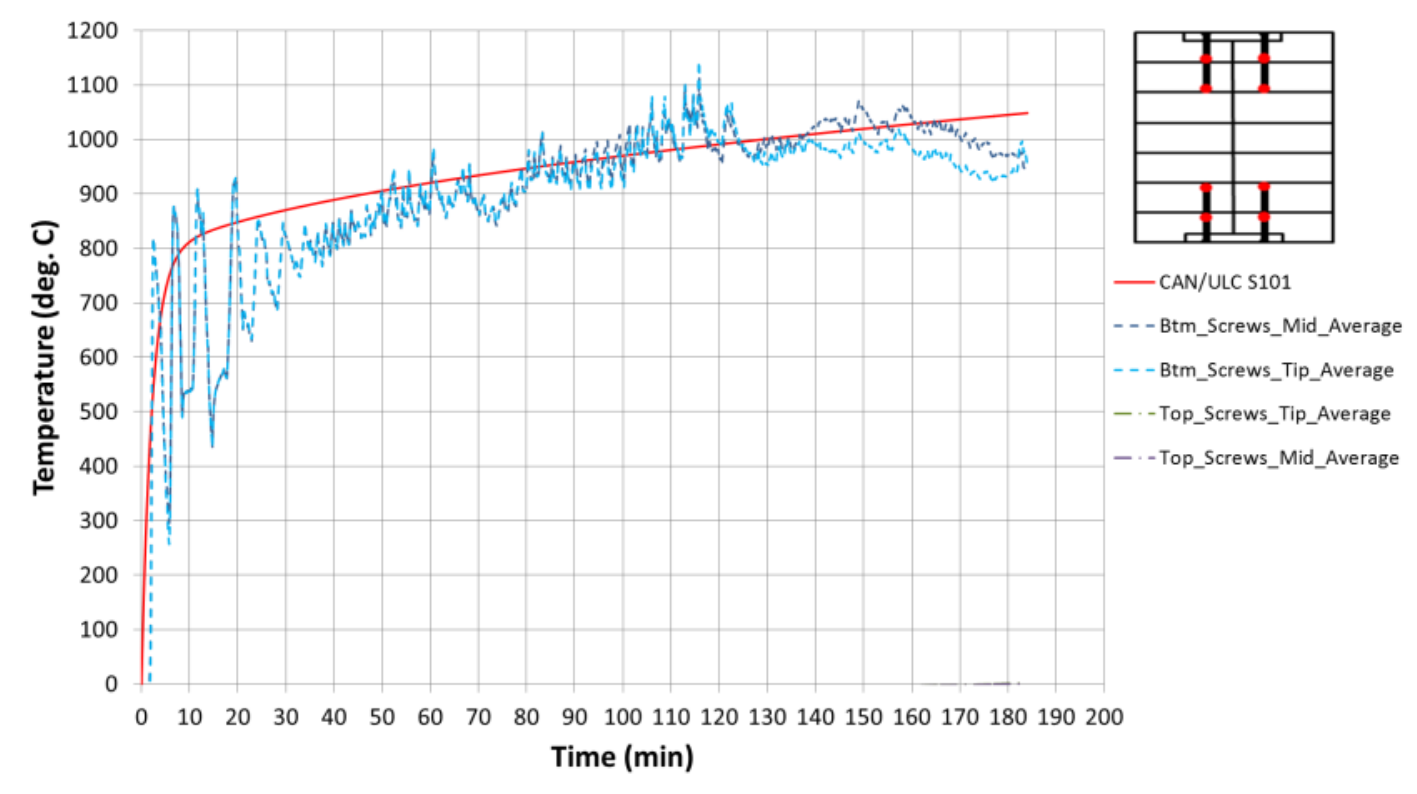

Figure A. 44 - Fire Test 10 temperature profiles of the self-tapping screws (average) 


\section{Appendix XI - Example from Coupled Thermal-Structural Model}

This section provides a detailed design example using the coupled thermal-structural model presented in Chapter 5 of this study. The CLT floor assembly consists in a 5-ply E1 stress-grade CLT panel manufactured with $35-\mathrm{mm}$ thick lamination. The panels are connected together using a half-lapped joint and self-tapping screw $(\phi 6-160 / 100 \mathrm{~mm})$.

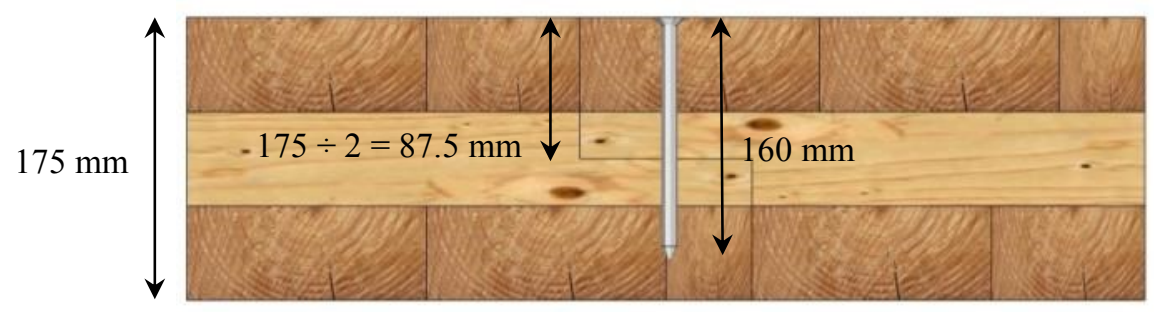

Failure criterion - Minimum penetration depth of $22 \mathrm{~mm}$

1. Determine the maximum char depth that would respect the $22 \mathrm{~mm}$ criterion.

$d_{\text {char }}=D-\frac{D}{2}-22=175-87.5-22=65.5 \mathrm{~mm}$

As such, the entire $1^{\text {st }}$ lamination and a portion of the $2^{\text {nd }}$ lamination $(30.5 \mathrm{~mm})$ can be charred.

2. Determine the time to char each layers respectively.

Charring rate of $1^{\text {st }}$ lamination $=0.65 \mathrm{~mm} / \mathrm{min}$ (MSR 1950 $\mathrm{f}_{\mathrm{b}}$ lumber)

$t_{1}=\frac{35}{0.65}=53.8 \mathrm{~min}$

Charring rate of $2^{\text {nd }}$ lamination $=0.75 \mathrm{~mm} / \mathrm{min}$ (SPF No.3 grade)

$t_{2}=\frac{30.5}{0.75}=40.6 \mathrm{~min}$

3. Calculate the total of all times to char each layer.

$t_{\text {failure }}=\sum_{i=1}^{n} t_{i}=53.8+40.6=94.4 \mathrm{~min}$ 


\section{Failure criterion - $67 \%$ Strength Loss of Connection}

1. Determine the initial lateral resistance of the connection using CSA O86 equations. Side member thickness, $t_{1}$

$t_{1}=\frac{175}{2}=87.5 \mathrm{~mm}$

Side member embedment strength, $f_{1}$

$f_{1}=50 G\left(1-0.01 d_{F}\right)=50 \cdot 0.42 \cdot(1-0.01 \cdot 4.4)=20.1 \mathrm{MPa}$

Main member thickness, $t_{2}$

$t_{2}=\frac{175}{2}-(175-160)=72.5 \mathrm{~mm}\left(\approx 16.5 d_{F}>>8 d_{F} \rightarrow J_{P L}=1\right)$

Main member embedment strength, $f_{2}$

$f_{2}=50 G\left(1-0.01 d_{F}\right)=50 \cdot 0.42 \cdot(1-0.01 \cdot 4.4)=20.1 M P a$

Self-tapping screw yield strength, $f_{y}$

$f_{y}=969 M P a$

Unit lateral strength resistance parallel-to-grain, $p_{u, 0}$

(a) $f_{1} d_{F} t_{1}=20.1 \cdot 4.4 \cdot 87.5=7738 \mathrm{~N}$

(b) $f_{2} d_{F} t_{2}=20.1 \cdot 4.4 \cdot 72.5=6412 \mathrm{~N}$

(c) $f_{1} d_{F}^{2}\left(\sqrt{\frac{1}{6} \cdot \frac{f_{2}}{\left(f_{1}+f_{2}\right)} \cdot \frac{f_{y}}{f_{1}}}+\frac{1}{5} \cdot \frac{t_{1}}{d_{F}}\right)$

$=20.1 \cdot 4.4^{2} \cdot\left(\sqrt{\frac{1}{6} \cdot \frac{20.1}{(20.1+20.1)} \cdot \frac{969}{20.1}}+\frac{1}{5} \cdot \frac{87.5}{4.4}\right)=2327 \mathrm{~N}$

(d) $f_{1} d_{F}^{2}\left(\sqrt{\frac{1}{6} \cdot \frac{f_{2}}{\left(f_{1}+f_{2}\right)} \cdot \frac{f_{y}}{f_{1}}}+\frac{1}{5} \cdot \frac{t_{2}}{d_{F}}\right)$

$=20.1 \cdot 4.4^{2} \cdot\left(\sqrt{\frac{1}{6} \cdot \frac{20.1}{(20.1+20.1)} \cdot \frac{969}{20.1}}+\frac{1}{5} \cdot \frac{72.5}{4.4}\right)=2062 \mathrm{~N}$

(e)

$$
f_{1} d_{F}^{2} \frac{1}{5}\left(\frac{t_{1}}{d_{F}}+\frac{f_{2}}{f_{1}} \cdot \frac{t_{2}}{d_{F}}\right)=20.1 \cdot 4.4^{2} \cdot \frac{1}{5} \cdot\left(\frac{87.5}{4.4}+\frac{20.1}{20.1} \cdot \frac{72.5}{4.4}\right)=2830 \mathrm{~N}
$$


(f)

$$
f_{1} d_{F}^{2} \sqrt{\frac{2}{3} \cdot \frac{f_{2}}{\left(f_{1}+f_{2}\right)} \cdot \frac{f_{y}}{f_{1}}}=20.1 \cdot 4.4^{2} \cdot \sqrt{\frac{2}{3} \cdot \frac{20.1}{(20.1+20.1)} \cdot \frac{969}{20.1}}=1560 \mathrm{~N}(\text { governs })
$$

Lateral resistance (parallel-to-grain loading) at time $=0 \mathrm{~min}$.

$P_{r, 0}(N)=\varphi\left(p_{u, 0} K_{D} K_{T} K_{S F}\right) n_{F} J_{G} J_{P L}=0.6 \cdot(1560 \cdot 1.15 \cdot 1 \cdot 1) \cdot 1 \cdot 1 \cdot 1=1076 \mathrm{~N}$

2. Determine the lateral resistance of the connection at time $=94 \mathrm{~min}$.

Side member thickness, $t_{1}$

$t_{1}=\frac{175}{2}=87.5 \mathrm{~mm}$

Side member embedment strength, $f_{1}$

$$
f_{1}=50 G\left(1-0.01 d_{F}\right)=50 \cdot 0.42 \cdot(1-0.01 \cdot 4.4)=20.1 \mathrm{MPa}
$$

Main member thickness, $t_{2}$

$t_{2}=22 \mathrm{~mm}\left(=5 d_{F} \rightarrow J_{P L}=0.625\right)$

Main member embedment strength, $f_{2}$

$f_{2}=50 G\left(1-0.01 d_{F}\right)=50 \cdot 0.42 \cdot(1-0.01 \cdot 4.4)=20.1 \mathrm{MPa}$

Self-tapping screw yield strength, $f_{y}$

$f_{y}=969 M P a$

Unit lateral strength resistance parallel-to-grain, $p_{u, 94}$

(a) $f_{1} d_{F} t_{1}=20.1 \cdot 4.4 \cdot 87.5=7738 \mathrm{~N}$

(b) $f_{2} d_{F} t_{2}=20.1 \cdot 4.4 \cdot 22=1945 \mathrm{~N}$

(c) $f_{1} d_{F}^{2}\left(\sqrt{\frac{1}{6} \cdot \frac{f_{2}}{\left(f_{1}+f_{2}\right)} \cdot \frac{f_{y}}{f_{1}}}+\frac{1}{5} \cdot \frac{t_{1}}{d_{F}}\right)$

$$
=20.1 \cdot 4.4^{2} \cdot\left(\sqrt{\frac{1}{6} \cdot \frac{20.1}{(20.1+20.1)} \cdot \frac{969}{20.1}}+\frac{1}{5} \cdot \frac{87.5}{4.4}\right)=2327 \mathrm{~N}
$$

(d) $f_{1} d_{F}^{2}\left(\sqrt{\frac{1}{6} \cdot \frac{f_{2}}{\left(f_{1}+f_{2}\right)} \cdot \frac{f_{y}}{f_{1}}}+\frac{1}{5} \cdot \frac{t_{2}}{d_{F}}\right)$

$$
=20.1 \cdot 4.4^{2} \cdot\left(\sqrt{\frac{1}{6} \cdot \frac{20.1}{(20.1+20.1)} \cdot \frac{969}{20.1}}+\frac{1}{5} \cdot \frac{22}{4.4}\right)=1169 \mathrm{~N}(\text { governs })
$$


(e) $f_{1} d_{F}^{2} \frac{1}{5}\left(\frac{t_{1}}{d_{F}}+\frac{f_{2}}{f_{1}} \cdot \frac{t_{2}}{d_{F}}\right)=20.1 \cdot 4.4^{2} \cdot \frac{1}{5} \cdot\left(\frac{87.5}{4.4}+\frac{20.1}{20.1} \cdot \frac{22}{4.4}\right)=1936 \mathrm{~N}$
(f) $f_{1} d_{F}^{2} \sqrt{\frac{2}{3} \cdot \frac{f_{2}}{\left(f_{1}+f_{2}\right)} \cdot \frac{f_{y}}{f_{1}}}=20.1 \cdot 4.4^{2} \cdot \sqrt{\frac{2}{3} \cdot \frac{20.1}{(20.1+20.1)} \cdot \frac{969}{20.1}}=1560 \mathrm{~N}$

Lateral resistance (parallel-to-grain loading) at time $=94 \mathrm{~min}$.

$P_{r, 94}(N)=\varphi\left(p_{u, 0} K_{D} K_{T} K_{S F}\right) n_{F} J_{G} J_{P L}=0.6 \cdot(1169 \cdot 1.15 \cdot 1 \cdot 1) \cdot 1 \cdot 1 \cdot 0.625=504 N$

Strength loss ratio

$\frac{P_{r, 94}}{P_{r, 0}} \times 100=\frac{504}{1076} \times 100=47 \%(>33 \% \rightarrow o k)$

At 94 min, time at which the minimum penetration depth of the self-tapping screw into the main member reaches $22 \mathrm{~mm}$, the connection resistance has reduced to $47 \%$ of its initial resistance (i.e. strength loss of 53\%, which is lower than the $67 \%$ threshold).

The calculations shown above can easily be implemented into a spreadsheet so the reduced penetration, yield modes and failure time can be calculated as a function of time. 